Wolfgang Scherf

\title{
Der \\ Länderfinanzausgleich in Deutschland
}

Ungelöste Probleme und Ansatzpunkte einer Reform 


\section{Wolfgang Scherf}

\section{Der Länderfinanzausgleich in Deutschland}

Der Länderfinanzausgleich in Deutschland steht vor einer grundlegenden Neuordnung. Das Gutachten für das Land Hessen analysiert den heutigen Länderfinanzausgleich einschließlich der Bundesergänzungszuweisungen aus finanzwissenschaftlicher Sicht. Ausgehend von den Defekten des bestehenden Systems werden die Möglichkeiten einer zielgerichteten Reform erörtert. Der Verfasser plädiert für die Beseitigung aller Sonderregelungen und für die Abschaffung der Bundesergänzungszuweisungen mit Ausnahme der Hilfen für die neuen Länder. Darüber hinaus empfiehlt er eine deutliche Reduktion der Nivellierungsintensität des horizontalen Länderfinanzausgleichs durch ein flexibles Tarifmodell, das positive Leistungsanreize für Zahler- wie Empfängerländer sicherstellt.

Wolfgang Scherf wurde 1956 in Trier geboren. Er ist Professor für Volkswirtschaftslehre, insbesondere Öffentliche Finanzen, an der Universität Gießen. 
Der Länderfinanzausgleich

in Deutschland 


\section{FINANZWISSENSCHAFTLICHE SCHRIFTEN}

Herausgegeben von den Professoren

Albers, Krause-Junk, Littmann, Oberhauser, Pohmer, Schmidt

Band 101

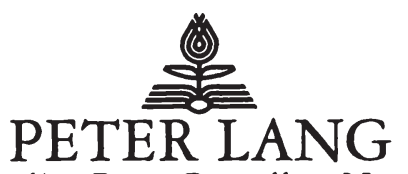

Frankfurt am Main · Berlin · Bern · Bruxelles - New York · Oxford · Wien 


\section{Wolfgang Scherf}

\section{Der Länderfinanzausgleich in Deutschland}

Ungelöste Probleme und Ansatzpunkte einer Reform

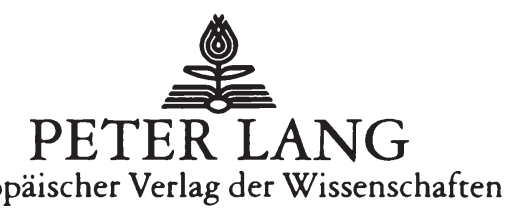


Die Deutsche Bibliothek - CIP-Einheitsaufnahme

Scherf, Wolfgang:

Der Länderfinanzausgleich in Deutschland : ungelöste Probleme und Ansatzpunkte einer Reform / Wolfgang Scherf. - Frankfurt am Main ; Berlin ; Bern ; Bruxelles ; New York ; Oxford ; Wien : Lang, 2000

(Finanzwissenschaftliche Schriften ; Bd. 101)

ISBN3-631-36866-6

Open Access: The online version of this publication is published on www.peterlang.com and www.econstor.eu under the international Creative Commons License CC-BY 4.0. Learn more on how you can use and share this work: http://creativecommons. org/licenses/by/4.0.

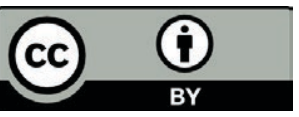

This book is available Open Access thanks to the kind support of ZBW - Leibniz-Informationszentrum Wirtschaft.

Gedruckt auf alterungsbeständigem, säurefreiem Papier.

\author{
ISSN 0170-8252 \\ ISBN 3-631-36866-6 \\ ISBN 978-3-631-75181-7 (eBook) \\ (C) Peter Lang GmbH \\ Europäischer Verlag der Wissenschaften \\ Frankfurt am Main 2000 \\ Alle Rechte vorbehalten.
}

Das Werk einschließlich aller seiner Teile ist urheberrechtlich geschützt. Jede Verwertung außerhalb der engen Grenzen des Urheberrechtsgesetzes ist ohne Zustimmung des Verlages unzulässig und strafbar. Das gilt insbesondere für Vervielfältigungen, Übersetzungen, Mikroverfilmungen und die Einspeicherung und Verarbeitung in elektronischen Systemen.

Printed in Germany 123467 


\section{Inhaltsverzeichnis}

Abbildungen $\quad 10$

Tabellen 11

\section{Teil 1}

Der Länderfinanzausgleich - Grundlagen, Darstellung und Wirkungen

I. Problemstellung und Aufbau der Arbeit 15

A. Der Hintergrund des Gutachtens 15

B. Die Vorgehensweise im Überblick 15

II. Föderalismus und Finanzausgleich aus ökonomischer Sicht 19

A. Begriff und Funktionen des Finanzausgleichs 19

B. Die Verteilung der Aufgaben, Ausgaben und Einnahmen 21

1. Okonomische Kriterien der Aufgabenverteilung 22

a. Orientierung an den Bürgerpräferenzen 22

b. Effiziente Produktion staatlicher Leistungen 25

c. Distributive und stabilitätspolitische Aspekte 27

2. Konsequenzen für die primăre Verteilung der Einnahmen 28

a. Die vertikale Verteilung der Steuereinnahmen 29

b. Die horizontale Verteilung der Steuereinnahmen 32

3. Die Umverteilung der Einnahmen (Finanzausgleich i. e. S.) 33

a. Umverteilung über allgemeine Finanzzuweisungen 33

b. Kostenersatz bei fremdbestimmten Leistungen 35

c. Die Kompensation von Spillover-Effekten 37

d. Die Angleichung der Infrastrukturausstattung 40

4. Finanzausgleich zwischen Effizienz und Verteilung 41

a. Finanzausgleich aus allokativer Sicht 41

b. Finanzausgleich aus distributiver Sicht 43

C. Kooperation und Wettbewerb im Föderalismus 45 
III. Darstellung und Wirkungen des Länderfinanzausgleichs

A. Die verschiedenen Stufen des Länderfinanzausgleichs 49

1. Die vertikale Steuerverteilung 50

2. Die horizontale Steuerverteilung 52

a. Die Verteilung der Einkommensteuer $\quad 52$

b. Die Verteilung der Umsatzsteuer 54

3. Der Finanzausgleich unter den Ländern 56

a. Finanzkraft und Finanzbedarf $\quad 57$

b. Ausgleichszuweisungen und Ausgleichsbeiträge $\quad 58$

c. Verteilungseffekte des Länderfinanzausgleichs i. e.S. 60

4. Die Bundesergänzungszuweisungen 61

a. Fehlbetrags-Bundesergänzungszuweisungen 62

b. Sonderbedarfs-Bundesergänzungszuweisungen 64

5. Der Fonds "Deutsche Einheit" 67

B. Finanzielle Auswirkungen des Ausgleichsverfahrens 69

1. Zur Messung der Umverteilungseffekte 69

2. Die einzelnen Stufen der Umverteilung 71

a. Umverteilung durch Umsatzsteuer-Vorwegausgleich 71

b. Umverteilung durch den Länderfinanzausgleich i.e. S. 73

c. Umverteilung durch Bundesergänzungszuweisungen 74

3. Die Gesamtwirkungen der Umverteilung 77

a. Die durchschnittlichen Belastungen und Entlastungen $\quad 77$

b. Veränderungen der relativen Finanzkraftpositionen 80

4. Die Grenzbelastungen 84

a. Ermittlung der marginalen Abschöpfungsquoten 85

b. Ursachen und Wirkungen einer hohen Grenzbelastung 87 


\section{Teil 2}

\section{Kritik des Länderfinanzausgleichs und Ansatzpunkte einer Reform}

I. Probleme des Länderfinanzausgleichs im Überblick

II. Fragen der vertikalen und horizontalen Steuerverteilung

A. Besteuerungskompetenzen und regionale Steuerverteilung

B. Horizontaler Finanzausgleich über die Umsatzsteuerverteilung

100

1. Kritik des Umsatzsteuer-Vorwegausgleichs

2. Die Ergănzungsanteile als Sockelgarantie

3. Die Netto-Verteilungseffekte der Ergănzungsanteile

4. Bewertung des Umsatzsteuer-Vorwegausgleichs

III. Der horizontale Lănderfinanzausgleich im engeren Sinne

A. Verminderung der Finanzkraftmeßzahl: Die "Hafenlasten“

1. Grundprobleme der Anrechnung von Sonderbedarfen

2. Begründung und Kritik der Hafenlastenregelung

a. Die "Tradition" der Hafenlastenregelung

b. Positive externe Effekte der Seehăfen

c. Zur Internalisierung der externen Effekte

3. Verteilungseffekte der Hafenlastenregelung

4. Beurteilung der Hafenlastenregelung

B. Erhőhung der Ausgleichsmeßzahl: Das „Stadtstaatenprivileg“

1. Zur Begründung der Einwohnerwertung der Stadtstaaten

2. Kritik der Einwohnerwertung der Stadtstaaten

a. Stadtstaaten als Großstădte ohne Umland

b. Fehlender kommunaler Finanzausgleich

c. Einwohnerwertung zum Ausgleich externer Effekte

3. Verteilungseffekte der Einwohnerwertung

4. Alternativen zur Einwohnerwertung der Stadtstaaten 130

a. Anderung der Lohnsteuerzerlegung 131

b. Alternative Ausgleichsmaßnahmen 
C. Die Berücksichtigung der kommunalen Finanzkraft

1. Bestimmungen des Finanzausgleichsgesetzes 139

2. Grundfragen der Einbeziehung der Gemeindefinanzen 140

a. Teil- oder Vollanrechnung kommunaler Finanzkraft? 140

b. Finanzautonomie und Grenzbelastungen der Länder 142

c. Verteilungseffekte der hälftigen Anrechnung 145

3. Die Ermittlung der Finanzkraft der Gemeinden 148

a. Abgrenzung der ausgleichsrelevanten Einnahmen 148

b. Die Normierung der Einnahmen aus den Realsteuern 149

4. Die Problematik der Einwohnerwertung der Gemeinden 153

a. Zur Begründung der Einwohnerwertung 153

b. Finanzwissenschaftliche Kritik der Einwohnerwertung 154

c. Verteilungseffekte der kommunalen Einwohnerwertung 158

5. Zur künftigen Behandlung der Gemeindesteuern 160

D. Die Problematik des progressiven Ausgleichstarifs 162

1. Bestimmungen des Finanzausgleichsgesetzes 162

2. Rechtliche Grenzen der Ausgleichspflicht 133

3. Okonomische Analyse alternativer Ausgleichstarife 164

a. Anforderungen an den Ausgleichsmechanismus 164

b. Kritik des progressiven Stufentarifs 166

c. Verteilungseffekte des progressiven Stufentarifs 168

d. Abbau der Grenzbelastungen durch einen linearen Tarif 172

4. Ein Vorschlag zur Reform des Ausgleichstarifs 175

a. Entwicklung der Eckpunkte des Tarifmodells 175

b. Die Funktionsweise des Ausgleichsmechanismus $\quad 179$

c. Unterschiede zu anderen Modellen 182

d. Der Reformvorschlag im Überblick 183

IV. Die Bundesergänzungszuweisungen - „Mädchen für alles“ 185

A. Die Fehlbetrags-Bundesergänzungszuweisungen 185

B. Die Sonderbedarfs-Bundesergănzungszuweisungen 190

1. Zuweisungen wegen der Kosten politischer Führung 190

a. Die gesetzliche Regelung und ihre Verteilungseffekte 190

b. Kritik der Anrechnung der Kosten politischer Führung 193 
2. Die Übergangs-Bundesergănzungszuweisungen 198

a. Die gesetzliche Regelung und ihre Verteilungseffekte 198

b. Kritik der Übergangs-Bundesergänzungszuweisungen 200

3. Die Sanierungs-Bundesergănzungszuweisungen 204

a. Begründung und Verteilungseffekte der Zuweisungen 204

b. Der Stand der Konsolidierungsbemühungen 206

c. Mögliche Ursachen einer Haushaltsnotlage 209

d. Okonomische Fehlanreize durch Sanierungshilfen 210

e. Finanzkrisen und Finanzverfassung 213

4. Bundesergănzungszuweisungen für die neuen Länder 214

a. Die gesetzliche Regelung und ihre Verteilungseffekte 214

b. Zur Begründung der Hilfen für die neuen Länder 217

c. Der Ausgleich der kommunalen Finanzschwäche 218

d. Der Abbau der teilungsbedingten Sonderlasten 219

e. Bewertung der Bundesergänzungszuweisungen 222

V. Konsequenzen für eine Reform des Länderfinanzausgleichs 225

A. Übermäßige Nivellierung und extrem hohe Grenzbelastungen 225

B. Zweifelhafte Maßstäbe im horizontalen Länderfinanzausgleich 226

C. Bundesergănzungszuweisungen - notwendig oder überflüssig? 228 


\section{Abbildungen}

Abbildung 1: Wirkungen der Umsatzsteuerverteilung 56

$\begin{array}{lll}\text { Abbildung 2: Horizontaler Lănderfinanzausgleich } & 60\end{array}$

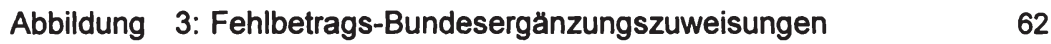

Abbildung 4: Sonderbedarfs-Bundesergänzungszuweisungen 64

Abbildung 5: Umverteilung durch Umsatzsteuer-Vorwegausgleich 72

Abbildung 6: Umverteilung durch Länderfinanzausgleich i. e. S. 73

Abbildung 7: Umverteilung durch Bundesergänzungszuweisungen $\quad 76$

Abbildung 8: Normierte Abschöpfungs- und Zuweisungsquoten 78

Abbildung 9: Abschöpfungs- und Zuweisungsquoten ohne BEZ 80

Abbildung 10: Relative Finanzkraft vor und nach Finanzausgleich 82

Abbildung 11: Relative Finanzkraft vor und nach LFA ohne BEZ 83

Abbildung 12: Grenzbelastungen im Finanzausgleich 86

Abbildung 13: Grenzbelastungen und Gemeindesteuern 144

Abbildung 14: Linearer Tarif mit Umsatzsteuer-Vorwegausgleich 173

Abbildung 15: Linearer Tarif ohne Umsatzsteuer-Vorwegausgleich 174

Abbildung 16: Ausgleichssatz und Grenzbelastung 180 


\section{Tabellen}

Tabelle 1: Verteilungseffekte des Umsatzsteuer-Vorwegausgleichs 104

Tabelle 2: Verteilungseffekte der Hafenlastenregelung 118

Tabelle 3: Funktionsüberschüsse im Dienstleistungsbereich 127

Tabelle 4: Verteilungseffekte der Einwohnerwertung der Stadtstaaten 129

Tabelle 5: Lohnsteuerzerlegung zu $50 \%$ nach dem Betriebsstättenprinzip

Tabelle 6: Verteilungseffekte einer Lohnsteuerzerlegung zu $50 \%$ nach dem Betriebsstättenprinzip

Tabelle 7: Verteilungseffekte der Anrechnung der Gemeindesteuern 146

Tabelle 8: Verteilungseffekte der Einwohnerwertung der Gemeinden 159

Tabelle 9: Verteilungseffekte des progressiven Ausgleichstarifs $\quad 169$

Tabelle 10: Fehlbetrags-Bundesergänzungszuweisungen 187

Tabelle 11: Ergănzungszuweisungen für Kosten politischer Führung 192

Tabelle 12: Übergangs-Bundesergänzungszuweisungen 199

Tabelle 13: Belastungen der alten Länder infolge der Integration der neuen Länder in den Länderfinanzausgleich 202

Tabelle 14: Sanierungs-Bundesergănzungszuweisungen 206

Tabelle 15: Bundesergänzungszuweisungen für die neuen Länder 215 
Wolfgang Scherf - 978-3-631-75181-7

Downloaded from PubFactory at 01/11/2019 07:24:58AM

via free access 
TEIL 1

DER LÄNDERFINANZAUSGLEICH - GRUNDLAGEN, DARSTELLUNG UND WIRKUNGEN 
Wolfgang Scherf - 978-3-631-75181-7

Downloaded from PubFactory at 01/11/2019 07:24:58AM

via free access 


\section{Problemstellung und Aufbau der Arbeit}

\section{A. Der Hintergrund des Gutachtens}

Die Hessische Landesregierung hat im Januar 1999 einen Normenkontrollantrag beim Bundesverfassungsgericht eingereicht, der darauf abzielt, die Verfassungswidrigkeit des Finanzausgleichsgesetzes (FAG) festzustellen. Der Antrag richtet sich gegen $\S 1$ Absatz 3, $\$ 7$ Absatz 1 Satz 3 und Absatz $3, \S 9$ Absätze 2 und $3, \S 10$ sowie $\S 11$ Absätze 2, 3 und 5 des Finanzausgleichsgesetzes, die nach Auffassung der Hessischen Landesregierung mit dem Grundgesetz, insbesondere mit Artikel 107 und Artikel 20 Absatz 1 GG, unvereinbar sind.

Mit Blick auf die angestrebte Reform des Länderfinanzausgleichs und grundsätzlich unabhängig von dem anstehenden Verfassungsstreitverfahren sieht die Hessische Landesregierung erheblichen Diskussions- und Verhandlungsbedarf. Das vorliegende Gutachten hat die Aufgabe, den heutigen Länderfinanzausgleich einschließlich der Bundesergänzungszuweisungen aus finanzwissenschaftlicher Sicht zu analysieren und Möglichkeiten einer zielgerichteten Weiterentwicklung aufzuzeigen. Dies dient der Vorbereitung der mit Wirkung ab 2005 ohnehin notwendigen Neuordnung des Finanzausgleichs, die nach Auffassung der Hessischen Landesregierung gegenüber dem heutigen System stärker auf ökonomische Anreize für Leistungssteigerungen setzen und den Nivellierungsgrad des Ausgleichsverfahrens reduzieren sollte. Dabei wird die Notwendigkeit einer weiteren Unterstützung des Aufbaus in den neuen Bundesländern anerkannt.

\section{B. Die Vorgehensweise im Überblick}

Das Gutachten gliedert sich in zwei Hauptteile. Der erste Teil ist den okonomischen Grundlagen des Länderfinanzausgleichs, der Darstellung des bundesdeutschen Systems und der Analyse seiner finanziellen Konsequenzen gewidmet. Im zweiten Teil erfolgt eine kritische Auseinandersetzung mit den verschiedenen Elementen des Ausgleichsverfahrens unter Berücksichtigung der Ansatzpunkte einer grundlegenden Reform. 
Teil 1 - Kapitel II gibt zunächst einen Überblick über die aus ókonomischer Sicht zentralen Aspekte der Finanzverfassung in einem föderativen Staat. Im Vordergrund steht dabei die Frage nach der ökonomisch rationalen Verteilung der Aufgaben, Ausgaben und Einnahmen auf die verschiedenen $\mathrm{Ge}$ bietskörperschaften. Aus einer vorwiegend allokativ begründeten Aufgabenund Ausgabenverteilung werden zunächst Konsequenzen für eine daran angepaßte Primärverteilung der Steuereinnahmen gezogen. Anschließend geht es um den Finanzausgleich im engeren Sinne, der teils aus allokativen, überwiegend jedoch aus distributiven Gründen eine Umverteilung der Einnahmen zwischen den Gebietskörperschaften herbeiführen soll.

Teil 1 - Kapitel III dient der Darstellung des Länderfinanzausgleichs und seiner Verteilungswirkungen. Der Aufbau folgt der Systematik der verschiedenen Ausgleichsstufen. Dem Länderfinanzausgleich im engeren Sinne gehen die vertikale Steuerverteilung zwischen Bund und Ländern und die horizontale Steuerverteilung unter den Ländern voraus. Im Zentrum des öffentlichen Interesses steht aber der horizontale Ausgleich unter den Ländern, der mit direkten Zahlungen zwischen armen und reichen Bundesländern verbunden ist. Gleichwohl verdienen die nachfolgend gewährten Bundesergänzungszuweisungen aufgrund ihrer qualitativen und quantitativen Bedeutung für die Finanzkraft der Länder ebensoviel Aufmerksamkeit.

Teil 2 - Kapitel I des Gutachtens enthält eine zusammenfassende Darstellung der Kritik am heutigen Länderfinanzausgleich. Das System weist aus ökonomischer Sicht einige grundlegende Defekte und noch mehr Unstimmigkeiten im Detail auf. Das Hauptproblem besteht in der überzogenen Nivellierung der Länderfinanzkraft, die mit extrem hohen Grenzbelastungen der Länderhaushalte durch den Finanzausgleich einhergeht. Neben diesen unter Anreizaspekten schädlichen Eigenschaften des Systems sind die geringe Autonomie der Länder, die widersprüchliche Gestaltung der verschiedenen Ausgleichsstufen, die mangelhafte Transparenz sowie die dadurch hervorgerufene Strategieanfälligkeit des Verfahrens zu beanstanden.

Teil 2 - Kapitel II eröffnet die detaillierte finanzwissenschaftliche Analyse und Beurteilung der verschiedenen Stufen des Länderfinanzausgleichs. Im ersten 
Schritt steht die vertikale und horizontale Verteilung der Steuereinnahmen zwischen den Gebietskörperschaften zur Debatte. Sie determiniert die Finanzkraft der Länder vor Finanzausgleich und beeinflußt damit in erheblichem Maße den Ausgleichsbedarf auf den weiteren Stufen. Entscheidende Bedeutung hat im heutigen System die Verteilung der Umsatzsteuer, die teilweise nach der Finanzkraft der Lănder erfolgt und damit bereits ein Element des horizontalen Ausgleichs unter den Ländern beinhaltet.

Teil 2 - Kapitel III ist dem horizontalen Länderfinanzausgleich im engeren Sinne und damit dem Brennpunkt des Systems gewidmet. Auf dieser Stufe des Ausgleichsverfahrens sind mit der Abgrenzung der Bemessungsgrundlagen und der Gestaltung des Umverteilungstarifs zwei Problemkreise zu differenzieren, die auf unterschiedliche Weise zur (Über-) Nivellierung beitragen. Die Bemessungsgrundlagen des Finanzausgleichs verdienen aus ökonomischer Sicht besondere Aufmerksamkeit, denn die Umverteilung zwischen den Ländern hängt in starkem Maße von der Art und Weise der Bestimmung ihrer Finanzkraft und ihres Finanzbedarfs ab. Diskussionsbedürftig erscheinen in diesem Zusammenhang die Hafenlastenregelung, die Einwohnenwertung der Stadtstaaten und die Einbeziehung der Gemeindesteuern einschließlich der besonderen Einwohnerwertung der Gemeinden. Im Zentrum der Kritik am heutigen Umverteilungstarif steht die progressive Abschöpfung der überdurchschnittlichen Finanzkraft sowie die daraus resultierende außerordentliche Grenzbelastung finanzstarker Länder, die aus fiskalischer Sicht negative Verhaltensanreize induzieren kann.

Teil 2 - Kapitel IV beschäftigt sich mit der Rolle der Bundesergänzungszuweisungen, die den finanzschwachen Lăndern aus unterschiedlichen Gründen und in unterschiedlichem Maße gewährt werden. Eine Umverteilung zu Lasten der Länder, die vor Finanzausgleich noch über eine überdurchschnittliche Finanzkraft verfügen und deshalb keine Bundesergänzungszuweisungen erhalten, kommt durch den impliziten Verzicht auf Umsatzsteuereinnahmen zustande. Diese könnten der Ländergesamtheit zufließen, wenn der Bund keine oder geringere Ergănzungszuweisungen zu leisten hătte. Die Bundesergänzungszuweisungen bewirken erheblichen Verschiebungen in den Finanzkraftpositionen der Länder, die das (Über-) Nivellierungsverbot 
grundsătzlich nur dann verletzen, wenn und soweit die Bundesergănzungszuweisungen sachlich nicht zu rechtfertigen sind. Problematisch erscheinen in dieser Hinsicht jedoch alle Bundesergänzungszuweisungen mit Ausnahme der Aufbauhilfen für die neuen Bundesländer.

Teil 2 - Kapitel V faßt die aus der Analyse des Länderfinanzausgleichs resultierenden Konsequenzen für eine zielgerichtete Reform zusammen. Da die einzelnen Ausgleichselemente ineinandergreifen und oftmals erst dadurch problematische Wirkungen zustande kommen, erfordert die Neugestaltung des Systems ein Gesamtkonzept. Isolierte Reformschritte kommen nur in Betracht, wenn sie mit diesem Konzept vereinbar sind und auch für sich genommen eine Verbesserung des Länderfinanzausgleichs bewirken.

Die Diskussion über den Länderfinanzausgleich wird verstăndlicherweise von den Beteiligten primär unter fiskalischen Gesichtspunkten geführt. Auch wenn eine finanzwissenschaftliche Beurteilung sich weniger an den quantitativen Ergebnissen als an den qualitativen Eigenschaften des Ausgleichsverfahrens zu orientieren hat, müssen dessen finanzielle Folgen aufgezeigt und mit den relevanten Alternativen konfrontiert werden. Alle dazu erforderlichen Berechnungen, die sich in der Regel auf den Länderfinanzausgleich des Jahres 1998 beziehen, wurden mit einem Simulationsprogramm des Hessischen Ministeriums der Finanzen durchgeführt ${ }^{1}$.

1 Eine Dokumentation des Simulationsprogramms LFA 95 liegt vor. Vgl. Weiß, 1996. 


\section{Föderalismus und Finanzausgleich aus ökonomischer Sicht}

\section{A. Begriff und Funktionen des Finanzausgleichs ${ }^{1}$}

Staatliche Aktivitäten konzentrieren sich in den meisten westlichen Industrieländern nicht bei einem Entscheidungsträger, sondern werden von verschiedenen Körperschaften mit differenzierten und teilweise autonomen Befugnissen ausgeübt. Der föderative Gehalt eines vertikal und horizontal gegliederten Staatsaufbaus wird durch die Zentralităt bzw. Dezentralităt der politischen Entscheidungsrechte bestimmt. In einem zentralisierten Finanzsystem mit einer einzigen Regierungseinheit mag es aus organisatorischen Gründen Untereinheiten mit Ausführungsbefugnissen geben, doch diese erhalten ihre Aufgaben und die erforderlichen Finanzmittel von der Zentralinstanz zugewiesen. Demgegenüber zeichnet sich ein dezentralisiertes Finanzsystem dadurch aus, daß neben der Zentralinstanz (Bund) weitere autonome Entscheidungseinheiten (Länder, Gemeinden) existieren. Wie die Entscheidungsbefugnisse auf die Gebietskörperschaften aufgeteilt werden sollten, ist eine primär verfassungsrechtliche, aber auch eine in hohem Grade okonomische Frage und als solche Gegenstand der okonomischen Theorie des Foderalismus.

Die Zuordnung von Kompetenzen auf unterschiedliche Ebenen kann nicht auf die Aufgaben und die damit verbundenen Ausgaben begrenzt werden. Die untergeordneten Gebietskörperschaften 2 benötigen im Sinne einer Finanzautonomie auch die ihren Aufgaben entsprechenden Finanzmittel und das (gegebenenfalls begrenzte) Recht, über Ausgaben und Einnahmen selbst bestimmen zu können. Daher ist die Aufgaben-, Ausgaben- und Einnahmenverteilung in einem fodderativen Staat, also die Regelung der gesamten Finanzverfassung, Gegenstand des Finanzausgleichs im weiteren Sinne. Der Finanzausgleich im engeren Sinne beschränkt sich dagegen auf Finanzzuweisungen zwischen den staatlichen Institutionen, insbesondere

1 Vgl. z. B. Peffekoven, 1980, S. 608 ff; Zimmermann/Henke, 1994, S. $171 \mathrm{ff}$.

2 Wenn hier und im folgenden von „untergeordneten“ oder „nachgeordneten“ Gebietskorperschaften die Rede ist, beziehen sich diese Begriffe nicht auf die verfassungsrechtliche Stellung der staatlichen Institutionen. 
zum Ausgleich einer bezogen auf den Finanzbedarf zu stark differierenden Finanzkraft der Gebietskörperschaften.

Der Finanzausgleich im weiteren Sinne hat eine vertikale und eine horizontale Komponente. Gegenstand des vertikalen Finanzausgleichs ist die Verteilung der Aufgaben, Ausgaben und Einnahmen zwischen Gesamtstaat (Bund) und Gliedstaaten (Länder). Dabei wird oftmals differenziert zwischen dem passiven Finanzausgleich, der die Zuordnung der Aufgaben auf die verschiedenen Ebenen betrifft, und dem aktiven Finanzausgleich, der die vertikale Ausstattung mit Finanzmitteln umfaßt. Beim vertikalen Finanzausgleich stehen Fragen des Staatsaufbaus, der Kompetenzverteilung und der Autonomie im Vordergrund, die beim horizontalen Finanzausgleich als weitgehend gelöst gelten.

Der horizontale Finanzausgleich bezieht sich auf die unterhalb der Zentralgewalt angesiedelten gleichrangigen Institutionen (Länder, Gemeinden). Auf der gleichen Ebene lassen sich Aufgaben, Ausgaben und Einnahmen nicht bei allen Gebietskörperschaften gleich gut zur Deckung bringen. Durch einen horizontalen Finanzausgleich können die nach vertikaler Verteilung der (Steuer-) Einnahmen noch verbleibenden Unterschiede zwischen Ausgaben (Finanzbedarf) und Einnahmen (Finanzkraft) abgebaut werden. In diesem Zusammenhang geht es vor allem um die exakte Ermittlung von Finanzkraft und Finanzbedarf sowie um adäquate Ausgleichsverfahren.

In der Praxis werden horizontale und vertikale Elemente des Finanzausgleichs häufig miteinander kombiniert, um horizontale Ausgleichsziele in den vertikalen Ausgleich zu integrieren 1 . In solchen Fällen spricht man von einem vertikalen Finanzausgleich mit horizontalem Effekt. Allerdings führt die Vermischung horizontaler und vertikaler Ausgleichsregelungen oftmals nicht zu einer optimalen Zielerreichung und in jedem Fall zu einer Erhöhung der Intransparenz des Ausgleichsverfahrens. Daher ist es angebracht, die verschiedenen Ebenen - zumindest in der theoretischen Analyse - klar voneinander zu trennen.

1 Beispiele im System des Länderfinanzausgleichs sind die Vorwegverteilung von 25 vH der Umsatzsteuer an die finanzschwachen Bundesländer und die Fehlbetrags-Bundesergänzungszuweisungen. 


\section{B. Die Verteilung der Aufgaben, Ausgaben und Einnahmen}

Die folgenden Überlegungen zur Begründung des Föderalismus und des Finanzausgleichs stellen die wirtschaftspolitischen Ziele in den Vordergrund. Dabei darf nicht verkannt werden, daß ein föderativer Staatsaufbau in starkem Maße nicht-ökonomischen Zielen dient. Die bundesstaatliche Ordnung wirkt einer staatspolitisch unerwünschten Machtkonzentration durch vertikale Gewaltenteilung entgegen. Die Dezentralisierung der Macht sichert Freiheitlichkeit und Pluralităt, erhöht die politischen Einflußmöglichkeiten der Bürger und schützt Minderheiten.

Die Funktionsfähigkeit einer bundesstaatlichen Ordnung ist freilich unmittelbar mit der Gestaltung der Finanzverfassung und des Finanzausgleichs verknüpft. Föderalismus setzt eine hinreichende Finanzausstattung und Finanzautonomie der verschiedenen staatlichen Ebenen voraus. Die Regelungen der Finanzverfassung und des Finanzausgleichs sollen nach Auffassung des Bundesverfassungsgerichts "eine Finanzordnung sicherstellen, die den Gesamtstaat und die Gliedstaaten am Gesamtertrag der Volkswirtschaft sachgerecht beteiligt; Bund und Länder müssen im Rahmen der verfügbaren Gesamteinnahmen so ausgestattet werden, daß sie die zur Wahrnehmung ihrer Aufgaben erforderlichen Ausgaben leisten können“1.

Die ökonomische Theorie des Föderalismus und des Finanzausgleichs versucht, die "sachgerechte" Verteilung der Aufgaben, Ausgaben und Einnahmen auf die verschiedenen staatlichen Ebenen ökonomisch zu begründen. Dabei spielen mehrere Kriterien eine Rolle, die sich aus den Zielen der Finanzpolitik ableiten und nach allokativen, distributiven sowie stabilitätspolitischen Gesichtspunkten differenzieren lassen2 2 . Die allokativen Kriterien, die eine effiziente Bereitstellung staatlicher Leistungen gemäß der Präferenzen der Bürger verlangen, spielen eine herausgehobene Rolle für die Begründung eines föderativen Staatsaufbaus, während distributive und stabilitätspolitische Kriterien eher für eine zentrale Aufgabenerfüllung sprechen.

1 BVerfGE 55, 274, S. 300.

2 Diese Differenzierung geht zurück auf Musgrave, 1969, S. $5 \mathrm{ff}$. 


\section{1. Ökonomische Kriterien der Aufgabenverteilung \\ a. Orientierung an den Bürgerpräferenzen}

Betrachtet man den Staat in erster Linie als eine Institution zur möglichst weitgehenden Verwirklichung der Bedürfnisse seiner Bürger ${ }^{1}$, so stellt sich die Frage, inwieweit ein föderativer Staatsaufbau dem Ziel der Präferenzerfüllung dient. Ein zentrales Problem ergibt sich in diesem Zusammenhang daraus, daß kollektive Beschlüsse aufgrund der damit einhergehenden Verhandlungskosten in der Regel nicht einstimmig und direkt von allen wahlberechtigten Bürgern gefällt werden können. Vielmehr erfolgen die Entscheidungen typischerweise im Rahmen einer repräsentativen Demokratie unter Anwendung der Mehrheitsregel. Charakteristisch für dieses Verfahren ist zum einen, daß die Vorstellungen der Wähler nicht unmittelbar, sondern über die Auswahl der Repräsentanten in die staatlichen Entscheidungen einfließen. Zum anderen können die Bedürfnisse der Minderheiten übergangen werden. Beides zusammen führt zwangslăufig zu Abweichungen vom Ziel der bestmöglichen Orientierung an den Präferenzen der Bürger.

Eine dezentrale Gliederung des Staates in verschiedene Gebietskörperschaften soll dazu beitragen, die Unvollkommenheiten des demokratischen Entscheidungsprozesses in ihrer Bedeutung zu mindern. Die größere Bürgernähe und die regionale Begrenztheit der untergeordneten Gebietskörperschaften erscheint aus der Perspektive einer bedarfsgerechten und insofern allokativ effizienten Versorgung mit staatlichen Leistungen vorteilhaft.

(1) Der Einfluß der Bürger auf die politischen Entscheidungen wächst mit abnehmender Größe der Entscheidungseinheit. Damit nehmen einerseits die Möglichkeiten zur (Mit-) Gestaltung des Angebots an öffentlichen Leistungen zu, andererseits müssen die Bürger ihre Präferenzen offenbaren, wenn sie, z. B. auf der Gemeindeebene, Einfluß auf die Politiker und damit auf die kollektiven Entscheidungen ausüben wollen.

1 Dies entspricht einer individualistischen Staatsauffassung, die dem Staat grundsätzlich keine eigenstăndigen, kollektiven Bedürfnisse zubilligt, sondern die Staatstătigkeit im wesentlichen aus den individuellen Bedürfnissen der Bürger ableitet und begründet. 
(2) Die Bürgerpräferenzen dürften zwischen den Regionen stärker streuen als innerhalb der regional begrenzten nachgeordneten Gebietskörperschaften. Daher ist die Gefahr, daß (regionale) Minderheitenpräferenzen übergangen werden, bei dezentraler Entscheidungsfindung geringer als bei zentralisiertem Angebot an Staatsleistungen ${ }^{1}$. Relativiert wird dieses Argument allerdings dadurch, daß größere Gebietskörperschaften differenziertere Leistungen anbieten und daher potentiell besser auf die Wünsche von Minderheiten eingehen können².

(3) Ein föderatives System bietet nicht nur bessere Voraussetzungen für eine an den Bürgerpräferenzen orientierte Bereitstellung staatlicher Leistungen, sondern auch einen besseren Schutz gegen die Nichtbeachtung des Bürgerwillens seitens der lokalen politischen Repräsentanten. Den Bürgern bleibt - neben der Abwahl - die Möglichkeit der Abwanderung in andere Regionen mit einem anderen Güterangebot, das $u$. U. mit entsprechenden Differenzen in der regionalen Steuerbelastung einhergeht ${ }^{3}$. Erschwert und in ihrer realen Bedeutung reduziert wird eine solche "Abstimmung mit den Füßen 4 freilich durch die (nicht nur monetären) Kosten der Wanderungen.

(4) Regional differenzierte Angebote an staatlichen Leistungen, eventuell verbunden mit unterschiedlichen Finanzierungssystemen, liefern Informationen und Erfahrungen, die für die Weiterentwicklung und Verbesserung der offentlichen Einrichtungen nützlich sein können. Der Föderalismus und der damit verbundene begrenzte Wettbewerb zwischen den Gebietskörperschaften ist so gesehen auch ein Entdeckungsverfahren für institutionelle Neuerungen.

1 Gemessen am Nutzen der Bürger ist eine dezentrale Bereitstellung offentlicher Güter einer einheitlichen zentralen Güterversorgung tendenziell überlegen (Dezentralisierungstheorem). Vgl. Oates, 1972, S. 35.

2 Vgl. Wissenschaftlicher Beirat beim Bundesministerium der Finanzen, 1992, S. 42.

3 Letzteres setzt eine gewisse Steuerautonomie voraus. Derzeit verfügen zwar die Gemeinden, nicht aber die Länder über einen begrenzten Gestaltungsspielraum durch das Hebesatzrecht bei den Realsteuern. Diese Kommunalsteuern knüpfen allerdings nicht am Einkommen der Bürger an, so daß deren Standortwahl kaum von steuerlichen Faktoren beeinflußt wird.

4 Vgl. Tiebout, 1956, S. $416 \mathrm{ff}$. 
Die skizzierten Argumente sprechen prinzipiell für eine dezentrale Bereitstellung offentlicher Güter und rechtfertigen die Übertragung der finanzpolitischen Verantwortung für Einnahmen und Ausgaben auf lokale Regierungen mit weitgehender Finanzautonomie. Diese ordnungspolitische Grundaussage bedarf allerdings der Bindung an bestimmte Voraussetzungen. Die Vorteilhaftigkeit eines föderalistischen Staatsaufbaus hängt insbesondere davon $a b, d a ß$ Entscheidungsträger, Nutznießer und Finanzierungsträger der Staatsleistungen räumlich weitgehend übereinstimmen. Nur in diesem Fall sind neben dem Autonomieprinzip auch die finanzwissenschaftlichen Prinzipien der Konnexität und der fiskalischen Åquivalenz erfüllt.

(1) Die Forderung nach Konnexität beinhaltet die Verknüpfung der Aufgaben- und Ausgabenkompetenz und damit die Übereinstimmung der Entscheidungs- und Kostenträger staatlicher Leistungen. Liegen Entscheidungs- bzw. Gesetzgebungskompetenz und Durchführungszuständigkeit bei unterschiedlichen Aufgabentrăgern, so soll die Entscheidungskompetenz den Ausschlag für die Finanzierungszuständigkeit geben. Andernfalls besteht die Gefahr, daß Beschlüsse ohne hinreichende Berücksichtigung ihrer finanziellen Folgen getroffen werden.

(2) Nach dem Prinzip der fiskalischen Áquivalenz sollen die Nutznießer der Staatsleistungen auch die mit der Bereitstellung verbundenen Kosten tragen. Diese Forderung ist für Gebietskörperschaften global erfültt, wenn die Gesamtsteuerzahlung der Bürger den Gesamtkosten der bereitgestellten Staatsleistungen entspricht' ${ }^{1}$. Die Anwendung des Äquivalenzprinzips zielt nicht zuletzt auf eine Begrenzung der Staatstätigkeit. Wenn die Nutznießer regionaler öffentlicher Güter Zuschüsse aus anderen Regionen oder vom Zentralstaat erhalten, besteht die Gefahr einer zu hohen und damit suboptimalen Nachfrage nach solchen Gütern².

1 Eine über diese gruppen- und kostenmäßige Aquivalenz hinausgehende Verknüpfung zwischen den Staatsleistungen und ihrer Finanzierung im Sinne einer individuellen, möglichst am persönlichen Nutzen orientierten Belastung der Bürger ist in der Regel nicht praktikabel. Wenn eine solche Verknüpfung hergestellt werden kann, ist der Staat auch nicht auf die Besteuerung angewiesen, sondern kann mit Gebühren und Beitrăgen operieren.

2 Sofern die regionalen Leistungen auch Gebietsfremden zugute kommen (positive exteme Effekte), ist eine Mitfinanzierung allerdings allokativ erwünscht. Vgl. S. 37 ff. 
Fiskalische Áquivalenz erhöht die Intensităt des Abwägens zwischen den positiven Wirkungen der offentlichen Ausgaben und den negativen Belastungseffekten der Besteuerung. Wenn die Entscheidungsträger alle relevanten Kosten und Nutzen berücksichtigen und keine Ausdehnung der Staatsleistungen zu Lasten Dritter beschließen können, ist auch das Prinzip der institutionellen Kongruenz erfüllt: „Der Kreis der Nutznießer deckt sich mit dem der Entscheidungsträger und dem der Steuerzahler ${ }^{\text {"1 }}$. Dies impliziert die Finanzierung einer Gebietskörperschaft aus eigenen (Steuer-) Mitteln unter weitgehendem Verzicht auf einen Finanzausgleich². Die Finanzierung ortlicher, überörtlicher und nationaler Aufgaben hat durch die entsprechenden Ebenen des Staates zu erfolgen. Innerhalb der für die Finanzierung lokaler und regionaler Aufgaben zuständigen Ebenen ist zudem eine răumliche Übereinstimmung der Aufgaben-, Ausgaben- und Einnahmenverantwortung erforderlich.

\section{b. Effiziente Produktion staatlicher Leistungen}

Die Erfüllung der Prinzipien der Autonomie, der Konnexităt und der fiskalischen Åquivalenz erhőht die Wahrscheinlichkeit eines an den regional unterschiedlichen Präferenzen der Bürger orientierten und in diesem Sinne struktureffizienten Angebots an offentlichen Gütern. Allokative Effizienz beinhaltet aber nicht nur die Berücksichtigung der individuellen Präferenzen, sondern auch die kosteneffiziente Bereitstellung staatlicher Leistungen 3 . Die Vorteilhaftigkeit einer moglichst dezentralen Aufgabenverteilung ist erheblich zu relativieren, wenn man die mit der Produktions- und Kosteneffizienz verbundenen Probleme in die Betrachtung einbezieht.

Produktionseffizienz spricht für eine zentrale Aufgabenerfüllung, wenn Skalenertrăge (economies of scale) andernfalls nicht genutzt werden können. Zunehmende Skalenertrăge in der Produktion laufen darauf hinaus, daß die Durchschnittskosten bei steigender Produktionsmenge (bereichsweise) sin-

1 Blankart, 1998, S. 533.

2 Ein Finanzausgleich ist aus der Sicht der institutionellen Kongruenz nur dann notwendig, wenn grenzüberschreitende Spillover-Effekte auftreten.

3 Vgl. z. B. Peffekoven, 1980, S. 613 ff; Andel, 1998, S. 504. 
ken. Daher können bestimmte Güter (z. B. Universitäten) nicht sinnvoll in kleinen Einheiten angeboten werden. Besteht zwischen der Zentralität und der Produktion zu minimalen Kosten ein positiver Zusammenhang, so erscheint eine stark dezentrale Aufgabenerfüllung unzweckmäßig1. Dies gilt zumindest in den Fällen, in denen staatliche Bereitstellung und Produktion der Leistungen nicht so getrennt werden können, daß eine kleine Gebietskörperschaft in der Lage wäre, die Leistungen in dem von ihr gewünschten Umfang von anderen öffentlichen oder privaten Produzenten zu erwerben.

Bei öffentlichen Gütern spielen neben den Skalenerträgen in der Produktion typischerweise Skalenerträge in der Nutzung eine Rolle². Offentliche Güter können von zusätzlichen Individuen innerhalb der vorhandenen Kapazitäten ohne Mehrkosten genutzt werden, solange keine Überfüllungsphänomene auftreten, welche die Durchschnittskosten wieder steigen lassen. Auch dieser Gesichtspunkt spricht gegen eine allzu dezentrale Aufgabenerfüllung. $\mathrm{Zu}$ beachten sind jedoch die Mehrkosten der Nutzer, die infolge einer stärkeren Zentralisierung zustande kommen, z. B. die höheren Fahrtkosten und der größere Zeitaufwand für die Inanspruchnahme der Leistungen, aber auch für die Beschaffung der Informationen über das staatliche Angebot ${ }^{3}$.

Insgesamt sprechen die allokativen Überlegungen nicht für eine möglichst dezentrale Versorgung der Bürger mit staatlichen Leistungen, sondern für ein differenziertes Angebot mit je nach Aufgabenstellung unterschiedlichem Zentralisierungsgrad. Die Differenzierung muß aber schon aus organisatorischen Gründen auf wenige staatliche Ebenen - Bund, Länder und Gemeinden (einschließlich der Gemeindeverbände) - begrenzt werden. Den kommunalen Gebietskörperschaften fallen im Rahmen eines idealtypischen föderativen Systems Aufgaben zu, deren Erfüllung nahezu ausschließlich die jeweiligen Einwohner (und die ortsansässigen Unternehmen) betrifft (z. B. Kindergärten, Gemeindestraßen). Der Zentralstaat hat dagegen für die Bereitstellung globaler offentlicher Güter zu sorgen, die alle Bürger berühren (z. B. innere und ăußere Sicherheit). Für die regional begrenzten Aufgaben,

1 Vgl. Zimmermann/Henke, 1994, S. 177.

2 Vgl. Blankart, 1998, S. 528-529.

3 Vgl. Wissenschaftlicher Beirat beim Bundesministerium der Finanzen, 1992, S. 44. 
die den Wirkungskreis der Gemeinden überschreiten, aber noch nicht den Gesamtstaat betreffen, sind die Länder als mittlere Gebietskörperschaften zuständig ${ }^{1}$. Alle diese staatlichen Institutionen benötigen eine hinreichende Autonomie auf der Einnahmen- und Ausgabenseite, wenn sie eigenständige Entscheidungen über ihr Angebot an offentlichen Gütern treffen sollen.

\section{c. Distributive und stabilitätspolitische Aspekte}

Verteilungs- und stabilitătspolitische Argumente sprechen überwiegend für eine zentrale Erfüllung der betreffenden Staatsaufgaben.

(1) Würden regionale Unterschiede im Ausmaß der personellen Umverteilung nur entsprechende Unterschiede in den Bürgerpräferenzen reflektieren, so wäre gegen eine dezentrale Aufgabenerfüllung wenig einzuwenden. Man muß aber beachten, daß der Wohlstand und damit der Umverteilungsspielraum regional unterschiedlich verteilt ist, was eine sehr ungleiche Versorgung der ärmeren Bevölkerungsschichten mit Sozialleistungen bewirken kann. Entscheidend ist jedoch, daß eine Föderation, die ihren Bürgern Freizügigkeit einräumt, keine effiziente dezentrale Verteilungspolitik betreiben kann, weil überdurchschnittlich zur Umverteilung neigende Gebietskörperschaften Steuerzahler abstoßen und Sozialleistungsempfänger anziehen. Solche Effekte, die der Verteilungspolitik die materielle Grundlage entziehen, lassen sich nur vermeiden, wenn die Distributionsaufgabe dem Zentralstaat übertragen wird.

(2) Auch bei der Erfüllung stabilitătspolitischer Funktionen ist der Zentralstaat gefordert. Die untergeordneten Gebietskörperschaften haben kein Interesse an der Durchführung konjunkturpolitischer Maßnahmen, die ihren Haushalt belasten, deren positive Wirkungen jedoch auch und vielleicht sogar überwiegend anderen Gebietskörperschaften zugute kommen (externe Effekte). Darüber hinaus verfügen einzelne kleine Gebietskörperschaften auch nicht über das Potential, konjunkturellen Krisen durch eine antizyklische Finanzpolitik wirksam entgegenzutreten. Infolgedessen verwundert es nicht, daß Länder und insbesondere Ge-

1 Vgl. Andel, 1998, S. 506 f. 
meinden in der Tendenz eine Parallelpolitik betreiben, $d$. h. ihre Ausgaben an den konjunkturell schwankenden Einnahmen orientieren. Zwischen föderativem Staatsaufbau und effizienter Stabilitătspolitik besteht insofern ein offenkundiger Zielkonflikt.

Die Zuordnung der distributiven und stabilitätspolitischen Aufgaben auf die zentrale Ebene bedeutet nicht zwangsläufig eine Alleinentscheidungskompetenz. Denkbar ist auch eine Kooperation der untergeordneten Gebietskörperschaften. Allerdings steigen dadurch die Kosten der Entscheidungsfindung, während die politische Verantwortung für die getroffenen Entscheidungen verwăssert wird.

\section{Konsequenzen für die primäre Verteilung der Einnahmen}

Die Verteilung der Aufgaben auf die Gebietskörperschaften determiniert in starkem Maße die Verteilung der Ausgaben, die als Kosten der Aufgabenerfüllung zu Buche schlagen. Wie erwähnt, sollte die Ausgabenkompetenz im Sinne des Konnexitätsprinzips möglichst eng mit der Aufgabenkompetenz gekoppelt sein. Bei der Primärverteilung der öffentlichen Einnahmen muß dann darauf geachtet werden, daß die einzelnen Gebietskörperschaften Finanzmittel erhalten, die der aus der Aufgabenerfüllung resultierenden Ausgabenbelastung möglichst gut entsprechen. Auch sollten die Einnahmen den Gebietskörperschaften dauerhaft zustehen, um eine verläßliche Haushalts- und Finanzplanung zu ermöglichen. Andererseits ist eine gewisse Flexibilität der Einnahmenverteilung erforderlich, um den im Zeitablauf eintretenden Verschiebungen in der Aufgabenerfüllung und der Ausgabenbelastung Rechnung tragen zu können.

Wenn den einzelnen Gebietskörperschaften aus staatspolitischen wie ökonomischen Gründen Autonomie bei den Ausgabenentscheidungen gewährt werden soll, erscheint es unabdingbar, auch auf der Einnahmenseite die Möglichkeit zur selbstverantwortlichen Ausschöpfung eigener Einnahmenquellen vorzusehen. Die Finanzierung aus Zuweisungen beinhaltet stets die Gefahr einer zu starken Einflußnahme der zahlenden Körperschaft auf Art und Umfang der Aufgabenerfüllung, aber auch das Risiko eines zu leichtfer- 
tigen Umgangs der empfangenden Körperschaft mit den zugewiesenen Mitteln. Eine unbeschränkte Steuerautomonie ist allerdings nicht anzustreben, weil sie aufgrund der Mehrfachbelastung der Steuerquellen, der möglicherweise starken regionalen Belastungsdifferenzen und der Vielzahl der Einzelsteuern mit dem Ziel einer rationalen Gestaltung des Steuersystems 1 nicht kompatibel wäre.

\section{a. Die vertikale Verteilung der Steuereinnahmen}

Hinsichtlich der Verteilung der (Steuer-) Einnahmen auf die verschiedenen staatlichen Ebenen kommen mehrere Formen einer begrenzten Autonomie in Betracht, die auch miteinander kombiniert werden können. Der Grad der Finanzautonomie der untergeordneten Ebenen ist dabei mit dem System der vertikalen Steuerverteilung verknüpft.

(1) Einen tendenziell hohen Autonomiegrad weist das gebundene Trennsystem $^{2}$ auf, bei dem den einzelnen Ebenen bestimmte Steuerquellen exklusiv zugewiesen werden. Die Unterformen reichen allerdings von der bloßen Ertragshoheit über das Aufkommen von Steuern, deren Bemessungsgrundlage und Tarif zentral festgelegt werden, über die Gestaltungsfreiheit bei den Steuersătzen (Hebesatzrecht) bis hin zur völlig autonomen Gestaltung und Ausschöpfung der zugewiesenen Steuerquellen durch die jeweilige Gebietskörperschaft.

(2) Auch ein Zuschlagsystem, das den untergeordneten Gebietskörperschaften die Möglichkeit einräumt, auf die von einer übergeordneten Ebene erhobenen Steuern einen prozentualen Zuschlag zu erheben, hat einen hohen Autonomiegrad, sofern der Zuschlag frei festgelegt werden kann. Bei vorgegebener Bandbreite oder gar Höhe der Zuschläge nähert man sich allerdings zunehmend dem Verbundsystem.

(3) Im Verbundsystem partizipieren mehrere Ebenen am Aufkommen einer Steuer, meist in Form eines gesetzlich fixierten prozentualen Anteils.

1 Vgl. dazu die "klassischen“ Arbeiten von Haller, 1981 und Neumark, 1970.

2 Das freie Trennsystem (Konkurrenzsystem) entspricht der unbeschränkten Steuerautonomie und kommt aus den genannten Gründen nicht in Betracht. 
Wenn die Befugnisse zur Gestaltung der Verbundsteuern und zur Festlegung des Verteilungsschlüssel allein beim Zentralstaat liegen, verfügt dieser über eine unbeschränkte, die untergeordneten Gebietskörperschaften dagegen über keinerlei Steuerautonomie. Häufig werden den untergeordneten Gebietskörperschaften jedoch Mitwirkungsrechte eingerăumt, die den freien Entscheidungsspielraum der Zentralinstanz reduzieren, bei Zustimmungspflicht sogar stark beeinträchtigen können.

Die bei der vertikalen Einnahmenverteilung zu treffende Auswahl der Systemelemente hängt wiederum von den allokativen, distributiven und stabilitätspolitischen Zielen der Finanzpolitik und ihrer Gewichtung ab. Grundsätzlich sollte aber jede aufgaben- und ausgabenverantwortliche Ebene über mindestens eine fiskalisch gewichtige Steuer verfügen, deren Aufkommen sie eigenständig zu beeinflussen vermag. Darüber hinaus verdienen bei der föderalen Mittelverteilung folgende Leitlinien Beachtung:

(1) Aus allokativer Sicht sollten den nachgeordneten Körperschaften (Gemeinden) die Steuern mit örtlich begrenztem Wirkungsgrad überlassen werden. Nach dem Åquivalenzprinzip sind staatliche Leistungen, die von untergeordneten Körperschaften in regional differenzierter Form angeboten werden, möglichst durch örtlich radizierbare Abgaben zu finanzieren. „Ein solches Vorgehen schafft zum einen Anreize zur Bereitstellung der jeweiligen Leistung und ruft zum anderen politischen Widerstand hervor, wenn die Wohlfahrtsverluste durch Abgabenbelastung größer werden als der Nutzen aus der bezogenen Leistung“1.

(2) Eine zentralstaatliche Gesetzgebungshoheit, die gleichwohl keine alleinige Ertragshoheit impliziert, erscheint angebracht bei Steuern, die nicht nach dem (gruppenmäßigen) Åquivalenzprinzip, sondern nach dem Leistungsfähigkeitsprinzip erhoben werden und eventuell darüber hinaus umverteilungspolitischen Zwecken dienen. Andernfalls wäre der distributive Erfolg gefährdet. Zudem könnten steuerinduzierte Verlagerungen ökonomischer Aktivitäten zustande kommen, die Zusatzkosten und womöglich auch allokative Verzerrungen hervorrufen würden.

1 Vgl. Dickertmann/Gelbhaar, 1996 a, S. 401. 
(3) Neben den besonders verteilungswirksamen sind auch die stark konjunkturreagiblen Steuereinnahmen zweckmäßigerweise dem Bund zuzuweisen. Dafür spricht vor allem, daß stabilitătspolitische Maßnahmen den Charakter von öffentlichen Gütern haben, die für die gesamte Volkswirtschaft bedeutsam sind ${ }^{1}$. Wăhrend unter Verteilungsaspekten eine zentrale Gesetzgebungshoheit ausreichend sein mag, verlangen die stabilitätspolitischen Kriterien in der Tendenz auch eine Ertragshoheit der zentralen Ebene, da gerade die untergeordneten Gebietskörperschaften häufig zu einer Parallelpolitik neigen.

Die genannten Kriterien der vertikalen Einnahmenverteilung lassen sich nicht in vollem Umfang gleichzeitig verwirklichen. Unter Berücksichtigung der begrenzten Anzahl von Steuerarten in einem rationalen Steuersystem ist es kaum möglich, jeder Ebene eine fiskalisch ergiebige Steuer zuzuordnen, die auch noch unter allokativen, distributiven und stabilitătspolitischen Gesichtspunkten der jeweiligen Ebene angemessen erscheint.

Die Hauptsteuern des deutschen Steuersystems, Einkommensteuer und Umsatzsteuer, wären - aus unterschiedlichen Gründen - Kandidaten für eine Übertragung an den Oberverband. Die Einkommensteuer bildet den zentralen Ansatzpunkt der Verteilungspolitik mit steuerlichen Instrumenten und ist darüber hinaus besonders konjunkturempfindlich. Die Umsatzsteuer zeichnet sich durch eine relativ starke regionale Streuung des Aufkommens aus, was sie nicht für untergeordnete Körperschaften prädestiniert, die ein ausgeglichenes Pro-Kopf-Aufkommen benötigen. Schon aus fiskalischen Gründen - mit Blick auf die gleichmäßige Deckung des Finanzbedarfs der verschiedenen Staatsebenen - können aber nicht beide Hauptsteuern allein dem Bund übertragen werden. Der herrschende Steuerverbund ist - bei all seinen Schwăchen - insofern durchaus als eine Lösung interpretierbar, die einen Kompromiß zwischen den Erfordernissen eines föderativen Staatsaufbaus und eines rationalen Steuersystems darstellt.

1 Vgl. Andel, 1998, S. 511. 


\section{b. Die horizontale Verteilung der Steuereinnahmen}

Mit der vertikalen Steuerverteilung ist die Finanzausstattung der Gebietskörperschaften vor Finanzausgleich (im engeren Sinne) noch nicht vollständig festgelegt. Die Steuerbefugnisse müssen - in Abhängigkeit von der Gestaltung der vertikalen Steuerverteilung - gegebenenfalls auch horizontal geregelt werden. Verfügen die nachgeordneten Körperschaften über eigene Steuerquellen, so richtet sich die horizontale Verteilung der Einnahmen nach dem Prinzip des örtlichen Aufkommens. Sind sie aber mit anderen gleichrangigen Körperschaften an einem Verbundsystem beteiligt, so stellt sich die Frage nach der adäquaten Aufteilung des einer staatlichen Ebene insgesamt zustehenden Steueraufkommens auf die einzelnen Gebietskörperschaften.

Der Zerlegungsschlüssel ist von entscheidender Bedeutung für die Verteilung der Finanzkraft vor Finanzausgleich. Da neben der Verteilung nach dem örtlichen Aufkommen auch andere Zerlegungsformen in Betracht kommen, etwa die Verteilung nach der Einwohnerzahl oder nach Betriebsstätten, erfordert die Wahl des Verteilungsschlüssels eine ökonomisch stichhaltige Begründung. Dabei muß man sehen, daß das Ausmaß horizontaler Ungleichgewichte zwischen Finanzkraft und Finanzbedarf und die Notwendigkeit kompensierender Ausgleichszahlungen auch von der Art der Steuerzerlegung beeinflußt wird.

Unter den Kriterien für die horizontale Steuerverteilung spielt das örtliche Aufkommen eine hervorgehobene Rolle, weil es mit der Finanzautonomie der Länder (und Gemeinden) korrespondiert. Das innerhalb des eigenen Gebiets erzielte Aufkommen bildet sozusagen den "natürlichen" Beteiligungsmaßstab für den Steueranteil eines Landes, weil darin die steuerliche Leistungskraft der Bevölkerung und der heimischen Wirtschaft zum Ausdruck kommt ${ }^{1}$. Allerdings findet dieses Prinzip dort seine Grenzen, wo verwaltungstechnische Gründe die Wahl des Finanzamts für die Abführung der Steuern bestimmen und deshalb kein Bezug zu den Bürgern oder den Unternehmen eines Landes hergestellt werden kann.

1 Vgl. Kommission für die Finanzreform, 1966, Z. 289. 
Dies gilt beispielsweise für die zentrale Abführung der Lohnsteuer (unabhängig vom Wohnort oder vom Arbeitsort der Steuerpflichtigen), der Körperschaftsteuer (unabhängig vom Produktionsstandort) und der Umsatzsteuer (unabhängig vom Ort der Produktion oder des Verbrauchs). In den genannten Fällen sind daher andere Verteilungsmaßstäbe heranzuziehen. Deren Aufgabe besteht jedoch letzten Endes in der möglichst engen Annäherung an das Prinzip des örtlichen Aufkommens.

Die Leistungsfähigkeit der Einwohner und die Wirtschaftskraft der Unternehmen bleiben daher die zentralen Orientierungsgrößen der Steuerverteilung. Schwierigigkeiten bereitet aber die Wahl geeigneter Indikatoren und damit verbunden - die Gewichtung der einzelnen Kriterien. So stellt sich beispielsweise die Frage, welche Steuern die ${ }_{n}$ Steuerleistung der Wirtschaft" reflektieren. Zweifellos rechnen dazu die Gewerbesteuer und die Körperschaftsteuer. Die Beschränkung auf diese beiden Steuern ist aber fragwürdig, denn auch die im Wertschöpfungsprozeß entstehenden Lohneinkommen sind Ausdruck der regionalen Wirtschaftskraft.

\section{Die Umverteilung der Einnahmen (Finanzausgleich i. e. S.)}

Im Anschluß an die primäre Verteilung der öffentlichen Einnahmen kann es aus verschiedenen Gründen notwendig erscheinen, eine davon abweichende sekundäre Einnahmenverteilung durch Zuweisungen zwischen den Gebietskörperschaften herbeizuführen. Dieser Finanzausgleich im engeren Sinne dient dem Abbau vertikaler und horizontaler Ungleichgewichte unter Einschluß der Internalisierung regionaler externer Effekte (Spillovers), die bei den nachgeordneten Gebietskörperschaften auftreten können. Als Instrumente der vertikalen und horizontalen Umverteilung kommen allgemeine und spezielle Finanzzuweisungen bzw. Ausgleichszahlungen in Betracht.

\section{a. Umverteilung über allgemeine Finanzzuweisungen}

Vertikale Ungleichgewichte stellen sich - ausgehend von einer ursprünglich bedarfsgerechten vertikalen Steuerverteilung - durch global divergierende Entwicklungen des Finanzbedarfs und der Finanzkraft auf den verschiede- 
nen Ebenen des Staates ein. Mögliche Ursachen sind das Auftauchen neuer bzw. das Wegfallen alter Aufgaben, eine bewußte Umverteilung der Aufgaben zwischen den Gebietskörperschaften oder eine nicht der Aufgabenentwicklung entsprechende Aufkommenselastizităt der Steuereinnahmen ${ }^{1}$. Derartige Verschiebungen rechtfertigen jedoch keine vertikalen Finanzzuweisungen, sondern müssen durch Ånderungen in der vertikalen Steuerverteilung ausgeglichen werden.

Dies gilt zumindest für ein Verbundsystem, das diese Aufgabe über eine Veränderung der Beteiligungsquoten relativ leicht lösen kann. Politisch sind Veränderungen der Anteile an den Gemeinschaftsteuern aufgrund der Eigeninteressen der Beteiligten (Bund und Länder) vielleicht nicht ohne weiteres realisierbar, doch gilt dieser Einwand auch für vertikal ausgleichende Finanzzuweisungen. Letztere können somit nur gerechtfertigt werden, wenn die vertikale Steuerverteilung einem Trennsystem folgt, die eigenen Einnahmen einer Ebene aber (bei vertretbarer Anspannung) zur Erfüllung der zugewiesenen Aufgaben nicht ausreichen.

Damit verbleiben im wesentlichen die horizontalen Ungleichgewichte zur Begründung einer Umverteilung der Steuereinnahmen. Soweit es sich um globale Finanzkraft- und Finanzbedarfsunterschiede handelt², können sie durch horizontale Finanzzuweisungen zwischen den Körperschaften einer Ebene korrigiert werden (z. B. Länderfinanzausgleich i. e. S.). Möglich ist aber auch der Einsatz ungebundener vertikaler Finanzzuweisungen mit horizontalem Effekt (z. B. Fehlbetrags-Bundesergänzungszuweisungen). Dieses Verfahren impliziert eine Finanzausstattung der höheren Ebene, die ihren eigenen Finanzbedarf übersteigt - tendenziell zu Lasten der Finanzausstattung der untergeordneten Ebene.

Zweckmäßig ist eine solche Vorgehensweise, wenn die hier in Rede stehenden globalen horizontalen Ausgleichsprobleme nicht auf der betreffenden Ebene selbst zufriedenstellend gelöst werden können. Bei gegebener

1 Vgl. Wissenschaftlicher Beirat beim Bundesministerium der Finanzen, 1992, S. 60.

2 Diese beziehen sich auf die laufende Haushaltsführung, nicht auf die Deckung von Sonderbedarfen, die spezielle vertikale Zuweisungen erforderlich machen können (insbesondere der Infrastruktur-Nachholbedarf der neuen Bundesländer). 
Finanzmasse (unter Einschluß des vertikalen Zuweisungsvolumens) sprechen für den vertikalen Ausgleich mit horizontalem Effekt eventuell Kostenvorteile, im wesentlichen aber nur finanzpsychologische Erwăgungen. Differenzierte Zuweisungen, die generell die Finanzkraft zu erhöhen scheinen ${ }^{1}$, werden von den gleichrangigen Körperschaften wohl leichter akzeptiert als der nachtrăgliche Verzicht auf zunächst einmal zugeflossene „eigene" Mittel zugunsten der finanzschwächeren Mitglieder derselben Ebene.

Finanzausgleichsauszahlungen in Form ungebundener horizontaler oder vertikaler Transfers sind Instrumente, um das regionale Ausgleichsziel der ${ }_{n}$ Herstellung gleichwertiger Lebensverhältnisse im Bundesgebiet ${ }^{2} 2$ zu erreichen. Sie dienen dem „angemessenen“ Ausgleich der unterschiedlichen Finanzkraft der Länder (Artikel 107 Absatz 2 GG). Im Sinne der Stărkung der Eigenverantwortung der Gebietskörperschaften und der Erhöhung der Transparenz des Ausgleichsverfahrens sollte der (Spitzen-) Ausgleich zwischen armen und reichen Regionen möglichst über direkte horizontale Ausgleichszahlungen zwischen den Ländern, und nicht über vertikale Finanzzuweisungen erfolgen ${ }^{3}$. Die Notwendigkeit eines solchen Ausgleichs ist im übrigen kaum umstritten, wohl aber der Umfang und die konkrete Ausgestaltung des Verfahrens im Spannungsfeld zwischen den allokativen und distributiven Zielen des Finanzausgleichs (vgl. S. $41 \mathrm{ff}$.).

\section{b. Kostenersatz bei fremdbestimmten Leistungen}

Allgemeine Finanzzuweisungen bzw. Ausgleichszahlungen dienen in erster Linie dem distributiven Ziel des Abbaus der horizontalen Ungleichgewichte zwischen Finanzkraft und Finanzbedarf (bezogen auf die laufende Haushaltsführung). Spezielle Finanzzuweisungen (Zweckzuweisungen) werden

1 Bei insgesamt gleicher Finanzmasse der untergeordneten Ebene findet nur ein Austausch zwischen Finanzzuweisungen und Steuereinnahmen statt (z. B. zwischen Fehlbetrags-Bundesergänzungszuweisungen und dem Umsatzsteueranteil der Länder).

2 Diese Formulierung findet sich auch in Artikel 72 Absatz 2 GG, der eine konkurrierende Gesetzgebungszustăndigkeit des Bundes $u$. a. mit diesem Ziel begründet.

3 Eine geringe Transparenz des Ausgleichsverfahrens mag allerdings den politischen Konsens erleichtern. Alle Beteiligten können auf für sie günstige Einzelregeln verweisen und einen Kompromiß leichter vertreten, wenn die Trennungslinie zwischen Nettoverlierem und Nettogewinnem unscharf bleibt. Vgl. Heilmann, 1992, S. 75. 
dagegen eingesetzt, um die allokativen Funktionen des Finanzausgleichs zu erfüllen. Sie liegen vor allem auf zwei Gebieten. Zum einen geht es um die Sicherstellung der Konnexităt und der fiskalischen Åquivalenz, zum anderen um die Berücksichtigung besonderer Bedarfslagen, insbesondere um die Verringerung gravierender Unterschiede in der Infrastrukturausstattung.

Das Konnexitätsprinzip wird oftmals durch das Auseinanderfallen von Gesetzgebungs- und Verwaltungskompetenz beeinträchtigt. In solchen Fällen erscheint es angebracht, daß der Oberverband, der die gesetzlichen Leistungen bestimmt, die Kosten ersetzt, die dem Unterverband aufgrund der Durchführung der vorgeschriebenen Aufgaben entstehen1. Das prominenteste Beispiel ist sicherlich die Sozialhilfe, die durch Bundesgesetze geregelt, aber von den kommunalen Gebietskörperschaften ausgeführt wird.

Nach dem Konnexitätsprinzip müßte der Bund bei der Gestaltung der Sozialhilfe die Belastungen der kommunalen Haushalte berücksichtigen. Direkte Ausgleichszahlungen wären zwar in diesem Fall angesichts der Vielzahl der betroffenen Gemeinden nicht sinnvoll2 . Der Bund könnte aber seiner Verpflichtung auch dadurch nachkommen, daß er den Ländern einen Betrag zur Verfügung stellt, der den im Land anfallenden spezifischen Sozialhilfeaufwendungen entspricht ${ }^{3}$. Die Länder müßten diese Mehreinnahmen dann zur zielgerichteten Entlastung ihrer Gemeinden (bzw. Gemeindeverbände) durch spezielle (Sozialhilfe-) Finanzzuweisungen verwenden 4 .

Bei einer solchen Vorgehensweise ist im Grunde für jede "Auftragsangelegenheit" ein spezieller Kostenersatz erforderlich. Es besteht dann die Ge-

1 Das Problem liegt eigentlich etwas tiefer und geht über das Konnexitätsprinzip hinaus. Die Ausführung eines Bundesgesetzes, das kostengünstige Regelungen vorsieht, kann durch eine aufwendige Verwaltung auf Länder- und Gemeindeebene verteuert werden, vor allem, wenn die Kosten nur den Bund treffen. Umgekehrt besteht aber auch die Gefahr, daß ein Bundesgesetz, dessen Kosten die Länder und Gemeinden tragen, zu perfektionistisch und verwaltungsaufwendig ausfällt. Vgl. Geske, 1998, S. 560.

2 Sie wären im übrigen auch verfassunsgrechtlich problematisch, weil das Grundgesetz keine direkten Zahlungen zwischen Bund und Kommunen vorsieht.

3 Freiwillige, auf Ermessensentscheidungen der Länder und Gemeinden beruhende Leistungen, sind dabei nicht zu berücksichtigen. Schwierig ist allerdings die Trennung der gesetzlichen von den freiwilligen Aufwendungen.

4 So gibt es z. B. in Hessen nach § 23 FAG einen Sozialhilfeausgleich bei den besonderen Zuweisungen im Rahmen des kommunalen Finanzausgleichs. 
fahr, daß ein System vielfältiger und am Ende kaum noch überschaubarer spezieller Finanzzuweisungen entsteht, deren Ausgleichseffekte sich zum Teil aufheben. Einfacher wäre es, Veränderungen des Volumens der "Auftragsangelegenheiten" bei der Festlegung der Anteile von Bund und Lăndern an der Umsatzsteuer anzurechnen und den Ländern die Regelung im Verhăltnis zu ihren Gemeinden im Rahmen des kommunalen Finanzausgleichs zu überlassen ${ }^{1}$. Diese Lösung wäre als pauschaler Kostenersatz sachlich vertretbar und hätte wohl auch den Vorteil der größeren Kosteneffizienz, denn die ausführenden Gebietskörperschaften werden sich eher um eine sparsame Durchführung bemühen, wenn sie keine spezielle, sondern eine pauschale Erstattung ihrer Aufwendungen erhalten.

Spezielle Finanzzuweisungen sind also zur Regelung des Problems der "Auftragsverwaltung" nicht zwingend erforderlich. Die Kosten der Erfüllung fremdbestimmter Aufgaben lassen sich auch über die Anteile an den Gemeinschaftsteuern ausbalancieren. Die Übereinstimmung der Kosten- und Entscheidungsträger ist auf diese Weise zwar nicht perfekt für jeden Einzelfall herzustellen, aber der Forderung nach Konnexität würde durch die Anlastung der finanziellen Folgen bei der gesetzgebenden Körperschaft weitgehend entsprochen.

\section{c. Die Kompensation von Spillover-Effekten}

Aus allokativer Sicht gelten spezielle Finanzzuweisungen auch als geeignetes Instrument zur Kompensation von Spillover-Effekten, die eine perfekte fiskalische Äquivalenz zwischen Nutznießern und Kostenträgern der Staatsleistungen verhindern ${ }^{2}$. Spillover-Effekte kommen zustande, wenn Gebietsfremde von der Bereitstellung bestimmter öffentlicher Güter profitieren, ohne

1 In der Praxis wird auch grundsätzlich so verfahren. Allerdings herrscht oftmals Uneinigkeit über Art und Höhe der ausgleichsrelevanten Budgetpositionen im Rahmen einer Deckungsquotenberechnung für die verschiedenen staatlichen Ebenen.

2 In der finanzwissenschaftlichen Literatur werden Finanzausgleichsregelungen außerdem als Versicherung gegen eine ungünstige wirtschaftliche Entwicklung interpretiert. Eine solche Versicherung wäre jedoch nicht sinnvoll, weil sie moralisches Fehlverhalten (moral-hazard) herausfordert. Eine Versicherung könnte kaum kontrollieren, ob die ungünstige Entwicklung der Finanzkraft eines Landes auf Ereignisse zurückgeht, die das Land nicht zu vertreten hat, oder ob sie die Folge einer verfehlten Wirtschafts- und Finanzpolitik ist. Vgl. Lichtblau, 1999, S. 97-98. 
sich an den Kosten beteiligen zu müssen. In solchen Fällen besteht die $\mathrm{Ge}-$ fahr eines suboptimalen Angebots dieser Güter, denn die regionalen Entscheidungsträger werden nur ihren eigenen, aber nicht den externen ( $\mathrm{Zu}$ satz-) Nutzen berücksichtigen ${ }^{1}$. Mit Hilfe vertikaler Zweckzuweisungen können die unteren Ebenen zwar zu einer Vergroßßerung ihres Angebots bewegt werden, doch erscheint ein solches Vorgehen aus allokativer Sicht nur angemessen, wenn der externe Nutzen global anfällt, d. h. allen anderen Mitgliedern der betreffenden Ebene zugute kommt ${ }^{2}$.

Verteilt sich der Zusatznutzen dagegen nur auf einzelne benachbarte Körperschaften, so ist eine Vereinbarung unter den direkt Betroffenen der naheliegendere und unter Åquivalenzgesichtspunkten auch der bessere Weg. Während vertikale Zweckzuweisungen nur die Differenz zwischen Kosten und Nutzen in der anbietenden Region kompensieren können, stellen horizontale Ausgleichszahlungen die fiskalische Åquivalenz auch in der Region her, die von den Spillover-Effekten profitiert. Allerdings wäre ein umfassendes System horizontaler Ausgleichszahlungen zur Internalisierung externer Zusatznutzen öffentlicher Güter, die von nachgeordneten Gebietskörperschaften bereitgestellt werden, technisch-administrativ aufwendig und bei lückenhaften Kenntnissen über die regionale Verteilung der externen Effekte auch nicht unbedingt zielführend.

Eine (Näherungs-) Lősung des Spillover-Problems auf der Länderebene lieBe sich durch den kombinierten Einsatz verschiedener Instrumente dennoch tendenziell erreichen. Es wurde bereits darauf hingewiesen, daß den Ländern bei der vertikalen Steuerverteilung die regional nur wenig streuenden Steuern zugewiesen werden müßten. Auf der Ausgabenseite bietet sich eine verstärkte Gebührenfinanzierung der Leistungen an, die in erheblichem Maße auch von Gebietsfremden genutzt werden. Eine Kooperation zwi-

1 Bei klarer Dominanz des externen Nutzens werden die öffentlichen Güter von kleinen Gebietskörperschaften möglicherweise überhaupt nicht angeboten. In solchen Fällen wäre eine Zuweisung der Aufgabenkompetenz an die höhere Ebene eher angezeigt als der Versuch, über Zweckzuweisungen eine Bereitstellung durch nachgeordnete Körperschaften herbeizuführen.

2 Zweckzuweisungen sind auch dann das richtige Instrument, wenn der Oberverband eine Angebotsausweitung bei bestimmten offentlichen Leistungen anstrebt, weil er diese Leistungen als meritorische Güter betrachtet, für deren Bereitstellung nicht allein die örtlichen Präferenzen ausschlaggebend sein sollen. 
schen den betroffenen Gebietskörperschaften erscheint zumindest bei gröBeren Projekten naheliegend, bei denen die Spillover-Effekte auf der Hand liegen und eine gemeinsame Durchführung erhebliche Kostenersparnisse ermöglicht. Vertikale Finanzausgleichsmaßnahmen sollten demgegenüber nur ergänzenden Charakter haben. Sie müssen zudem im Sinne einer effizienten Mittelverwendung zweckgebunden erfolgen und mit einer Eigenbeteiligung der Empfănger verbunden werden 1 .

Fehlplaziert wäre demgegenüber der Versuch, Spillover-Effekte im Rahmen der allgemeinen, aus distributiven Gründen erfolgenden Umverteilung zwischen gleichrangigen Gebietskörperschaften zu internalisieren. Die Heranziehung aller Länder zur Finanzierung öffentlicher Ausgaben, die nur zwei benachbarten Ländern zugute kommen, würde deren Anreiz erhöhen, die Menge solcher Projekte auszuweiten. Sie hätten den vollen Nutzen, müßten aber (allein oder gemeinsam) nur einen Teil der Kosten tragen. Dies stünde im Widerspruch zum Prinzip der fiskalischen Aquivalenz und wäre gerade nicht geeignet, den Spillover-Effekten verursachergerecht zu begegnen?

Externalitäten entstehen im übrigen nicht nur durch Spillover-Effekte, sondern auch durch Bevölkerungswanderungen. Die Haushalte berücksichtigen nämlich bei ihren Standortentscheidungen nicht, daß die Durchschnittskosten der Bereitstellung öfentlicher Güter steigen (sinken), wenn sie nach Abwanderung (Zuwanderung) von weniger (mehr) Einwohnern zu finanzieren sind. Derartige fiskalische Externalitäten, die möglicherweise zu einer ineffizienten räumlichen Bevölkerungsverteilung führen, können allerdings kaum durch Finanzausgleichsmaßnahmen internalisiert werden ${ }^{3}$.

1 Die oftmals empfohlene Internalisierung der Spillover-Effekte durch Zusammenschluß der betreffenden Gebietskörperschaften (Neugliederung des Bundesgebietes) wird hier nicht näher geprüft. Gegen eine solche Lösung sprechen folgende Argumente: (1) Die Spillover-Effekte kőnnen auch die Grenzen größerer Länder überschreiten. (2) Angesichts der prinzipiellen Vorzüge eines föderativen Systems erscheint es widersprüchlich, ein aus dem Autonomieprinzip resultierendes Problem durch Zentralisierung Iösen zu wollen. (3) Die Bürgerpräferenzen verlangen, wie der Versuch mit Berlin und Brandenburg belegt, offenbar keinen Zusammenschluß. Allerdings können die Präferenzen durch den Finanzausgleich verzerrt sein. Vgl. dazu S. $184 \mathrm{ff}$.

2 Vgl. Lichtblau, 1999, S. 96.

3 In Betracht kommen wiederum Verhandlungslossungen und eine nachdrücklicher dem (individuellen) Aquivalenzprinzip verpflichtete Abgabenpolitik. Teilweise wird aber auch eine Berücksichtigung im Finanzausgleich gefordert. Vgl. z. B. Färber, 1999, S. 95. 


\section{d. Die Angleichung der Infrastrukturausstattung}

Neben den Spillover-Effekten begründen erhebliche Unterschiede in der Infrastrukturausstattung zwischen den Bundesländern einen Finanzausgleich mit allokativer Zielrichtung. Ein sinnvoller föderativer Wettbewerb setzt einigermaßen vergleichbare Startchancen der beteiligten Gebietskörperschaften voraus. Diese Vergleichbarkeit ist zwischen alten und neuen Bundesländern in vielerlei Hinsicht und nach übereinstimmender Auffassung in Wissenschaft und Politik derzeit noch nicht gegeben. Dabei stellt die vergleichsweise bescheidene Ausstattung der neuen Bundesländern mit öffentlicher Infrastruktur einen spezifischen Standortnachteil dar, der private Investoren abschreckt und damit den wirtschaftlichen Aufholprozeß erschwert.

Aus allokativen und wachstumspolitischen Gründen sollte der Nachholbedarf der neuen Bundesländer im Finanzausgleich berücksichtigt werden. Dafür spricht vor allem, daß die Grenzproduktivităt öffentlicher Investitionen in Ostdeutschland höher sein dürfte als in Westdeutschland. Reichere Länder haben jedoch keine Anreize, staatliche Infrastruktur in ärmeren Ländern zu finanzieren, selbst wenn die Investitionsrenditen dort höher ausfallen. Eine allokativ vorteilhafte Angleichung der Grenzerträge öffentlicher Investitionen, die zudem ineffizienten Faktorwanderungen entgegenwirken würde, kann daher nur über den Finanzausgleich herbeigeführt werden.

Es bietet sich an, diese Ausgleichsmaßnahmen durch den Bund zu organisieren. Eine Lösung im Rahmen des horizontalen Länderfinanzausgleichs kommt dagegen nicht in Betracht. Schon mit Blickauf das verfassungsrechtliche Nivellierungsverbot ist das vorübergehend notwendige Überholen der alten durch die neuen Länder - gemessen an der Pro-Kopf-Finanzkraft nach Finanzausgleich - nur durch spezielle Maßnahmen abseits des normalen Finanzkraftausgleichs zu erreichen. Hierin liegt die Begründung für spezielle Bundeshilfen, deren Gestaltung freilich inrem Sondercharakter entsprechen sollte. So dürften zweck- und damit investitionsgebundene Zuweisungen des Bundes mit einer Selbstbeteiligung der neuen Länder der Effizienz der Mittelverwendung zugute kommen, und zwar sowohl infolge 
der Bindung an Infrastrukturinvestitionen, als auch infolge der kritischeren Prüfung dieser Ausgaben seitens der Empfängerländer.

\section{Finanzausgleich zwischen Effizienz und Verteilung}

\section{a. Finanzausgleich aus allokativer Sicht}

Wären die Prinzipien der Autonomie, der Konnexität und der fiskalischen Åquivalenz vollständig erfüllt, so bestünde aus allokativer Sicht kein Anlaß für einen Finanzausgleich zwischen den Regionen. Nun ist aber eine Finanzverfassung, welche diesen Leitlinien voll entspricht, aus den genannten Gründen nicht realisierbar ${ }^{1}$. Die Primärverteilung wird immer - wenn auch in unterschiedlichem und politisch beeinflußbarem Maße - von der allokativ optimalen Lösung abweichen und eine Korrektur über den Finanzausgleich i. e. S. nahelegen. Die vorstehenden Überlegungen haben jedoch unter anderem gezeigt, daß einer allokationspolitisch vertretbaren Umverteilung zwischen den Gebietskörperschaften enge Grenzen gezogen sind.

(1) Eine vertikale Umverteilung durch allgemeine Finanzzuweisungen zwischen Bund und Ländern ist nicht erforderlich, um globale vertikale Ungleichgewichte in der Finanzausstattung der verschiedenen Staatsebenen zu korrigieren. Diese Aufgabe kann besser durch bedarfsbezogene Anderungen der Beteiligungsquoten im Verbundsystem gelöst werden.

(2) Allgemeine vertikale Finanzzuweisungen mit horizontalem Effekt dienen dem distributiven Ziel eines Abbaus globaler horizontaler Ungleichgewichte. Im Finanzausgleich unter den Ländern lassen sich die horizontalen Ausgleichsziele jedoch einfacher und transparenter ansteuern als es über vertikale Zuweisungen des Bundes möglich ist?2.

1 Der deutsche Länderfinanzausgleich weist allerdings in allokativer Hinsicht eine Reihe durchaus behebbarer Mängel auf. Den Kriterien der Autonomie, der Konnexität und der fiskalischen Äquivalenz könnte und sollte stärker Rechnung getragen werden, nicht zuletzt, um den Finanzausgleich i. e. S. auf seine zwingend notwendigen Funktionen konzentrieren und begrenzen zu können.

2 Der Einsatz vertikaler Zuweisungen kann den horizontalen Finanzausgleich erleichtern und kostengünstiger gestalten. Dies gilt beispielsweise für den kommunalen Finanzausgleich, aber nicht für den Länderfinanzausgleich, in dem aufgrund der begrenzten und noch überschaubaren Teilnehmerzahl direkte Ausgleichszahlungen problemlos 
(3) Die Kostenübernahme bei fremdbestimmten Aufgaben kann - im Sinne des Konnexitätsprinzips - über spezielle vertikale Finanzzuweisungen erfolgen. Eine zweckmäßigere Alternative besteht jedoch in der pauschalen Berücksichtigung der Kosten der „Auftragsverwaltung“ bei der Festlegung der Anteile an den Gemeinschaftsteuern.

(4) Die allokativ erwünschte Internalisierung von Spillover-Effekten rechtfertigt nur im Ausnahmefall globaler externer Nutzen spezielle vertikale Finanzzuweisungen. Besser geeignete Instrumente sind die Gebührenfinanzierung staatlicher Leistungen und Verhandlungslösungen. In den allgemeinen Finanzausgleich zwischen den Ländern lassen sich regionale Spillover-Effekte jedenfalls nicht sinnvoll integrieren.

(5) Auch der Nachholbedarf der neuen Bundesländer ist nicht innerhalb des als Spitzenausgleich konzipierten Länderfinanzausgleichs i. e. S. zu bewältigen. Hier erscheinen vertikale Bundeszuweisungen allokativ gerechtfertigt, um die teilungsbedingten Standortnachteile dieser Länder und die daraus resultierenden Verzerrungen im föderativen Wettbewerb zu überwinden 1 .

Insgesamt bleibt festzuhalten, daß es aus allokativer Sicht keine überzeugenden Gründe für einen allgemeinen, ungebundenen Finanzausgleich zwischen den Regionen gibt. Spezielle, zweckgebundene Maßnahmen sind nur mit Blick auf den wirtschaftlichen Aufholprozeß in Ostdeutschland wirklich notwendig. Wenn dennoch eine viel weitergehende Angleichung der Finanzkraft zwischen den Ländern über allgemeine Finanzzuweisungen bzw. Ausgleichszahlungen angestrebt wird, so müssen dafür im wesentlichen distributive Gründe vorliegen².

abgewickelt werden können. Die Vorteile des direkten Ausgleichsverfahrens sprechen auch gegen die Fehlbetrags-Bundesergänzungszuweisungen zur (weiteren) Anhebung der Finanzkraft relativ finanzschwacher Länder.

1 Erhebliche Unterschiede in der konsumtiven Infrastruktur, die direkt das Wohlfahrtsniveau der Bürger betreffen, rechnen auch zu den distributiven Problemen, die allgemeine Ausgleichszahlungen rechtfertigen können.

2 Vgl. Wissenschaftlicher Beirat beim Bundesministerium der Finanzen, 1992, S. 48 ff. 


\section{b. Finanzausgleich aus distributiver Sicht}

Verteilungsaspekte sind für die Gestaltung des Finanzausgleichs vor allem dann von Bedeutung, wenn erhebliche regionale Einkommens-, Finanzkraftund Infrastrukturdisparitäten vorliegen ${ }^{1}$, die sich auf andere Weise nicht beseitigen lassen und der Gleichwertigkeit der Lebensverhältnisse entgegenstehen $^{2}$. Auch kann ein starkes Wohlstandsgefälle zwischen den Regionen die politische Stabilităt einer Föderation gefährden. Ziel des distributiven Finanzausgleichs ist die Reduktion der Finanzkraftdifferenzen zwischen den Gebietskörperschaften. Dabei muß das intendierte Ausmaß des Ausgleichs im Spannungsfeld zwischen den Effizienz- und Verteilungsaspekten letzten Endes politisch festgelegt werden.

Trotz der Notwendigkeit einer politischen Bestimmung des Ausgleichsniveaus lassen sich prinzipielle distributive Anforderungen an den horizontalen Finanzausgleich formulieren, die im Sinne einer rationalen Gestaltung der Ausgleichszahlungen zu beachten sind ${ }^{3}$.

(1) Das Ausgleichsniveau darf nicht zu hoch sein und jedenfalls nicht bei annăhernd $100 \%$ liegen, denn eine exzessive Nivellierung impliziert die Gefahr, daß die empfangsberechtigten und die ausgleichspflichtigen Gebietskörperschaften das Interesse an der Pflege ihrer eigenen Steuerquellen verlieren. Der Länderfinanzausgleich ist deshalb auf einen Spitzenausgleich zu beschränken und so zu gestalten, daß die finanzielle Eigenverantwortung der Länder möglichst unangetastet bleibt, der Wille der finanzschwachen Länder zur Selbsthilfe nicht geschwächt und

1 Die Disparităten zwischen den Ländern dürfen aber auch nicht zu groß sein. Der horizontale Länderfinanzausgleich kann nicht die Aufgaben der Struktur- und Raumordnungspolitik übernehmen. Vgl. Kitterer, 1994, S. 16.

2 Die Gleichwertigkeit der Lebensverhältnisse kann finanzwissenschaftlich als fiscalequity-Ziel interpretiert werden. Vgl. Buchanan, 1950; Musgrave, 1961; Scott, 1964. Obwohl es eine Vielzahl fiskalischer Gleichheitsziele gibt, dürften die meisten Bürger darunter die Gleichheit der Versorgungsniveaus mit offentlichen Leistungen und die Gleichheit der steuerlichen Belastung verstehen.

3 Im folgenden werden nur die distributions- und allokationspolitisch zentralen Eigenschaften des Ausgleichsverfahrens erläutert, nicht die formalen Kriterien. Dies bedeutet keine Geringschätzung der Nützlichkeit eines axiomatischen Ansatzes bei der Festlegung konkreter Ausgleichsmechanismen. Vgl. Buhl/Pfingsten, 1991; Lenk, 1995. 
die Fähigkeit der übrigen Länder zu eigener Initiative und Leistungssteigerung nicht übermäßig beeinträchtigt wird“ ${ }^{1}$.

Neben den aus allokativer Sicht bedeutsamen negativen Anreizwirkungen einer ausgeprägten Nivellierung der Finanzkraft ist auch deren distributive Berechtigung zweifelhaft. In einem föderativen Staat sind Unterschiede in der Struktur und der Intensităt der Erfüllung staatlicher Aufgaben grundsätzlich erwünscht. Sie stehen nicht im Widerspruch zu der Forderung nach gleichwertigen Lebensverhältnissen, soweit entsprechende regionale Unterschiede in den Bürgerpräferenzen vorliegen.

(2) Empfehlenswert erscheint vor dem Hintergrund des zentralen distributiven Ziels der Gewährleistung gleichwertiger Lebensverhältnisse im Bundesgebiet die Festlegung eines Mindestniveaus der Finanzausstattung je Einwohner im Sinne einer ${ }_{n}$ Sockelgarantie“. Daß ein garantiertes Mindestniveau bis zu dieser Grenze die "Leistungsanreize" der besonders finanzschwachen Gebietskörperschaften nahezu beseitigt, ist ein allokativer Nachteil des Verfahrens, der sich jedoch begrenzen läßt².

(3) Der horizontale Finanzkraftausgleich darf die Finanzkraftrangfolge der daran beteiligten Gebietskörperschaften nicht umkehren. Eine Umkehrung der Finanzkraftrangfolge würde nicht nur gegen das verfassungsrechtliche Verbot der Übernivellierung verstoßen, sondern auch dem distributiven Zweck des Verfahrens widersprechen, das auf eine Verminderung vorhandener und nicht auf die Schaffung neuer Finanzkraftdifferenzen gerichtet ist.

Die Forderung nach einer unveränderten Finanzkraftrangfolge kann allerdings nicht erhoben werden, wenn besondere Bedarfe vorliegen, die im Finanzausgleich i. w. S. zu berücksichtigen sind (z. B. Nachholbedarfe bei den neuen Bundesländern). Es macht keinen Sinn, den reinen

1 Kommission für die Finanzreform, 1966, Z. 282.

2 Hierin liegt eine Analogie zur Sozialhilfe. Wenn eine Gesellschaft jedem Staatsbürger ein sozial-kulturelles Existenzminimum garantieren will, muß sie billigend in Kauf nehmen, daß Arbeitsanreize bis zur existenzminimalen Lohnhöhe nicht bestehen; ein Sachverhalt, der als "Armutsfalle" bezeichnet wird. Vgl. zu den Möglichkeiten einer Verbesserung der Anreize für die finanzschwachen Länder S. $175 \mathrm{ff}$. 
Finanzkraftausgleich mit solchen Sondermaßnahmen zu saldieren und das Gesamtergebnis einer "Nivellierungsprüfung" zu unterziehen. Da die Sondermaßnahmen auf einer völlig anderen Ausgleichsebene angesiedelt sind, können sie auch nicht anhand der Maßstäbe des horizontalen Finanzkraftausgleichs beurteilt werden.

Allokative Effizienz und distributive Gerechtigkeit stehen (nicht nur) im Finanzausgleich in einem Spannungsverhältnis. Unvereinbar sind die beiden Hauptziele (bzw. Zielkomplexe) nicht, doch ist gerade bei der Festlegung des anzustrebenden Ausgleichsniveaus ein politischer Spielraum gegeben, der eine sorgfältige Abwägung zwischen Effizienz und Verteilung verlangt. Die (Finanz-) Wissenschaft kann diesbezüglich nur den Rahmen näher spezifizieren, innerhalb dessen die Entscheidung zu erfolgen hat ${ }^{1}$. Dennoch sei in diesem Zusammenhang darauf hingewiesen, daß der Nivellierungsgrad des bundesdeutschen Länderfinanzausgleichs von den meisten Finanzwissenschaftlern als völlig überzogen eingestuft wird22.

\section{Kooperation und Wettbewerb im Föderalismus}

Die Finanzverfassung der Bundesrepublik Deutschland entspricht heute sicher nicht den in der ökonomischen Theorie des Föderalismus entwickelten Kriterien einer föderalen Ordnung. Infolge einer egalitären Interpretation der "Gleichwertigkeit der Lebensverhältnisse“ zeichnet sich das System durch einen hohen Stellenwert der distributiven bei entsprechend geringer Bedeutung der allokativen Kriterien der Finanzverfassung aus. Historisch gesehen läßt sich dabei ein Bedeutungsverlust der Prinzipien der Autonomie, Konnexität und fiskalischen Áquivalenz beobachten ${ }^{3}$.

Für die eingetretene Schwächung der Finanzautonomie der deutschen Bundesländer sind im wesentlichen folgende Faktoren verantwortlich4:

1 Gleiches gilt wohl für die verfassungsrechtliche Bewertung der Nivellierungsintensităt des Länderfinanzausgleichs.

2 Auf die Problematik des (zu) hohen Nivellierungsgrades wird im weiteren Verlauf der Untersuchung noch ausführlich eingegangen. Vgl. S. $77 \mathrm{ff}$.

3 Vgl. zur Entwicklung des deutschen Foderalismus Arnim, 1999, S. 37 ff.; Reformkommission Soziale Marktwirtschaft, 1998.

4 Vgl. Vesper, 1998 a, S. 5 ff. 
(1) Die Gesetzgebung wird weitgehend vom Bund (Art. $70 \mathrm{ff} G \mathrm{G}$ ), der Vollzug dagegen von den Ländern (Art. 83 ff GG) wahrgenommen. Viele Leistungen, die von den Ländern erbracht werden, sind durch Bundesgesetze fixiert und insofern fremdbestimmt.

(2) Die wichtigsten Steuern sind Gemeinschaftssteuern, bei denen die Länder keinen direkten Einfluß auf ihre Einnahmen ausüben können. Selbst die Lăndersteuern sind bundesgesetzlich geregelt.

(3) Der Bund beteiligt sich an den "Gemeinschaftsaufgaben“. Damit soll das Angebot bestimmter staatlicher Leistungen sichergestellt werden, deren Bereitstellung die Lănder allein überfordert und typischerweise mit positiven externen Effekten einhergeht (z. B. der Bau von Hochschulen).

Diesen Zentralisierungstendenzen haben die Länder allerdings weitgehend und keineswegs unbedacht zugestimmt. Ihren Autonomieverlusten standen in der Regel finanzielle Gewinne, vor allem aber die gewachsenen Mitwirkungsmöglichkeiten des Bundesrates bei der Gesetzgebung gegenüber. Daher war der Bund auch kein Zentralisierungsgewinner. Der Übergang zum "kooperativen Föderalismus" verschaffte paradoxerweise beiden Ebenen Kompetenzgewinne - mit der inzwischen klar erkennbaren Folge einer wechselseitigen Einmischung bis hin zur Blockade der (finanz-) politischen Entscheidungen. Die Kosten der Konsensfindung haben erheblich zugenommen, während die Flexibilităt des Systems zunehmend gefährdet erscheint. In der skizzierten Entwicklung kann man durchaus eine Tendenz zur Pervertierung des Föderalismus erkennen1.

Die Befürworter eines wettbewerbsorientierten Föderalismus empfehlen vor diesem Hintergrund eine Trennung der Zuständigkeiten von Bund und Län-

1 Der Föderalismus setzt ${ }_{n}$ Kompetenzen des Parlaments, Verantwortlichkeiten der Regierung gegenüber dem Parlament und damit dem Volk und einen Leistungswettbewerb zwischen den Ländern voraus. Doch genau daran fehlt es. Die vom Volk gewählten Landesparlamente leiden an politischer Auszehrung. Ein Wettbewerb um die bessere Gestaltung findet - wegen der Übertragung der zentralen Gestaltungskompetenzen auf den Bund - nur noch sehr eingeschränkt statt. Die Landesregierungen sind auf Bundesratsebene und auf der "dritten « und "vierten " Ebene in Absprachen mit anderen Länderregierungen und dem Bund eingebunden und werden dadurch für den Inhalt der Entscheidungen nicht nur gegenüber ihren Parlamenten, sondern auch gegenüber dem Volk weitgehend »unverantwortlich «". Arnim, 1999, S. 43. 
dern 1 . Angestrebt wird in der Tendenz eine Aufgaben- und Steuerverteilung, "die die Gemeinschaftsaufgaben weitgehend den Ländern überträgt, bei den Steuern eine Trennung der Steuerertragskompetenz in großen Bereichen vorsieht und auf dauerhafte Bundesergänzungszuweisungen verzichtet"2. Ein solch ambitioniertes Vorhaben wird in diesem Gutachten nicht weiter verfolgt. Ein reiner Wettbewerbsföderalismus ist so weit von der gegenwärtig eher kooperativ ausgerichteten Finanzverfassung entfernt, daß der Weg einer schrittweisen Verbesserung des heutigen Systems - durchaus mit dem Ziel der Stärkung wettbewerblicher Elemente - erfolgversprechender erscheint. Dies gilt um so mehr, als die wesentlichen Probleme des Lănderfinanzausgleichs im Rahmen der bestehenden Ordnung und daher mit vergleichsweise geringem Umstellungsaufwand gelost werden können. Selbst eine größere Steuerautonomie ist ohne gravierende Anderungen der gegebenen Finanzverfassung über ein Zuschlagsystem bei der Einkommen- und Körperschaftsteuer erreichbar ${ }^{3}$.

1 Vgl. z. B. Reformkommission Soziale Marktwirtschaft, 1998; Lenk/Schneider, 1999.

2 Lenk/Schneider, 1999, S. 1.

3 Vgl. Wissenschaftlicher Beirat beim Bundesministerium der Finanzen, 1992, S. 92 ff; Huber, 1999 a, S. 55 ff. Ein Wettbewerb der Steuersätze dürfte gegenüber einem Wettbewerb der Bemessungsgrundlagen insgesamt der bessere Weg zu mehr Steuerautonomie sein. Er vermeidet die Nachteile des freien Trennsystems und ermöglicht auch weiterhin eine flexible Anpassung der vertikalen Steuerverteilung über die Gemeinschaftsteuern. 
Wolfgang Scherf - 978-3-631-75181-7

Downloaded from PubFactory at 01/11/2019 07:24:58AM

via free access 


\section{Darstellung und Wirkungen des Länderfinanzausgleichs}

Der bundesdeutsche Finanzausgleich ist in seinen grundlegenden Elementen bereits im Grundgesetz geordnet. Die Finanzbeziehungen zwischen Bund und Ländern sowie zwischen den Ländern werden darüber hinaus durch das "Gesetz über den Finanzausgleich zwischen Bund und Ländern" (FAG) geregelt. Das Grundgesetz enthält hinsichtlich der Erfüllung staatlicher Aufgaben den Grundsatz der Länderzuständigkeit (Art. $30 \mathrm{GG}$ ). Vom Prinzip der generellen Lănderzuständigkeit wird allerdings in wichtigen Fällen abgewichen. Der Bund verfügt in einigen Aufgabenbereichen über das Recht der ausschließlichen (Außenpolitik, Verteidigung, Währung) oder konkurrierenden Gesetzgebung (Rechtswesen, Fürsorge, Umweltschutz, Verkehr). Diese Möglichkeiten hat der Bund in der Vergangenheit weitgehend ausgeschöpft. Darüber hinaus kommt es im Rahmen der Gemeinschaftsaufgaben zu einer vom Gesetzgeber beabsichtigten Vermischung der Kompetenzen von Bund und Ländern (Artikel 91a GG). Insgesamt kann man daher sagen, daß die Gesetzgebung in Deutschland trotz der Generalklausel zugunsten der Länder überwiegend vom Bund ausgeübt wird. Bei der Verwaltungskompetenz dominieren dagegen die Länder, die in der Regel die Bundesgesetze ausführen. Auch besitzen die Länder über den Bundesrat weitreichende Mitwirkungsrechte. Finanzausgleichsrelevant sind insbesondere die grundgesetzliche Regelung der Steuerertragshoheit und die Zustimmungspflicht des Bundesrates bei allen Bundesgesetzen, welche die Steuereinnahmen der Länder und Gemeinden betreffen.

\section{A. Die verschiedenen Stufen des Länderfinanzausgleichs}

Der Länderfinanzausgleich erfolgt in einem mehrstufigen Verfahren. Die verschiedenen Elemente greifen ineinander und dürfen daher nicht isoliert gesehen werden. Insgesamt sind vier Stufen zu unterscheiden: (1) die vertikale Steuerverteilung zwischen Bund und Lándern, (2) die horizontale Verteilung der Landessteuern und des Länderanteils an den Gemeinschaftsteuern, (3) der Finanzausgleich unter den Ländern im engeren Sinne und (4) die Bundesergänzungszuweisungen. Auf jeder dieser Stufen besteht, wenn auch in unterschiedlichen Maße, Diskussions- und Reformbedarf. 


\section{Die vertikale Steuerverteilung}

Im Rahmen der vertikalen Steuerverteilung wird festgelegt, welche Steuerarten den einzelnen Gebietskörperschaften zufließen. In Deutschland steht die Ertragshoheit über einige Steuern allein dem Bund ${ }^{1}$, den Ländern ${ }^{2}$ oder den Gemeinden ${ }^{3}$ (bzw. Gemeindeverbänden) zu. Die jeweils nur einer Gebietskörperschaft zugewiesenen Steuern machen zwar den überwiegenden Teil der Steuerarten aus, doch beträgt deren Aufkommen insgesamt nur rund ein Fünftel der gesamten Steuereinnahmen. Die aufkommensergiebigen Steuern - Lohn- und Einkommensteuer, Körperschaftsteuer, Umsatzsteuer und letztlich auch die Gewerbesteuer - sind dagegen Gemeinschaftsteuern, deren Erträge mehreren oder allen staatlichen Ebenen zufließen (Anteil an den kassenmäßigen Steuereinnahmen 1998: 78,5\%). Dabei gelten folgende Regelungen:

(1) Vom Aufkommen der Lohnsteuer und der veranlagten Einkommensteuer stehen Bund und Ländern jeweils 42,5\%, den Gemeinden $15 \%$ zu4.

(2) Die nicht veranlagten Steuern vom Ertrag (Kapitalertragsteuer) und die Körperschaftsteuer teilen sich Bund und Länder jeweils zur Hälfte.

(3) Gleiches gilt für die Gewerbesteuerumlage, mit der Bund und Länder an der Gewerbesteuer beteiligt werden. Der Anteil von Bund und Ländern variiert; er lag 1997 bei $18 \%$ des Aufkommens.

(4) Das flexible Element im vertikalen Ausgleich ist die Umsatzsteuer. Die Anteile betragen derzeit $50,5 \%$ für den Bund und $49,5 \%$ für die Länder.

1 Zölle, Kapitalverkehrsteuer, Versicherungsteuer, Wechselsteuer, Solidaritätszuschlag, Abgaben im Rahmen der Europăischen Union, Verbrauchsteuern mit Ausnahme der Biersteuer, d. h. Branntweinsteuer, Schaumweinsteuer, Zwischenerzeugnissteuer, Kaffesteuer, Tabaksteuer, Mineralölsteuer.

2 Erbschaftsteuer, Grunderwerbsteuer, Kraftfahrzeugsteuer, Biersteuer, Rennwett- und Lotteriesteuer, Feuerschutzsteuer, Spielbankabgabe.

3 Gewerbesteuer (ohne Gewerbesteuerumlage), Grundsteuer, Ortliche Verbrauch- und Aufwandsteuern (z. B. Hundesteuer, Vergnügungsteuer).

4 Seit dem 1.1.1994 erhalten die Gemeinden auch einen Anteil am Zinsabschlag in Höhe von $12 \%$. Der abgesenkte Gemeindeanteil am Zinsabschlag ergibt sich daraus, daß auch körperschaftsteuerpflichtige Unternehmen den Zinsabschlag zahlen, die Gemeinden aber nicht an der Körperschaftsteuer beteiligt sind. Vgl. Bundesministerium der Finanzen, 1999 b, S. 5 . 
Seit 1998 beziehen sich diese Quoten auf das Umsatzsteueraufkommen nach Abzug der Vorabanteile des Bundes und der Gemeinden1.

Die Umsatzsteuerverteilung hat sich nach der Deutschen Einheit stark zugunsten der Länder und zu Lasten des Bundes verschoben. Mit der Neuregelung des Länderfinanzausgleichs 1995 wurde der Lănderanteil um 7 Prozentpunkte von $37 \%$ auf $44 \%$ angehoben. Seit 1996 beträgt der Länderanteil sogar $49,5 \% 2$. Es verwundert daher auf den ersten Blick nicht, daß 1995 noch alle Bundesländer der Neuregelung zugestimmt haben. Allerdings kann man zeigen, daß der neue Länderfinanzausgleich gegenüber der Fortführung des alten Systems (getrennter Ausgleich zwischen Ost und West bei geringerem Umsatzsteueranteil der Länder) über 1995 hinaus die alten Bundesländer netto stark belastet hat. Die jährlichen Gesamtverluste der westlichen Lảnder lagen zwischen 10,7 Mrd. DM (1995) und 14 Mrd. DM (1998). Als einziges westdeutsches Land profitierte Schleswig-Holstein 1996 und 1997 von der Reform.

Der flexiblen und sachgerechten Handhabung der Umsatzsteuerverteilung kommt im bundesdeutschen Steuerverbund erhebliche Bedeutung für eine dem jeweiligen Finanzbedarf angepaßte Finanzausstattung der Bundesund der Länderebene zu. Daß dabei Streitigkeiten an der Tagesordnung sind, verwundert angesichts der quantitativen Bedeutung der Gemeinschaftsteuern nicht. Sie wären aber auch durch ein Trennsystem nicht völlig vermeidbar, denn dieses schützt nicht vor Änderungen bzw. Verschiebungen der Aufgaben und damit des Finanzbedarfs zwischen Bund und Ländern. Allerdings wären die daraus resultierenden Anpassungserfordernisse im

1 Nach dem Gesetz zur Finanzierung eines zusätzlichen Bundeszuschusses zur gesetzlichen Rentenversicherung erhält der Bund vorab einen Ausgleich in Höhe von 3,64\% (ab 1999: 5,63 \%) des Umsatzsteueraufkommens. Die Gemeinden wurden zum Ausgleich der Mindereinnahmen infolge der Abschaffung der Gewerbekapitalsteuer zum 1.1.1998 mit 2,2 \% an dem danach verbleibenden Umsatzsteueraufkommen beteiligt. Vgl. Bundesministerium der Finanzen, 1998, S. $143 \mathrm{f}$.

2

Die erneute Anteilsänderung geht auf die Neuregelung des Familienlastenausgleichs ab 1.1.1996 zurück, die infolge der Integration des Kindergeldes in die Einkommensbesteuerung zu Einnahmenausfällen bei den Lăndern (und Gemeinden) führte. Eine endgültige Berücksichtigung der Lasten der Umstrukturierung war damit übrigens nicht beabsichtigt. Zu beachten ist auch, daß der Bund aus seinem Anteil noch die (Mehrwertsteuer-) Mitgliedszahlungen an die EU entrichtet, so daß ihm letzten Endes deutlich weniger als $50 \%$ des Umsatzsteueraufkommens verbleiben. 
(reinen) Trennsystem kaum noch zufriedenstellend zu lösen, weil das flexible Scharnier zwischen den Ebenen fehlen würde. Revisionsbedürttig erscheint freilich das Verfahren der Verănderung der Verbundanteile. Dieses Problem bleibt im folgenden unberücksichtigt, weil es den Kern des Länderfinanzausgleichs nicht betrifft, sollte aber im Rahmen einer grundlegenden, über den Länderfinanzausgleich hinausgehenden Reform der Finanzverfassung aufgegriffen werden 1 .

\section{Die horizontale Steuerverteilung}

Die horizontale Steuerverteilung unter den Bundesländern basiert nach Art. 107 Abs.1 GG auf dem „Prinzip des örtlichen Aufkommens“. Den einzelnen Ländern stehen die Landessteuern und der Länderanteil an der Einkommenund Körperschaftsteuer grundsätzlich in dem Maße zu, in dem sie von den jeweiligen Finanzbehörden vereinnahmt werden. Das ungefilterte Prinzip des örtlichen Aufkommens ist allerdings immer dann durch eine geeignete Steuerzerlegung zu modifizieren, wenn verwaltungstechnische Gründe die Wahl des Finanzamts bestimmen und deshalb kein direkter Bezug zu den Steuerpflichtigen oder zur Wirtschaft eines Landes hergestellt werden kann.

\section{a. Die Verteilung der Einkommensteuer}

Die Zerlegung der Lohnsteuer und der Körperschaftsteuer ${ }^{2}$ dient der Korrektur der Aufkommensverzerrungen, die dadurch zustande kommen, daß ein Unternehmen mit Betriebsstătten in mehreren Bundesländern seine Lohnund Körperschaftsteuer in dem Bundesland abführt, in dem es seinen Unternehmenssitz hat.

1 Dabei geht es um operationale Verteilungsregeln, die den politischen Streit um knappe Finanzmittel zwischen Bund und Ländern auf eine rationale Grundlage stellen sollen. Vgl. Wissenschaftlicher Beirat beim Bundesministerium der Finanzen, 1996.

2 Auf den Zinsabschlag wird im folgenden nicht năher eingegangen. Wegen der Anonymităt des Quellenabzugsverfahrens gilt derzeit folgende Regelung: Der Länder- und Gemeindeanteil am Aufkommen wird in einen Westanteil (91\%) und einen Ostanteil (9\%) aufgeteilt. Der Westanteil wird auf die einzelnen Länder nach einem Mischschlüssel verteilt (Einkünfte aus Kapitalvermögen $70 \%$, Körperschaftsteueraufkommen $20 \%$, Aufkommen der veranlagten Einkommensteuer $10 \%$ ). Die Verteilung des Ostanteils erfolgt nach der Einwohnerzahl der Länder. Das Zerlegungsgesetz sieht vor, daß sich ab dem Jahr 2002 die Zerlegungsanteile am Zinsabschlag nach der Höhe des auf die Einkommen- und Korperschaftsteuer angerechneten Zinsabschlags bemessen. 
(1) Der Lănderanteil an der Lohnsteuer wird nach dem Wohnsitzprinzip unter den Ländern verteilt. Der Anteil der einzelnen Länder an der Einkommensteuer richtet sich also nach dem Anteil ihrer Bürger am (steuerpflichtigen) Einkommen und damit nach der Einkommensverteilung. Die Steuerzerlegung trägt hier nur dem Tatbestand der zentralen Lohnsteuerabführung am Unternehmenssitz Rechnung. Die Orientierung an der Einkommensverteilung selbst ist dagegen nicht ohne weiteres zu begründen, denn auch die alternative Orientierung an der Einkommensentstehung (Betriebsstăttenprinzip) wäre - als wirtschaftsbezogene Variante - mit dem Prinzip des ortlichen Aufkommens vereinbar ${ }^{1}$.

(2) Nach dem Betriebsstättenprinzip wird bei der Zerlegung der Körperschaftsteuer verfahren. Zerlegungsmaßstab sind die in den einzelnen Betriebsstätten gezahlten Arbeitsentgelte. Wiederum kann nur die Zerlegung als solche, nicht aber das konkrete Zerlegungsverfahren zweifelsfrei gerechtfertigt werden. Die Körperschaftsteuer ist keine Sondersteuer für Unternehmen, sondern eine Folgesteuer der persönliche Einkommensteuer ${ }^{2}$. Es wäre daher aus steuersystematischer Sicht keineswegs abwegig, wenn auch aus verwaltungstechnischen Gründen nicht empfehlenswert, eine Steuerzerlegung nach dem Wohnsitz der Anteilseigner vorzunehmen. Eine solche Lösung wäre auch nach dem Prinzip des örtlichen Aufkommens - nunmehr in der einwohnerbezogenen Variante - vertretbar.

Diese Überlegungen unterstreichen, daß der Begriff des örtlichen Aufkommens unterschiedlich interpretiert werden kann. Mit dem Wohnsitz- und dem Betriebsstättenprinzip stehen (mindestens) zwei Verfahren zur Debatte, die zu einer unterschiedlichen Verteilung der Steuererträge zwischen den Lăn-

1 Peffekoven begründet das Wohnsitzprinzip steuersystematisch mit der Belastungskonzeption der Lohnsteuer. Vgl. Peffekoven, 1987, S. $186 \mathrm{ff}$. Dagegen spricht, daß die Steuerleistung zwar vom Arbeitnehmer erbracht wird, aber nicht an seinem Wohnort. Das Leistungsfähigkeitsprinzip regelt auch nur die Verteilung der Steuerlasten auf die Bürger, nicht die Verteilung des Steueraufkommens auf die Gebietskörperschaften.

2 Das Anrechnungsverfahren für die ausgeschütteten Gewinne gewăhrleistet, daß diese letzten Endes nur der persönlichen Einkommensteuer des Anteilseigners unterliegen. Die Körperschaftsteuer dient nur der effektiven Besteuerung der einbehaltenen Gewinne und damit der Gewinnverwendungs-, Rechtsform- und Wettbewerbsneutralität der Einkommensbesteuerung. 
dern führen, gleichwohl aber dem Prinzip des örtlichen Aufkommens genügen. Daher muß politisch über das relative Gewicht der beiden Zerlegungsmaßstäbe ${ }_{n}$ Einwohner" und "Wirtschaftskraft" entschieden werden.

Die heutige Lösung ist im übrigen nicht schon deshalb ausgewogen, weil bei der Lohnsteuer das Wohnsitzprinzip und bei der Körperschaftsteuer das Betriebsstättenprinzip angewandt wird. Die Körperschaftsteuer erbringt ein vergleichsweise geringes Aufkommen, so daß de facto das Wohnsitzprinzip bei der Steuerzerlegung klar dominiert. Dieser Sachverhalt wird im Zusammenhang mit der Relevanz grenzüberschreitender Pendlerverflechtungen für den Finanzausgleich zu berücksichtigen sein. Davon sind in erster Linie die Stadtstaaten und Flächenländer mit großen Wirtschaftszentren (Hessen) betroffen, die Arbeitsplätze für Einpendler aus anderen Ländern bieten 1 .

\section{b. Die Verteilung der Umsatzsteuer}

Die als Verbrauchsteuer konzipierte Umsatzsteuer wird nicht am Ort des Konsums, sondern am Ort des Verkaufs (oder beim zuständigen Zollamt) erhoben. Daher ist eine Zerlegung des Länderanteils an der Umsatzsteuer erforderlich. Während der Ort der Einkommensentstehung (Betriebsstätten der Unternehmen) und der Ort der Einkommensverteilung (Wohnsitz der Einwohner) naheliegende Ansatzpunkte einer Zerlegung der Steuern vom Einkommen bilden, wird für die Verteilung der Umsatzsteuer die Zahl der natürlichen Einwohner herangezogen. Im Grundsatz überzeugender wäre jedoch - mit Blick auf das Prinzip des örtlichen Aufkommens - eine Verteilung nach dem regionalen privaten Verbrauch.

Dennoch ist die einwohnerorientierte Umsatzsteuerzerlegung keine ungeeignete Lősung. Das Verfahren unterstellt der Einfachheit halber, daß keine gravierenden regionalen Unterschiede im umsatzsteuerpflichtigen Pro-KopfVerbrauch vorliegen. Unter dieser (tatsächlich nicht ganz zutreffenden) Prämisse kann man die Einwohnerzahl als Indikator des regionalen Endverbrauchs heranziehen. Die Methode mag nicht perfekt sein, ist aber unkompliziert, transparent und nicht zuletzt eingespielt. Der Übergang zu einer

$1 \mathrm{Vgl}$. zur Bedeutung überregionaler Verflechtungen im Finanzausgleich S. $125 \mathrm{ff}$. 
(noch) stärker konsumbezogenen Zerlegung erscheint daher nicht empfehlenswert. Finanzausgleichspolitisch ist allerdings zu beachten, daß die einwohnerbezogene Umsatzsteuerzerlegung - gegenüber einer am regionalen Verbrauch orientierten Lơsung - einen nivellierenden Effekt hat ${ }^{1}$.

Von praktisch größerer Bedeutung als die grundsătzliche Frage nach der einwohner- oder verbrauchsbezogenen Zerlegung des Länderanteils an der Umsatzsteuer ist die Regelung der sogenannten Ergänzungsanteile für die Vorweganhebung der Finanzkraft finanzschwacher Länder. Damit wird erstmals ein horizontaler Finanzkraftausgleich im engeren Sinne herbeigeführt. Die finanzstarken verzichten zugunsten der finanzschwachen Lănder auf bis zu $25 \%$ des Umsatzsteueraufkommens der Länder, das innen nach dem (in der Einwohnerzahl konkretisierten) Prinzip des ortlichen Aufkommens zustehen würde. Ziel ist eine Aufstockung der Finanzkraft der finanzschwachen Länder auf mindestens $92 \%$ des Länderdurchschnitts. Wenn die verfügbaren Mittel zur Erfüllung der ${ }_{n}$ Sockelgarantie" nicht ausreichen, werden die Ergänzungsanteile reduziert und der Zielwert unterschritten; im umgekehrten Fall wird der verbleibende Betrag nach der Einwohnerzahl verteilt.

Der Umsatzsteuer-Vorwegausgleich hat durch die Einbeziehung der neuen Bundesländer in den Länderfinanzausgleich erheblich an Bedeutung gewonnen. Abbildung 1 illustriert die Wirkungen der Umsatzsteuerverteilung für 1998. Die Lảnder wurden nach ihrer relativen Pro-Kopf-Finanzkraft vor Umsatzsteuerverteilung geordnet. Erkennbar ist dabei die ausgeprăgte Finanzschwäche der fünf neuen Bundesländer. Die Ergänzungsanteile sorgen bereits für eine weitgehende Angleichung der relativen Finanzkraftpositionen, von der 1998 ausschließlich die finanzschwachen neuen Bundesländer und das Saarland profitieren. Die neuen Bundesländer, die gemessen an den Einnahmen aus Lăndersteuern nur über eine relative Finanzkraft zwischen $35,9 \%$ und $43,2 \%$ verfügen, erreichen nach Umsatzsteuerverteilung bereits ein Niveau von $89,3 \%$ der durchschnittlichen Länderfinanzkraft.

1 Vgl. Wissenschaftlicher Beirat beim Bundesministerium der Finanzen, 1992, S. 59. Das Kriterium der Einwohnerzahl kann daher auch als pauschalisierender Bedarfsmaßstab mit nivellierender Wirkung interpretiert werden. Vgl. Carl, 1995, S. 37 ff. Der Nivellierungseffekt setzt voraus, daß der Einwohneranteil finanzschwacher Lănder ihren Anteil am privaten Verbrauch übersteigt. 


\section{Abbildung 1}

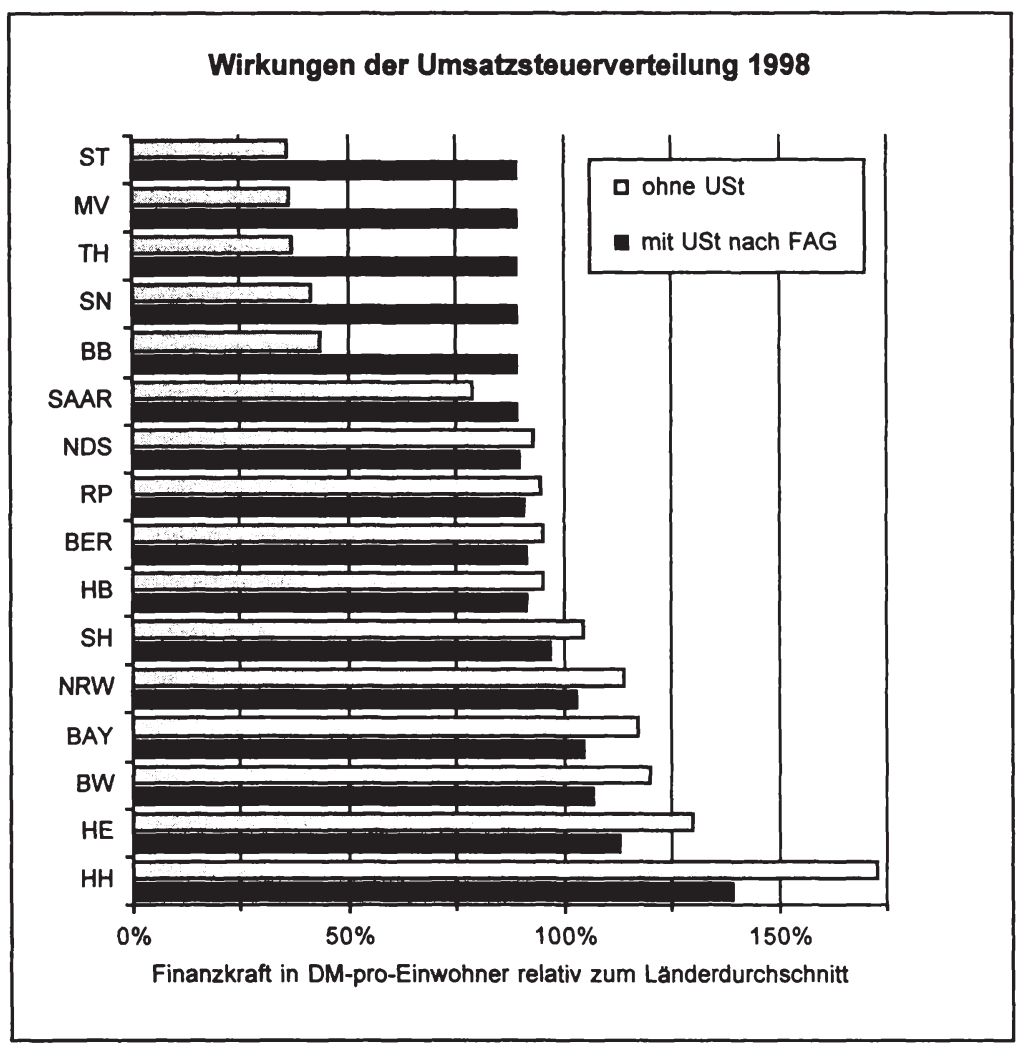

\section{Der Finanzausgleich unter den Ländern}

Besonders umstritten ist die dritte Stufe des Länderfinanzausgleichs. Der horizontale Lănderfinanzausgleich im engeren Sinne dient der (weiteren) Verringerung der Finanzkraftunterschiede zwischen den Ländern gemessen an der Pro-Kopf-Finanzkraft. Der Ausgleich erfolgt durch direkte Zahlungen zwischen den Bundesländern. Es handelt sich um ein "Nullsummenspiel", d. h. die Zuweisungen an die finanzschwachen Länder müssen den Zahlungen der finanzstarken Länder entsprechen. 


\section{a. Finanzkraft und Finanzbedarf}

Im Zentrum des horizontalen Länderfinanzausgleichs stehen die Ermittlung der Finanzkraft und des Finanzbedarfs sowie die Festlegung des AusmaBes, in dem Diskrepanzen zwischen diesen Größen ausgeglichen werden. Die relative Finanzkraft wird dabei nicht - wie noch im Rahmen der Umsatzsteuerverteilung - an den Steuereinnahmen der Länder pro Kopf gemessen. Maßgeblich ist vielmehr die Finanzkraftmeßzahl, die sich aus den Ländersteuern, den Anteilen an den Gemeinschaftsteuern nach Zerlegung und Umsatzsteuer-Vorwegausgleich, den bergrechtlichen Förderabgaben 1 sowie $50 \%$ der (modifizierten) Gemeindesteuern ergibt².

Diese Finanzkraftrechnung wird allerdings durch die unsystematische Einbeziehung von Bedarfselementen verzerrt; denn Bremen, Hamburg, Niedersachsen und Mecklenburg-Vorpommern, nicht aber Schleswig-Holstein, dürfen ihre Steuerkraft durch den Abzug von Pauschalbeträgen für "Seehafenlasten “3 reduzieren. Infolgedessen kann die Finanzkraftmeßzahl nur mit Einschränkungen als Indikator der tatsächlichen Steuereinnahmen eines Landes (und seiner Kommunen) angesehen werden.

Der Finanzbedarf wird mit Hilfe der sogenannten Ausgleichsmeßzahl abgesteckt. Grundsätzlich geht man von einem je Einwohner gleichen Finanzbedarf in allen Lăndern aus. Die Ausgleichsmeßzahl resultiert demgemäß aus den bundesdurchschnittlichen Länder- und Gemeindeeinnahmen (im Sinne des FAG) pro Einwohner multipliziert mit der Einwohnerzahl des Landes. Jedoch orientiert man sich nicht an den tatsächlichen Einwohnerzahlen, sondern verwendet einen davon abweichenden Einwohnerschlüssel.

(1) Die Ländersteuereinnahmen der Flăchenstaaten gehen mit einer Einwohnerwertung von $100 \%$ in die Ausgleichsmeßzahl ein.

1 Die Einbeziehung der Förderabgaben ist gerechtfertigt, da sie die Dispositionskraft der Länder genauso erhöhen wie die Steuern. Allerdings ist die Regelung inkonsequent, weil die nicht anders einzustufenden Konzessionsabgaben unberücksichtigt bleiben.

2

Bei den Realsteuern müssen die Einnahmen der Gemeinden, die auch von der kommunalen Hebesatzpolitik abhängen, über Nivellierungshebesätze normiert werden. Vgl. zur Anrechnung der kommunalen Finanzkraft im Länderfinanzausgleich S. $139 \mathrm{ff}$.

3 Vgl. zur Problematik der Hafenlastenregelung S. $110 \mathrm{ff}$. 
(2) Die Einwohner der Stadtstaaten werden dagegen mit $135 \%$ gewichtet. Pro tatsächlichem Einwohner können die Stadtstaaten daher einen um 35 \% über dem Durchschnitt liegenden Finanzbedarf geltend machen. Das "Stadtstaatenprivileg“, das durch den Einbezug Berlins quantitativ erheblich an Bedeutung gewonnen hat, stellt eine massive Vergünstigung dar und ist nicht zufällig eines der besonders umstrittenen Elemente des horizontalen Länderfinanzausgleichs ${ }^{1}$.

(3) Auch bei den ausgleichsrelevanten Einnahmen der Gemeinden werden die Einwohnerzahlen innerhalb der Bundesländer mit Prozentsätzen zwischen $100 \%$ (für die ersten 5.000 Einwohner) und $130 \%$ (für die über 1.000.000 hinausgehende Einwohnerzahl) gewichtet. Gemeinden mit mehr als 500.000 Einwohnern erhalten darüber hinaus Zuschläge zwischen $2 \%$ und $6 \%$ in Abhängigkeit von der Bevölkerungsdichte2.

Die Einwohnerwertungen durchbrechen das Prinzip des gleichen Pro-KopfBedarfs in erheblichem Maße. Dabei muß man berücksichtigen, daß der „Finanzbedarf" keine Größe ist, die aus einer echten Bedarfsanalyse resultiert. Vielmehr bedeutet die Orientierung an den bundesdurchschnittlichen Länder- und Gemeindeeinnahmen je Einwohner nur, daß der horizontale Länderfinanzausgleich allen Bundesländern eine an den Durchschnitt angenäherte Finanzausstattung vermitteln soll. Der Länderfinanzausgleich ist als Finanzkraftausgleich konzipiert, dem besondere Bedarfselemente eigentlich fremd sind. Die Ausgleichsmeßzahl kann allenfalls als Ausdruck eines allgemeinen, am Bedarfsträger "Einwohner" anknüpfenden Finanzbedarfs interpretiert werden, was wiederum gegen eine Einwohnergewichtung spricht.

\section{b. Ausgleichszuweisungen und Ausgleichsbeiträge}

Die Relation zwischen Finanzkraftmeßzahl (FKM) und Ausgleichsmeßzahl (AMZ) bildet die Schlüsselgröße für den horizontalen Länderfinanzausgleich. Auf der Grundlage der relativen Finanzkraft (FKM/AMZ) findet der Ausgleich zwischen den Ländern statt. Finanzschwache Länder (im Sinne

1 Vgl. zur Einwohnerwertung der Stadtstaaten S. $121 \mathrm{ff}$.

2 Vgl. zur Einwohnerwertung der Gemeinden S. $153 \mathrm{ff}$. 
des FAG), deren Ausgleichsmeßzahl ihre Finanzkraftmeßzahl übersteigt $(A M Z>F K M)$, sind ausgleichsberechtigt; finanzstarke Länder, deren Finanzkraftmeßzahl ihre Ausgleichsmeßzahl übersteigt ( $F K M>A M Z$ ), sind ausgleichspflichtig. Da die Summe der Ausgleichsmeßzahlen der Summe der Finanzkraftmeßzahlen entspricht, gleichen sich die Ausgleichszuweisungen und Ausgleichsbeiträge insgesamt aus.

Ein zentrales Problem des horizontalen Länderfinanzausgleichs ist der Umverteilungstarif. Der Ausgleich erfolgt so, daß Fehlbeträge bis $92 \%$ zu $100 \%$ und Fehlbeträge zwischen $92 \%$ und $100 \%$ zu 37,5\% ausgeglichen werden, d. h. alle Länder erreichen nach horizontalem Finanzausgleich mindestens $95 \%$ der durchschnittlichen Finanzkraft (bezogen auf die gewichteten Einwohner). Ausgleichspflichtige Länder werden progressiv belastet. Von ihrer über dem Finanzbedarf liegenden Finanzkraft werden im Bereich zwischen $100 \%$ und $101 \%$ der durchschnittlichen Finanzkraft $15 \%$, zwischen $101 \%$ und $110 \%$ der durchschnittlichen Finanzkraft $66 \%$ und über $110 \%$ der durchschnittlichen Finanzkraft $80 \%$ in den Ausgleich einbezogen. Davon ist ein einheitlicher Prozentsatz abzuführen, der so festgelegt werden muß, daß die Ausgleichszuweisungen den Ausgleichszahlungen entsprechen1.

Die effektiven Abschöpfungsquoten werden also erst im Finanzausgleich bestimmt. Die ohnehin schon sehr hohe Grenzbelastung von $80 \%$ in der dritten Zone kann dadurch noch überschritten werden². Solche Grenzbelastungen sind unter Anreizgesichtspunkten fragwürdig. Zwar bewirkt der progressive Umverteilungstarif allein noch keine Übernivellierung, aber im Spannungsfeld zwischen den allokativen und distributiven Zielen des Finanzausgleichs wird der Verteilungsgesichtspunkt doch zu stark betont.

1 Sofern die Belastungsverteilung nicht mit den ${ }_{n}$ absurden, extrem komplizierten und undurchsichtigen Garantieklauseln" (Andel, 1998, S. 525) vereinbar ist, muß das Umverteilungsvolumen nochmals angepaßt werden. Die vielleicht wichtigste Klausel besagt, daß kein Zahlerland in der Rangfolge hinter ein anderes Zahlerland zurückfallen darf. 1998 profitierten Bremen, Hamburg und Schleswig-Holstein von den Garantieklauseln (zusammen 23,2 Mio. DM). Belastet waren Baden-Württemberg, Bayern, Hessen und Nordrhein-Westfalen (zusammen 51,3 Mio. DM). Der Bund sparte infolge der Garantieklauseln 28,2 Mio. DM bei den Fehlbetrags-Bundesergänzungszuweisungen.

2 Die garantierte Maximalabschøpfung von $15 \%$ der um $1 \%$ über der $A M Z$ liegenden Finanzkraft und $80 \%$ der um mehr als $1 \%$ über der AMZ liegenden Finanzkraft ( $\S 10$ Abs. 4 FAG) bezieht sich auf die durchschnittliche Abschöpfung und hat insofem keine Bedeutung für die Grenzbelastungen. Vgl. zu den Grenzbelastungen S. $84 \mathrm{ff}$. 


\section{c. Verteilungseffekte des Lănderfinanzausgleichs i. e. S.}

Abbildung 2 illustriert - anhand der Relation zwischen Finanzkraftmeßzahl und Ausgleichsmeßzahl - die Wirkungen des Länderfinanzausgleichs i.e.S. für das Jahr 1998. Zwei Aspekte verdienen besondere Aufmerksamkeit.

\section{Abbildung 2}

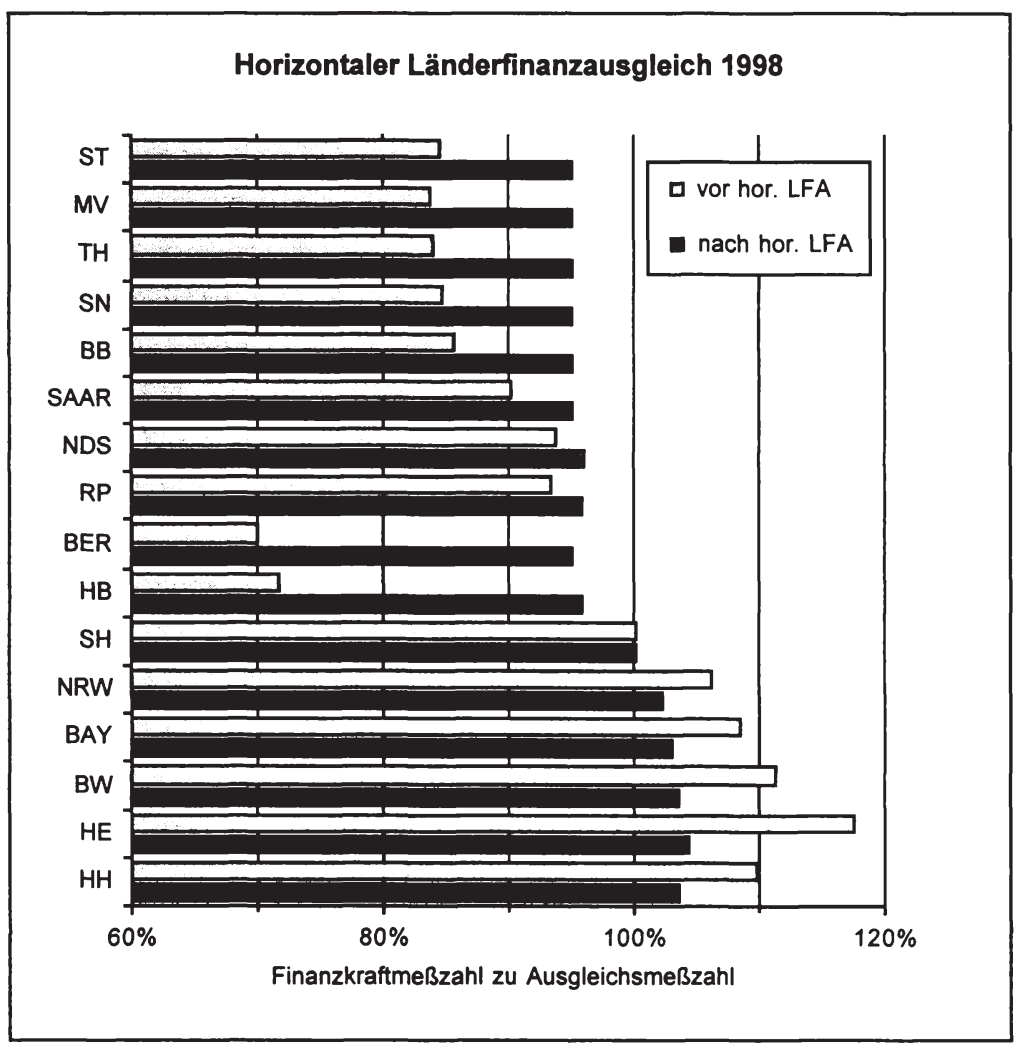

(1) Die Stadtstaaten profitieren erheblich von der Einwohnergewichtung, durch die sie relativ finanzschwach gerechnet werden. Berlin und Bremen sind nach den Maßstäben des Finanzausgleichsgesetzes vor Länderfinanzausgleich die ärmsten Bundesländer und erhalten dementsprechend hohe Ausgleichsleistungen. Hamburg rutscht in der Finanz- 
kraftrangfolge von Platz 1 nach der Umsatzsteuerverteilung auf Platz 3 und profitiert davon durch relativ geringe Ausgleichszahlungen.

(2) Die Finanzkraftdifferenzen zwischen den Ländern werden noch einmal erheblich reduziert. Die finanzschwachen Länder erreichen nun $95 \%$ der durchschnittlichen Finanzkraft'. Die großten Einbußen verzeichnet Hessen, das sich von 117,6 \% der durchschnittlichen Finanzkraft vor $\mathrm{Fi}$ nanzausgleich auf $104,3 \%$ nach horizontalem Finanzausgleich verschlechtert. Hessen zahlt auf dieser Stufe des Länderfinanzausgleichs ca. 570 DM pro Einwohner; das sind insgesamt etwa 3,4 Mrd. DM.

Der horizontale Länderfinanzausgleich steht im Zentrum der Kritik am heutigen System. Nach weitgehend übereinstimmender Auffassung in der Finanzwissenschaft erscheint neben der Problematik der Hafenlasten und der Einwohnerwertung insbesondere der stark progressive Tarif reformbedürftig. Vorgeschlagen wird meist ein linearer Ausgleichstarif mit deutlich gesenktem Ausgleichssatz. Dabei bilden die im horizontalen Lănderfinanzausgleich erzielten Ausgleichseffekte, die ein Mindestniveau von $95 \%$ der länderdurchschnittlichen Finanzkraft garantieren, noch nicht einmal die Obergrenze der Nivellierung. Diese Grenze wird erst auf der năchsten Stufe des Lănderfinanzausgleichs durch die (Fehlbetrags-) Bundesergänzungszuweisungen auf ein Niveau angehoben, das nahezu Vollnivellierung bedeutet.

\section{Die Bundesergänzungszuweisungen}

Im Anschluß an den horizontalen Länderfinanzausgleich i. e. S. sorgen die Bundesergănzungszuweisungen für weitere Verănderungen der Länderfinanzkraft. Klar differenziert werden muß hinsichtlich ihrer Funktion und Berechtigung zwischen den Fehlbetrags- und den Sonderbedarfs-Bundesergänzungszuweisungen.

1 Bremen liegt 1998 sogar bei 95,8 \% des Durchschnittswerts, was auf die Ländersteuergarantie für finanzschwache Länder zurückzuführen ist. 


\section{a. Fehlbetrags-Bundesergänzungszuweisungen}

Die Fehlbetrags-Bundesergänzungszuweisungen können als Fortsetzung des horizontalen Länderfinanzausgleichs mit anderen Mitteln interpretiert werden. Es handelt sich um vertikale Finanzzuweisungen mit horizontalem Effekt, mit denen die zu $100 \%$ noch fehlende Finanzkraft der finanzschwachen Länder nach Länderfinanzausgleich zu $90 \%$ ausgeglichen wird. Die Folge ist, daß alle Länder nach Finanzausgleich und Fehlbetrags-Bundesergänzungszuweisungen über mindestens $99,5 \%$ der durchschnittlichen Finanzkraft verfügen.

\section{Abbildung 3}

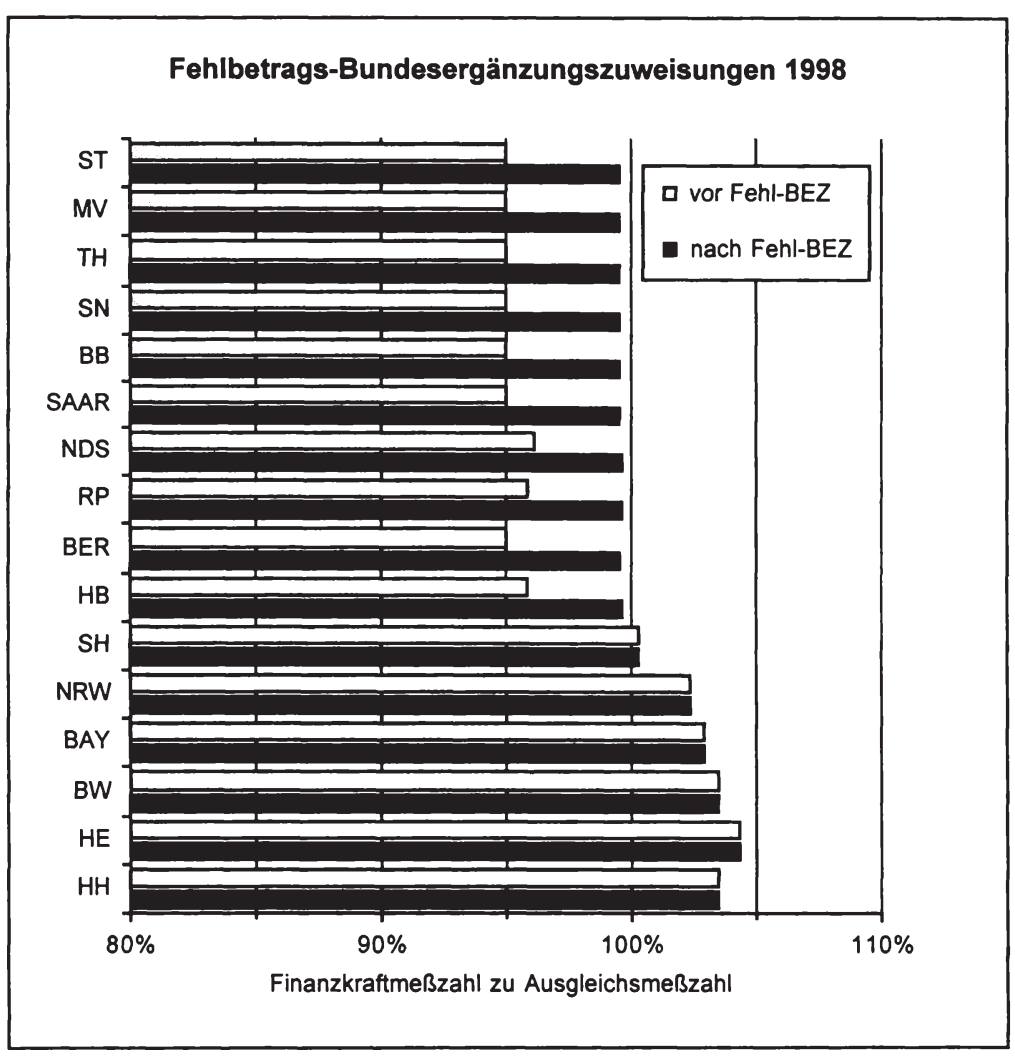


Im Vergleich zu den 13,5 Mrd. DM, die 1998 im horizontalen Ausgleich zwischen den Ländern umgeschichtet wurden, erreichten die Fehlbetrags-Bundesergänzungszuweisungen mit einem Gesamtvolumen von rund 5,8 Mrd. DM eine beachtliche Größenordnung. Sie tragen wesentlich zur übermäßigen Nivellierungswirkung des heutigen Systems bei. Abbildung 3 verdeutlicht dies anhand der Veränderung der relativen Finanzkraft (FKM zu AMZ). Von den Fehlbetrags-Bundesergănzungszuweisungen profitieren zehn der sechzehn Bundesländer. Sie können nach horizontalem Länderfinanzausgleich längst nicht mehr als besonders finanzschwach gelten. Ihre Finanzausstattung wird nun aber praktisch auf den Länderdurchschnitt angehoben.

Die Fehlbetrags-Bundesergänzungszuweisungen werden überwiegend kritisch beurteilt. Sie erhöhen nicht nur die Nivellierungsintensităt, sondern verstärken auch die vertikale zu Lasten der horizontalen Ausgleichskomponente. Angesichts der Zielsetzung einer (zusätzlichen) Verringerung der Finanzkraftdifferenzen stellt sich schon die Frage, weshalb der Bund den Ländern nicht insgesamt einen höhere Anteil an den Gemeinschaftsteuern überlassen und im Gegenzug die Fehlbetrags-Bundesergänzungszuweisungen abschaffen soll. Die Folge wäre eine Verlagerung der horizontalen Umverteilung auf die dafür primär zuständige Ebene bei einem insgesamt reduziertem Ausgleichsniveau (abhängig von der mit dieser Umschichtung eventuell einhergehenden Anpassung des Ausgleichstarifs im horizontalen Länderfinanzausgleich).

Die übermäßige Nivellierungsintensität des Länderfinanzausgleichs hat im übrigen problematische Folgen, die auf den ersten Blick nicht erkennbar sind. Der heutige Finanzausgleich führt dazu, daß sich eine Verbesserung der Finanzkraft eines Bundeslandes kaum noch in seinem Landeshaushalt bemerkbar macht bzw. in vielen Fällen sogar eine Minderung der Landeseinnahmen bewirkt. Hessen verbleiben z. B. von 1 Mrd. DM Mehreinnahmen bei der Lohnsteuer nur noch 42 Mio. DM. In Mecklenburg-Vorpommern führen die gleichen Mehreinnahmen sogar zu einem Verlust für den Staatshaushalt in Höhe von 64 Mio. DM; ein Ergebnis, das sich auch bei anderen finanzschwachen Länder einstellt. Auf die (Anreiz-) Problematik der Nivellierungseffekte wird im folgenden noch näher eingegangen ( $v g l . ~ S .87$ ff.). 


\section{b. Sonderbedarfs-Bundesergänzungszuweisungen}

Neben der generellen Anhebung der Finanzkraft finanzschwacher Länder gewährt der Bund aus unterschiedlichen Gründen Sonderbedarfs-Bundesergänzungszuweisungen 1 . Sie werden gezahlt für Kosten der politischen Führung, Haushaltsnotlagen, Übergangslasten finanzschwacher alter Bundesländer und Sonderbedarfe der neuen Bundesländer. Abbildung 4 zeigt die Bedeutung der verschiedenen Zuweisungen in DM pro Einwohner.

\section{Abbildung 4}

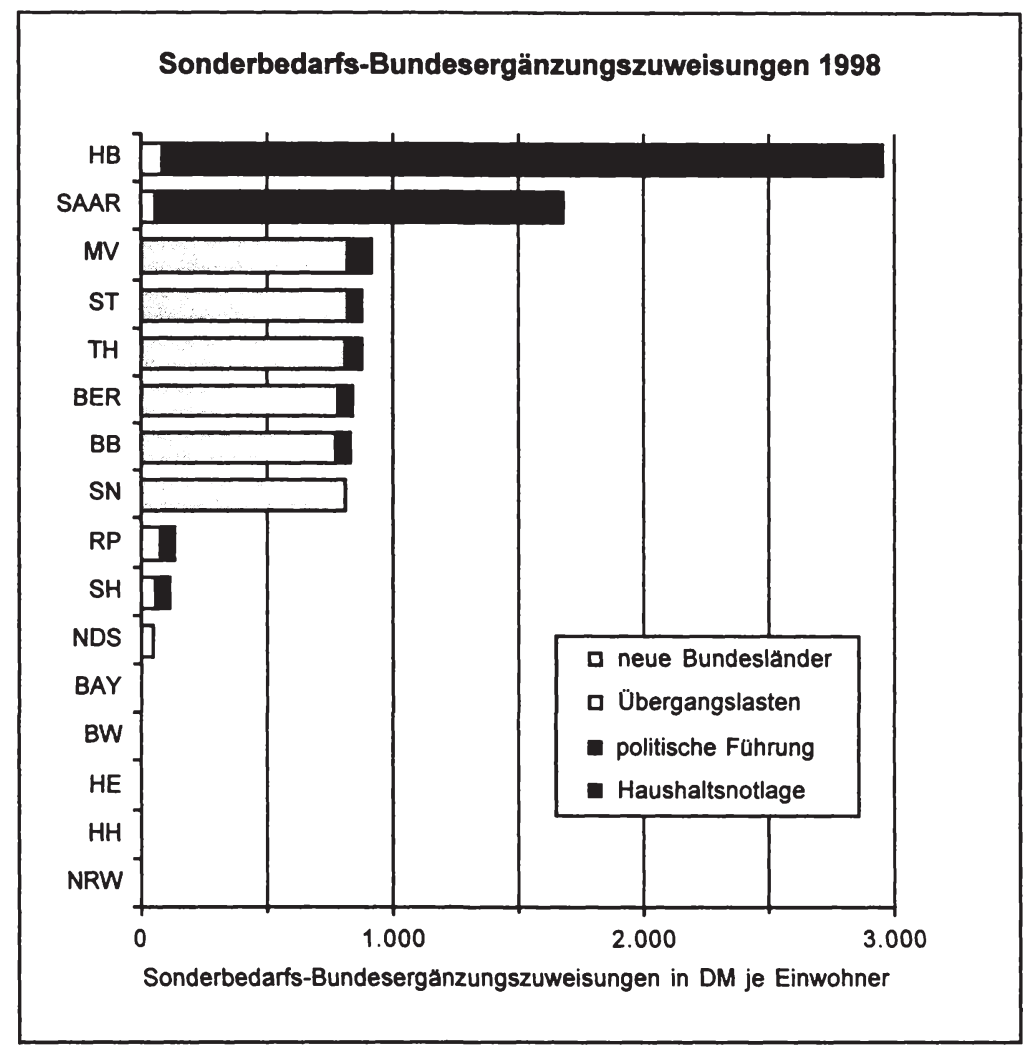

1 Der Begriff "Sonderbedarfs-Bundesergănzungszuweisungen“ dient der Unterscheidung dieser Zuweisungen von den Bundesergănzungszuweisungen zur ergänzenden Dekkung des allgemeinen Finanzbedarfs. 
(1) Die 1988 eingeführten Sonderbedarfs-Bundesergänzungszuweisungen wegen überdurchschnittlich hoher Kosten politischer Führung und der zentralen Verwaltung ( $\$ 11$ Abs. 3 FAG) erhalten neun der sechzehn Bundesländer ${ }^{1}$ in Höhe von insgesamt 1,5 Mrd. DM jährlich. Empfänger sind alle Länder mit weniger als 4 Millionen Einwohnern mit der nicht näher begründeten Ausnahme Hamburgs. Die Zuweisungen sollen einen Ausgleich der überproportionalen "Kosten der Kleinheit“ bewirken.

(2) Sonderbedarfs-Bundesergänzungszuweisungen zum Abbau teilungsbedingter Sonderbelastungen und für den Ausgleich unterproportionaler kommunaler Finanzkraft ( $\$ 11$ Abs. 4 FAG) gehen in Höhe von 14 Mrd. DM an die neuen Bundesländer (einschließlich Berlin). Sie dienen dem Abbau von Infrastrukturdefiziten und damit auch der langfristigen Stärkung der Wirtschafts- und Finanzkraft der neuen Länder.

(3) Sogenannte Übergangs-Bundesergänzungszuweisungen ( $\$ 11$ Abs. 5 FAG) fließen in Höhe von insgesamt 942 Mio. DM (1998) an fünf Bundesländer (Bremen, Niedersachsen, Rheinland-Pfalz, Saarland, Schleswig-Holstein). Sie dienen über einen Zeitraum von zehn Jahren der Entlastung der von der Integration der neuen Länder in den Länderfinanzausgleich besonders betroffenen finanzschwachen alten Bundesländer.

(4) Bundesergänzungszuweisungen zur Haushaltssanierung (§ 11 Abs. 6 FAG) erhalten das Saarland (1998: 1,6 Mrd. DM) und Bremen (1998: 1,8 Mrd. DM) ${ }^{2}$. Diese Mittel sind zur Schuldentilgung zu verwenden. Dadurch eingesparte Zinsen müssen für Investitionen zur Stärkung der Wirtschafts- und Finanzkraft oder für eine Senkung der Nettokreditaufnahme eingesetzt werden.

Die Bundesergănzungszuweisungen haben ihren ursprünglich (zumindest beabsichtigten) subsidiären Charakter nicht zuletzt infolge der Einführung

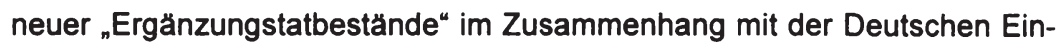

1 Berlin, Brandenburg, Bremen, Mecklenburg-Vorpommern, Rheinland-Pfalz, Saarland, Sachsen-Anhalt, Schleswig-Holstein und Thüringen.

21999 erhalten Bremen 1,8 Mrd. DM und das Saarland 1,2 Mrd. DM. Diese Beträge verringern sich bis 2004 auf 700 Mio. DM für Bremen und 500 Mio. DM für das Saarland. Nach 2004 sollen keine Sanierungs-Bundesergänzungszuweisungen gezahlt werden. 
heit verloren. Mit 1998 insgesamt 25,7 Mrd. DM, von denen 19,9 Mrd. DM auf die Sonderbedarfs-Bundesergănzungszuweisungen entfallen, hat ihr Volumen inzwischen nahezu das Doppelte der Transfers im Rahmen des horizontalen Länderfinanzausgleichs (1998: 13,5 Mrd. DM) erreicht. Dies signalisiert einen erheblichen Bedeutungszuwachs und unterstreicht die Notwendigkeit der Auseinandersetzung mit der Berechtigung und der Gestaltung der verschiedenen Bundesergänzungszuweisungen1.

Mit Ausnahme der Bundesergănzungszuweisungen für die neuen Länder sind alle Sonderbedarfs-Bundesergänzungszuweisungen schon im Grundsatz umstritten. Die Kritik richtet sich insbesondere auf die nachfolgend skizzierten Punkte.

(1) Gegen die Bundesergänzungszuweisungen wegen überdurchschnittlich hoher Kosten politischer Führung spricht, daß die Berücksichtigung dieser Kosten im Widerspruch zum föderativen Gedanken steht und freiwillige, kostensenkende Kooperations- und Fusionslösungen behindert2.

(2) Die Übergangs-Bundesergänzungszuweisungen sind kaum mehr als verkappte Fehlbedarfs-Ergänzungszuweisungen. Sie berücksichtigen keinen spezifischen Bedarf, sondern verbessern in unsystematischer Weise die Finanzkraft einiger (aber nicht aller) finanzschwacher Länder.

(3) Die Bundesergänzungszuweisungen zur Milderung von Haushaltsnotlagen können - insbesondere für kleine Länder - Anreize zu finanzpolitischem Fehlverhalten setzen. Auch ist die Unterstützung notleidender Länder nicht allein Sache des Bundes.

Die Notwendigkeit der Sonderbedarfs-Bundesergänzungszuweisungen für die neuen Länder wird dagegen mit Blick auf den Aufholprozeß im Osten weitgehend anerkannt. Diskussionsbedürftig ist aber ihre Gestaltung, denn sie werden ohne Zweckbindung und Eigenbeteiligung gemäß der Einwohnerzahl an die neuen Bundesländer verteilt3.

1 Vgl. zur Problematik der Bundesergănzungszuweisungen im einzelnen S. $185 \mathrm{ff}$.

2 Vgl. Homburg, 1994, S. 317.

3 Vgl. Peffekoven, 1994, S. 299 ff. 
Betrachtet man die quantitative Bedeutung der Sonderbedarfs-Bundesergänzungszuweisungen ( $v g l$. Abbildung 4), so zeigt sich, daß die neuen Bundesländer und Berlin von den Bundesergänzungszuweisungen wegen der Kosten politischer Führung, insbesondere aber von den Bundesergänzungszuweisungen für die neuen Lănder profitieren (1998: insgesamt zwischen 812 und 911 DM pro Einwohner). Unter Einschluß der Bundesergänzungszuweisungen überholen die vor Finanzausgleich besonders finanzschwachen neuen Bundesländer auch die ursprünglich finanzstarken alten Bundesländer (gemessen an der Finanzkraft pro Einwohner). Die größten Nutznießer der Sonderbedarfs-Bundesergänzungszuweisungen sind aber zwei alte Bundesländer, nămlich Bremen (1998: 2.955 DM pro Einwohner) und das Saarland (1998: 1.680 DM pro Einwohner). Sie erhalten - mit Ausnahme der Zuweisungen für die neuen Bundesländer - alle Varianten der Bundesergänzungszuweisungen und werden vor allem durch die Bundesergänzungszuweisungen zur Haushaltssanierung massiv begünstigt.

\section{Der Fonds „Deutsche Einheit“}

Bei der Analyse des Finanzausgleichs spielt auch der Fonds "Deutsche Einheit" eine gewisse Rolle. Er hatte " nach der Wiedervereinigung bis zur Neuregelung des Finanzausgleich zum 1.1.1995 die Aufgabe, in einem betrăchtlichen Umfang den Finanzbedarf der neuen Lănder durch überwiegend kreditfinanzierte Finanzzuweisungen zu decken. Seitdem wickelt er den Schuldendienst für die aufgenommenen Kredite $a b^{41}$.

Die alten Bundesländer tragen sowohl nach ihrer Einwohnerzahl als auch nach ihrer Finanzkraft in unterschiedlichem Maß zum Fonds "Deutsche Einheit" bei. Zudem werden die finanzschwächeren westlichen Bundesländer noch durch die finanzstärkeren entlastet. Wenn man diese Leistungen, die sich praktisch einnahmemindernd auswirken, im Hinblick auf ihre Ausgleichseffekte betrachtet, ergibt sich eine (weitere) Reduzierung der Finanzkraft der finanzstärkeren Länder ${ }^{2}$.

1 Andel, 1998, S. 13.

2 Vgl. Normenkontrollantrag des Landes Hessen, Kapitel A.II.5. 
Der Fonds "Deutsche Einheit“ ist letzten Endes das Resultat der unmittelbar nach der Wiedervereinigung nicht sofort möglichen Einbeziehung der neuen Länder in den Länderfinanzausgleich. Sowohl quantitativ, als auch im Hinblick auf eine Reform des Länderfinanzausgleichs hat er nur noch geringe Bedeutung1. Für die Länder unterscheidet sich die Abfinanzierung des Fonds grundsätzlich nicht von der Verzinsung und Tilgung anderer Kreditverpflichtungen. Finanzausgleichsrelevant ist allein die Erhöhung bzw. Ermäßigung der Beitrăge gemäß § 1 Abs. 3 FAG. Sie läuft auf eine Begünstigung der finanzschwachen alten Bundesländer hinaus und entspricht damit in Motivation und Wirkung den Übergangs-Bundesergänzungszuweisungen (vgl. S. 198 ff.). Da sich die Kritik der Übergangs-Bundesergänzungszuweisungen bezüglich der Beitragsmodifikationen auf den Fonds "Deutsche Einheit“ übertragen läßt, kann auf eine gesonderte Würdigung dieser „Altlasten“ der Wiedervereinigung verzichtet werden.

1 Der Umfang der Annuitäten lag 1998 zwischen 47 DM je Einwohner (Berlin) und 88 DM je Einwohner (Hamburg). 


\section{B. Finanzielle Auswirkungen des Ausgleichsverfahrens}

Im Rahmen der Darstellung der verschiedenen Stufen des Länderfinanzausgleich wurden die finanziellen Konsequenzen der Regelungen zum Teil bereits angesprochen, aber noch nicht systematisch zu einer Gesamtschau verknüpft. Dies soll nunmehr - in Kenntnis der grundsätzlichen Funktionsweise des Ausgleichsverfahrens - geschehen. Dabei geht es zunächst um das Ausmaß der Umverteilung, das der Finanzausgleich auf den einzelnen Stufen und in seiner Gesamtheit bewirkt. Von besonderem Interesse sind darüber hinaus die Grenzbelastungen, die sich im Falle einer isolierten Veränderung der Finanzkraft eines Landes ergeben und das finanzpolitische Kalkül der Länder (mit-) bestimmen. Schließlich stellt sich die Frage, ob und in welchem Sinne das heutige System eine Übernivellierung, also eine Vertauschung in der Finanzkraftrangfolge der Länder bewirken kann.

\section{Zur Messung der Umverteilungseffekte}

Um das Ausmaß der im Finanzausgleich eintretenden Umverteilung zwischen den Ländern zu spezifizieren, bedarf es zunächst einer Nullinie, an der die Verschiebungen der Finanzkraft gemessen werden können. Die Suche nach einer solchen Meßlatte wird schon dadurch erschwert, daß im Finanzausgleich selbst unterschiedliche Maßstäbe angewandt werden. So orientiert sich die Umsatzsteuerverteilung an der tatsächlichen Einwohnerzahl und der Pro-Kopf-Steuerkraft, während der horizontale Länderfinanzausgleich i. e. S. mit gewichteten Einwohnern operiert und in die Finanzkraftrechnung Förderabgaben, Hafenlasten und vor allem die Gemeindesteuern einbezieht. Die Ergebnisse einer Verteilungsrechnung bzw. einer Nivellierungsprüfung hăngen aber naturgemäß vom verwendeten Maßstab der Umverteilung ab, dessen Eignung stets umstritten sein wird.

Angesichts der grundsätzlichen Unlösbarkeit des Nullinien-Problems wird zur Illustration der Verteilungseffekte im folgenden ein pragmatischer Ansatz gewăhlt und durchgăngig auf die Veränderungen der Finanzkraft der Lănder bezogen auf die tatsăchliche Einwohnerzahl abgestellt. Die Relativierung mit der tatsächliche Einwohnerzahl ermöglicht überhaupt erst einen 
Vergleich unterschiedlich großer Länder. Der Ansatz hat darüber hinaus den Vorteil, daß der Einwohner als der primäre Bedarfsträger gelten kann, an den sich die staatlichen Leistungsangebote richten. Dies schließt keineswegs aus, daß bei der Zerlegung der Steuereinnahmen auch andere elementare Bedarfsmerkmale, etwa die erforderlichen Leistungen für die Wirtschaft, berücksichtigt werden. Entscheidend ist im vorliegenden Zusammenhang nur, daß für die Messung der Umverteilung, also der Differenz zwischen Primär- und Sekundärverteilung, die Einwohnerzahl als relativierender Faktor akzeptiert wird.

Dahinter steht die Überlegung, daß die Steuer- und Finanzkraft je Einwohner - analog zum Einkommen einer privaten Wirtschaftseinheit - die für jeden offentlichen Bedarf bestimmende Restriktion darstellt. "Sie bildet daher die Bemessungsgrundlage für den Finanzausgleich, und ihre Bedeutung wird für alle Länder in gleichem Maße, d. h. ohne Unterscheidung spezieller Bedarfslagen, anerkannt. Es wird davon ausgegangen, daß Länder mit gleicher Finanzkraft die gleiche Fähigkeit zur globalen Mittelverausgabung haben. Treten in der Fähigkeit zur Verausgabung, wie sie sich durch die Finanzkraft je Einwohner darstellt, zu große Unterschiede auf, erscheint ein angemessener Ausgleich wünschenswert"1.

Um Mißverständnissen vorzubeugen, sei an dieser Stelle gesagt, was die Verwendung von Pro-Kopf-Indikatoren nicht bedeutet.

(1) Aus der Verwendung der Finanzkraft pro Einwohner als Orientierungsgröße des Länderfinanzausgleichs folgt nicht, daß Länder mit gleicher Finanzkraft pro Einwohner auch einen in jeder Hinsicht gleichen Finanzbedarf pro Einwohner aufweisen.

(2) Des weiteren garantieren gleiche Ausgaben pro Kopf keine gleichen Versorgungsniveaus in den einzelnen Gebietskörperschaften. Die staatlichen Leistungen differieren vielmehr in den einzelnen Ländern in ihrer Struktur und in der Intensităt der Erfüllung einzelner Aufgaben.

1 Kitterer, 1994, S. 15. 
(3) Die Finanzkraft je Einwohner kann die Verteilungseffekte einzelner Ausgleichselemente nur illustrieren, ist aber deshalb noch kein geeigneter Maßstab für ihre finanzausgleichspolitische Bewertung. Dies gilt insbesondere für Regelungen, die auf Sonderbedarfstatbestände abstellen.

Die Anerkennung der Finanzkraft je Einwohner als Vergleichsmaßstab - als Nullinie - läuft also nicht unmittelbar auf die Forderung hinaus, der Finanzausgleich solle sich nur auf eine begrenzte Annäherung der so gemessenen Finanzkraftpositionen konzentrieren. Allerdings sind Regelungen, die sich nicht an der tatsächlichen Einwohnerzahl orientieren, kritisch auf ihre Berechtigung zu überprüfen. Nicht der Einwohnermaßstab, sondern die Abweichungen von dieser Lơsung bedürfen einer speziellen Begründung.

\section{Die einzelnen Stufen der Umverteilung}

\section{a. Umverteilung durch Umsatzsteuer-Vorwegausgleich}

Als erstes Element der horizontalen Umverteilung im Länderfinanzausgleich wurde die Gewährung der Ergänzungsanteile an die finanzschwachen Bundesländer identifiziert. Sie modifiziert die Verteilung nach dem Prinzip des regionalen Aufkommens, die bei der Umsatzsteuer näherungsweise durch eine einwohnerbezogene Zerlegung herbeigeführt werden kann. Daraus resultiert eine Belastung Berlins und aller alten Bundesländer mit Ausnahme des Saarlandes in Höhe von 214 DM je Einwohner. Die neuen Bundesländer gewinnen zwischen 922 DM und 1.095 DM je Einwohner (vgl. Abbildung 5). Insgesamt werden durch den Umsatzsteuer-Vorwegausgleich 14,3 Mrd. DM zwischen den Ländern umgeschichtet - ein Volumen, das noch über dem der Ausgleichszahlungen im horizontalen Länderfinanzausgleichs liegt (1998: 13,5 Mrd. DM).

Diese Zahlen unterstreichen für sich genommen die erhebliche Bedeutung des Umsatzsteuer-Vorwegausgleichs. Bei der isolierten Betrachtung der Ausgleichsstufen gerăt allerdings der Gesamtzusammenhang zwischen den einzelnen Elementen leicht aus dem Blick. Ein Übergang zur rein einwohnerbezogenen Umsatzsteuerverteilung hätte per saldo keine so dramatische Verteilungswirkungen zur Folge, wie es die obigen Angaben suggerie- 
ren. Infolge des überhöhten Nivellierungsgrades des gesamten Systems würde der größte Teil der Umschichtungen über veränderte Ausgleichsbeiträge und -zahlungen im horizontalen Länderfinanzausgleich sowie über veränderte Fehlbetrags-Bundesergänzungszuweisungen kompensiert. Dies gilt in ähnlicher Form auch für andere Ausgleichselemente. Bei der Analyse der Reformoptionen wird dem Aspekt des Systemzusammenhangs daher besondere Aufmerksamkeit zu schenken sein 1 .

\section{Abbildung 5}

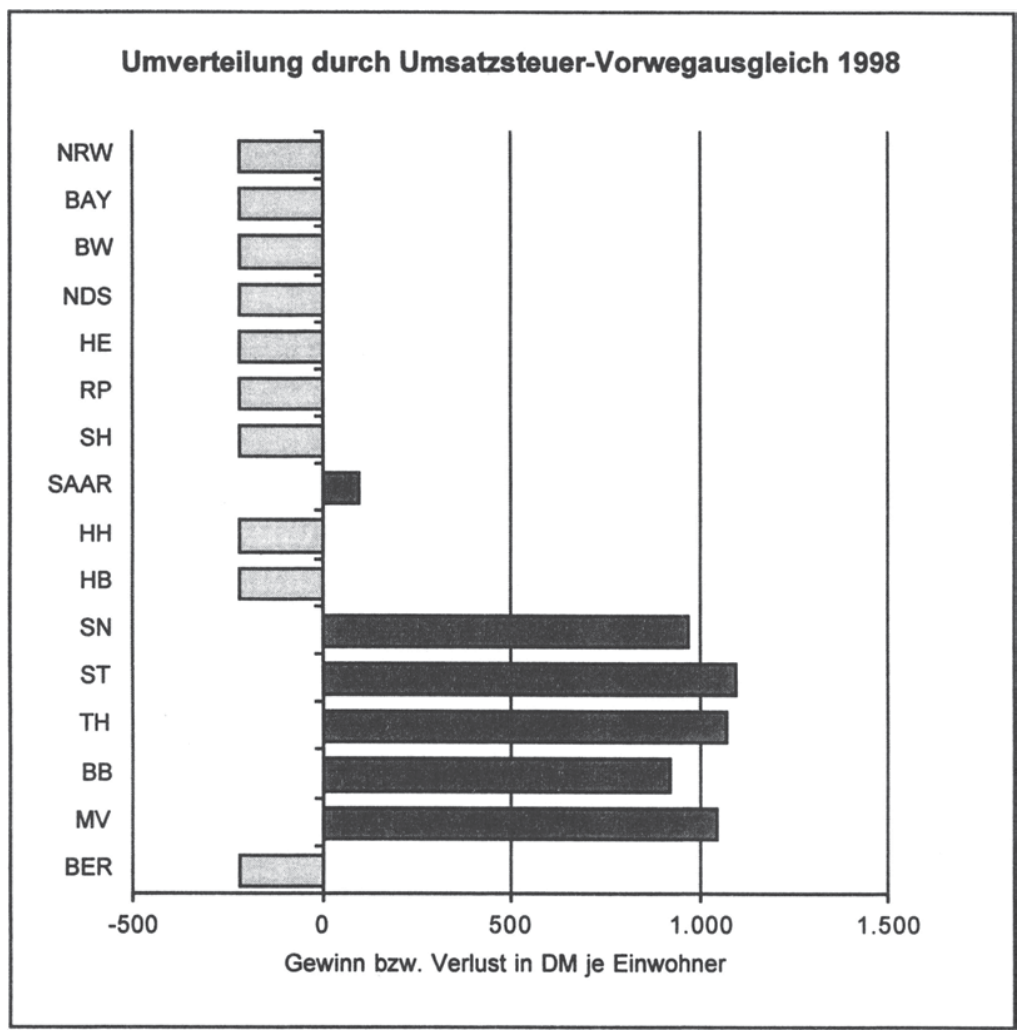

$1 \mathrm{Vgl}$. zu den Nettoeffekten des Umsatzsteuer-Vorwegausgleichs S. $93 \mathrm{ff}$. 


\section{b. Umverteilung durch den Länderfinanzausgleich i. e. S.}

Die Gewinne und Verluste der einzelnen Bundesländer sind im horizontalen Länderfinanzausgleich leicht zu identifizieren. Die auf dieser Stufe anfallenden direkten Zahlungen zwischen den ausgleichspflichtigen und den ausgleichsberechtigten Ländern müssen nur in DM-je-Einwohner-Werte umgerechnet werden.

\section{Abbildung 6}

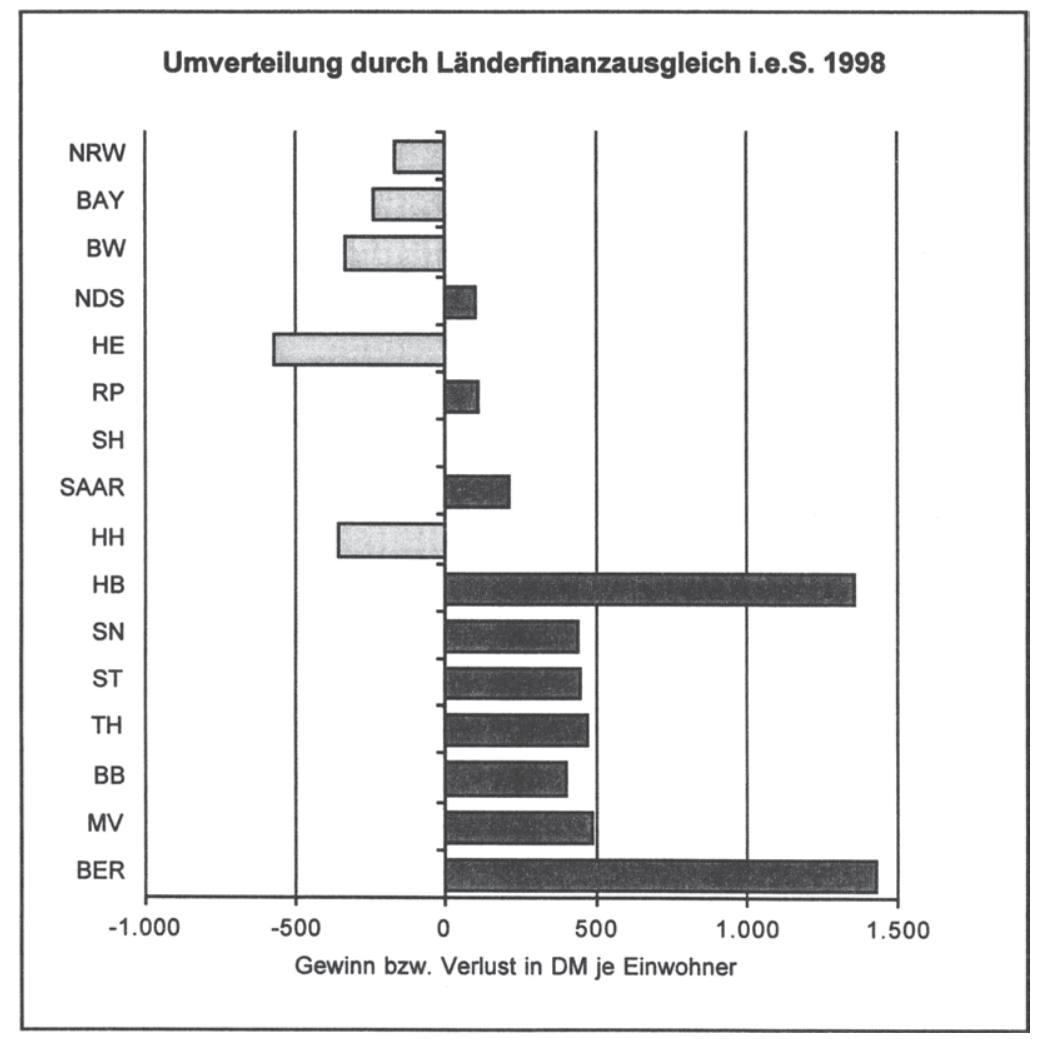

Abbildung 6 zeigt die Umschichtungen in der Finanzausstattung der Bundesländer. Das Gesamtvolumen der Umverteilung erreicht auf dieser Stufe des Ausgleichsverfahrens im Jahr 1998 13,5 Mrd. DM. 
Fünf Nettozahlern (Nordrhein-Westfalen, Bayern, Baden-Württemberg, Hessen und Hamburg) stehen neun Nettoempfänger gegenüber. Für SchleswigHolstein ist der Länderfinanzausgleich 1998 (nahezu) neutral. Die verhältnismäßig stärkste Belastung erfährt Hessen mit 570 DM je Einwohner. Alle neuen Bundesländer werden mit $403 \mathrm{DM}$ bis $486 \mathrm{DM}$ je Einwohner relativ gleichmäßig begünstigt. Die Hauptgewinner sind Bremen und Berlin mit 1.360 DM bzw. 1.430 DM je Einwohner - eine Folge der Einwohnerwertung, von der auch Hamburg profitiert. Dessen Vorteil wird zunächst nicht ganz deutlich, weil Hamburg zu den Nettozahlern rechnet. Das vor Länderfinanzausgleich mit Abstand finanzstärkste Bundesland, das im Vergleich zu Hessen über eine um 912 DM höhere Pro-Kopf-Finanzkraft verfügt, muß jedoch 209 DM je Einwohner weniger in den horizontalen Ausgleich zahlen.

Die im Verhältnis zwischen Stadt- und Flächenstaaten ungleichmäßigen Verteilungseffekte des horizontalen Ausgleichs sind noch nicht ohne weiteres zu beanstanden. Ihre Vertretbarkeit hängt letzten Endes von der Einstufung der umstrittenen Einwohnerwertung der Stadtstaaten ab, mit der das Prinzip der Orientierung an der tatsächliche Einwohnerzahl durchbrochen und ein Bedarfsaspekt in den Finanzkraftausgleich hineingetragen wird. Der Blick auf die Pro-Kopf-Umschichtungen belegt die herausragende finanzausgleichspolitische Bedeutung der Einwohnerwertung, die einen entsprechenden Stellenwert in der Reformdiskussion verlangt.

\section{c. Umverteilung durch Bundesergänzungszuweisungen}

Sehr viel schwieriger als die bislang erläuterten Elemente des Finanzausgleichs sind die Bundesergänzungszuweisungen unter Verteilungsaspekten zu beurteilen. Sie werden vom Bund gezahlt und scheinen keines der Länder zu belasten, sondern diese nur, wenn auch in recht unterschiedlichem Maße, zu begünstigen. Eine solche Betrachtungsweise ist jedoch vordergründig, denn über die Finanzausstattung der Lănderebene entscheidet die den Ländern insgesamt zur Verfügung gestellte Finanzmasse, unabhängig von der Art des Zuflusses. Eine Vergrößerung dieser Finanzmasse kann der Bund den Ländern durch Bundesergänzungszuweisungen, aber eben auch in Form höherer Quoten bei den Gemeinschaftsteuern zugestehen. Insofern 
lassen sich die Bundesergănzungszuweisungen durchaus als vorenthaltene und nach den Maßstäben des Bundes umverteilte Länderfinanzkraft interpretieren.

Die Verteilungseffekte der Bundesergänzungszuweisungen hängen aus dieser Sicht von der als Alternative herangezogenen Erhőhung der Länderanteile an den Gemeinschaftsteuern ab. Dabei macht es einen großen Unterschied, ob der Anteil an der Einkommensteuer oder der Anteil an der Umsatzsteuer zum Vergleich herangezogen wird. Da das Einkommensteueraufkommen sehr viel ungleichmäßiger streut als die primär einwohnerbezogen verteilte Umsatzsteuer, würde eine Anpassung des Einkommensteueranteils die Finanzausstattung der Länder heterogener machen als eine Anpassung des Umsatzsteueranteils.

Im folgenden wird keine der genannten steuerlichen Alternativen, sondern eine Verteilung des Volumens der Bundesergänzungszuweisungen nach der Einwohnerzahl als Vergleichsgröße gewählt. Dieser Ansatz kommt allerdings - bis auf den Vorwegausgleich - der Umsatzsteuerlösung recht nahe. Er vermeidet damit jedenfalls eine Überzeichnung der Umverteilung, die sich unter der Annahme einer Anpassung des Einkommensteueranteils ergeben würde. Konkret basieren die in Abbildung 7 dargestellten Ergebnisse darauf, daß die tatsächlich bezogenen Bundesergănzungszuweisungen der einzelnen Länder mit den aus einer Pro-Kopf-Gleichverteilung des Zuweisungsvolumens resultierenden fiktiven Zuflüssen saldiert werden.

Alle Nettozahler des horizontalen Länderfinanzausgleichs, die effektiv keine Bundesergänzungszuweisungen erhalten, werden in Höhe des ihnen "vorenthaltenen“ Pro-Kopf-Anteils von 313 DM je Einwohner belastet. Nettoverlierer sind des weiteren die übrigen alten Bundeslănder bis auf das Saarland und Bremen, die auch in der Saldenbetrachtung am stärksten profitieren. Zu den Gewinnern rechnen erwartungsgemäß die neuen Bundesländer und Berlin mit einer Nettoentlastung zwischen 692 DM und 791 DM je Einwohner.

Insgesamt erreicht das betragsmäßige Ausmaß der durch Bundesergänzungszuweisungen bedingten (fiktiven) Umschichtung zwischen den Lăn- 
dern 1998 ein (Netto-) Volumen von 16,6 Mrd. DM. Damit übertreffen die Bundesergänzungszuweisungen in ihrer quantitativen Bedeutung den horizontalen Länderfinanzausgleich (1998: 13,5 Mrd. DM) und auch den Umsatzsteuer-Vorwergausgleich (1998: 14,3 Mrd. DM). Insgesamt tragen alle drei Stufen des Ausgleichsverfahrens jeweils grob gerechnet ein Drittel zu der gesamten Umverteilung bei.

\section{Abbildung 7}

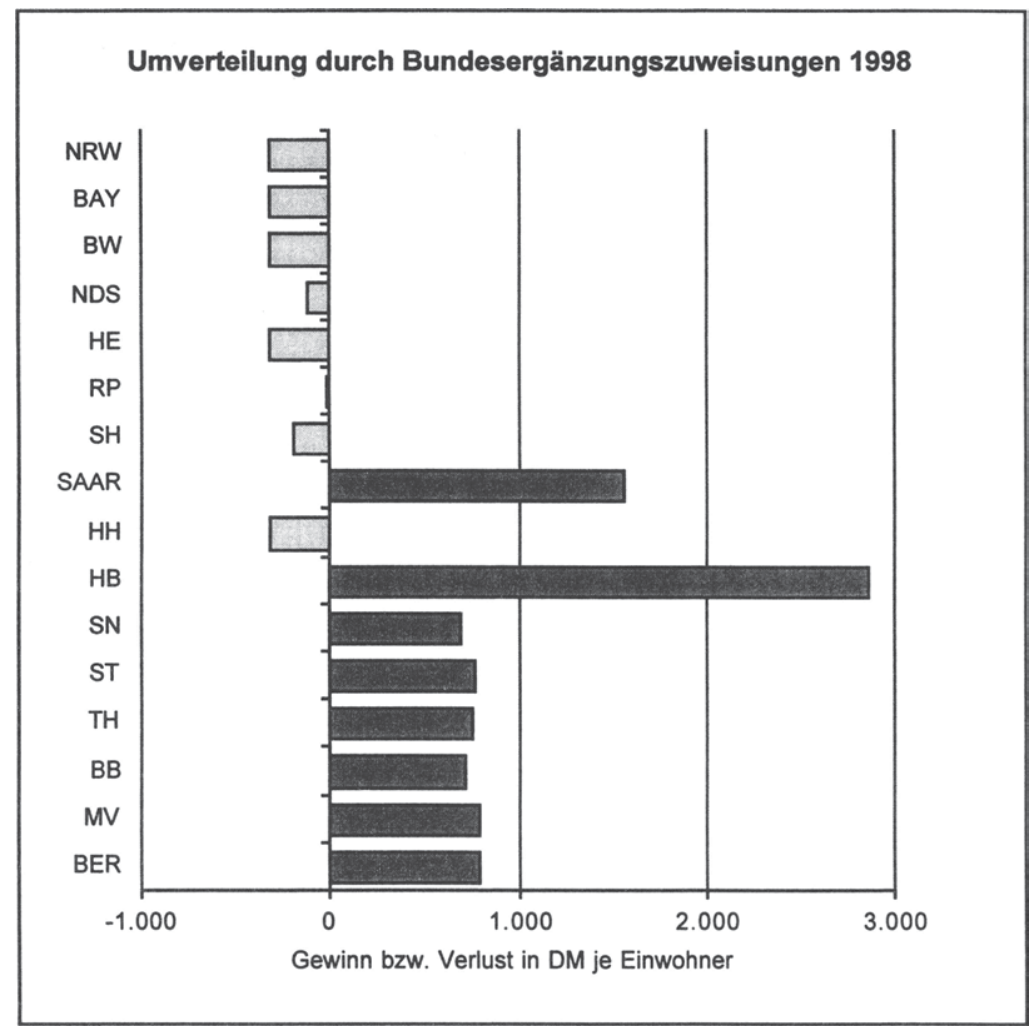

Das dargestellte Ausmaß der durch die Bundesergänzungszuweisungen bewirkten Umverteilung bedeutet keine Bewertung ihrer Sachgerechtigkeit. Wiederum muß klar differenziert werden zwischen der Messung und der 
Bewertung der Umverteilungsvorgänge, die im weiteren Verlauf der Arbeit eine Auseinandersetzung mit der Begründung und Gestaltung der Bundesergänzungszuweisungen erfordert.

\section{Die Gesamtwirkungen der Umverteilung}

Die auf den verschiedenen Stufen des Ausgleichsverfahrens ermittelten Gewinne und Verluste der einzelnen Lănder lassen sich aufgrund der Verwendung einer einheitlichen Bezugsgröße problemlos zu einem Gesamtindikator der Umverteilung aggregieren. Hierin liegt ein weiterer Vorzug der Relativierung der Finanzkraftzahlen mit den tatsächlichen Einwohnern. Die (nicht gesondert dargestellte) Zusammenfassung der Pro-Kopf-Gewinne und Verluste macht bereits das enorme Ausmaß der durch den Länderfinanzausgleich insgesamt hervorgerufenen Umverteilung deutlich. Zwischen dem größten Verlierer - Hessen mit einer Einbuße von 1.097 DM je Einwohner (bzw. 6,6 Mrd. DM für den Landeshaushalt) - und dem größten Gewinner - Bremen mit einem Zuwachs von 4.001 DM je Einwohner - liegen mehr als 5.000 DM je Einwohner.

\section{a. Die durchschnittlichen Belastungen und Entlastungen}

Aussagefăhiger werden diese Daten, wenn man den Finanzausgleichssaldo auf den Landeshaushalt bezieht. Dessen Volumen bedarf dazu der gleichen Normierung, der die Finanzausgleichselemente unterzogen wurden. Die ohne Finanzausgleich potentiell verfügbare Einnahmen der einzelnen Länder (pro Kopf) setzen sich zusammen aus den Steuern der Länder, der ausschließlich nach Einwohnern verteilten Umsatzsteuer sowie den ebenfalls nach der Einwohnerzahl zugerechneten Bundesergänzungszuweisungen. Auf diesen normierten Landeshaushalt wird der jeweilige Finanzausgleichssaldo bezogen. Man gelangt so zu den in Abbildung 8 dargestellten durchschnittlichen Belastungen bzw. Entlastungen der Länder durch den gesamten Finanzausgleich 1998. Die Werte können als durchschnittliche Abschöpfungs- bzw. Zuweisungsquoten interpretiert werden. 
Mit Abstand am stärksten belastet wird Hessen, das $23 \%$ der dem Land potentiell zustehenden Einnahmen und damit nahezu ein Viertel des Landeshaushaltes im Finanzausgleich verliert. Das ohne Finanzausgleich reichste Bundesland Hamburg wird dagegen mit vergleichsweise bescheidenen $15,4 \%$ seiner normierten Einnahmen zur Kasse gebeten. Auf der Gewinnerseite fallen die Zuweisungsquoten betragsmäßig noch deutlich höher aus. Berlin und das Saarland können ihre normierte Finanzkraft um mehr als $50 \%$ aufstocken. Für die neuen Bundesländer ergeben sich Werte zwischen rund $75 \%$ und $90 \%$. Der Hauptgewinner, der von allen Stufen des Finanzausgleich profitiert, ist Bremen, das seine normierte Finanzkraft über den Finanzausgleich mehr als verdoppeln kann.

\section{Abbildung 8}

Normierte Abschöpfungs- und Zuweisungsquoten 1998

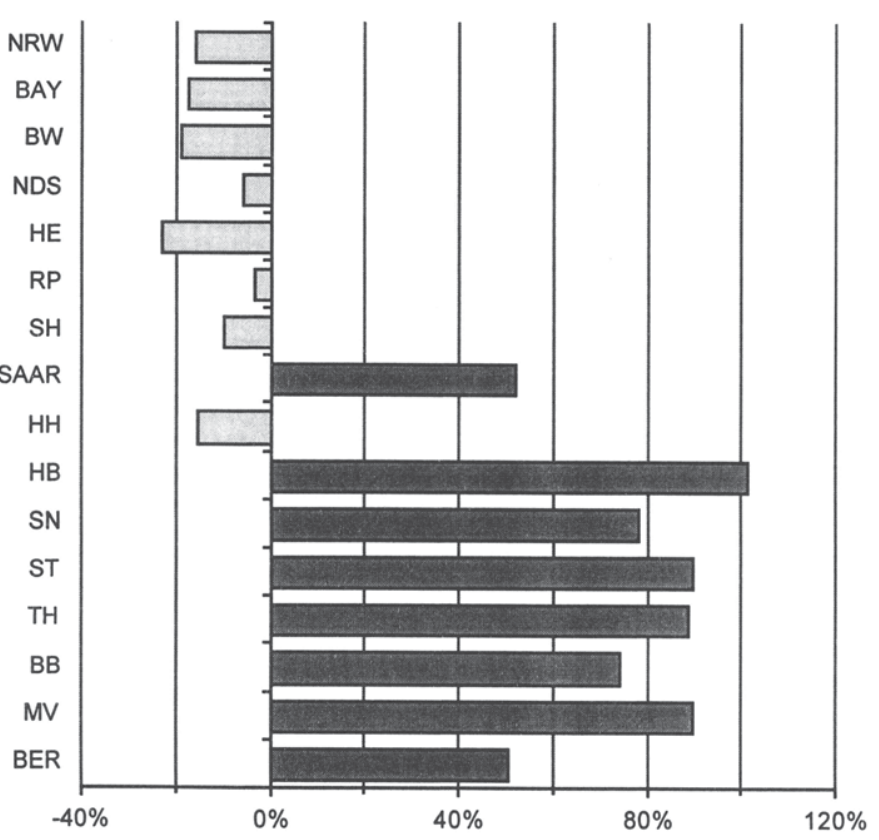

Belastung bzw. Entlastung bezogen auf den normierten Landeshaushalt 
Gegen die hier vorgenommene Analyse der durchschnittlichen Belastungen und Entlastungen könnte eingewandt werden, daß die Steuereinnahmen der Gemeinden in der Länderfinanzkraft nicht enthalten sind. Hier geht es aber nicht um die Ermittlung einer Finanzkraftmeßzahl zum Zwecke der Bestimmung von Ausgleichsleistungen, sondern um die Aufdeckung der unmittelbaren Wirkungen des Finanzausgleichs auf die Länderhaushalte. Diese Wirkungen bleiben auch dann von Interesse, wenn man grundsätzlich der Auffassung ist, daß die Länder und Gemeinden zusammen die öffentlichen Leistungen in ihrer Region erbringen und insofern im Verbund gesehen werden müssen. Hinzu kommt, und dies ist im vorliegenden Zusammenhang entscheidend, daß die Einbeziehung der Gemeindesteuerkraft (gemäß FAG) nur das Niveau der Abschöpfungs- und Zuweisungsquoten in gewissem Umfang reduzieren, an der Struktur der abgeleiteten Umschichtungen aber wenig ändern würde 1 .

Die hier berechneten durchschnittlichen Abschöpfungs- und Zuweisungsquoten unterscheiden sich aber auch durch den Einbezug der Bundesergänzungszuweisungen von den Ergebnissen anderer Untersuchungen². Die gewählte Vorgehensweise hat den Vorzug, die Wirkungen des gesamten Systems deutlich zu machen, während sich andere Autoren auf Teilbereiche des Finanzausgleichs beschränken. Im Gegensatz zu den Gemeindesteuern üben die Bundesergänzungszuweisungen freilich einen spürbaren Einfluß auf die Struktur der ermittelten Abschöpfungs- und Zuweisungsquoten aus. Daher werden die Ergebnisse einer Belastungsrechnung ohne Bundesergănzungszuweisungen zusătzlich in Abbildung 9 dargestellt.

Zu beachten ist bei einem Vergleich, daß die Bundesergänzungszuweisungen nun weder im normierten Landeshaushalt, noch im Finanzausgleichssaldo erscheinen. Dramatische Verschiebungen ergeben sich daraus für Bremen und das Saarland, die in besonderer Weise von den (Sanierungs-)

1 Auf eine gesonderte Abbildung kann daher verzichtet werden. Hessen hätte bezogen auf die um die Gemeindesteuern erhöhte normierte Finanzkraft $19,6 \%$ abzuführen, Hamburg dagegen nur 12,9\%. Die prozentualen Gewinne Berlins und des Saarlandes lägen bei knapp $45 \%$. Die neuen Bundesländer erzielten Zuwächse zwischen 66,6\% und $81,5 \%$, und Bremen bliebe mit $84,4 \%$ an der Spitze.

2 Vgl. z. B. Lichtblau, 1999, S. 102; Huber/Lichtblau, 1997 und 1998. 
Bundesergănzungszuweisungen abhängig sind. Bremens Zuweisungsquote sinkt von 101,2 \% auf nur noch 31,5\%; die des Saarlandes von $52,3 \%$ auf nur noch $9,4 \%$. Ihre Spitzenpositionen behalten - im positiven Sinne - die neuen Bundesländer (54,5\% bis $68,3 \%$ ) und - im negativen Sinne - der größte Nettozahler Hessen (-17,6\%).

\section{Abbildung 9}

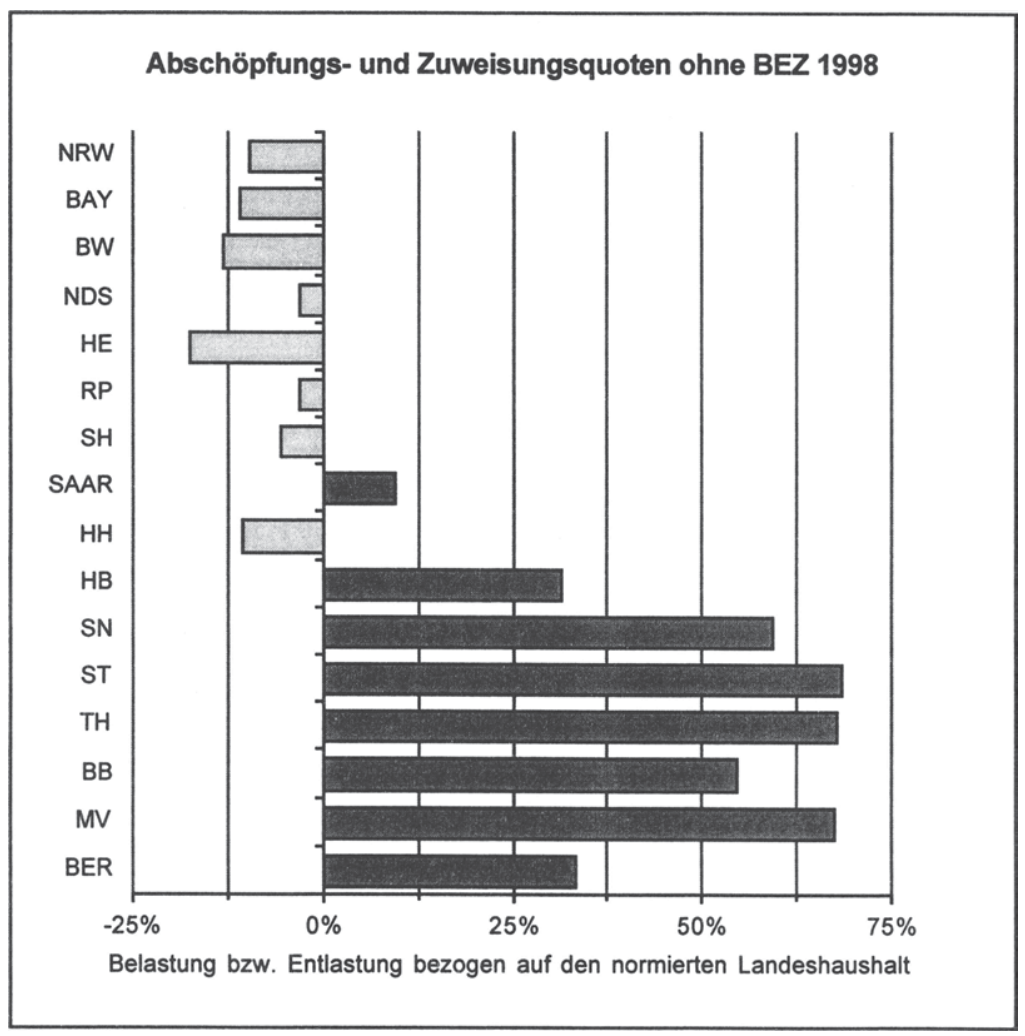

b. Verănderungen der relativen Finanzkraftpositionen

Die vorgenommene Standardisierung der Länderhaushalte ermöglicht auch einen Vergleich der relativen Finanzkraftpositionen der Länder vor und nach Finanzausgleich. Die relative Finanzkraft eines Landes entspricht seiner 
normierten Pro-Kopf-Finanzkraft relativ zum Durchschnitt der Länder. Wie erwähnt, umfaßt die normierte Finanzkraft vor Finanzausgleich die Steuern der Länder, die nach Einwohnern verteilte Umsatzsteuer sowie die ebenfalls nach Einwohnern zugerechneten Bundesergänzungszuweisungen. Die normierte Finanzkraft nach Finanzausgleich setzt sich dementsprechend zusammen aus den Steuern der Länder, der mit Vorwegausgleich verteilten Umsatzsteuer, den Ausgleichsbeiträgen bzw. Ausgleichszahlungen im horizontalen Länderfinanzausgleich sowie den tatsächlich erhaltenen Bundesergänzungszuweisungen.

Ordnet man die Länder nach ihrer normierten relativen Finanzkraft vor Finanzausgleich, so ergibt sich die durch die Ländersteuern bestimmte Rangfolge. Sie entspricht - modifiziert um den Niveaueffekt der Umsatzsteuer und der Bundesergänzungszuweisungen - der aus Abbildung 1 bekannten Reihung. Wăhrend nach den Maßstäben des FAG allerdings immer nur eine weitgehende Annäherung der relativen Finanzkraftpositionen abzuleiten war, erweist sich nun - unter Berücksichtigung der erst bei einer Pro-KopfBetrachtung erkennbaren Umverteilungsvorgänge - der Finanzausgleich in seiner Gesamtwirkung als wesentlich weiter gehend. Vor Finanzausgleich finanzstarke Bundesländer werden nun im Finanzausgleich von den ursprünglich finanzschwachen Bundesländern überholt - ein Phänomen, das von vielen Kritikern als Übernivellierung bezeichnet wird. Abbildung 10 enthălt die Verănderungen der relativen Finanzkraftpositionen.

Die Struktur der Nettogewinner und -verlierer des Finanzausgleichs entspricht dem bereits aus Abbildung 8 für die Abschopfungen und Zuweisungen geläufigen Bild. Deutlich wird nun aber auch, daß die Gewinner am Ende über eine höhere Finanzkraft verfügen als die Nettozahler. Hessen als finanzstärkstes Flächenland mit einer relativen Finanzkraft von $117,1 \%$ vor Finanzausgleich (Rang 2) fällt nach Finanzausgleich auf nur noch knapp $90 \%$ zurück (Rang 16). Dies ist wiederum der größte Verlust aller Länder.

Die dargestellten Ergebnisse machen verständlich, weshalb der heutige Finanzausgleich vor allem aufgrund einer $z u$ starken Abschöpfung der überdurchschnittlichen Finanzkraft und der damit einhergehenden „Übernivellie- 
rungseffekte" kritisiert wird. Übernivellierung liegt vor, wenn die Monotoniebedingung verletzt ist, $d . h$. die ursprüngliche Rangfolge in der Finanzkraft je Einwohner durch die Ausgleichsleistungen verändert wird. Nach vorherrschender Auffassung sollte ein rationales Finanzausgleichssystem vor allem aus anreizpolitischen Gründen, aber auch aus Gerechtigkeitsüberlegungen diese Monotonie-Eigenschaft erfüllen 1 .

\section{Abbildung 10}

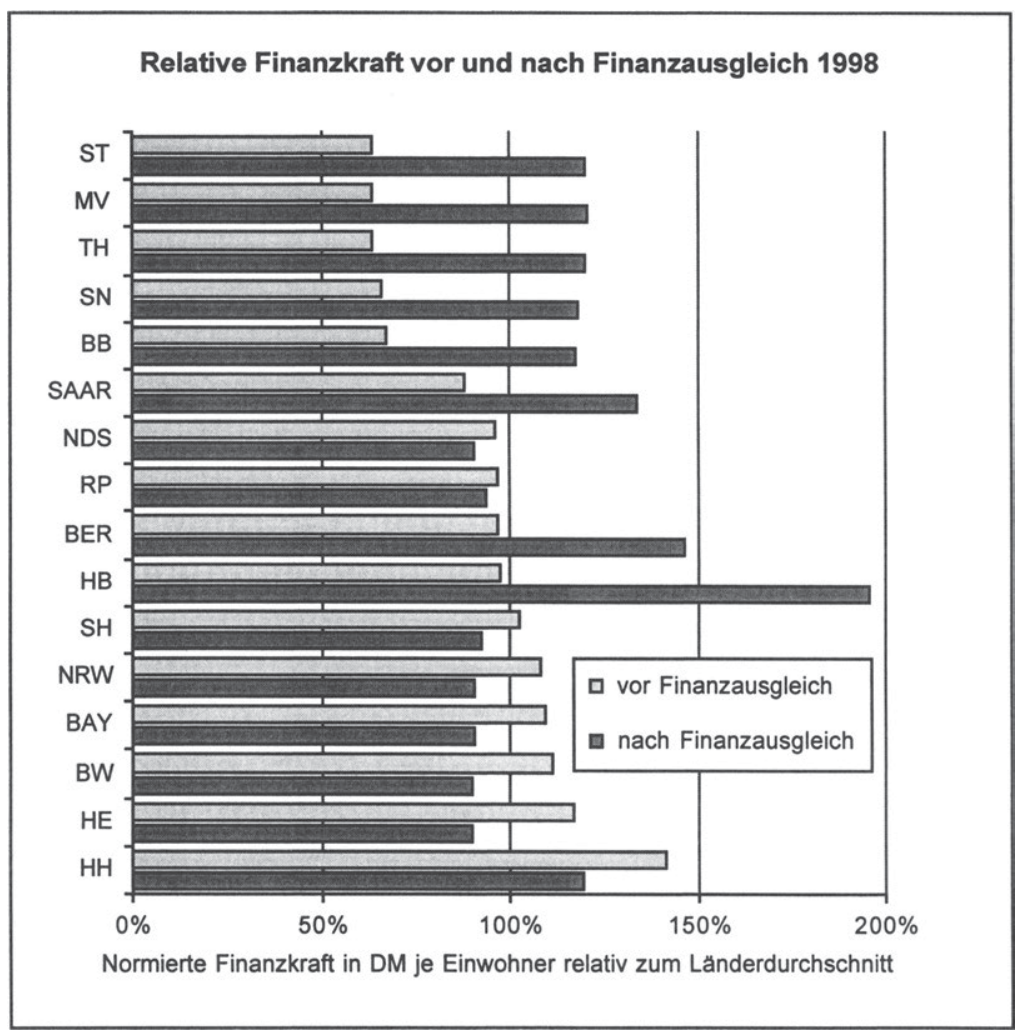

Ob die Ergebnisse des Finanzausgleichs legitimerweise als Übernivellierung bezeichnet werden können, ist jedoch umstritten. Die Übernivellierung

1 Vgl. Lichtblau, 1999, S. 102. 
kommt hier letzten Endes dadurch zustande, daß als Ausgangsbasis die Steuerkraft je Einwohner verwendet wird, während die Leistungen im Finanzausgleich darauf keinen Bezug nehmen. Insbesondere bei der Gestaltung der Bundesergänzungszuweisungen stehen andere Kriterien im Vordergrund. Daher erscheint es angebracht, zusätzlich eine um den Effekt der Bundesergänzungszuweisungen bereinigte Finanzkraftrechnung durchzuführen, deren Ergebnisse in Abbildung 11 enthalten sind.

\section{Abbildung 11}

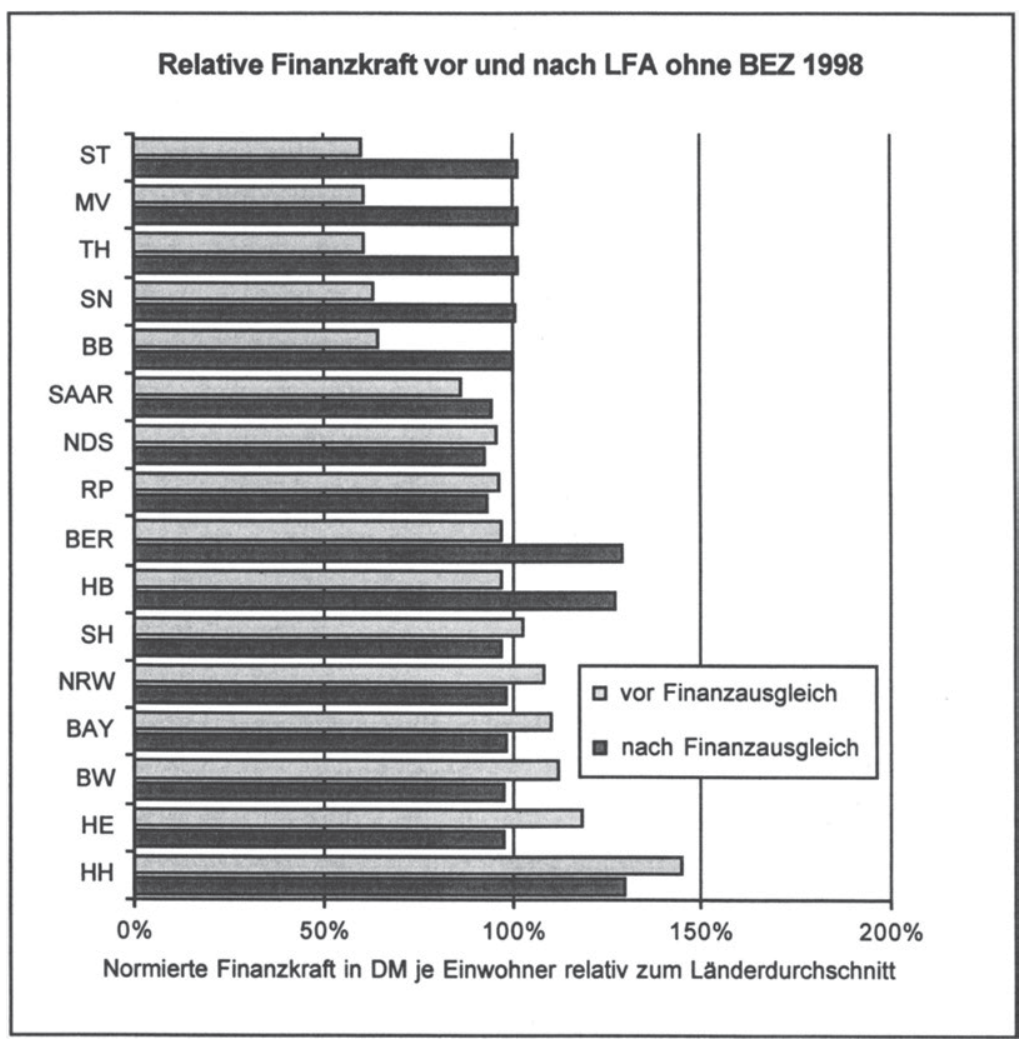

Auch hier ergeben sich Verschiebungen in der Finanzkraftrangfolge der Länder (ohne Berücksichtigung der Gemeindesteuerkraft). Während Ham- 
burg seine Spitzenposition halten kann und die beiden anderen Stadtstaaten das Hamburger Niveau erreichen, reduziert sich Hessens relative Finanzkraft von $118,5 \%$ des Länderdurchschnitts (Rang 2) auf nur noch $97,6 \%$ (Rang 12). Auch die übrigen vor Finanzausgleich finanzstarken Flächenländer Baden-Württemberg, Bayern und Nordrhein-Westfalen landen auf den hinteren Plätzen und vor allem unter dem Bundesdurchschnitt.

Das Übernivellierungsphänomen geht also nicht allein auf die Bundesergänzungszuweisungen zurück. Verantwortlich sind an dieser Stelle die vom Einwohnerprinzip abweichenden Regelungen im horizontalen Länderfinanzausgleich (Hafenlasten, Einwohnerwertung). Akzeptiert man die spezifischen Finanzkraft- und Finanzbedarfsbegriffe des Finanzausgleichsgesetzes, dann wird die darauf bezogene Monotoniebedingung allerdings nicht verletzt. Dies belegen auch die oben dargestellten Wirkungen des Ausgleichsverfahrens unter Verwendung der Relation zwischen Finanzkraftmeßzahl und Ausgleichsmeßzahl (vgl. S. 60 ff.). Eine zielführende Diskussion über das Nivellierungsverbot muß daher die Sachgerechtigkeit der verschiedenen Ausgleichselemente prüfen. Erst wenn sich, um ein Beispiel zu nehmen, die Einwohnerwertung der Stadtstaaten als unbegründet erweist, können die aus der Einwohnerwertung resultierenden Entlastungseffekte zu Recht mit dem Begriff „Übernivellierung“ belegt werden.

\section{Die Grenzbelastungen}

Neben der Frage nach den durchschnittlichen Belastungen und Entlastungen der Bundesländer und der damit verknüpften Übernivellierungsproblematik spielen aus ökonomischer Sicht die Grenzbelastungen eine entscheidende Rolle, denen die Nettozahler ebenso wie die Nettoempfänger im Finanzausgleich unterworfen sind. Dabei ist zu prüfen, in welchem Ausmaß zusätzliche Steuereinnahmen eines Bundeslandes durch den Finanzausgleich abgeschöpt werden. Dies geschieht entweder durch wachsende Ausgleichsverpflichtungen bei den finanzstarken oder - teilweise in noch stärkerem Maße - durch sinkende Ausgleichsansprüche bei den finanzschwachen Ländern. Die hohen Grenzbelastungen gelten als ein zentraler Schwachpunkt des heutigen Länderfinanzausgleichs. 


\section{a. Ermittlung der marginalen Absch ̋̈pfungsquoten}

Relevant sind im Rahmen einer Grenzbelastungsanalyse nur die Einnahmen der Länder, die in einem unmittelbaren Zusammenhang zu ihrer Steuerkraft stehen. Berücksichtigt werden müssen dementsprechend der Umsatzsteuer-Vorwegausgleich, der horizontale Lănderfinanzausgleich i. e. S. und die Fehlbetrags-Bundesergänzungszuweisungen, nicht aber die Sonderbedarf-Bundesergănzungszuweisungen. Die Grenzbelastungen werden unter sonst gleichen Bedingungen am Beispiel einer isolierten Erhöhung der Lohn- und Einkommensteuer um 1 Mio. DM in jedem Land diskutiert.

Von den Lohnsteuermehreinnahmen in Höhe von 1.000.000 DM erhält das Land $42,5 \%$ bzw. 425.000 DM. Dieser Betrag ist die primäre Bezugsgröße der Ermittlung marginaler Abschöpfungsquoten, denn er würde dem Landeshaushalt ohne Finanzausgleich in vollem Umfang zufließen. Netto verbleiben dem Land jedoch nur wesentlich geringere Betrăge, weil der Finanzausgleich den Anstieg der Finanzkraft zum größten Teil an andere Länder (über den Umsatzsteuer-Vorwegausgleich und den horizontalen Länderfinanzausgleich) und gegebenenfalls auch an den Bund (über die Fehlbetrags-Bundesergänzungszuweisungen) umverteilt.

Abbildung 12 verdeutlicht das enorme Ausmaß der marginalen Belastungen. Die Ergebnisse sind für die meisten Länder grotesk. Mehreinnahmen bei der Lohnsteuer ${ }^{1}$ führen bei elf Bundesländern, darunter alle finanzschwachen Länder und die Stadtstaaten, zu Mindereinnahmen im Landeshaushalt ${ }^{2}$. Nur den finanzstarken Flăchenländern verbleiben gewisse Ein-

1 Man könnte auch ein regionales Mehraufkommen bei der Umsatzsteuer zum Ausgangspunkt der Analyse der Grenzbelastungseffekte nehmen. In welchem Land diese Mehreinnahmen anfallen, wäre bei dem heutigen System der Umsatzsteuerverteilung für die Grenzbelastungen irrelevant. Die Abschöpfungsquoten erreichen 1998 - bezogen auf die Mehreinnahmen der Länder (effektiv 46,65\% der zusătzlichen Umsatzsteuer) - Werte zwischen $75 \%$ (Nordrhein-Westfalen) und knapp über $100 \%$ (Mecklenburg-Vorpommern). Die meisten Lănder liegen deutlich über $90 \%$.

2 Eine isolierte Erhöhung des Realsteueraufkommens führt - wegen der Einbeziehung der kommunalen Steuerkraft in die Finanzkraftmeßzahl - ebenfalls zu einer Belastung für das Land. Diese Rückwirkung auf den Landeshaushalt stellt jedoch keine Grenzbelastung im üblichen Sinne der Abschøpfung zusätzlicher eigener Steuereinnahmen des Landes dar. Auch dürften die Realsteuern keine ausschlaggebende Rolle im Entscheidungskalkül eines Landespolitikers spielen. Fehlanreize wie bei der Abschöpfung der Einnahmen aus den Ländersteuern sind infolgedessen kaum zu befürchten. 
nahmenzuwächse, doch liegen auch ihre Abschöpfungsquoten extrem hoch - zwischen $67 \%$ für Nordrhein-Westfalen und $90 \%$ für Hessen ${ }^{1}$. Solche Werte würden bei der persönlichen Einkommensteuer ohne Zweifel als konfiskatorisch angesehen, und sie können auch im Verhältnis der Länder kaum anders interpretiert werden.

\section{Abbildung 12}

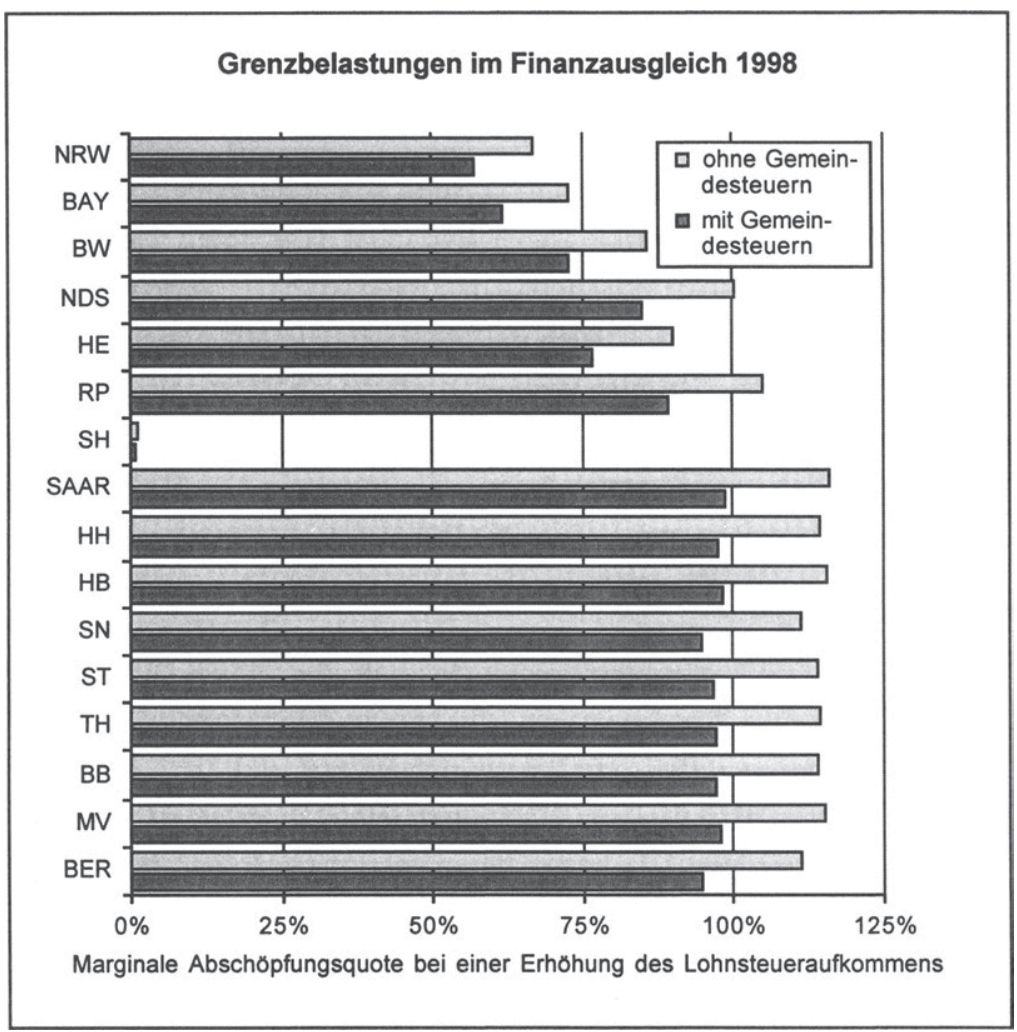

Gegen die ausschließliche Verwendung der Daten für die Landeshaushalte mag wieder eingewandt werden, daß in diesen Größen die Gemeindeein-

1 Schleswig-Holstein bildet eine Ausnahme, weil sich das Land 1998 auf einem Finanzkraftniveau bewegt, das annähernd dem Durchschnitt entspricht, und bei dem Mehreinnahmen im wesentlichen keine zusätzlichen Ausgleichspflichten (oder rückläufige Ausgleichszahlungen) begründen. 
nahmen aus der Einkommensteuer nicht enthalten sind. Stellt man im Sinne des Finanzausgleichsgesetzes $50 \%$ der zusätzlichen Gemeindesteuern in die Belastungsrechnung ein (75.000 DM), so erhălt man als Bezugspunkt Mehreinnahmen von 500.000 DM statt 425.000 DM. Auch die Nettogewinne steigen (bzw. die Nettoverluste sinken) jeweils um 75.000 DM. Die daraus resultierenden Grenzbelastungen sind ebenfalls in Abbildung 12 enthalten.

Das Bild von einem geradezu konfiskatorischen Zugriff des Länderfinanzausgleichs auf die zusătzliche Steuerkraft eines Landes wird durch die Einbeziehung der kommunalen Steuerkraft nicht wesentlich getrübt. Zwar entfălt in dieser Betrachtung der absurde Effekt einer Umwandlung von Mehreinnahmen in Mindereinnahmen. Die Abschöpfungsquoten bleiben aber auf einem exorbitant hohen Niveau. Die meisten Länder verlieren über $95 \%$ ihrer zusätzlichen Einnahmen, und auch das finanzstarke Bundesland Hessen muß immer noch rund $77 \%$ des Lohnsteuermehraufkommens abtreten.

\section{b. Ursachen und Wirkungen einer hohen Grenzbelastung}

Die Höhe der Grenzbelastung hängt von verschiedenen Faktoren ab. Es trifft allerdings nicht $\mathbf{z u}$, daß ein Teil der Grenzbelastung durch den Steuerverbund verursacht sei, weil jedes Land von der Lohnsteuer $42,5 \%$ an den Bund abführen müsse ${ }^{1}$. Die dem Land von vornherein nicht zustehenden Mehreinnahmen haben in einer Grenzbelastungsrechnung nichts verloren.

Entscheidend für die Abschőpfung zusătzlicher Steuereinnahmen ist aus der Sicht finanzschwacher Empfängerländer die Garantie einer relativen Finanzkraft in Höhe von mindestens $99,5 \%$ des Länderdurchschnitts, die über den Umsatzsteuer-Vorwegausgleich, die Zuweisungen im horizontalen Lănderfinanzausgleich und die Fehlbetrags-Bundesergänzungszuweisungen realisiert wird. Dagegen beruht die marginale Belastung der finanzstarken Zahlerländer insbesondere auf dem progressiven Umverteilungstarif.

Die übermäßigen Grenzbelastungen der Länder können erhebliche Fehlanreize für die Wirtschafts- und Finanzpolitik hervorrufen. Sie hängen eng mit

1 Diese Argumentation findet sich bei Lichtblau, 1999, S. 104. 
der Verletzung des Prinzips der fiskalischen Áquivalenz durch den Finanzausgleich zusammen 1 .

(1) Die Ansiedlung von Unternehmen ist für ein Land in der Regel mit zusătzlichen (Infrastruktur-) Ausgaben verbunden, denen aber auch zusätzliche Steuereinnahmen gegenüberstehen. Werden die Mehreinnahmen jedoch durch den Finanzausgleich abgeschöpft, so hat ein Bundesland deutlich weniger Anreize, den Standort für neue Unternehmen attraktiv zu machen (und für eingesessene Unternehmen attraktiv zu halten). Was dem Land bleibt, sind die positiven Beschäftigungswirkungen einer Industrieansiedlung, doch rein fiskalisch (und damit sicher etwas verkürzt) gesehen lohnt sich der Aufwand eben nicht.

(2) Eng mit den tendenziell negativen Konsequenzen für das regionale Wirtschaftswachstum verbunden und diese verschärfend ist die aus dem Finanzausgleich resultierende Begünstigung der konsumtiven gegenüber den investiven Staatsausgaben2 ${ }^{2}$ Dieser Effekt stellt sich ein, weil die hochgradige Abschöpfung der zukünftigen Erträge staatlicher Investitionen (in Form von Steuermehreinnahmen) deren Opportunitätskosten gegenüber solchen Staatsleistungen erhöht, die den Bürgern sofort und unmittelbar zugute kommen. Die interregionale Umverteilung vermindert die Zustimmung der Bürger "zu den meist schmerzhaften wachstumsfreundlichen Maßnahmen. Und niemand kann es der Landesregierung, die auf Wählerstimmen angewiesen ist, verdenken, wenn sie ihr Verhalten entsprechend einrichtet ${ }^{4} 3$.

(3) Schließlich ist auf ein fiskalisches Problem von nicht zu unterschätzender praktischer Relevanz hinzuweisen. Bei der Steuerverwaltung, die den Bundesländern obliegt, sind beispielsweise die Kosten der Einstellung zusătzlicher Steuerprüfer vom Land zu tragen. Die wahrscheinlich weit über den Zusatzkosten liegenden Mehreinnahmen gehen dem Landeshaushalt jedoch verloren. Es darf daher nicht verwundern, wenn sich

1 Vgl. z. B. Homburg, 1994, S. 313 ff.; Huber, 1999 b, S. 13 ff.; Lichtblau, 1999, S. 105.

2 Dazu trăgt auch die einwohnerzentrierte Steuerzerlegung bei. Vgl. S. $131 \mathrm{ff}$.

3 Homburg, 1994, S. 315. 
jedes einzelne Land als Trittbrettfahrer verhält und für die Lăndergesamtheit vorteilhafte Maßnahmen letzten Endes unterbleiben. Dies ist im übrigen schon deshalb zu erwarten, weil eine gegenüber der Wirtschaft zurückhaltende Steuerdurchsetzung ein positiver Standortfaktor sein kann, der nicht primär zu Lasten des eigenen Haushalts, sondern zu Lasten der Steuerkraft der übrigen Länder (und des Bundes) geht'1.

Insgesamt bleibt festzuhalten, daß der heutige Länderfinanzausgleich nicht nur eine hohe Durchschnittsbelastung und - je nach Perspektive - eine Ånderung der Finanzkraftrangfolge bewirkt; er verursacht auch und vor allem extrem hohe Grenzbelastungen, die Fehlanreize in die Wirtschafts- und Finanzpolitik hineintragen. Es mag schon sein, daß sich die Landespolitiker nicht nur und auch nicht primär von fiskalischen Erwägungen leiten lassen, doch wäre ein Abbau dieser potentiell störenden Einflüsse auf ihre Entscheidungen zweifellos von Vorteil.

Eine zielführende Reform des Länderfinanzausgleichs muß daher auf eine Reduktion der Nivellierungsintensităt des Gesamtsystems gerichtet sein. Sie liegt im Interesse aller Beteiligten, der Nettozahler wie der Nettoempfänger, was die Durchsetzbarkeit entsprechender Vorschläge verbessern sollte. Allerdings darf die Reformdiskussion nicht auf das Grenzbelastungsproblem beschränkt werden. Andere Defekte des heutigen Systems, vor allem einige unsystematische und systemfremde Vergünstigungen für einzelne Länder (-gruppen), sind bei einer Neuregelung ebenfalls zu beachten.

1 Die Länder hătten es allerdings in der Hand, die positiven externen Effekte einer konsequenteren Steuereintreibung durch Vereinbarungen untereinander zu internalisieren, etwa durch den Beschluß, die Zahl der Steuerprüfer überall um einen bestimmten Prozentsatz aufzustocken. 
Wolfgang Scherf - 978-3-631-75181-7

Downloaded from PubFactory at 01/11/2019 07:24:58AM

via free access 
TEIL 2

KRITIK DES LÄNDERFINANZAUSGLEICHS UND ANSATZPUNKTE EINER REFORM 
Wolfgang Scherf - 978-3-631-75181-7

Downloaded from PubFactory at 01/11/2019 07:24:58AM

via free access 


\section{Probleme des Länderfinanzausgleichs im Überblick}

Die Darstellung des Länderfinanzausgleichs und seiner Verteilungswirkungen deutet darauf hin, daß das bestehende System aus ökonomischer Sicht in zentralen Punkten der kritischen Analyse und der darauf aufbauenden Neuordnung bedarf. Gegen den heutigen Länderfinanzausgleich sprechen sowohl grundsätzliche Überlegungen, als auch zahlreiche Unstimmigkeiten im Detail. Im folgenden werden die wichtigsten Kritikpunkte zunächst skizziert. Vor diesem Hintergrund erfolgt anschließend eine detaillierte Auseinandersetzung mit den verschiedenen Stufen des Finanzausgleichs und den Ansatzpunkten einer Reform. Bei der Diskussion der einzelnen Elemente ist stets ihre Stellung im Gesamtsystem zu bedenken, dessen Teile ineinandergreifen und daher nicht isoliert beurteilt werden können.

In der öffentlichen Diskussion über den Länderfinanzausgleich dominiert der Eindruck eines Streits der Gebietskörperschaften um Kompetenzen und noch mehr um Finanzen. „Jeder will seine verfügbare Finanzmasse erhöhen und möglichst andere an der Finanzierung der Aufgaben beteiligen, die für inn wichtig sind"1. Hinter dem allzu leicht als Verteilungsstreit abqualifizierten Ringen um einen von allen Beteiligten als fair empfundenen Anteil an den staatlichen Einnahmen verbergen sich jedoch eine Reihe gravierender ökonomischer Probleme und grundsätzlicher Fragen der Finanzverfassung.

Die föderale Ordnung dient vor allem der möglichst optimalen, den Präferenzen der Bürger angepaßten Versorgung mit staatlichen Leistungen, die nach den Prinzipien der Autonomie, der Konnexität und der fiskalischen Áquivalenz bereitzustellen sind. Der (Länder-) Finanzausgleich im engeren Sinne hat dabei die Funktion eines Korrektivs der allokativen und mehr noch der distributiven Defekte eines unbegrenzten Wettbewerbs der Regionen2. Der Ausgleich darf jedoch nicht so weit gehen, daß dadurch die Grundfunktionen der föderalen Ordnung außer Kraft gesetzt werden. Dieser Vorwurf kann aber gegenüber dem heutigen System zu Recht erhoben werden.

1 Lichtblau, 1999, S. 95.

2 Vgl. zu den Aufgaben des Finanzausgleichs S. $19 \mathrm{ff}$. 
(1) Übermäßige Nivellierung: Das Hauptproblem des geltenden Länderfinanzausgleichs besteht in der extremen Nivellierung, teilweise Übernivellierung der Finanzausstattung. Die Umverteilung zwischen den Ländern erreicht ein Ausmaß, das "die Idee des Wettbewerbs völlig auf den Kopf stellt ${ }^{4}{ }^{1}$ und mit den Prinzipien einer föderalen Ordnung nicht mehr zu vereinbaren ist. Wenn alle Länder nach Finanzausgleich - selbst gemessen an den Kriterien des FAG - über eine nahezu übereinstimmende Finanzkraft verfügen, kann keine Rede mehr davon sein, daß die finanzielle Eigenverantwortung der Länder unangetastet bleibt und inr Wille zur Selbsthilfe nicht geschwächt wird. Dies gilt um so mehr, wenn man die exorbitanten Grenzbelastungen in Rechnung stellt, denen die Länder im Finanzausgleich unterworfen sind.

(2) Geringer Autonomiegrad: Zwischen dem Ausmaß der Umverteilung und dem insgesamt geringen Autonomiegrad, den die bundesdeutsche $\mathrm{Fi}$ nanzverfassung den Ländern zubilligt, besteht ein innerer Zusammenhang. Die faktische Vollnivellierung impliziert "eine bundesweit uniforme Angleichung des wertmäßigen Pro-Kopf-Angebotes öffentlicher Leistungen. Die Minimum-Orientierung an einem Duchschnittswert ist dabei geeignet, den gesamten Staatsanteil über das effiziente Maß hinaus zu erhöhen. In jedem Fall wirkt diese Nivellierung der Staatstätigkeit auf hohem Niveau dem Grundgedanken einer - auch einnahmebezogenen Länderautonomie entgegen"2. Die Idee der Steuerautonomie ist nämlich unabdingbar mit der Bereitschaft verbunden, unterschiedliche Versorgungsniveaus mit öffentlichen (und privaten) Gütern zu akzeptieren. Insofern stellt die Reduktion des Nivellierungsgrades des Länderfinanzausgleichs auch eine Vorbedingung für die Einführung eigenständiger Besteuerungsmöglichkeiten der Länder dar.

(3) Okonomische Fehlanreize: Neben der übermäßigen Nivellierung der Finanzkraft verursachen weitere spezielle Regelungen des Finanzausgleichs ökonomische Fehlanreize. Hinzuweisen ist etwa auf die Problematik der Bundesergănzungszuweisungen zur Haushaltssanierung, die

1 Homburg, 1994, S. 313.

2 Dickertmann/Gelbhaar, 1996 b. S. 493-494. 
mit der Gefahr einer Ausbeutung der Gesamtheit durch kleine Bundesländer verbunden sind, solange haushaltspolitisches Fehlverhalten nicht wirksam sanktioniert werden kann. Ineffizient ist wohl auch die unzureichende Bindung der Hilfen für die neuen Länder an eine investive Mittelverwendung.

(4) Systematische Widersprüche: Die negativen Wirkungen der überzogenen Umverteilung werden begleitet von systematischen Widersprüchen bei der Gestaltung der verschiedenen Ausgleichsschritte. Eine wesentliche Ursache besteht darin, daß der horizontale Finanzkraftausgleich auf drei Stufen verteilt und zudem verschiedentlich von Bedarfsgesichtspunkten überlagert wird. Schon die Verfolgung eines primären Ausgleichziels - Annäherung der relativen Finanzkraftpositionen - mit drei unterschiedlichen, Instrumenten - Umsatzsteuer-Vorwegausgleich, horizontale Ausgleichszahlungen und Fehlbetrags-Bundesergänzungszuweisungen - führt mit hoher Wahrscheinlichkeit zu Ungereimtheiten. Wenn die einzelnen Ausgleichselemente dann auch noch unterschiedlichen Maßstäben folgen (z. B. mit der Orientierung am tatsächlichen bzw. am veredelten Einwohner), sind widersprüchliche Ausgleichsergebnisse geradezu vorprogrammiert.

(5) Unstimmigkeiten im Detail: Neben dem unkoordinierten Nebeneinander der verschiedenen Ausgleichsschritte fallt auf, daß den einzelnen Regelungen oftmals die innere Konsistenz fehlt. Beispiele dafür sind die Ungleichbehandlung der Länder im Rahmen der Hafenlastenregelung, von der Schleswig-Holstein ausgeschlossen ist, und der Bundesergänzungszuweisungen für die Kosten politischer Führung, bei denen Hamburg unberücksichtigt bleibt. Auch die nur hälftige Einbeziehung der Gemeindeeinnahmen bei der Ermittlung der Finanzkraft ist eine letztlich inkonsequente Lơsung.

(6) Geringe Transparenz: Die systematischen Widersprüche und die Unstimmigkeiten im Detail erwecken nicht nur den Eindruck der Beliebigkeit und politischen Willkü; sie tragen auch zur hochgradigen Komplexität und damit zur Intransparenz des gesamten Länderfinanzausgleichs 
bei. Die verschiedenen Ausgleichselemente und ihr Zusammenwirken erschließen sich dem Beobachter erst nach einer gründlichen Analyse. Es verwundert daher nicht, daß die politische Unzufriedenheit bei allen Beteiligten zunimmt. Jeder fühlt sich, wenn auch aus unterschiedlichen Gründen, durch das kaum noch überschaubare und beherrschbare System benachteiligt. Erschwerend kommt hinzu, daß den Bürgern eine Kontrolle der Finanzpolitik ihres Landes nahezu unmöglich gemacht wird. Darin kann man durchaus einen Verstoß gegen das Demokratieprinzip sehen.

(7) Strategieanfälligkeit: Die Komplexităt des Systems ist schließlich eine Hauptursache seiner Anfälligkeit für Versuche einzelner Länder, ihre Position über Verănderungen des Finanzausgleichs zu verbessern. Die Aussichten auf einen anhaltenden Verteilungsstreit steigen mit der Zahl der im Finanzausgleich verfügbaren Aktionsparameter. Insofern muß die Vermischung des primär angestrebten Finanzkraftausgleichs mit der Berücksichtigung von Sonderbedarfen nicht nur aus systematischen Gründen kritisiert werden; sie hat auch erheblich zur Strategieanfälligkeit des bestehenden Regelwerkes beigetragen 1 .

Ausgehend von der skizzierten Kritik wird die Reformbedürttigkeit der einzelnen Ausgleichselemente - unter Berücksichtigung ihres Systemzusammenhangs - im folgenden überprüft. Dabei geht es im Kern um die Frage, wie der Länderfinanzausgleich gestaltet werden muß, damit er den allokativen und distributiven Kriterien eines rationalen Finanzausgleichs entspricht.

1 Der Wissenschaftliche Beirat beim Bundesministerium der Finanzen unterscheidet vier Optionen der Länder zur Verbesserung ihrer Position im Finanzausgleich: (1) Niedriger Ansatz der eigenen und hoher Ansatz der Finanzkraft anderer Lánder; (2) Integration bislang nicht berücksichtigter Einnahmen in die Finanzkraftmeßzahl, sofern diese Einnahmen vorwiegend in anderen Ländern anfallen; (3) Verstärkung oder Abschwächung der Einwohnergewichtung der Länder und/oder der Gemeinden; (4) Reklamation eigener Sonderbedarfe und Nichtanerkennung der Sonderbedarfe anderer Lănder. Vgl. Wissenschaftlicher Beirat beim Bundesministerium der Finanzen, 1992, S. 17 ff. 


\section{Fragen der vertikalen und horizontalen Steuerverteilung}

Die vertikale Verteilung der Steuereinnahmen zwischen Bund und Ländern sowie die horizontale Verteilung unter den Ländern bilden die ersten Stufen eines umfassend verstandenen Länderfinanzausgleichs. Die Primărverteilung der Steuereinnahmen entscheidet über die finanziellen Ausgangspositionen der Länder und damit über den Bedarf an sekundärer Umverteilung durch den horizontalen Länderfinanzausgleich im engeren Sinne.

\section{A. Besteuerungskompetenzen und regionale Steuerverteilung}

Der erste Schritt des Finanzausgleichs i. w. S. beinhaltet die Aufteilung der Besteuerungskompetenzen zwischen Bund und Ländern (einschließlich der Gemeinden, die als dritte Ebene im folgenden nicht gesondert berücksichtigt werden). Gesetzgebungs-, Verwaltungs- und Ertragskompetenz müssen ebenso festgelegt werden wie die Regeln für die räumliche Verteilung der Erträge der einzelnen Steuern.

Hinsichtlich der bisherigen Verteilung der Besteuerungskompetenzen zwischen Bund und Ländern kann man mit dem Wissenschaftlichen Beirat beim Bundesministerium der Finanzen der Auffassung sein, daß kein zwingender Reformbedarf besteht, da und "wenn nur diejenigen Finanzausgleichsregelungen geändert werden sollten, die sich eindeutig nicht bewährt haben "1. Eine wichtige Ausnahme bildet allein die fehlende Möglichkeit der Länder zur Variation ihrer Steuereinnahmen. Hier könnte die Gewährung eines Hebesatz- oder Zuschlagsrechts bei der Einkommen- und Körperschaftsteuer in Erwăgung gezogen werden ${ }^{2}$.

Am einfachsten wäre ein Zuschlagsystem zu realisieren. Dabei könnten die Ländern auf ihren Anteil an der Einkommen- und Körperschaftsteuer einen proportionalen Zuschlag oder Abschlag auf die Steuerschuld vornehmen.

1 Wissenschaftlicher Beirat beim Bundesministerium der Finanzen, 1992, S. 56.

2 Dies würde den wesentlichen Motiven der Befüworter eines Trennsystem entgegenkommen, ohne die damit verbundenen Nachteile in Kauf nehmen zu müssen. Denkbar wären darüber hinaus Gestaltungsmöglichkeiten bei den reinen Ländersteuern, z. B. bei der Erbschaftsteuer, die jedoch aufgrund des geringen Aufkommens keinen nennenswerten Beitrag zur Vergrößerung der Finanzautonomie der Länder leisten würden. 
Die daraus resultierenden Mehr- oder Mindereinnahmen dürften im Finanzausgleich nicht berücksichtigt werden. Andernfalls würden die positiven wie negativen Konsequenzen autonomer steuerpolitischer Entscheidungen der Bundesländer auf die Ländergesamtheit überwälzt.

Mit einer regionalen Steuerautonomie sind aber auch Nachteile verbunden1. Gerade wenn ausgeprägte Finanzkraftdifferenzen zwischen den Ländern vorliegen, ist die Wahrscheinlichkeit groß, daß die Finanzschwäche (Finanzstärke) eines Landes mit einer hohen (geringen) Steuerbelastung seiner Bürger einhergeht. Die regionalen Divergenzen in den Lebensverhältnissen würden dann durch mehr Steuerautonomie verstärkt. Auch ist mit Ausweichreaktionen der Wirtschaftssubjekte in Form von Wohnsitzverlagerungen zu rechnen. Um dem entgegenzuwirken, sollte das Zuschlagsrecht nach oben und unten begrenzt werden 2 .

Ohne eigenstăndige Besteuerungsrechte der Lănder determiniert die Primärverteilung der Steuereinnahmen die regionale Streuung des Steueraufkommens und damit auch die Finanzkraftdifferenzen der Länder. Insbesondere mit der progressiven Einkommensteuer sind in dieser Hinsicht gewisse Probleme verbunden, die auch im Finanzausgleich Beachtung verdienen 3 .

(1) Das Pro-Kopf-Steueraufkommen steigt bei der Einkommensteuer tendenziell mit der Wirtschaftskraft eines Landes. Bezogen auf die regionale Streuung des gesamten Steueraufkommens wird dieser Zusammen-

1 Auf die erheblichen administrativen Probleme sei hier nur hingewiesen. Bei der Einkommensteuer wäre beispielsweise eine Zwangsveranlagung aller Steuerpflichtigen mit ihren gesamten Einkünften erforderlich, um eine korrekte Zuschlagsbesteuerung sicherzustellen. Bei der Körperschaftsteuer müßten die nicht ausgeschütteten Gewinne nach Betriebsstätten zerlegt und dann in den einzelnen Ländern der Zuschlagsbesteuerung unterworfen werden. Huber empfiehlt daher, auf die Einbeziehung der Körperschaftsteuer ganz zu verzichten. Vgl. Huber, 1999 a, S. 64. Sinnvoller wäre aber - mit Blick auf die sonst eintretenden Wettbewerbsverzerrungen zwischen Personalunternehmen und Kapitalgesellschaften - die Zusatzbesteuerung der einbehaltenen Gewinne mit dem bundesdurchschnittlichen Zuschlagsatz.

2 Der Wissenschaftliche Beirat beim Bundesministerium der Finanzen ist der Meinung, daß sich die negativen Konsequenzen einer ausgedehnten Steuerautonomie durch einen vergleichsweise höheren Nivellierungsgrad des Länderfinanzausgleichs begrenzen lassen. Vgl. Wissenschaftlicher Beirat beim Bundesministerium der Finanzen, 1992, S. 94. Diese Aussage kann sich wohl nur auf einen (nach den Beiratsvorstellungen) reformierten Länderfinanzausgleich mit deutlich reduziertem Nivellierungsgrad beziehen.

3 Vgl. Färber, 1999, S. $139 \mathrm{ff}$. 
hang jedoch durch die Verteilung der Umsatzsteuer nach Einwohnern erheblich relativiert ${ }^{1}$. Auch muß man sehen, daß die ungleichmäßige Streuung des Steueraufkommens zwar die Notwendigkeit eines Finanzausgleichs (mit-) begründen, aber sicher nicht die völlige Nivellierung der Pro-Kopf-Finanzkraft der Regionen rechtfertigen kann.

(2) Regional differenzierende Effekte haben ferner die mit der Einkommensteuer verbundenen vielfältigen Steuervergünstigungen, nicht zuletzt die steuerliche Förderung der neuen Länder. Daraus resultierende Steuerausfälle treffen vor allem die finanzstarken Länder, in denen die Steuervorteile faktisch stärker in Anspruch genommen werden (können). Auf diese Weise kommt ein verdeckter Finanzausgleich zugunsten der neuen Länder zustande. Die wirtschaftspolitisch motivierten Steuervergünstigungen geben vielleicht Anlaß zu einer Reform der Einkommensteuer und der Förderprogramme; ihre regionalen Verteilungswirkungen können aber im Finanzausgleich nicht zielgerichtet korrigiert werden.

Im Zusammenhang mit der regionalen Verteilung der Verbundsteuern stehen auch die Zerlegungsvorschriften zur Debatte, denen erhebliche Bedeutung für den Anteil der einzelnen Lănder an der den Lăndern insgesamt zustehenden Finanzmasse zukommt. Die Frage, ob das Wohnsitzprinzip bei der Zerlegung der Einkommensteuer beibehalten, oder durch das Betriebsstättenprinzip ergänzt werden sollte, hängt eng mit der Stadtstaatenproblematik zusammen, und wird daher an späterer Stelle aufgegriffen (vgl. S. $130 \mathrm{ff}$.) 2.

Abgesehen von der denkbaren Erweiterung der Besteuerungskompetenzen der Länder durch ein Zuschlagsystem kann die vertikale Verteilung der Steuereinnahmen zwischen Bund und Ländern im wesentlichen beibehalten werden. Sofern der heutige Länderfinanzausgleich in zentralen Punkten reformiert werden sollte, besteht jedoch Anlaß zur Variation der Anteile an den Gemeinschaftsteuern. Bundes- und Lănderhaushalte sind insbesondere

1 Die partielle Verteilung der Umsatzsteuer nach der Finanzkraft ist bereits ein Element des horizontalen Ausgleichs und als solches hier nicht zu berücksichtigen.

2 Eine partielle Zerlegung der Einkommensteuer nach dem Betriebsstättenprinzip steht in gewissem Widerspruch zu einem Zuschlagsystem, denn die Zuschläge lassen sich wohl kaum nach Wohnsitz und Arbeitsplatz differenzieren. 
über die Bundesergänzungszuweisungen so stark miteinander verknüpft, daß fundamentale Anderungen ohne kompensatorische Verschiebungen in den Verbundquoten kaum realisierbar sein dürften.

Dabei ist zu beachten, daß die Haushalte keinen einseitigen, sondern einen wechselseitigen Zusammenhang aufweisen. Eine Senkung der Ausgleichsquote bei den Fehlbetrags-Bundesergänzungszuweisungen entlastet beispielsweise den Bund und belastet die (finanzschwachen) Länder. Umgekehrt führt eine Senkung des Ausgleichniveaus im horizontalen Länderfinanzausgleich über höhere Fehlbetrags-Bundesergänzungszuweisungen zu einer Belastung des Bundes. Derartige Rückkopplungen verlangen gegebenenfalls eine entgegengerichtete Variation der Verbundquoten, die am einfachsten und mit den geringsten Verwerfungen im Finanzausgleich bei der Umsatzsteuerbeteiligung erfolgen kann. Eine Variation des Einkommensteueranteils hätte den Nachteil der ungleichmäßigeren Verteilungseffekte.

\section{B. Horizontaler Finanzausgleich über die Umsatzsteuerverteilung}

Die Verteilung des Länderanteils an der Umsatzsteuer erfolgt gemäß Art. 107 Abs. 1 GG zu mindestens $75 \%$ nach der Einwohnerzahl und zu höchstens $25 \%$ nach der Steuerkraft der Länder. Finanzschwache Länder, deren Pro-Kopf-Steuereinnahmen ohne Umsatzsteuer und ohne Gemeindesteuern unter $92 \%$ des Länderdurchschnitts liegen, erhalten Ergänzungsanteile, bis sie das $92 \%$-Niveau erreicht haben ( $\$ 2$ Abs. 2 FAG). Der verbleibende Betrag wird im Verhăltnis der Einwohnerzahlen auf die Länder verteilt (§ 2 Abs. 1 FAG). Die partielle Verteilung der Umsatzsteuer nach der Finanzkraft enthält bereits Elemente des horizontalen Ausgleichs. Sie muß daher - als nur formal vorgelagerte Stufe - dem horizontalen Länderfinanzausgleich im engeren Sinne zugerechnet werden.

\section{Kritik des Umsatzsteuer-Vorwegausgleichs}

Die einwohnerorientierte Zerlegung der Umsatzsteuer ist in der finanzwissenschaftlichen Literatur weitgehend unumstritten. Sie kommt dem Prinzip der Verteilung nach dem regionalen Aufkommen recht nahe. Zwar wäre ei- 
ne konsumbezogene Zerlegung theoretisch denkbar, aber nicht sonderlich praktikabel. Die konzeptionell erforderliche Zuordnung der Konsumausgaben auf die Wohnorte der Bürger würde erhebliche Schwierigkeiten bereiten, weil der Konsumort in der Regel nicht mit dem Einkaufsort übereinstimmt, an dem die (Einzelhandels-) Umsätze erfolgen. Die Einwohnerorientierung bietet hier einen einfachen und unproblematischen Ausweg.

Kritik hervorgerufen hat aber die Regelung der Ergänzungsanteile zur Vorweganhebung der Finanzkraft finanzschwacher Länder. Sie gilt als „ein systemfremdes Element im Verfahren der horizontalen Steuerverteilung. Diese soll sich im Prinzip an der regionalen Steuerleistung ausrichten, nicht aber an Bedarfgesichtspunkten "1. Darüber hinaus wird moniert, daß die nach der (Pro-Kopf-) Finanzkraft vor Umsatzsteuer verteilten Ergänzungsanteile im anschließenden Länderfinanzausgleich zur originären Finanzkraft eines jeden Landes gehören. „Demzufolge verringern die Ländereinnahmen aus einer Umsatzsteuer-Vorabauffüllung die zu erwartenden Ausgleichszahlungen in der ,zweiten Stufe' des horizontalen Finanzausgleichs. Der Umverteilungseffekt der Gesamtregelung wird insoweit abgeschwächt oder verschwindet - nicht zuletzt aufgrund der Fehlbetrags-Bundesergänzungszuweisungen - nahezu vollständig“2.

\section{Die Ergänzungsanteile als Sockelgarantie}

Die genannten Kritikpunkte liegen auf unterschiedlichen Ebenen. Der erste Einwand ist grundsătzlicher Natur, aber inhaltlich von untergeordneter Bedeutung. Die ursprüngliche Funktion des Umsatzsteuer-Vorwegausgleichs besteht in der finanzausgleichspolitisch erwünschten Garantie einer Mindestfinanzkraft in Relation zum Lănderdurchschnitt (Sockelgarantie). Diese Aufgabe kann zwar problemlos in den horizontalen Länderfinanzausgleich i. e. S. integriert werden. Die Verteilungsergebnisse der in Betracht kommenden Verfahren unterscheiden sich aber nicht, sofern von identischen Ausgleichszielen ausgegangen wird.

1 Peffekoven, 1994, S. 294.

2 Dickertmann/Gelbhaar, 1996 b, S. 493. 
Im Prinzip existieren drei äquivalente Methoden zur simultanen Realisierung einer Sockelgarantie und der darüber hinausgehenden (begrenzten) Annäherung der relativen Finanzkraftpositionen 1 .

(1) Die Mindestauffüllung erfolgt im Rahmen der Verteilung des Länderanteils an der Umsatzsteuer. In der zweiten Stufe werden die Differenzen in der relativen Finanzkraft nach Umsatzsteuerverteilung durch Ausgleichsbeiträge und Ausgleichszuweisungen zum Teil abgebaut.

(2) Die Umsatzsteuer wird ausschließlich nach Einwohnern verteilt. Im anschließenden horizontalen Ausgleich unter den Ländern wird zunächst der ${ }_{n}$ normale" Umverteilungstarif auf die Finanzkraft nach Umsatzsteuerverteilung angewandt. Erreichen einzelne Länder dadurch die garantierte Mindestfinanzkraft noch nicht, so werden die verbleibenden Fehlbeträge von den übrigen Ländern proportional zu ihrer Finanzkraft nach der tarifmäßigen Ụmverteilung aufgebracht.

(3) Die nach Verfahren 2 in den horizonzalen Ausgleich integrierte Mindestauffüllung kann den ersten Schritt bilden. Der Unterschied zu Verfahren 1 besteht dann lediglich in der Aufbringung der erforderlichen Mittel. Sie können von den Ländern finanziert werden, die nach der Pro-Kopf-Verteilung der Umsatzsteuer über der Auffüllgrenze liegen. Möglich wäre auch eine Beteiligung des Bundes anstelle der heutigen FehlbetragsBundesergänzungszuweisungen².

Alle Verfahren gewährleisten die Einhaltung derselben Garantiegrenze, sofern die Umverteilungsparameter (Mindestauffüllung und Umverteilungstarif) zielgerichtet eingesetzt werden. Infolgedessen sind keine inhaltlichen Differenzen hinsichtlich der Ausgleichseffekte, sondern weitergehende Überlegungen für die Wahl der Ausgleichstechnik entscheidend. Für das zuletzt

1 Vgl. Wissenschaftlicher Beirat beim Bundesministerium der Finanzen, 1992, S. 79 ff.

2 Der Sachverständigenrat zur Begutachtung der gesamtwirtschaftlichen Entwicklung hat ein Modell mit Bundesbeteiligung vorgeschlagen. Der Bund übernimmt eine Vorabauffüllung, die gewährleistet, daß alle Länder mindestens $85 \%$ der durchschnittlichen originären Finanzkraft der Länder bei Pro-Kopf-Verteilung der Umsatzsteuer erhalten. Im anschließenden Länderfinanzausgleich wird ein linearer Ausgleichstarif mit einer Quote von $60 \%$ angewandt (bezogen auf die nach Vorabauffüllung erhöhte durchschnittliche Länderfinanzkraft). Vgl. Sachverständigenrat, 1992, Z. $370 \mathrm{ff}$. 
genannte Verfahren spricht eigentlich nur die Option einer Beteiligung des Bundes, die aber mit einer finanzausgleichspolitisch problematischen Vermischung horizontaler und vertikaler Ausgleichszahlungen einhergeht ${ }^{1}$.

Das erste Verfahren der Vorverlagerung der Mindestauffüllung in die Umsatzsteuerverteilung hat gegenüber den beiden anderen den finanzpsychologischen Vorteil einer (scheinbaren) Reduktion des Ausgleichsvolumens im eigentlichen Länderfinanzausgleich, dem der Nachteil einer Vermischung von Primär- und Sekundärverteilung und der damit verbundenen geringeren Transparenz gegenüberzustellen ist. Beide Aspekte sind nicht so gewichtig, daß sie eine Entscheidung für die eine oder andere Lösung erzwingen. Insgesamt kann der Umsatzsteuer-Vorwegausgleich - bei zielgerichtetem Einsatz zur Gewährleistung einer Sockelgarantie - daher nicht schon mit dem grundsätzlich richtigen Hinweis auf seine systemfremde Plazierung in der Steuerverteilung abgelehnt werden.

\section{Die Netto-Verteilungseffekte der Ergänzungsanteile}

Der zweite der oben angeführten Einwände gegen die Ergänzungsanteile rekurriert auf den per saldo nur geringen Umverteilungseffekt des Umsatzsteuer-Vorwegausgleichs. Seine Relevanz hăngt in starkem Maße von der Nivellierungsintensität des Gesamtsystems ab. Im heutigen Länderfinanzausgleich, der am Ende ein Mindestniveau von 99,5\% der durchschnittlichen Finanzkraft (im Sinne des FAG) gewährleistet, stellt sich tatsächlich die Frage nach der Berechtigung der Ergänzungsanteile, die das insgesamt wenig transparente und technisch aufwendige Verfahren jedenfalls nicht vereinfachen. Ein Blick auf die Netto-Verteilungseffekte der Ergänzungsanteile unterstreicht die Problematik der unkoordinierten Aneinanderreihung der verschiedenen Ausgleichsstufen im derzeitigen System.

Tabelle 1 enthălt die Veränderungen, die sich durch den Umsatzsteuer-Vorwegausgleich in Relation zu einem Finanzausgleich mit reiner Pro-Kopf-Ver-

1 Der Sachverstăndigenrat sieht den Vorteil einer vom Bund finanzierten Vorabauffüllung darin, daß eine Verbesserung der Finanzkraft der neuen Länder zunächst vor allem den Bund entlasten würde, der in besonderem Maße für den Aufbau der Infrastruktur in den neuen Bundesländem verantwortlich ist. Vgl. Sachverstăndigenrat, 1992, Z. 368. 


\section{Tabelle 1}

Verteilungseffekte des Umsatzsteuer-Vorwegausgleichs 1998

\begin{tabular}{|c|c|c|c|c|c|}
\hline Land & \multicolumn{2}{|c|}{ GuV } & USt & LFA & BEZ \\
\hline & $\mathrm{DM} / \mathrm{E}$ & Mio. DM & \multicolumn{3}{|c|}{$\mathrm{DM} / \mathrm{E}$} \\
\hline NRW & 8,80 & 158,1 & $-214,47$ & 223,43 & 0,00 \\
\hline BAY & 16,25 & 196,1 & $-214,47$ & 230,94 & 0,00 \\
\hline BW & 17,66 & 183,9 & $-214,47$ & 232,37 & 0,00 \\
\hline NDS & $-9,32$ & $-73,2$ & $-214,47$ & 113,42 & 90,95 \\
\hline $\mathrm{HE}$ & $-0,61$ & $-3,7$ & $-214,47$ & 213,94 & 0,00 \\
\hline RP & $-9,33$ & $-37,5$ & $-214,47$ & 113,29 & 91,07 \\
\hline $\mathrm{SH}$ & $-28,73$ & $-79,3$ & $-214,47$ & 185,58 & 0,00 \\
\hline SAAR & 2,82 & 3,0 & 94,36 & $-62,79$ & $-28,42$ \\
\hline $\mathrm{HH}$ & 52,16 & 88,7 & $-214,47$ & 267,18 & 0,00 \\
\hline HB & 3,73 & 2,5 & $-214,47$ & 256,26 & $-37,60$ \\
\hline SN & 3,15 & 14,2 & 970,45 & $-938,93$ & $-28,36$ \\
\hline ST & 3,15 & 8,5 & $1.094,55$ & $-1.063,08$ & $-28,32$ \\
\hline TH & 3,14 & 7,8 & $1.074,40$ & $-1.042,98$ & $-28,28$ \\
\hline BB & 3,14 & 8,1 & 922,23 & $-890,82$ & $-28,26$ \\
\hline MV & 3,14 & 5,7 & $1.049,41$ & $-1.017,98$ & $-28,28$ \\
\hline BER & 4,20 & 14,4 & $-214,47$ & 256,48 & $-37,81$ \\
\hline West & 6,80 & 438,7 & $-209,32$ & 200,25 & 15,87 \\
\hline Ost & 3,35 & 58,6 & 773,50 & $-739,98$ & $-30,17$ \\
\hline Alle & 6,06 & 497,2 & 0,00 & 0,00 & 6,06 \\
\hline GuV & \multirow{2}{*}{\multicolumn{5}{|c|}{$\begin{array}{l}\text { Erhöhung (+) bzw. Verminderung (-) der Ländereinnahmen gegenüber } \\
\text { einem LFA ohne Umsatzsteuer-Vorwegausgleich } \\
49,5 \% \text { Länderanteil nach Einwohnern }\end{array}$}} \\
\hline USt & & & & & \\
\hline
\end{tabular}

Umsatzsteueranteil der Länder angepaßt

\begin{tabular}{|l|rr|rrr|}
\hline \multicolumn{1}{c}{ Land } & \multicolumn{2}{c}{ GuV } & \multicolumn{1}{c|}{ USt } & \multicolumn{1}{c|}{ LFA } & \multicolumn{1}{c|}{ BEZ } \\
\hline NRW & DM / E & Mio. DM & & DM / E & \\
BAY & 2,83 & 50,9 & $-220,49$ & 223,48 & 0,00 \\
BW & 10,28 & 124,1 & $-220,49$ & 230,99 & 0,00 \\
NDS & 11,70 & 121,7 & $-220,49$ & 232,42 & 0,00 \\
HE & $-15,20$ & $-119,4$ & $-220,49$ & 113,45 & 91,06 \\
RP & $-6,58$ & $-39,7$ & $-220,49$ & 213,99 & 0,00 \\
SH & $-15,21$ & $-61,1$ & $-220,49$ & 113,31 & 91,17 \\
SAAR & $-34,69$ & $-95,8$ & $-220,49$ & 185,63 & 0,00 \\
HH & $-3,03$ & $-3,3$ & 88,34 & $-62,38$ & $-28,66$ \\
HB & 44,52 & 75,7 & $-220,49$ & 265,57 & 0,00 \\
SN & $-4,16$ & $-2,8$ & $-220,49$ & 254,71 & $-37,93$ \\
ST & $-2,69$ & $-12,1$ & 964,43 & $-938,52$ & $-28,60$ \\
TH & $-2,70$ & $-7,3$ & $1.088,53$ & $-1.062,67$ & $-28,56$ \\
BB & $-2,70$ & $-6,7$ & $1.068,38$ & $-1.042,56$ & $-28,52$ \\
MV & $-2,71$ & $-7,0$ & 916,21 & $-890,41$ & $-28,51$ \\
BER & $-2,70$ & $-4,9$ & $1.043,39$ & $-1.017,57$ & $-28,53$ \\
West & $-3,69$ & $-12,6$ & $-220,49$ & 254,94 & $-38,13$ \\
Ost & 0,78 & 50,4 & $-215,34$ & 200,24 & 15,88 \\
Alle & $-2,89$ & $-50,6$ & 767,48 & $-739,95$ & $-30,43$ \\
\hline GuV & Erhöhung & $-0,1$ & $-6,02$ & 0,00 & 6,02 \\
\hline USt & einem bzw. Verminderung & $(-)$ der Ländereinnahmen gegenüber \\
\hline & $49,7 \%$ Länderanteil nach Einwohnern & & \\
\hline
\end{tabular}


teilung der Umsatzsteuer ergeben. Im oberen Teil der Tabelle werden alle anderen Ausgleichsparameter konstant gesetzt, wăhrend im unteren Teil die Länderquote an der Umsatzsteuer so angepaßt wird, daß im Bund-Lănder-Verhältnis keine finanziellen Verschiebungen eintreten. Dieser Teil der Tabelle enthält mithin die besonders aussagefähigen, um Niveaueffekte bereinigten Daten zur Netto-Umverteilung unter den Ländern.

Schon die unbereinigten Daten zeigen, daß die Wirkungen der Ergänzungsanteile weitgehend durch entgegengerichtete Variationen der Ausgleichssalden im horizontalen Länderfinanzausgleich sowie der Fehlbetrags-Bundesergänzungszuweisungen kompensiert werden. Erhalten die neuen Bundesländer bei isolierter Betrachtung der Umverteilung auf den einzelnen Stufen noch zwischen 970 DM und 1.095 DM je Einwohner durch den Umsatzsteuer-Vorwegausgleich, so reduziert sich dieser Vorteil nach Länderfinanzausgleich und Bundesergänzungszuweisungen netto auf nur noch 3,15 DM je Einwohner. Drastischer kann man die Bedeutungslosigkeit der Ergänzungsanteile für die Einhaltung der Sockelgarantie wohl nicht mehr zum Ausdruck bringen.

Aufschlußreich ist auch ein Blick auf die scheinbaren Verlierer des Vorwegausgleichs. Alle westlichen Bundesländer mit Ausnahme des Saarlandes verzichten durch die Ergänzungsanteile vordergründig auf rund 214 DM pro Einwohner zugunsten der finanzschwachen neuen Bundesländer. Tatsächlich aber profitieren die meisten dieser vermeintlichen Verlierer von den Ergänzungsanteilen. Infolge vergleichsweise geringerer Beiträge bzw. höherer Zuweisungen im horizontalen Länderfinanzausgleich stehen ihnen am Ende nicht weniger, sondern mehr Einnahmen zur Verfügung. Effektiv belastet sind nur Niedersachsen, Rheinland-Pfalz, Schleswig-Holstein und (in geringem Umfang) Hessen.

Am stärksten betroffen ist aber interessanterweise der Bund, der in einem System mit Umsatzsteuer-Vorwegausgleich 497 Mio. DM mehr (!) an Fehlbetrags-Bundesergänzungszuweisungen aufzubringen hat. Zwar spart der Bund erwartungsgemäß im Osten durch die Mindestauffüllung 527 Mio. DM ein, doch sind im Westen 1.024 Mio. DM zusätzlich bereitzustellen, die auf 
Mehrausgaben für die relativ finanzschwachen Lănder Niedersachsen und Rheinland-Pfalz (1.080 Mio. DM) bei nur geringen Einsparungen für Bremen und das Saarland (55,8 Mio. DM) zurückgehen.

Bei einer ausschließlichen Verteilung der Umsatzsteuer nach Einwohnern könnte der Bund den Lăndern einen auf 49,7 \% erhöhten Anteil an der Umsatzsteuer zur Verfügung stellen, ohne dadurch netto auf Einnahmen verzichten zu müssen. Er würde zwar 493,5 Mio. DM bei der Umsatzsteuer verlieren, würde aber den gleichen Betrag bei den Bundesergänzungszuweisungen einsparen. Mit anderen Worten: Der Umsatzsteuer-Vorwegausgleich entlastet heute zwar die Länder durch vergleichsweise höhere Bundesergänzungszuweisungen, aber sie bezahlen diesen Vorteil letzten Endes in Form eines relativ geringeren Anteils an der Umsatzsteuer.

Will man die Umverteilungseffekte des Vorwegausgleichs isolieren, so müssen die impliziten finanziellen Verschiebungen zwischen der Bundes- und der Länderebene herausgerechnet werden. Dies erfordert im vorliegenden Fall die Gegenüberstellung des heutigen Systems mit Ergänzungsanteilen mit einem Referenzsystem ohne Vorwegausgleich, aber mit höherem Umsatzsteueranteil der Lănder ${ }^{1}$. Tabelle 1 zeigt im unteren Teil die daraus resultierenden bereinigten Verteilungswirkungen der Ergänzungsanteile.

Aus dieser der Problematik sachlich angemessenen Perspektive erweist sich die Sockelgarantie im heutigen System nicht nur als materiell nahezu bedeutungslos, sondern auch noch als Ursache "perverser" Unverteilungseffekte. Die vor Finanzausgleich relativ finanzschwachen neuen Bundesländer profitieren nicht mehr von der Mindestauffüllung, sondern werden netto geringfügig belastet. Sie gewinnen zwar bei der Umsatzsteuer, verlieren aber noch mehr im horizontalen Länderfinanzausgleich und bei den Fehlbetrags-Bundesergănzungszuweisungen. Die einzigen Gewinner sind die finanzstarken Länder Nordrhein-Westfalen, Bayern, Baden-Württemberg

1 Der Bund könnte den Lăndern auch höhere Fehlbetrags-Bundesergänzungszuweisungen gewăhren. Dies wäre aber aufgrund der noch stärkeren Nivellierung kontraproduktiv. Interessanterweise entsprechen die Wirkungen qualitativ denen der hier diskutierten Anhebung des Umsatzsteueranteils und gehen quantitativ sogar darüber hinaus. 
und Hamburg. Die effektiven Verteilungswirkungen des Umsatzsteuer-Vorwegausgleichs laufen also den intendierten Wirkungen zuwider.

\section{Bewertung des Umsatzsteuer-Vorwegausgleichs}

Die abgeleiteten Ergebnisse unterstreichen einmal mehr, daß der heutige Länderfinanzausgleich fehlkonstruiert ist. Sie sprechen aber nicht grundsătzlich gegen den Vorwegausgleich. Die Ergănzungsanteile können ihren Charakter nur deshalb nicht entfalten, weil ihre Ausgleichseffekte an anderer Stelle konterkariert werden. In einem reformierten System mit deutlich geringerem Nivellierungsgrad, in dem die Sockelgarantie materiell eine Rot le spielen kann, ist der Umsatzsteuer-Vorwegausgleich ein durchaus vertretbares Element des Ausgleichverfahrens. Solange an der garantierten Mindest-Finanzkraft festgehalten wird, gibt es jedenfalls keinen durchschlagenden Grund für einen Wechsel zur Pro-Kopf-Verteilung der Umsatzsteuer.

Werden die Ergänzungsanteile beibehalten, so ist ihre Nivellierungswirkung allerdings bei der Festlegung der Ausgleichssätze im anschließenden horizontalen Länderfinanzausgleich zu berücksichtigen. Allgemein gilt: Hőhere Ergănzungsanteile senken die mit der garantierten Mindest-Finanzkraft zu vereinbarenden Ausgleichssătze. Ein Beispiel soll dies verdeutlichen. Vorausgesetzt wird die Orientierung aller Ausgleichsparameter an denselben Finanzkraftindikatoren sowie ein linearer Ausgleichstarif. Beträgt die Zielgrőße für die relative Mindest-Finanzkraft $95 \%$ und der Ausgleichssatz $50 \%$, so muß über den Umsatzsteuer-Vorwegausgleich ein Mindestniveau von genau $90 \%$ realisiert werden. Eine Auffullquote von $92 \%$ - wie im heutigen System - ist bei gleicher Sockelgarantie eben nur mit dem geringeren Ausgleichssatz von $37,5 \%$ vereinbar ${ }^{1}$.

Insgesamt kann die verbreitete Kritik am Umsatzsteuer-Vorwegausgleich nicht überzeugen. Zwar wird damit ein Element des horizontalen Lănderfinanzausgleichs formal in die Steuerverteilung verlagert. Bei potentiell iden-

1 Zwischen der Mindestauffulliquote $r$, der relativen Mindest-Finanzkraft $u$ und dem Ausgleichssatz $v$ besteht die Beziehung: $r=(u-v) /(1-v)$. Vgl. Wissenschaftlicher Beirat beim Bundesministerium der Finanzen, 1992, S. 80. 
tischen Ausgleichseffekten sollte aber der im Grunde instrumentellen Frage der technischen Umsetzung einer Sockelgarantie bei der Beurteilung des Ausgleichsverfahrens keine fundamentale Bedeutung beigemessen werden. Bei einer Integration der Sockelgarantie in den horizontalen Länderfinanzausgleich - und nur unter dieser Voraussetzung - ist allerdings gegen eine Abschaffung der Ergänzungsanteile auch wenig einzuwenden ${ }^{1}$.

1 Das weiter unten vorgestellte Modell eines linearen Ausgleichstarifs mit eingebauter Sockelgarantie entspricht dieser Vorgehensweise und benotigt daher keinen Umsatzsteuer-Vorwegausgleich. Vgl. S. $175 \mathrm{ff}$. 


\section{Der horizontale Länderfinanzausgleich im engeren Sinne}

Der Finanzausgleich unter den Ländern umfaßt nicht nur die Garantie einer Mindest-Finanzausstattung, sondern hat darüber hinaus die Aufgabe, die Finanzkraftdifferenzen zwischen den Ländern in gewissem Umfang abzubauen. Derzeit orientiert sich der horizontale Länderfinanzausgleich im engeren Sinne - im Gegensatz zum Umsatzsteuer-Vorwegausgleich - an der Finanzkraftmeßzahl und der Ausgleichsmeßzahl. Die Finanzkraftmeßzahl weicht jedoch erheblich von den auf die tatsächlichen Einwohner bezogenen Einnahmen der Länder ab. Ebensowenig repräsentiert die Ausgleichsmeßzahl die durchschnittlichen Ländereinnahmen pro Kopf. Daher sind auf dieser dritten Stufe des Ausgleichsverfahrens zwei Problemkreise zu differenzieren, die auf unterschiedliche Weise zur (Über-) Nivellierung beitragen.

(1) Zunächst ist die Eignung der verwendeten Meßzahlen für den Finanzausgleich zu beleuchten. Diskussionsbedürftig erscheinen in diesem Zusammenhang die Hafenlastenregelung, die Einwohnerwertung der Stadtstaaten und die Einbeziehung der Gemeindesteuern einschließlich der besonderen Einwohnerwertung der Gemeinden.

(2) Grundsătzlich unabhängig von den unter (1) genannten Punkten stößt der progressive Umverteilungstarif auf Kritik, weil er zur starken Nivellierung und den damit verbundenen negativen Verhaltensanreizen beiträgt. Gesucht ist daher ein Ausgleichsmechanismus, der einen besseren Kompromiß zwischen Effizienz- und Verteilungszielen ermöglicht.

Der Umverteilungstarif steht zwar im Vordergrund der öffentlichen Diskussion. Die aus ökonomischer Sicht gewichtigeren Probleme des heutigen Systems hăngen aber mit der Bestimmung von Finanzkraft und Finanzbedarf zusammen ${ }^{1}$. Sie bilden daher den Ausgangspunkt der weiteren Überlegungen zum Länderfinanzausgleich im engeren Sinne.

1 Hierin liegt eine Gemeinsamkeit mit der Steuerreformdebatte, in der auch zuviel über den Steuertarif und zuwenig über die Bemessungsgrundlage nachgedacht wird. 


\section{A. Verminderung der Finanzkraftmeßzahl: Die „Hafenlasten“}

Nach § 7 Abs. 3 FAG dürfen die Länder Bremen, Hamburg, MecklenburgVorpommern und Niedersachsen sogenannte Hafenlasten von den im Finanzausgleich zu berücksichtigenden Einnahmen absetzen. Diese Regelung steht im Widerspruch zum ansonsten angewandten Einwohnermaßstab bei der Berechnung der Finanzkraft und stellt insofern ein systemwidriges Element des Finanzausgleichs unter den Ländern dar. Die Hafenlastenregelung führt sofort zu einer grundsătzlichen Frage des (Länder-) Finanzausgleichs: Inwieweit sollen Bedarfsgesichtspunkte einzelner Länder im horizontalen Finanzausgleich berücksichtigt werden?

\section{Grundprobleme der Anrechnung von Sonderbedarfen}

Der Länderfinanzausgleich im engeren Sinne ist "nicht darauf gerichtet, unterschiedliche Bedarfe in den Ländern zu berücksichtigen. Er verfolgt vielmehr ausschließlich oder - soweit wenige Ausnahmen zugelassen werden - ganz primär das Ziel, bestehende Finanzkraftunterschiede unter den Ländern zu verringern"1. Gegen die Einbeziehung von tatsächlichen oder vermeintlichen Sonderlasten einzelner Länder in den horizontalen Finanzausgleich sprechen aus ökonomischer Sicht vor allem zwei Gründe.

(1) Ein Bedarfswettlauf zwischen den Ländern wäre wahrscheinlich, wenn der Gesetzgeber Sonderbedarfe der Länder einbeziehen und damit Anreize schaffen würde, spezielle finanzausgleichsrelevante Belastungen des eigenen Landes nachzuweisen2. Eine Ausweitung der Sondertatbestände hătte wohl auch zur Folge, daß sich deren Ausgleichseffekte tendenziell gegenseitig aufheben würden.

(2) Gegen eine Erfassung von Sonderbedarfen spricht ferner, daß dadurch die Notwendigkeit entfällt, eine (zusätzliche) Bewertung der Wichtigkeit öffentlicher Ausgaben im Hinblick auf den Finanzausgleich vorzunehmen. Dadurch können Streitigkeiten zwischen den einzelnen Bundes-

1 Wissenschaftlicher Beirat beim Bundesministerium der Finanzen, 1992, S. 68.

2 Vgl. Peffekoven, 1987, S. 205. 
ländern vermieden werden, wie sie heute schon zwischen Bund und Ländern bei der Deckungsquotenberechnung zu beobachten sind ${ }^{1}$.

Entscheidet sich der Gesetzgeber im Rahmen seines Beurteilungs- und Gestaltungsspielraumes dennoch dafür, etwaige Sonderbedarfe einzelner Länder anzuerkennen, so kann dies - obwohl dort grundsätzlich fehlplaziert im Länderfinanzausgleich im engeren Sinne auf zwei Wegen geschehen. Zum einen kann den betroffenen Ländern ein Abzugsbetrag von der Finanzkraftmeßzahl gewährt werden; zum anderen besteht die Möglichkeit der Addition des festgelegten Betrages zur Ausgleichsmeßzahl. Die Systematik

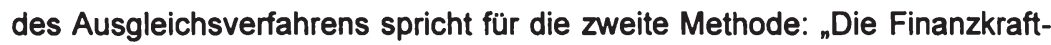
meßzahl spiegelt das absolute Finanzaufkommen der Länder [wider] und legt im Gefüge der Rechenschritte des [Finanzausgleichs-] Gesetzes den Gegenstand des Ausgleichs fest. Dieser erste Rechenschritt sollte von wertenden Entscheidungen, wozu auch die unterschiedlichen Formen der Bedarfsberücksichtigung gehören, freigehalten werden “2. Der Sonderbedarf einzelner Lănder müßte daher - wenn überhaupt - bei der Ermittlung der Ausgleichsmeßzahl erfaßt werden 3 .

\section{Begründung und Kritik der Hafenlastenregelung}

\section{a. Die „Tradition" der Hafenlastenregelung}

Das Bundesverfassungsgericht hat entgegen seiner grundsätzlichen Entscheidung, daß Sonderbedarfe im Rahmen des Länderfinanzausgleichs unberücksichtigt bleiben sollen, für die Hafenlasten ausdrücklich eine Ausnahme zugelassen 4 . Unter Hafenlasten werden im FAG die Kosten der Unterhaltung und Erneuerung der Seehäfen der Länder Bremen, Hamburg, Mecklenburg-Vorpommern und Niedersachsen verstanden.

1 Vgl. Peffekoven, 1987, S. 205; Korioth, 1997, S. 607.

2 Korioth, 1997, S. 601.

3 Vgl. Peffekoven, 1987, S. 204.

4 Vgl. BVerfGE 72, 330, S. 413. Das Verfassungsgericht machte allerdings in einem späteren Urteil auch deutlich, daß der Gesetzgeber nicht dazu verpflichtet ist, die Hafenlasten zu berücksichtigen. Vgl. BVerfGE 86, 148, S. 236. 
Nach § 7 Abs. 3 FAG können die genannten Länder zur Abgeltung der Sonderbelastungen von ihren Einnahmen (nach den Absätzen 1 und 2) folgende Betrăge absetzen: Bremen 90 Mio. DM, Hamburg 142 Mio. DM, Mecklenburg-Vorpommern 50 Mio. DM und Niedersachsen 18 Mio. DM. Statt den Finanzbedarf zu erhőhen, reduzieren die jeweiligen Beträge also die ausgleichsrelevanten Ländereinnahmen und damit die Finanzkraftmeßzahlen der betreffenden Länder. Höhere Ausgleichszuweisungen bzw. niedrigere Ausgleichszahlungen sind die zu erwartende Folge, die allerdings, wie noch zu zeigen sein wird, nicht in jedem Fall eintritt.

Die Höhe der einzelnen Abzugsbetrăge soll sich im übrigen an der relativen Bedeutung der einzelnen Seehäfen orientieren. Ein nachvollziehbarer Maßstab dafür ist allerdings im Gesetz nicht enthalten. Daß die Abzugsbeträge 1987 ohne năhere Begründung angehoben und seither unverändert beibehalten wurden ${ }^{1}$, spricht ebenfalls nicht für eine Vorgehensweise, die Ånderungen in der Bedeutung der Hafenlasten systematisch zu berücksichtigen versucht.

Das Bundesverfassungsgericht hat den offenkundigen Widerspruch in seiner Rechtsprechung damit gerechtfertigt, daß es sich bei den Hafenlasten um einen traditionellen Bestandteil des Finanzausgleichs handele. Zudem bewege sich die Ausnahme im Rahmen des Gestaltungsspielraums des Gesetzgebers $^{2}$. Diese Begründung kann aber nicht überzeugen, läuft sie doch darauf hinaus, eine gesetzliche Regelung trotz ihrer mehr als fragwürdigen ökonomischen Wirkungen nur deshalb nicht abzuschaffen, weil sie schon immer da gewesen ist.

Des weiteren ist mit Blick auf die innere Logik der Hafenlastenregelung zu beanstanden, daß nach dem Finanzausgleichsgesetz die Seehäfen Ham-

1 Auch der Betrag von 50 Mio. DM für den später einbezogenen Hafen Rostock wurde nicht năher begründet.

2 Vgl. BVerfGE 72, 330, S. 413. Die Seehafenlast ist seit 1923 Bestandteil des Finanzausgleichs. Allerdings hat sich die Art der Erfassung im Zeitablauf geăndert. Bis 1945 wurde der Seehafenlast der Länder Hamburg und Bremen durch vertikale Zuweisungen des damaligen deutschen Reiches Rechnung getragen. Erst mit der Finanzverfassung des Grundgesetzes wurde die Seehafenlast ein Bestandteil des horizontalen Finanzausgleichs. Vgl. zur geschichtlichen Entwicklung BVerfGE 72, 330, S. 413 ff.; Schuppert/Dahrendorf, 1985, S. 87 ff.; Peffekoven, 1988, S. 399 ff. 
burgs, Bremens, Niedersachsens und Mecklenburg-Vorpommerns berücksichtigt werden, während das Land Schleswig-Holstein für seine Seehäfen keinen Sonderbedarf geltend machen kann ${ }^{1}$. Sachlich ist dies nicht zu rechtfertigen, auch nicht mit dem Hinweis auf die okonomische Bedeutung der verschiedenen Häfen ${ }^{2}$. Ob eine solche Regelung noch dem föderalen Gleichbehandlungsgebot entspricht, erscheint mehr als fraglich.

\section{b. Positive externe Effekte der Seehäfen}

Aus finanzwissenschaftlicher Sicht wesentlich interessanter als die historische Rechtfertigung ist der Hinweis der Befürworter einer Berücksichtigung der Hafenlasten im Länderfinanzausgleich auf die positiven externen Effekte der Seehäfen für die gesamte Volkswirtschaft. Die Vorhaltung der Seehäfen sei ${ }_{n}$ durch ihre wichtige Bedeutung im Hinblick auf den internationalen Wettbewerb für die gesamte deutsche Wirtschaft und somit auch für die Bundesländer von Nutzen“3. Unterstellt wird dabei, daß die Länder mit Seehäfen Leistungen erbringen, deren Kosten sie allein tragen müssen, die aber auch den Einwohnern der übrigen Bundesländer zugute kommen. Die für eine effizienten Bereitstellung offentlicher Leistungen erforderliche fiskalische Åquivalenz zwischen Nutzern und Steuerzahlern wäre hier nicht erreichbar. Aus allokativen Gründen müsse daher eine Berücksichtigung der Hafenlasten im Länderfinanzausgleich erfolgen. Diese Begründung wird dadurch ergänzt, daß sich die Küstenländer aus topographischen Gründen, den Sonderlasten nicht entziehen könntent4.

Von den beiden genannten Argumenten verdient insbesondere das erste eine genauere Betrachtung. Es ist im folgenden zu klären, ob regionale Spillover-Effekte über den Länderfinanzausgleich effizient internalisiert werden können. Der Hinweis auf die Topographie bringt dagegen keine we-

$1 \mathrm{Zu}$ fragen ist auch, warum Niedersachsen für den Seehafen Wilhelmshaven keinen Sonderbedarf geltend machen kann.

2 Dies unterstreichen die Daten für den Güterumschlag der Seehäfen im Jahre 1997. Lübeck weist einen ebenso hohen Umschlag auf wie Rostock (jeweils 16,8 Mio. t). Die Häfen Kiel (3,6 Mio. t) und Brunsbüttel (7,4 Mio. $t$ ) sind vom Umschlag her wesentlich bedeutender als Emden (2,6 Mio. t). Vgl. Bundesministerium für Verkehr, 1998, S. 81.

3 BVerfGE 72, 330, S. 370.

4 Vgl. Schuppert/Dahrendorf, 1985, S. $89 \mathrm{ff}$. 
sentlichen Zusatzaspekte ins Spiel, sondern verleiht dem Spillover-Argument lediglich ein höheres Gewicht. Können bestimmte öffentliche Leistungen aus topographischen (oder anderen) Gründen nur an wenigen Stellen eines Landes erbracht werden, so steigt im allgemeinen das Ausmaß des externen relativ zum internen Nutzen'1.

Hinsichtlich der răumlichen Spillover-Effekte ist generell zu bemängeln, daß der Länderfinanzausgleich nur die Hafenlasten berücksichtigt, andere staatliche Leistungen, die ebenfalls Spillover-Effekte hervorrufen, jedoch nicht. Diese Vorgehensweise erscheint willkürlich und weist den Seehafenlasten eine Sonderrolle zu, die ökonomisch nicht überzeugend begründet werden kann. Mit ähnlichen Argumenten wie Hamburg und Bremen könnte Hessen beispielsweise einen Sonderbedarf für den Flughafen Frankfurt geltend machen. Nordrhein-Westfalen könnte mit dem Hinweis auf die überregionale Bedeutung des Binnenhafens Duisburg genauso verfahren.

\section{c. Zur Internalisierung der externen Effekte}

Die Internalisierung externer Effekte kann auf verschiedenen Wegen angestrebt werden ${ }^{2}$. Eine erste Möglichkeit besteht in der Bereitstellung von Leistungen, die erhebliche räumliche externe Effekte aufweisen, durch die zentrale Ebene. Die Seehäfen wären also in den Zuständigkeitsbereich des Bundes zu übertragen, was sicher nicht den Intentionen der Hafenländer entspricht. Deutlich wird an dieser Stelle, daß die Bundesländer durch die Reklamation von Sonderbedarfen und deren Rechtfertigung mit überregionalen, bundesweiten Spillover-Effekten ihren Kompetenzanspruch auf die autonome Erbringung solcher Leistungen unterminieren.

Eine Alternative zur Zentralisierung der Aufgabenverantwortung bilden Verhandlungen zwischen den betroffenen Gebietskörperschaften ${ }^{3}$. Dieser Ansatz hat den Nachteil, daß mehrere Beteiligte eine kooperative Lösung suchen müssen. Mit steigender Zahl der Verhandlungsteilnehmer wachsen je-

1 Vgl. Peffekoven, 1988, S. 404.

2 Vgl. z. B. Fischer, 1988, S. $54 \mathrm{ff}$.

3 Vgl. Wissenschaftlicher Beirat beim Bundesministerium der Finanzen, 1992, S. 87 ff. 
doch die Verhandlungskosten und die Neigung zum Trittbrettfahrerverhalten. Obwohl die Nutznießer einen Vorteil von der gemeinsam zu finanzierenden Leistung haben ${ }^{1}$, wollen sie sich um ihren Beitrag drücken - in der Hoffnung, daß andere schon für die Bereitstellung sorgen werden. Insgesamt ist daher kaum mit einer Verhandlungslösung zu rechen, wenn es sich, wie bei den Seehăfen, um Einrichtungen handelt, deren regionale Nutzenstreuung (angeblich) alle Länder, und diese auch noch in unterschiedlichem, nicht năher spezifizierbarem Maße betrifft.

Sofern sich kein Verhandlungsergebnis zwischen den beteiligten Ländern erreichen lăßt und die Höhe der externen Effekte für die einzelnen Länder nicht oder nur zu hohen Kosten ermittelt werden kann, kommen grundsătzlich zweckgebundene Finanzzuweisungen mit Eigenbeteiligung als Instrument der (Teil-) Internalisierung von Spillover-Effekten in Betracht2. Bei der Gestaltung der Zuweisungen und der Eigenbeteiligungsquote sind aus allokativer Sicht bestimmte, nachfolgend angeführte Kriterien zu beachten.

(1) Die optimale Hơhe der Eigenbeteiligung ergibt sich aus dem Verhältnis von internem Nutzen zu Gesamtnutzen. Der interne Nutzen soll aus eigenen Mitteln finanziert werden. In diesem Zusammenhang ist darauf hinzuweisen, daß die Seehäfen keineswegs nur eine Last für die betroffenen Länder darstellen. Den Nachteilen des Hafenbetriebs stehen schließlich die Vorteile der Küstenländer gegenüber, die sich aus der Schaffung von Arbeitsplätzen und dem Beitrag der Seehäfen zum regionalen Inlandsprodukt ergeben ${ }^{3}$. Die Forderung nach einer Kompensation kann sich höchstens auf einen eventuell negativen Saldo der Nutzen und Kosten der Seehäfen erstrecken, nicht auf die gesamten Kosten, die den Ländern durch die Unterhaltung und Erneuerung ihrer Seehäfen entstehen.

1 Andernfalls găbe es keine Spillover-Effekte, die man internalisieren müßte.

2 Mit diesem Instrument kann nur die leistungserbringende Körperschaft dazu veranlaßt werden, ein dem Gesamtnutzen entsprechendes Angebot bereitzustellen. Die Nutzenempfänger werden dagegen nicht direkt in die Entscheidungen über das Angebot und seine Finanzierung einbezogen, Faktisch müßte der Bund die Ausgleichszahlungen festlegen, wenn sich die Lănder nicht auf dem Verhandlungsweg einigen können. Vgl. Korioth, 1997, S. 604. 
(2) Die Hőhe der Zuweisungen sollte beim Empfänger dem Umfang der positiven externen Effekte entsprechen. Umgekehrt wären die Nutznießer der Leistungen in Höhe des empfangenen Nutzens zur Finanzierung der Ausgleichszahlungen heranzuziehen. Nun profitieren aber die einzelnen Bundesländer in sehr unterschiedlicher Höhe von den norddeutschen Seehăfen ${ }^{1}$. Diesem Tatbestand trägt das Finanzausgleichsgesetz jedoch nicht Rechnung. Vielmehr belastet (begünstigt) der Abzug der Hafenlasten die Zahlerländer (Empfängerländer) nach Maßgabe ihrer relativen Finanzkraftpositionen und damit ohne jeden Bezug zu den externen Nutzen.

Die bestehende Hafenlastenregelung entspricht also in keiner Weise den Anforderungen, die an rational gestaltete Maßnahmen zum Ausgleich von Spillover-Effekten zu stellen sind. Dennoch wäre es verfehlt, aufgrund dieses Befundes nach einer besseren Lobsung des Problems innerhalb des Finanzausgleichs zu suchen. So wäre die Berücksichtigung der Hafenlasten im Rahmen der Gemeinschaftsaufgaben nach Art. 91a und 91b GG oder im Rahmen der Finanzhilfen nach Art. 104a Abs. 4 GG zwar besser als das heutige Verfahren², doch würde damit unnötigerweise ein weiterer Fall der ökonomisch meist suboptimalen Mischfinanzierung und Kompetenzvermischung geschaffen. Die Berücksichtigung von Spillover-Effekten im Finanzausgleich ist nämlich gar nicht erforderlich, wenn es andere und vor allem besser geeignete Instrumente der Internalisierung gibt, die von den betroffenen Ländern selbst eingesetzt werden könnten.

An dieser Stelle kommt ein weiterer und aus okonomischer Sicht naheliegender Ansatzpunkt der Internalisierung ins Spiel, die Gebührenerhebung bzw. das Setzen kostendeckender Preise ${ }^{3}$. Ist eine solche (Markt-) Preislösung, die einen speziellen Finanzausgleich überflüssig macht, im Prinzip realisierbar, so müssen alle anderen Varianten aus ökonomischer Sicht als

1 Für die westlichen und südlichen Bundesländer sind die norddeutschen Seehäfen weniger bedeutsam als die niederländischen oder belgischen Häfen. Die Spillover-Effekte der norddeutschen Seehäfen werden durch die wachsende Bedeutung anderer europäischer Häfen erheblich relativiert. Vgl. Normenkontrollantrag des Landes Bayern, S. 85; Normenkontrollantrag des Landes Hessen, Kapitel C.V.1.b.cc.

2 Vgl. Peffekoven, 1988, S. 409 ff.

3 Vgl. Wust, 1981, S. 103. 
Second-best-Lösungen betrachtet werden ${ }^{1}$. Ein zusätzlicher und zudem auf den eventuell verbleibenden Fehlbetrag begrenzter Finanzausgleichsbedarf ergäbe sich bei Anwendung des Marktmodells nur noch, wenn eine kostendeckende Gebührenerhebung aus technischen oder politischen Gründen nicht möglich wäre. Nun sind aber die Seehäfen weder reine öffentliche Güter, bei denen das Ausschlußprinzip versagen würde, noch liegt ein besonderer Grund für Preissubventionen vor. Vielmehr haben es die betroffenen Länder weitgehend selbst in der Hand, die externen Effekte ihrer Häfen zu internalisieren². Die Möglichkeit des kostendeckenden Betriebs der Seehäfen stellt mithin den überzeugendsten okonomischen Grund für eine Nichtberücksichtigung vermeintlicher Hafenlasten im Länderfinanzausgleich dar.

\section{Verteilungseffekte der Hafenlastenregelung}

Die Verteilungswirkungen der ökonomisch unbegündeten Hafenlastenregelung illustriert Tabelle 2. Sie enthält die Gewinne und Verluste, die sich für die einzelnen Bundesländer infolge des $\S 7$ Abs. 3 FAG für das Finanzausgleichsjahr 1998 ergeben haben (relativ zu einem Finanzausgleich ohne Berücksichtigung der Hafenlasten).

Die Berechnungen dokumentieren, daß Bremen mit 86,8 Mio. DM, Hamburg mit rund 132 Mio. DM sowie Mecklenburg-Vorpommern mit 43,6 Mio. DM von der Hafenlastenregelung profitieren. Die Höhe der Entlastungswirkung weicht dabei - entgegen den früheren Berechnungen von Peffekoven und Taube $^{3}$ - nicht erheblich von den Abzugsbeträgen ab, obwohl sie deren

1 Daher führt auch der Versuch einer Quantifizierung der gesamtwirtschaftlichen Nutzen der Seehäfen und ihrer Verteilung nach Bundesländern als Basis für den Länderfinanzausgleich nicht weiter. Vgl. Planco Consulting GmbH, 1998, S. 45 ff. Entscheidend ist nicht die Existenz und die Hobhe der externen Nutzen, sondern ihre adäquate Internalisierung, die mittels kostendeckender Gebühren ohne Kenntnis der regionalen Nutzenverteilung erfolgen kann. Die Marktlösung hat eben auch den erheblichen Vorteil, nicht auf methodisch stets fragwürdige Nutzenschätzungen angewiesen zu sein.

$2 \mathrm{DaB}$ einzelne Hăfen an Konkurrenzfähigkeit verlieren, wenn sie kostendeckende $\mathrm{Ha}$ fengebühren verlangen, ist kein durchschlagender Einwand, denn die Abschaffung der Hafenlastenregel würde alle inländischen Hăfen (nahezu) gleichermaßen betreffen. Sollten ausländische Konkurrenzhäfen subventioniert werden, so wäre dies ein Problem, welches jedenfalls nicht im Länderfinanzausgleich gelöst werden könnte.

3 Vgl. Peffekoven, 1988, S. 401 ff.; Taube, 1990, S. 375 ff. Zu berücksichtigen ist dabei allerdings, daß in beiden Fallen die alte Fassung des Finanzausgleichsgesetzes zugrunde gelegt wurde, die sich von der jetzigen Regelung zum einen im Ausgleichstarif

Wolfgang Scherf - 978-3-631-75181-7 
volle Höhe nicht erreichen (können). Dennoch erhalten die einzelnen Länder keine gleich hohe prozentuale Entlastung bezogen auf ihren jeweiligen Abzugsbetrag. So wird Hamburg in Höhe von 92,9 \% des Abzugsbetrages entlastet, Bremen sogar in Hőhe von 96,4 \%. Dagegen erreicht die Entlastung für Mecklenburg-Vorpommern nur $87,2 \%$ des Abzugsbetrages.

Tabelle 2

Verteilungseffekte der Hafenlastenregelung 1998

\begin{tabular}{|l|rr|rrr|}
\hline \multicolumn{1}{|c}{ Land } & \multicolumn{2}{c}{ GuV } & \multicolumn{2}{c|}{ USt } & \multicolumn{2}{c|}{ LFA } & BEZ \\
\hline NRW & DM / E & Mio. DM & & \\
BAY & $-3,49$ & $-62,8$ & 0,0 & $-62,8$ & 0,0 \\
BW & $-3,81$ & $-45,9$ & 0,0 & $-45,9$ & 0,0 \\
NDS & $-4,78$ & $-49,7$ & 0,0 & $-49,8$ & 0,0 \\
HE & $-1,20$ & $-9,4$ & 0,0 & $-3,8$ & $-5,6$ \\
RP & $-5,65$ & $-34,1$ & 0,0 & $-34,2$ & 0,0 \\
SH & $-3,36$ & $-13,5$ & 0,0 & $-5,4$ & $-8,1$ \\
SAAR & $-0,07$ & $-0,2$ & 0,0 & $-0,1$ & 0,0 \\
HH & $-3,55$ & $-3,8$ & 0,0 & $-3,7$ & $-0,2$ \\
HB & 77,59 & 132,0 & 0,0 & 131,9 & 0,0 \\
SN & 129,40 & 86,8 & 0,0 & 86,9 & $-0,1$ \\
ST & $-3,55$ & $-16,0$ & 0,0 & $-15,3$ & $-0,7$ \\
TH & $-3,55$ & $-9,6$ & 0,0 & $-9,1$ & $-0,4$ \\
BB & $-3,55$ & $-8,8$ & 0,0 & $-8,4$ & $-0,4$ \\
MV & $-3,55$ & $-9,2$ & 0,0 & $-8,8$ & $-0,4$ \\
BER & 24,17 & 43,6 & 0,0 & 43,9 & $-0,3$ \\
West & $-4,79$ & $-16,4$ & 0,0 & $-15,6$ & $-0,7$ \\
Ost & $-0,01$ & $-0,7$ & 0,0 & 13,3 & $-14,0$ \\
Alle & $-0,93$ & $-16,3$ & 0,0 & $-13,3$ & $-3,0$ \\
\hline GuV & $-0,21$ & $-17,0$ & 0,0 & 0,0 & $-17,0$ \\
\hline USt & Erhöhung (+) bzw. Verminderung (-) der Ländereinnahmen gegenüber \\
\hline & einem LFA ohne Berücksichtigung der Hafenlasten & & \\
\hline
\end{tabular}

Für Niedersachsen stellt sich die Situation anders dar. Dieses Land wird durch den $\S 7$ Abs. 3 FAG mit 9,4 Mio. DM belastet. Zwar profitiert Niedersachsen gegenüber einer Situation, in der es keine Seehafenlast geltend machen könnte. Die konkrete Regelung des Finanzausgleichsgesetzes führt jedoch insgesamt dazu, daß Niedersachsen bei Wegfall der Hafenlastenregelung mehr Einnahmen zur Verfügung stehen würden als derzeit. Dieses

und zum anderen durch die fehlende Berücksichtigung Mecklenburg-Vorpommerns unterscheidet. Die grundsätzlichen Ergebnisse können jedoch auf das heutige Finanzausgleichsgesetz übertragen werden. 
Land wird also durch eine Regelung, von der es eigentlich profitieren sollte, benachteiligt. Die Ursache für den offenkundig widersinnigen Verteilungseffekt liegt darin, daß sich die Finanzkraftmeßzahl Niedersachsens bei Nichtanrechnung der Hafenlasten gegenüber Ländern ohne Seehäfen zwar geringfügig erhőhen, gegenüber Ländern mit Seehäfen jedoch deutlich verringern würde. Per saldo ist ein Einnahmenzuwachs die Folge.

Neben den übrigen Seehafenländern profitiert auch der Bund von der $\mathrm{Ha}$ fenlastenregelung, die inm Fehlbetrags-Bundesergänzungszuweisungen in Höhe von 17 Mio. DM erspart. Alle übrigen Länder sind durch die heutige Lösung schlechter gestellit'. Am stärksten betroffen ist Hessen, das 34 Mio. DM bzw. 5,65 DM pro Einwohner verliert.

\section{Beurteilung der Hafenlastenregelung}

Als Ergebnis der ökonomischen Analyse bleibt festzuhalten, daß die derzeitige Hafenlastenregelung des $\S 7$ Abs. 3 FAG nicht dazu geeignet ist, die unterstellten positiven externen Effekte zu internalisieren.

(1) Die Höhe der Zahlungen an die Seehafenländer hăngt allein von der Relation der Finanzkraftmeßzahlen zwischen den Bundesländern ab2. Sie richtet sich nicht nach der Höhe der positiven externen Effekte.

(2) Analog dazu variiert die Höhe der Ausgleichszahlungen der übrigen Länder mit ihrer relativen Finanzkraftposition, aber nicht mit ihren Vorteilen aus den Hafenleistungen ${ }^{3}$.

(3) Ferner bleibt zu beanstanden, daß die Zahlungen im Rahmen des Länderfinanzausgleichs im engeren Sinne und damit ohne die wünschenswerte Zweckbindung sowie Eigenbeteiligung der Hafenländer erfolgen.

(4) Erschwerend kommt hinzu, daß die heutige Regelung noch nicht einmal in sich schlüssig ist. Es fehlt eine nachvollziehbare Begründung für die

1 Für Schleswig-Holstein ist die Hafenlastenregelung im Jahr 1998 annăhernd neutral.

2 Vgl. Peffekoven, 1988, S. 400 f.; Korioth, 1997, S. 601.

3 Paradoxes Ergebnis ist z. B., daß Schleswig-Holstein, das durch seine răumliche Năhe zum Hamburger Hafen mit großer Wahrscheinlichkeit von diesem profitiert, keinerlei Zahlungen zu leisten hat. 
Nichtberücksichtigung Schleswig-Holsteins ebenso wie für die konkrete Höhe der im Gesetz vorgesehenen Abzugsbeträge. Letztere werden auch noch an der falschen Stelle - bei der Finanzkraftmeßzahl statt bei der Ausgleichsmeßzahl - in Anrechnung gebracht.

Am Beispiel der Hafenlasten wird noch einmal deutlich, daß der Länderfinanzausgleich im engeren Sinne ein ungeeigneter Ort für die Internalisierung externer Effekte ist. Dies gilt für alle Sonderbedarfe, denn die Be- und Entlastungswirkungen werden stets von der dafür völlig unmaßgeblichen relativen Finanzkraftposition der Länder bestimmt.

Soweit die Anrechnung der Hafenlasten zu einer Vertauschung der Finanzkraftpositionen der Lănder führt, fallen diese Wirkungen wohl auch unter das (Über-) Nivellierungsverbot. Nimmt man den regelimmanenten Verstoß gegen das Gebot der Gleichbehandlung der Länder hinzu, so spricht alles dafür, den $\S 7$ Abs. 3 FAG abzuschaffen. Dadurch würde eine willkürliche und ineffiziente Regelung beseitigt und die Gerechtigkeit und Transparenz des Finanzausgleichsverfahrens erhöht ${ }^{1}$.

Eine Alternative zur heutigen Regelung wären Verhandlungen über eine geeignete Kompensation zwischen den Ländern. Diese Lösung würde zwar dem föderativen Prinzips entsprechen, dürfte aber in der Praxis wenig Aussicht auf Erfolg haben. Der Ausweg über die Gemeinschaftsaufgaben oder die Finanzhilfen kann mit Blick auf das Autonomieprinzip nicht ohne weiteres empfohlen werden, zumal gerade im vorliegenden Fall mit der kostenorientierten Gebührenerhebung eine bessere Alternative besteht. Sie ermöglicht die selbständige Internalisierung der Spillover-Effekte nach Maßgabe der Inanspruchnahme der Seehäfen und macht damit eine Anrechnung der Hafenlasten im Lănderfinanzausgleich völlig überflüssig. Daß die Küstenländer diese Option bislang nicht ausgeschöpft haben, ist wohl auch eine Folge des Finanzausgleichs, keinesfalls aber ein Grund, an der unsystematischen Heranziehung der übrigen Bundesländer zur Finanzierung der Hafenlasten festzuhalten.

1 Auch das Bundesverfassungsgericht hat sich kritisch zu der bisherigen Regelung geaußßert und andere Lơsungen in Erwägung gezogen. Vgl. BVerfGE 86, 148, S. 238. 


\section{B. Erhöhung der Ausgleichsmeßzahl: Das „Stadtstaatenprivileg“}

Der Länderfinanzausgleich ist, wie bereits erwähnt, als Finanzkraftausgleich konzipiert. Damit korrespondiert die prinzipielle Orientierung des horizontalen Ausgleichs an einem für alle Länder identischen Pro-Kopf-Finanzbedarf. Eine bedeutende Abweichung von diesem Grundsatz betrifft die Stadtstaaten. Deren Einwohner werden nach $\S 9$ Abs. 2 FAG bei der Ermittlung der Ausgleichsmeßzahl mit $135 \%$ gewichtet, um einen überdurchschnittlichen Finanzbedarf im Vergleich zu den Flächenländern auszudrücken. Mit anderen Worten: Nach den Maßstäben des Finanzausgleichsgesetzes verfügt ein Stadtstaat erst dann über eine durchschnittliche Finanzkraft, wenn seine tatsächliche Pro-Kopf-Finanzkraft um $35 \%$ über dem Durchschnitt liegt.

\section{Zur Begründung der Einwohnerwertung der Stadtstaaten}

Durch den Einbezug Berlins hat das "Stadtstaatenprivileg" nach der deutschen Einheit quantitativ erheblich an Bedeutung gewonnen. Die Einwohnerveredelung stellt gegenüber einem am tatsächlichen Einwohner orientierten Finanzausgleich eine massive Vergünstigung dar. Beispielsweise erhielten im Jahr 1998 Hamburg 910 DM, Bremen 1.175 DM und Berlin 1.185 DM pro Einwohner zusätzlich im Vergleich zu einem Finanzausgleich ohne Einwohnerveredelung ${ }^{1}$. Zu prüfen ist, ob und inwieweit eine solche Vergünstigung mit den spezifischen Besonderheiten der Stadtstaaten gerechtfertigt werden kann. In diesem Zusammenhang werden vor allem die folgenden Argumente vorgetragen:

(1) Eine Sondersituation der Stadtstaaten wird darin gesehen, daß sie Großstädte ohne Umland sind. Als Ballungszentren zeichnen sie sich durch eine überdurchschnittliche Wirtschafts- und Steuerkraft aus, die im Finanzausgleich voll zu Buche schlägt. Vergleichbare Großstädte, die in einem Flächenland liegen, hätten demgegenüber den Vorteil eines internen Nivellierungseffektes, denn die im gleichen Flächenland vorhandenen wirtschafts- und steuerschwächeren Regionen reduzieren die durchschnittliche Finanzkraft pro Einwohner. Die Finanzkraft dieser

$1 \mathrm{Vgl}$. zu den Verteilungswirkungen im einzelnen S. $129 \mathrm{ff}$ 
Großstădte würde daher nur teilweise in den Länderfinanzausgleich einbezogen ${ }^{1}$. Infolge des fehlenden Nivellierungseffektes würde die Finanzkraft der Stadtstaaten im Länderfinanzausgleich dagegen überzeichnet?

(2) Mit dem Fehlen eines zum gleichen Bundesland gehörigen Umlandes ist ein zweites Problem verknüpft, das nur die Stadtstaaten betrifft. Im Gegensatz zu anderen Großstädten werden sie nicht in einen kommunalen Finanzausgleich integriert, der den besonderen Belangen der Großstädte Rechnung tragen könnte. Dies geschieht im übrigen häufig dadurch, daß bei den Gemeindeeinnahmen eine Einwohnerwertung erfolgt, die einen mit der Einwohnerzahl progressiv steigenden Finanzbedarf unterstellt (vgl. dazu S. 153 ff.).

(3) Die unter (1) und (2) angeführten Argumente machen die "spezifische Stadtstaatenproblematik“ 3 aus. Sie wird von weiteren Problemen überlagert und teilweise verschärft, die in ähnlicher Form auch bei den Flächenländer auftreten können. So erbringen die Stadtstaaten Leistungen, die auch dem durch Landesgrenzen getrennten Umland zugute kommen 4 . Wiederum fehlt die Möglichkeit einer Berücksichtigung dieser zentralörtlichen Funktionen durch einen kommunalen Finanzausgleich. Besondere Schwierigkeiten ergeben sich schließlich aus der Strukturschwäche von Bremen und Berlin und - auch für Hamburg - aus der Strukturschwäche der die Stadtstaaten umgebenden Flächenländer.

Bezogen auf die skizzierten Besonderheiten der Stadtstaaten stellen sich drei Fragen. Erstens ist zu prüfen, inwieweit die vorgetragenen Argumente einen spezifischen Nachteil der Stadtstaaten begründen. Zweitens muß diskutiert werden, ob ein gegebenenfalls vorhandener spezifischer Nachteil Berücksichtigung im Finanzausgleich verdient. Drittens ist zu klären, ob die

1 Vgl. Kitterer, 1994, S. 21.

2 Vgl. RW, 1999, S. 24.

3 Wissenschaftlicher Beirat beim Bundesministerium der Finanzen, 1992, S. 70.

4 Solche "spillovers" finden auch zwischen den Flächenländern statt, z. B. zwischen Hessen und Rheinland-Pfalz im Rhein-Main-Gebiet. 
Einwohnerwertung das richtige Instrument zur Kompensation eventuell vorhandener und finanzausgleichspolitisch relevanter Nachteile darstellt.

\section{Kritik der Einwohnerwertung der Stadtstaaten}

\section{a. Stadtstaaten als Großstădte ohne Umland}

Der interne Nivellierungseffekt, der in Flächenländern die landesdurchschnittliche Finanzkraft unter das Niveau der Großstădte bzw. Verdichtungsräume drückt, wirkt sich im Länderfinanzausgleich keineswegs als relative Entlastung der Flăchenlănder aus. Die durch den Nivellierungseffekt reduzierte durchschnittliche Steuerkraft bringt zum Ausdruck, daß ein Flächenland eben nicht nur wirtschaftsstarke, sondern auch wirtschaftsschwache Gebiete umfaßt. Kaum nachvollziehbar erscheint es, das Vorhandensein wirtschaftsschwacher Gebiete als Vorteil eines Flächenlandes zu interpretieren ${ }^{1}$. Für die Flächenlănder ergeben sich daraus zunăchst einmal zusätzliche Aufgaben. Sie müssen im Rahmen ihrer Wirtschaftspolitik den Belangen der unterschiedlich entwickelten und strukturierten Regionen des Landes Rechnung tragen und einen fairen (Finanz-) Ausgleich herbeiführen. Mit diesen Anforderungen werden die Stadtstaaten, die - bezogen auf den ungewichteten Einwohner - über eine höhere Wirtschafts- und Steuerkraft verfügen, nicht konfrontiert, was per saldo eher einen Vorteil als ein spezifisches Problem darstellt.

Nicht zutreffend ist auch die These, infolge des Nivellierungseffektes würde die Finanzkraft der Großstădte in den Flächenlăndern nur teilweise in den Lănderfinanzausgleich einbezogen, die Finanzkraft der Stadtstaaten dagegen überzeichnet. Vielmehr werden im Rahmen des Finanzausgleichsgesetzes alle Steuereinnahmen gleichermaßen in die Finanzkraft eingerechnet. So reflektiert der Durchschnittswert eines Flächenlandes in vollem Umfang die überdurchschnittliche Finanzkraft seiner Großstädte, ebenso und völlig zu Recht aber auch die unterdurchschnittliche Finanzkraft der übrigen

1 Analog dazu und mit gleichermaßen zweifelhafter Berechtigung könnte man behaupten, Hessen sei im Lănderfinanzausgleich benachteiligt, weil das Land - etwa im Vergleich zum angrenzenden Rheinland-Pfalz - nicht genügend finanzschwache Regionen umfasse, welche den Durchschnittswert der Finanzkraft senken würden. 
Gebiete des Landes. Insgesamt bleibt daher festzuhalten, daß der fehlende interne Nivellierungseffekt keinen stadtstaatenspezifischen Nachteil begründet, der für den Länderfinanzausgleich relevant sein könnte.

\section{b. Fehlender kommunaler Finanzausgleich}

Auch der fehlende kommunale Finanzausgleich kann nicht ohne weiteres als Nachteil der Stadtstaaten interpretiert werden. Zwar haben die Stadtstaaten Landes- und Gemeindeaufgaben zu erfüllen, doch erhalten sie dafür die gesamten Einnahmen aus den Kommunalsteuern, sind also in keiner Weise schlechter gestellt als andere Großstädte ${ }^{1}$. Ob die verbleibenden Unterschiede auf eine Benachteiligung oder Begünstigung der Stadtstaaten hinauslaufen, ist eine offene Frage. Der relevante Vergleich muß hier auf den Nettoeffekt einer (fiktiven) Einbeziehung in den kommunalen Finanzausgleich der angrenzenden Flächenländer abstellen.

Als Großstadt innerhalb eines Flächenlandes würde der Stadtstaat zwar Finanzzuweisungen vom Land erhalten, müßte aber auch auf die Einnahmen aus den Landessteuern verzichten, aus denen die Finanzzuweisungen gespeist werden. Nun kommt aber die Aufstockung der kommunalen Finanzkraft durch Finanzzuweisungen des Landes über die Schlüsselzuweisungen insbesondere den wirtschafts- und finanzschwachen Gemeinden zugute. Der zu erwartende Nettoeffekt für einen Stadtstaat mit überdurchschnittlicher kommunaler Steuerkraft ist daher tendenziell negativ; es sei denn, der kommunale Finanzausgleich honoriert zentralörtliche Funktionen in besonderem Maße und / oder operiert mit einer ausgeprägten Einwohnerwertung.

Da die Stadtstaaten vom Fehlen eines kommunalen Finanzausgleichs nicht systematisch benachteiligt werden, unter Umstănden sogar davon profitieren, liegt eine spezifische Stadtstaatenproblematik, die finanzausgleichspolitisch bedeutsam wäre, nicht vor. Was bleibt, ist der Hinweis auf die insbesondere für das direkte Umland positiven externen Effekte der Stadtstaaten.

1 Vgl. Homburg, 1996, S. 338. 


\section{c. Einwohnerwertung zum Ausgleich externer Effekte}

Hinsichtlich der Spillover-Effekte muß zunächst einmal darauf hingewiesen werden, daß den Leistungen der Stadtstaaten für das Umland entgegengerichtete externe Effekte aufgrund der Leistungen der Umlandregionen für die Bewohner der Stadtstaaten gegenüberstehen. Nicht zuletzt profitieren die Oberzentren vom Umland in Form höherer Einnahmen aus der Gewerbe-, Einkommen- und Körperschaftsteuer. Diese Vorteile müssen bei der Ermittlung der Netto-Spillovers berücksichtigt werden. Per saldo dürften die zentralörtlichen Funktionen der Stadtstaaten jedoch überwiegen.

Da ein landesinterner Ausgleich nicht möglich ist, stellt sich die Frage, ob das Stadt-Umland-Problem im Länderfinanzausgleich adäquat berücksichtigt werden kann. Dagegen spricht zunächst einmal, daß die (Netto-) Leistungen für das Umland nur die angrenzenden Flächenstaaten und nicht alle Bundesländer betreffen. Infolgedessen erscheint es zwar naheliegend, die angrenzenden Flächenländer an der Finanzierung der innen zugute kommenden Leistungen der Stadtstaaten zu beteiligen, nicht aber die gesamte Solidargemeinschaft der Länder.

Die Einwohnergewichtung, die alle Flächenländer belastet, scheidet daher als Instrument aus. Sie ist völlig ungeeignet, einen halbwegs plausiblen Zusammenhang zwischen den externen (Netto-) Nutzen der Stadtstaaten und der finanziellen Belastung der davon Begünstigten herzustellen. Infolge der fehlenden Identităt von Nutzern und Kostenträgern verstößt die Einwohnergewichtung gegen eine wesentliche Bedingung für allokative Effizienz.

In diesem Zusammenhang muß auch darauf hingewiesen werden, daß eine einheitliche Einwohnergewichtung der Stadtstaaten - vor allem nach der Integration von Berlin - kaum plausibel ist. Die Größe der Stadtstaaten variiert erheblich, und damit dürften auch entsprechende Unterschiede in der Bedeutung für das Umland einhergehen. Wollte man an der Einwohnergewichtung festhalten, so wäre jedenfalls anhand geeigneter Indikatoren zu prüfen, ob eine einheitliche Lơsung für alle Stadtstaaten noch vertretbar er- 
scheint ${ }^{1}$. Dieser Gesichtspunkt wird hier jedoch nicht weiter verfolgt, da die Einwohnergewichtung ohnehin kein taugliches Mittel zur Internalisierung regionaler Spillover-Effekte darstellt.

Die Sicht der Stadtstaatenfrage als Stadt-Umland-Problem greift allerdings nach Auffassung des RWI zu kurz². Eine solche Betrachtung ließe die überregionale Bedeutung der Stadtstaaten insbesondere für das nationale Wirtschaftswachstum außer Acht. Damit wird das Argument der externen Effekte ausgeweitet auf bundesweite Spillovers, die das Stadtstaatenproblem wieder von der bilateralen auf die nationale Ebene heben.

Solche auch nach Auffassung des RWI kaum quantifizierbaren gesamtwirtschaftlichen Impulse gehen aber nicht nur von den Stadtstaaten aus, sondern auch von anderen Verdichtungsräumen, die zu den Wachstumspolen einer Volkswirtschaft rechnen ${ }^{3}$. Eine bevorzugte Behandlung der Stadtstaaten - etwa gegenüber dem Rhein-Main-Gebiet - läßt sich mit diesem

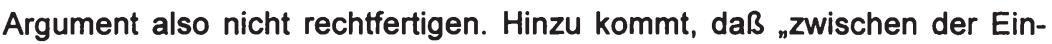
wohnerzahl und der ökonomisch-funktionalen Stellung der Stadtstaaten kein enger Zusammenhang besteht" ${ }^{4}$.

Auch aus methodischer Sicht ist die RWI-Studie angreifbar. Als Indikator der überregionalen sozioökonomischen Verflechtung der Stadtstaaten, aus der eine gemeinsame Verantwortung von Bund und Ländern für eine angemessene Finanzausstattung abgeleitet wird, dient im wesentlichen der ${ }_{\text {}}$ Funktionsüberschuß“ im Dienstleitsungsbereich. Gemessen wird dabei die Mehrbeschäftigung gegenüber einer ausschließlichen Versorgung der ortsansässigen Bevölkerung. Nach einer vom RWI verwendeten Studie von Ek-

1 Anhand eines (methodisch umstrittenen) Vergleichs mit westdeutschen Großstädten hatte das Ifo-Institut 1987 in einem Gutachten die bestehende Einwohnerwertung der Stadtstaaten Bremen und Hamburg gerechtfertigt. Vgl. Hummel/Leibfritz, 1987 a, S. 7 ff. Schon damals lagen die für Bremen und Hamburg getrennt ermittelten Indikatoren auseinander, wenn auch nur um 2 Punkte. Auf die heutigen Verhältnisse - nach der auch quantitativ bedeutenden Einbeziehung des Landes Berlin - dürften sich die Ergebnisse des Ifo-Instituts jedoch nicht mehr übertragen lassen.

2 Vgl. RW, 1999, S. $27 \mathrm{ff}$.

3 Ein besonderer Beitrag Hamburgs für das Wachstums anderer Länder läßt sich auch empirisch nicht nachweisen. Vgl. Münzenmaier, 1999, S. $16 \mathrm{ff}$.

4 RWI, 1999, S. 38. 
key/Klemmer ${ }^{1}$ lag der Funktionsüberschuß im Jahr 1985 für Hamburg bei etwa 250.000 Beschäftigten im Dienstleistungssektor. Die gleiche Studie weist allerdings für Frankfurt am Main mit rund 210.000 Beschäftigten einen annähernd genauso großen Funktionsüberschuß aus, obwohl die Stadt Frankfurt deutlich weniger als die Hälfte der Einwohnerzahl Hamburgs hat.

Eine Aktualisierung der Berechnungen von Eckey/Klemmer (vgl. Tabelle 3) zeigt, daß der Funktionsüberschuß im gesamten Dienstleistungssektor (einschließlich Handel und Verkehr) mittlerweile in Frankfurt schon absolut gröBer ist als in Hamburg. Normiert mit der Einwohnerzahl übersteigt er das Hamburger Niveau sogar um das 2,7-fache. Von daher bestätigt sich die oben vorgetragene Argumentation, daß sich die Stadtstaaten hinsichtlich ihrer überregionalen Bedeutung nicht grundsätzlich von anderen Großstädten unterscheiden.

\section{Tabelle 3}

Funktionsüberschüsse im Dienstleistungsbereich 1997

\begin{tabular}{|c|c|c|c|c|}
\hline & Frankfurt & Hamburg & Hessen & Nord-Region ${ }^{3}$ \\
\hline Funktionsüberschuß ${ }^{1}$ & 229.700 & 221.900 & 160.800 & 109.600 \\
\hline $\begin{array}{l}\text { Normierter Funktions- } \\
\text { überschuß }{ }^{2}\end{array}$ & 355,2 & 130,0 & 26,7 & 8,5 \\
\hline \multicolumn{5}{|c|}{$\begin{array}{l}1 \text { Mehrbeschäftigung gegenüber einer ausschließlichen Versorgung der ortsansässigen Bevölkerung. } \\
2 \text { Funktionsüberschuß pro Einwohner x } 1.000 . \\
3 \text { Hamburg, Bremen, Niedersachsen, Schleswig-Holstein. } \\
\text { Quelle: Statistisches Bundesamt. Berechnungen des Hessischen Ministeriums der Finanzen. }\end{array}$} \\
\hline
\end{tabular}

Auch wenn alle Großstädte typischerweise einen Funktionsüberschuß im Dienstleistungsbereich aufweisen, ist im übrigen noch nicht gesagt, daß ihre privat- und finanzwirtschaftlichen Aktivitäten auf ganz Deutschland und darüber hinaus ausstrahlen ${ }^{2}$. Berechnet man nämlich für Frankfurt und Hamburg die Funktionsüberschüsse der Umlandregionen (Hessen und die NordRegion: Hamburg, Bremen, Niedersachsen, Schleswig-Holstein), so zeigt sich, daß die Funktionsüberschüsse der Großstädte in ganz erheblichem

1 Vgl. Eckey/Klemmer, 1988, S. 37.

2 Vgl. RW, 1999, S. 29. 
Maße durch hohe Funktionsdefizite der Umlandregionen kompensiert werden. Interessanterweise spiegelt sich die Relation der normierten Funktionsüberschüsse zwischen Frankfurt und Hamburg $(2,7)$ im Vergleich der Regionen. Der normierte Funktionsüberschuß im gesamten Dienstleistungssektor liegt mit 26,7 Beschäftigten für Hessen bei etwa dem 2,8-fachen Wert der gesamten Nord-Region, die mit 8,5 Beschäftigten einen nur noch geringfügigen Funktionsüberschuß aufweist.

Aus diesen Berechnungen 1 läßt sich nun keineswegs eine herausragende überregionale bzw. gesamtwirtschaftliche Bedeutung Hamburgs ableiten, die eine gesonderte Behandlung im Länderfinanzausgleich ökonomisch rechtfertigen würde. Im Gegenteil, die Argumentation des RWI würde eher die Forderung nach einer Berücksichtigung der Spillover-Effekte des Banken- und Dienstleistungszentrums Frankfurt und des Landes Hessen im Finanzausgleich stützen2 ${ }^{2}$. Damit sprechen auch die empirischen Daten gegen die Einwohnerwertung der Stadtstaaten als Instrument der Internalisierung positiver externer Effekte.

Schließlich ist darauf hinzuweisen, daß eine Berücksichtigung von Wachstumszielen im horizontalen Finanzausgleich, wie sie das RWI unter dem Gesichtspunkt der "dynamischen Effizienz" befürwortet, in zweierlei Hinsicht problematisch erscheint ${ }^{3}$. Zum einen ist der Länderfinanzausgleich kein sonderlich geeignetes Mittel der direkten Wachstumsförderung. Sie müßte wenn überhaupt - über vertikale Ausgleichsinstrumente (Gemeinschaftsaufgaben, Finanzhilfen, regional orientierter Einsatz von Bundesmitteln) betrieben werden. Zum anderen würde der Länderfinanzausgleich vor allem durch eine Reduktion der Nivellierungsintensität an dynamischer Effizienz gewinnen. Den Vorteil hätten alle Länder, nicht nur die Stadtstaaten, deren Einwohnerwertung die Flächenländer belastet und im Wachstum hemmt.

1 Auf die grundsätzliche Problematik des Indikators ${ }_{n}$ Funktionsüberschuß“ muß an dieser Stelle nicht näher eingegangen werden, da sich die daran anknüpfenden Schlußfolgerungen bereits als irreführend erwiesen haben. Es sei jedoch darauf hingewiesen, daß Funktionsüberschüsse nur dann eine besondere Belastung der Großstädte hervorrufen können, wenn sie mit einem überdurchschnittlichen Infrastrukturaufwand einhergehen, dem keine entsprechenden Steuermehreinnahmen gegenüberstehen.

2 Zu dieser Schlußfolgerung gelangt auch Münzenmaier, 1999, S. 16.

3 Vgl. Peffekoven, 1999, S. 13. 


\section{Verteilungswirkungen der Einwohnerwertung}

Die Verteilungswirkungen der Einwohnerwertung der Stadtstaaten werden in der Tabelle 4 dargestellt. Sie zeigt für das Jahr 1998 die Gewinne und Verluste der einzelnen Bundesländer, die sich aus dem § 9 Abs. 2 FAG im Vergleich zu einem Länderfinanzausgleich ohne Stadtstaatenprivileg ergeben. Alle Stadtstaaten profitieren in erheblichem Maße von dieser Vergünstigung. Die DM-pro-Einwohner-Gewinne liegen zwischen 910 DM für Hamburg und 1.185 DM für Berlin. Absolut gesehen beansprucht allein Berlin mit 4.051 Mio. DM mehr als 2/3 der gesamten Gewinne der Stadtstaaten, was noch einmal den drastischen Anstieg der quantitativen Bedeutung dieser Regelung infolge der deutschen Einheit unterstreicht.

\section{Tabelle 4}

Verteilungseffekte der Einwohnerwertung der Stadtstaaten 1998

\begin{tabular}{|l|rr|rrr|}
\hline \multicolumn{1}{|c}{ Land } & \multicolumn{2}{c}{ GuV } & \multicolumn{2}{c|}{ USt } & \multicolumn{1}{c|}{ LFA } \\
\hline & DM /E & Mio. DM & \multicolumn{3}{c|}{ Mio. DM } \\
NRW & $-75,94$ & $-1.364,5$ & 0,0 & $-1.369,8$ & 0,0 \\
BAY & $-82,97$ & $-1.001,2$ & 0,0 & $-1.005,4$ & 0,0 \\
BW & $-99,96$ & $-1.040,4$ & 0,0 & $-1.045,5$ & 0,0 \\
NDS & $-86,33$ & $-677,8$ & 0,0 & $-392,9$ & $-285,7$ \\
HE & $-130,73$ & $-788,6$ & 0,0 & $-793,1$ & 0,0 \\
RP & $-86,28$ & $-346,7$ & 0,0 & $-198,9$ & $-148,1$ \\
SH & $-74,99$ & $-207,0$ & 0,0 & $-82,8$ & $-124,0$ \\
SAAR & $-89,61$ & $-96,5$ & 0,0 & $-92,6$ & $-4,4$ \\
HH & 910,16 & $1.548,0$ & 0,0 & $1.562,0$ & 0,0 \\
HB & $1.175,48$ & 788,4 & 0,0 & 759,1 & 36,0 \\
SN & $-90,01$ & $-405,7$ & 0,0 & $-387,4$ & $-18,3$ \\
ST & $-90,01$ & $-242,2$ & 0,0 & $-231,2$ & $-11,0$ \\
TH & $-90,01$ & $-222,4$ & 0,0 & $-212,3$ & $-10,1$ \\
BB & $-90,01$ & $-232,3$ & 0,0 & $-221,8$ & $-10,5$ \\
MV & $-90,01$ & $-162,3$ & 0,0 & $-155,0$ & $-7,3$ \\
BER & $1.185,44$ & $4.051,0$ & 0,0 & $3.867,7$ & 183,2 \\
West & $-49,36$ & $-3.186,3$ & 0,0 & $-2.660,1$ & $-526,2$ \\
Ost & 159,48 & $2.786,1$ & 0,0 & $2.660,1$ & 126,0 \\
Alle & $-4,88$ & $-400,2$ & 0,0 & 0,0 & $-400,2$ \\
\hline GuV & Erhohung (+) bzW. Verminderung (-) der Ländereinnahmen gegenüber \\
USt & einem LFA ohne Einwohnerwertung der Stadtstaaten & \\
\hline
\end{tabular}

Alle übrigen Bundesländer rechnen zu den Verlierern. Relativ am stärksten betroffen ist Hessen mit $131 \mathrm{DM}$ pro Einwohner. Insgesamt entgehen der 
Landeskasse allein durch die pauschale Einwohnerveredelung der Stadtstaaten rund 780 Mio. DM. Bei den finanzschwachen Bundesländern fällt auf, daß sie nicht nur im Rahmen des horizontalen Länderfinanzausgleichs i.e.S., sondern auch bei den (Fehlbetrags-) Bundesergänzungszuweisungen Mittel verlieren, weil die Einwohnerwertung die durchschnittliche Länderfinanzkraft und damit die Orientierungsgröße der Ausgleichsmaßnahmen reduziert. Umgekehrt erhalten Berlin und Bremen zusätzliche Bundesergänzungszuweisungen 1 .

Per saldo profitiert auch der Bund von der Einwohnerwertung der Stadtstaaten. Das Gesamtvolumen der Fehlbetrags-Bundesergänzungszuweisungen liegt um immerhin $\mathbf{4 0 0}$ Mio. DM unter dem Wert, der sich bei einem Finanzausgleich ohne Stadtstaatenprivileg ergeben würde 2 . Wenn man bedenkt, daß die primäre Begründung der Regelung in den Leistungen der Stadtstaaten für das Umland gesehen werden muß, kann ein solcher Verteilungseffekt kaum gerechtfertigt werden. Genauso wenig ist einzusehen, weshalb die weit entfernten Flächenländer Baden-Württemberg, Bayern, Hessen und Nordrhein-Westfalen mit insgesamt 4.194 Mio. DM den Löwenanteil der Kosten einer Internalisierung von Spillover-Effekten zu tragen haben, die innen praktisch nicht zugute kommen.

\section{Alternativen zur Einwohnerwertung der Stadtstaaten}

Als Ergebnis der bisherigen Überlegungen bleibt festzuhalten, daß die besondere Einwohnerwertung der Stadtstaaten im Länderfinanzausgleich nicht überzeugend begründet werden kann. Den zentralörtlichen Funktionen der Stadtstaaten muß mit Hilfe anderer Instrumente des Finanzausgleichs Rechnung getragen werden. Dabei ist von vornherein zu berücksichtigen, daß die Instrumente auch bei vergleichbaren Problemen der Flächenstaaten greifen müssen. Als Alternative zur Einwohnergewichtung kommt aus dieser Perspektive insbesondere eine modifizierte Steuerzerlegung in Betracht.

1 Die nicht eigens ausgewiesenen Veränderungen der Länderbeitrăge zum Fonds „Deutsche Einheit" fallen demgegenüber nicht ins Gewicht.

2 Bei einem Wegfall der Einwohnerwertung müßte entweder der Länderanteil an der Umsatzsteuer oder die Ausgleichsquote bei den Fehlbetrags-Bundesergänzungszuweisungen reduziert werden, um eine zusătzliche Belastung des Bundes zu vermeiden.

Wolfgang Scherf - 978-3-631-75181-7 


\section{a. Änderung der Lohnsteuerzerlegung1}

Die horizontale Verteilung der Landessteuern und des Länderanteils an der Einkommen- und Körperschaftsteuer erfolgt grundsătzlich nach dem örtlichen Aufkommen. Dieser Begriff ${ }_{\text {}}$ knüpft an der Vereinnahmung der Steuern durch die jeweils zuständigen Finanzbehörden an und lenkt etwas von der Tatsache ab, daß im Grunde entschieden werden muß, ob das Wohnsitzprinzip oder das Betriebsstättenprinzip (Quellenprinzip) oder eine Kombination dieser Prinzipien angewendet werden soll"2 2 . Bei der Einkommensteuer wird derzeit überwiegend das Wohnsitzprinzip, bei der Körperschaftsteuer das Betriebsstăttenprinzip angewandt. Da die Einkommensteuer mit der Lohnsteuer den quantitativ bedeutendsten Teil umfaßt, dominiert im heutigen System die Zerlegung nach dem Wohnsitz der Einkommensempfänger und orientiert sich damit an der Einkommensverteilung.

Diese Regel kann als Benachteiligung der Länder mit hohem (Netto-) Einpendleranteil angesehen werden ${ }^{3}$. Davon sind nicht nur die Stadtstaaten betroffen, sondern auch die Flächenländer mit ihren länderübergreifenden Pendlerverflechtungen. Abhilfe schaffen könnte eine stärkere Orientierung der Steuerzerlegung an der Einkommensentstehung. Dies erscheint schon deshalb angezeigt, weil die Bundesländer Leistungen erbringen, die sowohl der Wohnbevölkerung als auch den Unternehmen zugute kommen. Die Bereitstellung einer adäquaten Wirtschafts- und Verkehrsinfrastruktur setzt aber voraus, daß die Verteilung der Finanzierungsgrundlagen nicht einseitig haushaltsbezogen erfolgt. Inwiefern eine stärkere Gewichtung der Betriebsstätten eine Umverteilung zugunsten der Stadtstaaten herbeiführen kann, die dem Wegfall der Einwohnergewichtung entgegenwirken würde, bedarf der empirischen Überprüfung.

1 Diese Alternative wird auch vom RWI in Erwägung gezogen. Das Institut bezeichnet eine stärker wirtschaftsbezogene Steuerzerlegung zwar als allokativ wünschenswert, hălt sie aber - mit Blick auf die strukturellen Besonderheiten der Stadtstaaten - nicht für ein geeignetes Substitut der Einwohnerwertung. Vgl. RWI, 1999, S. 41 ff. Da eine spezifische Stadtstaatenproblematik, wie oben gezeigt, nicht überzeugend begründet werden kann, ist diese Bewertung des RW jedoch nicht aufrechtzuerhalten.

2 Wissenschaftlicher Beirat beim Bundesministerium der Finanzen, 1992, S. 58.

3 Vgl. Kitterer, 1994, S. 7 ff.; RWI, 1999, S. 41; Wissenschaftlicher Beirat beim Bundesministerium der Finanzen, 1992, S. 72. 
Eine Abschătzung der finanziellen Konsequenzen des Vorschlags, bei der Lohnsteuerzerlegung auch das Betriebsstättenland zu berücksichtigen, wird dadurch erschwert, daß aus den Steuerstatistiken nicht hervorgeht, inwieweit die heutige Lohnsteuerzerlegung auf die zentrale Lohnsteuerabführung einerseits und das Auseinanderfallen von Betriebsstătten- und Wohnsitzland (Pendler) andererseits zurückzuführen ist ${ }^{1}$. Daher muß zur Ermittlung des Pendlereinflusses auf andere statistische Quellen und Plausibilitătsüberlegungen zurückgegriffen werden.

Im folgenden wird davon ausgegangen, daß (1) die Steuerzerlegung je zur Hälfte nach dem Wohnsitz- und nach dem Betriebsstättenprinzip erfolgt. (2) Die Pendlerverflechtungen werden auf der Basis der Angaben des Statistischen Bundesamts über die Struktur der sozialversicherungspflichtig Beschäftigten ${ }^{2}$ auf die Gesamtzahl der abhängig Beschäftigten ${ }^{3}$ hochgerechnet. (3) Unter der Annahme einer durchschnittlichen Lohnsteuerbelastung der Pendler in jedem Bundesland4 erhält man die infolge des Auseinanderfallens von Betriebsstätten- und Wohnsitzland zerlegte Lohnsteuer.

Unter den genannten Voraussetzungen entfällt gut die Hälfte des gesamten Zerlegungsvolumens (5,8 Mrd. von 10,9 Mrd. DM) auf grenzüberschreitende Pendlerbewegungen 5 . Die Tabelle 5 zeigt, daß Hamburg mit über 1,8 Mrd. DM und Hessen mit 933 Mio. DM die betragsmäßig größten pendlerbedingten Zerlegungssalden aller Zahlerlănder aufweisen. In DM je Einwohner gerechnet sind aber die Stadtstaaten erwartungsgemäß am stärksten betroffen, insbesondere Hamburg und Bremen mit über 1.000 DM je Einwoh-

1 Bei der zentralen Lohnsteuerabführung wird am Hauptsitz großer Unternehmens auch die Lohnsteuer für Arbeitnehmer in Betriebsstätten in anderen Bundesländern abgeführt, was eine Zerlegung bei Anwendung des Wohnsitzprinzips unumgänglich macht. Die Lohnsteuerkarten enthalten aber neben dem Finanzamt nur den Wohnort, nicht den Betriebsstättenort der Beschäftigten.

2 Vgl. Statistisches Bundesamt, Fachserie 1, Reihe 4.2.1.

3 Vgl. Statistisches Bundesamt, Fachserie 1, Reihe 4.1.1.

4 Diese Prämisse impliziert tendenziell eine Unterschätzung der Konsequenzen einer pendlerorientierten Lohnsteuerzerlegung für die finanzstarken Bundesländer (auch für Hamburg), deren Lohnsteueraufkommen pro Kopf überdurchschnittlich hoch ist.

5 Das verbleibende Zerlegungsvolumen von 5,1 Mrd. DM ist auf die zentrale Lohnsteuerabführung zurückzuführen. 
ner ${ }^{1}$. Hessen ist mit rund $155 \mathrm{DM}$ je Einwohner das am stärksten belastete Flächenland. Mit Zuflüssen zwischen 290 bis 320 DM je Einwohner profitieren die Länder Schleswig-Holstein, Brandenburg und Rheinland-Pfalz am stärksten von der jetzigen Zerlegungsregelung. Auch Niedersachsen und die übrigen neuen Länder gehören zu den Gewinnern.

\section{Tabelle 5}

\section{Lohnsteuerzerlegung zu 50 \% nach dem Betriebsstättenprinzip 1998}

\begin{tabular}{|c|c|c|c|c|c|}
\hline \multirow[t]{2}{*}{ Land } & \multicolumn{2}{|c|}{ Zerlegungssaldo ${ }^{1}$} & \multicolumn{3}{|c|}{ Gewinn und Verlust ${ }^{2}$} \\
\hline & $\mathrm{DM} / \mathrm{E}$ & Mio. DM & $\begin{array}{c}\text { Land } \\
(42,5 \%)\end{array}$ & $\begin{array}{c}\text { Gemeinden } \\
(15 \%)\end{array}$ & $\begin{array}{c}\text { insgesamt } \\
(100 \%)\end{array}$ \\
\hline HB & $-1113,0$ & $-746,4$ & 158,6 & 56,0 & 373,2 \\
\hline $\mathrm{HH}$ & $-1080,1$ & $-1837,1$ & 390,4 & 137,8 & 918,5 \\
\hline BER & $-172,9$ & $-600,1$ & 127,5 & 45,0 & 300,0 \\
\hline $\mathrm{HE}$ & $-154,7$ & $-933,2$ & 198,3 & 70,0 & 466,6 \\
\hline BW & $-78,6$ & $-818,1$ & 173,8 & 61,4 & 409,0 \\
\hline SAAR & $-42,9$ & $-46,2$ & 9,8 & 3,5 & 23,1 \\
\hline NRW & $-36,9$ & $-662,3$ & 140,7 & 49,7 & 331,2 \\
\hline BAY & $-12,5$ & $-151,0$ & 32,1 & 11,3 & 75,5 \\
\hline SN & 53,3 & 243,6 & $-51,8$ & $-18,3$ & $-121,8$ \\
\hline NDS & 169,1 & 1327,4 & $-282,1$ & $-99,6$ & $-663,7$ \\
\hline ST & 174,6 & 478,1 & $-101,6$ & $-35,9$ & $-239,0$ \\
\hline MV & 182,8 & 333,2 & $-70,8$ & $-25,0$ & $-166,6$ \\
\hline TH & 243,4 & 609,4 & $-129,5$ & $-45,7$ & $-304,7$ \\
\hline $\mathrm{RP}$ & 291,6 & 1171,8 & $-249,0$ & $-87,9$ & $-585,9$ \\
\hline BB & 295,8 & 752,1 & $-159,8$ & $-56,4$ & $-376,0$ \\
\hline SH & 318,3 & 878,7 & $-186,7$ & $-65,9$ & $-439,4$ \\
\hline \multicolumn{6}{|c|}{$\begin{array}{l}1 \text { Pendlerbedingte Erhöhung ( }+ \text { bzw. Verminderung }(-) \text { des Lohnsteueraufkommens. } \\
2 \text { Erhöhung (+) bzw. Verminderung }(-) \text { des Lohnsteueraufkommens bei einer Lohnsteuerzerlegung } \\
\text { zu } 50 \% \text { nach dem Betriebsstăttenprinzip. } \\
\text { Quelle: Berechnungen des Hessischen Ministeriums der Finanzen. }\end{array}$} \\
\hline
\end{tabular}

Eine Lohnsteuerzerlegung zu 50 \% nach dem Betriebsstättenprinzip würde gegenüber der heutigen Regelung allen Stadtstaaten, aber auch generell den finanzstarken Länder sowie dem Saarland zugute kommen. Diese Länder könnten mit einem höheren Lohnsteueraufkommen rechnen. Dabei dürfte die Schätzung die untere Grenze der finanziellen Auswirkungen markieren. Allerdings hăngen die Nettoeffekte einer modifizierten Lohnsteuer-

1 Der Zerlegungsgewinn einer fiktiven Nord-Region (HH, HB, NDS, SH) lăge nur bei 80,2 Mio. DM. Auch dieser Befund spricht gegen die Annahme globaler Spillover-Effekte. 
zerlegung vom gesamten System des Länderfinanzausgleichs ab. Tabelle 6 illustriert die Auswirkungen des heutigen Systems.

\section{Tabelle 6}

\section{Verteilungseffekte einer Lohnsteuerzerlegung zu $50 \%$ nach dem Betriebsstättenprinzip 1998}

\begin{tabular}{|c|c|c|c|c|c|}
\hline Land & $\begin{array}{l}\text { Länder } \\
\text { vor LFA }\end{array}$ & $\begin{array}{l}\text { Länderfinanz- } \\
\text { ausgleich }{ }^{1}\end{array}$ & $\begin{array}{l}\text { Länder } \\
\text { nach LFA }\end{array}$ & Gemeinden & $\begin{array}{l}\text { Länder und } \\
\text { Gemeinden }\end{array}$ \\
\hline & \multicolumn{5}{|c|}{ Mio. DM } \\
\hline $\mathrm{HH}$ & 390,4 & $-335,6$ & 54,8 & 137,8 & 192,6 \\
\hline HE & 198,3 & $-119,1$ & 79,2 & 70,0 & 149,2 \\
\hline BW & 173,8 & $-101,7$ & 72,2 & 61,4 & 133,5 \\
\hline HB & 158,6 & $-185,3$ & $-26,7$ & 56,0 & 29,3 \\
\hline NRW & 140,7 & $-84,9$ & 55,9 & 49,7 & 105,6 \\
\hline BER & 127,5 & $-150,0$ & $-22,5$ & 45,0 & 22,5 \\
\hline BAY & 32,1 & 14,9 & 47,0 & 11,3 & 58,3 \\
\hline SAAR & 9,8 & $-11,5$ & $-1,7$ & 3,5 & 1,7 \\
\hline SN & $-51,8$ & 60,9 & 9,1 & $-18,3$ & $-9,1$ \\
\hline MV & $-70,8$ & 83,3 & 12,5 & $-25,0$ & $-12,5$ \\
\hline ST & $-101,6$ & 119,5 & 17,9 & $-35,9$ & $-17,9$ \\
\hline $\mathrm{TH}$ & $-129,5$ & 152,4 & 22,9 & $-45,7$ & $-22,9$ \\
\hline BB & $-159,8$ & 188,0 & 28,2 & $-56,4$ & $-28,2$ \\
\hline $\mathrm{SH}$ & $-186,7$ & 178,7 & $-8,1$ & $-65,9$ & $-74,0$ \\
\hline RP & $-249,0$ & 279,6 & 30,5 & $-87,9$ & $-57,3$ \\
\hline \multirow[t]{2}{*}{ NDS } & $-282,1$ & 315,0 & 32,9 & $-99,6$ & $-66,7$ \\
\hline & \multicolumn{5}{|c|}{ DM je Einwohner } \\
\hline $\mathrm{HB}$ & 236,5 & $-276,3$ & $-39,8$ & 83,5 & 43,6 \\
\hline $\mathrm{HH}$ & 229,5 & $-197,3$ & 32,2 & 81,0 & 113,2 \\
\hline BER & 36,7 & $-43,2$ & $-6,5$ & 13,0 & 6,5 \\
\hline HE & 32,9 & $-19,7$ & 13,1 & 11,6 & 24,7 \\
\hline BW & 16,7 & $-9,8$ & 6,9 & 5,9 & 12,8 \\
\hline SAAR & 9,1 & $-10,7$ & $-1,6$ & 3,2 & 1,6 \\
\hline NRW & 7,8 & $-4,7$ & 3,1 & 2,8 & 5,9 \\
\hline BAY & 2,7 & 1,2 & 3,9 & 0,9 & 4,8 \\
\hline SN & $-11,3$ & 13,3 & 2,0 & $-4,0$ & $-2,0$ \\
\hline NDS & $-35,9$ & 40,1 & 4,2 & $-12,7$ & $-8,5$ \\
\hline ST & $-37,1$ & 43,6 & 6,5 & $-13,1$ & $-6,5$ \\
\hline MV & $-38,8$ & 45,7 & 6,9 & $-13,7$ & $-6,9$ \\
\hline $\mathrm{TH}$ & $-51,7$ & 60,9 & 9,1 & $-18,3$ & $-9,1$ \\
\hline RP & $-62,0$ & 69,6 & 7,6 & $-21,9$ & $-14,3$ \\
\hline BB & $-62,9$ & 74,0 & 11,1 & $-22,2$ & $-11,1$ \\
\hline SH & $-67,6$ & 64,7 & $-2,9$ & $-23,9$ & $-26,8$ \\
\hline \multicolumn{6}{|c|}{$\begin{array}{l}1 \text { Umsatzsteuerausgleich, Länderfinanzausgleich, Fehlbetrags-Bundesergănzungszuweisungen und } \\
\text { Beitrăge Fonds „Deutsche Einheit". }\end{array}$} \\
\hline Quelle: & ingen des $\mathrm{He}$ & chen Ministeri & der Finanzen & & \\
\hline
\end{tabular}


Zwar könnten alle Länder, die von der Neuregelung der Lohnsteuerzerlegung profitieren, auch nach Finanzausgleich noch mit Gewinnen rechnen, aber nur bezogen auf die Lănder- und Gemeindehaushalte insgesamt. Betrachtet man allein die Landeshaushalte, so verwandeln sich bei den finanzschwachen Lảndern Mehreinnahmen vor Finanzausgleich zu Mindereinnahmen nach Finanzausgleich. Umgekehrt steigt bei den vor Finanzausgleich belasteten Länder das Ländersteueraufkommen nach Finanzausgleich. Verantwortlich für diese auf den ersten Blick absurden Ergebnisse sind wiederum die marginalen Auffüll- bzw. Abschöpfungsquoten von über $100 \%$ bezogen auf die Länderhaushalte, die sich infolge der Anrechnung der Gemeindefinanzkraft im Ausgleichsverfahren ergeben.

Trotz der in vielerlei Hinsicht unbefriedigenden Verteilungseffekte des Länderfinanzausgleichs liegen die beiden Stadtstaaten Hamburg und Bremen bei den Pro-Kopf-Gewinnen vor und nach Finanzausgleich vorn. Dies unterstreicht aus empirischer Sicht, daß der Übergang zu einer stärkeren Berücksichtigung wirtschaftsbezogener Indikatoren bei der Steuerzerlegung durchaus geeignet erscheint, den Belangen der Stadtstaaten Rechnung zu tragen. Daß davon auch andere (Flächen-) Länder profitieren würden, wäre kein Nachteil, sondern ein Vorteil einer solchen Lösung, denn sie würde im Gegensatz zur Einwohnerwertung der Stadtstaaten - die überregionale Bedeutung der wirtschaftsstarken Regionen allgemein und systematisch reflektieren. Ein nicht zu unterschătzender Vorzug wăre dabei die automatische Anpassung der Wirkungen an Veränderungen der Spillover-Effekte im Zeitablauf.

Die Verănderung der primären Steuerverteilung zugunsten der Stadtstaaten kann deren finanzielle Situation allerdings nur spürbar verbessern, wenn der Länderfinanzausgleich insgesamt reformiert wird. "In dem vorgegebenen System des horizontalen Länderfinanzausgleichs hat jede Erhöhung der Finanzkraft eines Landes zur Folge, daß entweder die Ausgleichszuweisungen, die ein finanzschwaches Land empfăngt, abnehmen, oder die Ausgleichsbeträge, die finanzstarke Lănder zu zahlen haben, steigen “1. Den-

1 Kitterer, 1994, S. 12. 
noch wăre eine stărkere Berücksichtigung des Betriebsstättenprinzips bei der Steuerzerlegung in jedem Fall erwünscht. Es ist besser, den Ländern bereits im ersten Schritt eine möglichst adäquate Finanzausstattung zukommen zu lassen, als in einem (dadurch auch noch unnötig aufgeblähten) Finanzausgleich die Fehler bei der Primärverteilung nachträglich korrigieren zu wollen.

\section{b. Alternative Ausgleichsmaßnahmen}

In der Diskussion über die Stadtstaatenproblematik werden weitere Ansätze als Alternative zur Einwohnerwertung in Erwägung gezogen, die jedoch gegenüber einer veränderten Steuerzerlegung nicht überzeugen können.

(1) Wertschöpfungsbezogene Einwohnerwertung: Kitterer schlägt neben einer Lohnsteuerzerlegung nach dem Betriebsstättenprinzip vor, die Einwohnerwertung wertschöpfungsbezogen zu gestalten ${ }^{1}$. Da ein höherer Agglomerationsgrad in der Regel mit einer höheren Wirtschaftskraft je Einwohner (gemessen am Bruttoinlandsprodukt) einhergehe, sei auch eine bessere fiskalische Ausstattung angebotsseitig (und nicht aufgrund von Bedarfsüberlegungen) gerechtfertigt. Die Einwohnerwertung solle sich dementsprechend am Verhältnis des Bruttoinlandsproduktes von Stadtstaaten und Flächenländern orientieren. Der Vorteil einer solchen Lösung gegenüber dem heutigen System liege nicht zuletzt in der Flexibilisierung und Dynamisierung der Einwohnerwertung.

Es stellt sich allerdings die Frage, weshalb nur im Verhältnis zwischen dem jeweiligen Durchschnitt der Stadt- und Flächenstaaten so vorgegangen werden soll. Das Verfahren ließe sich doch auch (und mit unveränderter Begründung) generell anwenden. Dann aber würde offenkundig, daß eine wertschöpfungsbezogene, nicht mit einem strukturell höheren Finanzbedarf begründete Einwohnerwertung nichts anderes bedeutet als eine Festschreibung der Unterschiede in der ökonomischen Leistungskraft der Länder ${ }^{2}$. Man mag ja aus guten Gründen die

1 Vgl. Kitterer, 1994, S. 22 ff.

2 Bei isolierter Anwendung auf die Stadtstaaten würden diese allein priviligiert. 
Nivellierungsintensităt des heutigen Verfahrens als zu hoch einstufen, aber dies sollte nicht hinter einer modifizierten Einwohnerwertung versteckt, sondern durch eine offene, die Transparenz des Systems erhöhende Reform korrigiert werden.

(2) Verfahren der fiktiven Integration: Der Wissenschaftliche Beirat beim Bundesministerium der Finanzen hat den Vorschlag diskutiert, das Stadtstaatenproblem durch eine fiktive Integration der norddeutschen Bundesländer sowie der Länder Berlin und Brandenburg zu lösen 1 . Dabei werden (1) die integrierten Regionen im Länderfinanzausgleich wie ein Flächenland behandelt und (2) die Stadtstaaten anschließend einem simulierten kommunalen Finanzausgleich unterworfen, in dem sie wie die Großstädte der jeweiligen Flächenländer behandelt werden müßten. Eine solche Lösung ist aber (auch nach Auffassung des Beirats) kaum praktikabel. Gleiches gilt für die als Ausweg in Erwägung gezogenen politischen Verhandlungen zwischen den beteiligten Länder, die schon aufgrund der relativen Finanzschwäche der umgebenden Flächenstaaten ${ }^{2}$ kaum zustande kommen dürften. Im Vergleich zur partiellen Lohnsteuerzerlegung nach dem Betriebsstättenprinzip hätte jede Verhandlungslösung darüber hinaus den Nachteil der ökonomischen Unbestimmtheit und der Irreversibilität der einmal erzielten Ergebnisse.

(3) Vertikale Finanzzuweisungen: Wenn Verhandlungslösungen nicht realisierbar sind, bietet die Theorie des Finanzausgleichs immer noch das Instrument der vertikalen Finanzzuweisungen durch den Oberverband (Bund). Soweit aber das Grundproblem in der Internalisierung regional begrenzter Spillover-Effekte besteht, ist es eben nur hinsichtlich der Produzenten positiver externer Effekte durch vertikale Finanzzuweisungen lösbar, aber nicht hinsichtlich der Nutznießer und der Finanzierung die-

1 Vgl. Wissenschaftlicher Beirat beim Bundesministerium der Finanzen, 1992, S. 73 ff. Die Möglichkeit einer tatsächlichen Integration im Sinne einer Neugliederung des Bundesgebietes scheint nach dem gescheiterten Versuch mit Berlin und Brandenburg auf absehbare Zeit ausgeschlossen.

2 Daß die Strukturschwäche der Flächenstaaten nur mit einer „zielorientierten Strukturpolitik“ zu bekämpfen sei, mag zutreffen, hilft aber hinsichtlich der Reform des Länderfinanzausgleichs zunächst nicht weiter. Vgl. Wissenschaftlicher Beirat beim Bundesministerium der Finanzen, 1992, S. 74. 
ser Ausgleichszahlungen. Gegen eine solche Losung spricht aus foderativer Sicht auch die damit einhergehende, aber sachlich nicht notwendige wachsende Abhăngigkeit der Stadtstaaten vom Bund.

Insgesamt bleibt daher festzuhalten, daß die traditionelle Einwohnerwertung der Stadtstaaten ein durchaus legitimes Anliegen - die Berücksichtigung der Leistungen der Stadtstaaten für das Umland - im Finanzausgleich an der falschen Stelle zu lösen versucht. Überzeugende Gründe für den Einsatz gerade dieses Instrumentes sind nicht ersichtlich. Bei einem Wegfall der Einwohnerwertung bietet sich mit der partiellen Lohnsteuerzerlegung nach dem Betriebsstättenprinzip ein einfaches und flexibles Verfahren als die bessere Lösung an.

Unter Berücksichtigung der Überlegungen zur Steuerzerlegung können Veränderungen der Finanzkraftrangfolge der Lănder infolge der Einwohnerwertung der Stadtstaaten nicht grundsătzlich als Übernivellierung interpretiert werden. Der relevante Vergleich darf das heutige System nicht einfach mit einem Länderfinanzausgleich ohne Stadtstaatenprivileg konfrontieren, sondern muß die Wirkungen einer sachdienlichen Reform der Lohnsteuerzerlegung einkalkulieren. Nur soweit die Verteilungseffekte der Einwohnerwertung von dieser Norm abweichen, sind sie aus okonomischer Sicht zu beanstanden, und nur insoweit können sie auch willkürliche Rangplatzvertauschungen nach sich ziehen, die gegen das Nivellierungsverbot verstoßen. 


\section{Die Berücksichtigung der kommunalen Finanzkraft}

Nach Art. 107 Abs. 2 GG werden die steuerlichen Einnahmen der Gemeinden (und Gemeindeverbănde) im horizontalen Länderfinanzausgleich einkalkuliert. Diese Vorgehensweise reflektiert die verfassungsrechtliche Stellung der kommunalen Gebietskörperschaften, die als Glieder des betreffenden Landes gelten. Ihre Aufgaben und Ausgaben werden denen des Landes zugerechnet ${ }^{1}$.

\section{Bestimmungen des Finanzausgleichsgesetzes}

Die kommunalen Steuereinnahmen erhöhen nach dem Finanzausgleichsgesetz die Finanzkraftmeßzahl ( $§ 6$ Abs. 1 FAG) und die Ausgleichsmeßzahl ( $§ 6$ Abs. 2 FAG) eines Landes. Die Steuereinnahmen umfassen die Gemeindeanteile an der Einkommensteuer und an der Umsatzsteuer, die Einnahmen aus der Gewerbesteuer (abzüglich der Gewerbesteuerumlage) und die Einnahmen aus der Grundsteuer ( $\$ 8$ Abs. 1 FAG). Bei der Ermittlung der kommunalen Realsteuereinnahmen werden normierte Hebesătze zugrunde gelegt. Sie belaufen sich bei der Grundsteuer A auf $180 \%$, bei der Grundsteuer B - in Abhängigkeit von der Höhe der Grundbeträge - auf $180 \%$ bis $250 \%$ und bei der Gewerbesteuer auf $250 \%$ ( 8 Abs. 2 FAG). Diese Gemeindeeinnahmen gehen zur Hälfte in die Finanzkraftmeßzahl ein (§ 8 Abs. 5 FAG).

Die Ausgleichsmeßzahl wird als Summe der getrennt für Länder und Gemeinden festgestellten Ausgleichsmeßzahlen berechnet. Die Ausgleichsmeßzahl der Gemeinden entspricht den bundesdurchschnittlichen Gemeindeeinnahmen pro Kopf multipliziert mit der Gemeindeeinwohnerzahl des jeweiligen Bundeslandes. Die Einwohner der Gemeinden werden "veredelt“. Die Gewichtung liegt zwischen $100 \%$ bei den ersten 5.000 Einwohnern und $130 \%$ für die über der Millionengrenze liegende Einwohnerzahl. Eine zusătzliche Veredelung erfolgt bei Gemeinden mit mehr als 500.000 Einwohnern. In Abhängigkeit von der Einwohnerzahl je Quadratkilometer erhalten die Gemeinden Zuschläge in Hơhe von $2 \%$ bis $6 \%$ ( 9 Abs. 3 FAG).

1 Vgl. BVerfGE 86,148, S. 215 f. 
Aus finanzwissenschaftlicher Sicht wirft die Verknüpfung der Länder- und Gemeindehaushalte zu einem fiktiven Landesgesamthaushalt zwei Fragen auf. (1) Zunächst ist grundsätzlich zu klären, in welchem Maße die Einnahmen der Gemeinden für den Finanzausgleich unter den Ländern herangezogen werden sollen. (2) Im zweiten Schritt müssen die mit der Bestimmung der kommunalen Finanzkraft- und Ausgleichsmeßzahl verbundenen Probleme diskutiert werden. Dabei geht es einerseits um die Normierung der kommunalen Steuerkraft und andererseits um die spezifische Einwohnerwertung der Gemeinden.

\section{Grundfragen der Einbeziehung der Gemeindefinanzen}

Soweit sich Autoren aus finanzwissenschaftlicher Sicht zu dem Problem der Integration der Gemeindefinanzen in den Länderfinanzausgleich äußern, sprechen sie sich im allgemeinen für eine hundertprozentige Einbeziehung der kommunalen Finanzkraft aus. Dieser Vorschlag stößt allerdings auf erhebliche politische Widerstände1.

\section{a. Teil- oder Vollanrechnung kommunaler Finanzkraft?}

Die vorbehaltlose Anrechnung der Gemeindesteuern bei der Ermittlung der Finanzkraftmeßzahl basiert auf der Vorstellung, daß die Lănder zusammen mit ihren Gemeinden die regionalen offentlichen Leistungen erbringen. Länder und Gemeinden müßten daher hinsichtlich der Fähigkeit, die Wünsche der Bürger eines Landes befriedigen zu können, als Einheit betrachtet werden. Diese Verknüpfung sei schon deshalb angezeigt, weil andernfalls Unterschiede in der weitgehend von den Ländern bestimmten Aufgabenverteilung zwischen Ländern und Gemeinden auf den Finanzausgleich unter den Ländern durchschlagen würden².

Für eine Berücksichtigung der kommunalen Finanzkraft wird des weiteren angeführt, daß zwischen den Länder- und den Gemeindehaushalten enge

1 Die Bundesregierung hat schon einmal erfolglos versucht, die Einbeziehungsquote auf 60 \% zu erhőhen. Vgl. Heilmann, 1992, S. 69 f.; Gesetzentwurf der Bundesregierung vom 15.9.1987, BT-Drucksache 11/789.

2 Vgl. Wissenschaftlicher Beirat beim Bundesministerium der Finanzen, 1992, S. 54 f. 
finanzielle Verflechtungen bestehen. Die Gemeinden und Gemeindeverbände finanzieren einen wesentlichen Teil ihrer Ausgaben aus Zuweisungen der Länder. Mit diesen Zuweisungen werden sie gemäß Art. 106 Abs. 7 GG anteilig an den Einnahmen der Länder aus den Gemeinschaftsteuern beteiligt (obligatorischer Steuerverbund). Die Länder können den Steuerverbund mit den kommunalen Gebietskörperschaften auf die Ländersteuern ausdehnen (fakultativer Steuerverbund).

Über die Finanzzuweisungen besteht ein indirekter Zusammenhang zwischen der finanziellen Leistungsfähigkeit der Gemeinden und der Finanzkraft der Länder. Je geringer die Finanzkraft der Kommunen ist, um so gröBer müssen die Zuweisungen der Lănder ausfallen, wenn ein mit anderen Bundesländern vergleichbares Angebot an offentlichen Leistungen auf der kommunalen Ebene bereitgestellt werden soll1. Daher plädieren zahireiche Okonomen für eine vollständige Einbeziehung der kommunalen Steuerkraft in den Lănderfinanzausgleich2. Dieser Auffassung ist jedoch entgegenzuhalten, daß sie von den Besonderheiten der kommunalen Steuern ebenso abstrahiert wie von der Finanzautonomie der Lănder und Gemeinden.

Hinsichtlich der Gemeindesteuern muß nach Ansicht des Bundesverfassungsgerichts berücksichtigt werden, daß sie zum Teil ein Áquivalent für die spezifischen Lasten darstellen (sollen), die den Gemeinden aus den Steuerobjekten erwachsen. Dies gilt aber nur für die Realsteuern (Grund- und Gewerbesteuer $\left.{ }^{3}\right)$, nderen Ertrag nicht unwesentlich von den Verhältnissen in der Gemeinde abhăngt. Das Steueraufkommen und die durch die Steuerobjekte verursachten Lasten sind eng miteinander verknüpft. Diese örtliche radizierbare Verknüpfung rechtfertigt es, im Länderfinanzausgleich dem Land, in dessen Gebiet die Grundstücke und Gewerbebetriebe belegen sind

1 Vgl. Peffekoven, 1987, S. 196.

2 Vgl. Sachverstăndigenrat zur Begutachtung der gesamtwirtschaftlichen Entwicklung, 1992, Z. 370; Wissenschaftlicher Beirat beim Bundesministerium der Finanzen, 1992, S. 54. Ausgenommen werden nur die ortlichen Verbrauch- und Aufwandsteuern.

3 Die Gewerbesteuer erfullt in ihrer heutigen Form die Anforderungen an eine untemehmensbezogene lokale Áquivalenzsteuer nicht mehr. Dies spricht für eine Gewerbesteuerreform, aber noch nicht für die volle Einbeziehung in den Lảnderfinanzausgleich. 
und dessen Gemeinden die dadurch verursachten Lasten zu tragen haben, einen Teil der Realsteuern nicht als Finanzkraft anzurechnen“1.

Der gebührenăhnliche Charakter der Realsteuern spricht eventuell für einen Abschlag bei der Einbeziehung in den Länderfinanzausgleich. Dessen Höhe läßt sich wissenschaftlich nicht exakt festlegen. Dem Gesetzgeber könnte insofern - und nur auf diese Komponente der kommunalen Finanzkraft bezogen - ein Ermessensspielraum eingeräumt werden. Der Hinweis auf den Áquivalenzcharakter der Kommunalsteuern gilt aber kaum für den Anteil der Gemeinden an der Einkommensteuer (und neuerdings an der Umsatzsteuer). Das Bundesverfassungsgericht rechtfertigt die hälftige Einbeziehung mit der pauschalen Berücksichtigung des kommunalen Finanzbedarfs, die dem Gesetzgeber gestattet sei2 ${ }^{2}$. Diese Argumentation ist jedoch problematisch, weil damit nahezu jede beliebige (Nicht-) Einbeziehungsquote begründet werden kann. Außerdem wird hier ein (anfechtbarer) Bedarfsgesichtspunkt eingeführt, der jedenfalls im Kontext mit der Bestimmung der Finanzkraftmeßzahl keine Rolle spielen sollte ${ }^{3}$.

Festzuhalten bleibt also, daß die Besonderheiten der kommunalen Steuern nur sehr begrenzt gegen eine vollstăndige Einbeziehung in den Länderfinanzausgleich sprechen. Vertretbar erscheint allenfalls die Forderung nach einem Abschlag für die Realsteuern, aber keine generelle Teilanrechnung der kommunalen Steuereinnahmen.

\section{b. Finanzautonomie und Grenzbelastungen der Länder}

Angesichts der finanzwirtschaftlichen Autonomie, die den Ländern und Gemeinden in einem föderativen Staat bewußt eingeräumt wird, geht die Frage der Teil- oder Vollanrechnung der kommunalen Finanzkraft jedoch über die Betrachtung der spezifischen Merkmale kommunaler Steuern hinaus. Die Gemeinden stellen auch haushaltsrechtlich innerhalb der Lănder selbständige Körperschaften dar. Die Haushalte der Länder und ihrer Gemeinden

\footnotetext{
1 BVerfGE 86, 148, S. 232.

2 Vgl. BVerfGE 86, 148, S. 232.

3 Vgl. Korioth, 1997, S. 573.
} 
bilden also keine Einheit, und die Länder können auch nicht unmittelbar auf die Gemeindefinanzen zurückgreifen ${ }^{1}$. Dieser Sachverhalt gewinnt eine entscheidende Bedeutung im Zusammenhang mit der ausgeprăgten Nivellierungsintensität und den hohen Grenzbelastungen, die das heutige Ausgleichsverfahren für die Länderhaushalte mit sich bringt.

Das Ausmaß dieser Grenzbelastungen hängt auch von der Intensität der Einbeziehung der kommunalen Finanzkraft in den Länderfinanzausgleich ab. Grundsätzlich erhöht die Einbeziehung der Gemeindefinanzkraft die marginalen Abschöpfungsquoten bezogen auf die Länderhaushalte. Dies belegt folgende einfache Rechnung. Von einer Erhöhung des regionalen Lohnsteueraufkommens erhalten die Länder $42,5 \%$ und die Gemeinden $15 \%$. Bei einem effektiven marginalen Ausgleichssatz im Länderfinanzausgleich ${ }^{2}$ von beispielsweise $75 \%$ verlieren die Länder $3 / 4$ ihrer Mehreinnahmen, sofern die Gemeindesteuern überhaupt nicht berücksichtigt werden. Eine hälftige Einbeziehung erhöht die Grenzbelastung der Länderhaushalte bereits auf $88,2 \%$, und die Vollanrechnung führt zu $101,5 \%$, also zu einer Situation, in der die Länderhaushalte durch Mehreinnahmen bei der Lohnsteuer netto belastet werden ${ }^{3}$.

Tatsächlich erreichen die marginalen Abschöpfungsquoten bezogen auf die Lohn- und Einkommensteuer für die Länderhaushalte derzeit - bei nur fünfzigprozentiger Anrechnung der Kommunalsteuern - schon bei elf Bundeslăndern Werte von über $100 \% 4$. Würde man die Einbeziehungsquote auf $100 \%$ anheben, so hătte dies eine weitere Erhöhung der ökonomisch unvertretbaren Grenzbelastungen zur Folge (vgl. Abbildung 13). Zu den Ländern mit marginalen Abschöpfungsquoten von mehr als $100 \%$ würde sich Hessen gesellen. Die oberen Werte lägen um ca. 17 Prozentpunkte über dem heutigen Niveau; mit einem Spitzenwert von $133,6 \%$ für das Saarland.

1 Vgl. Normenkontrollantrag des Landes Hessen, Kapitel C.IV.1.

2 Umsatzsteuer-Vorwegausgleich, horizontaler Länderfinanzausgleich i. e. S. und Fehlbetrags-Bundesergănzungszuweisungen.

3 Die marginale Abschöpfung $m$ hăngt von der Einbeziehungsquote der Gemeindesteuern e, dem Ausgleichssatz a und den Anteilen der Länder I bzw. Gemeinden $g$ an der Lohnsteuer $a b: m=[1+e(g /)]$ a.

4 Vgl. zur Ermittlung der Grenzbelastungen S. $84 \mathrm{ff}$. 
Manche Kritiker versuchen, das Problem der hohen Grenzbelastungen und der daraus resultierenden Fehlanreize mit dem Hinweis auf die Gemeindehaushalte, denen ein Teil der Steuermehreinnahmen zugute kommt, zu re-

\section{Abbildung 13}

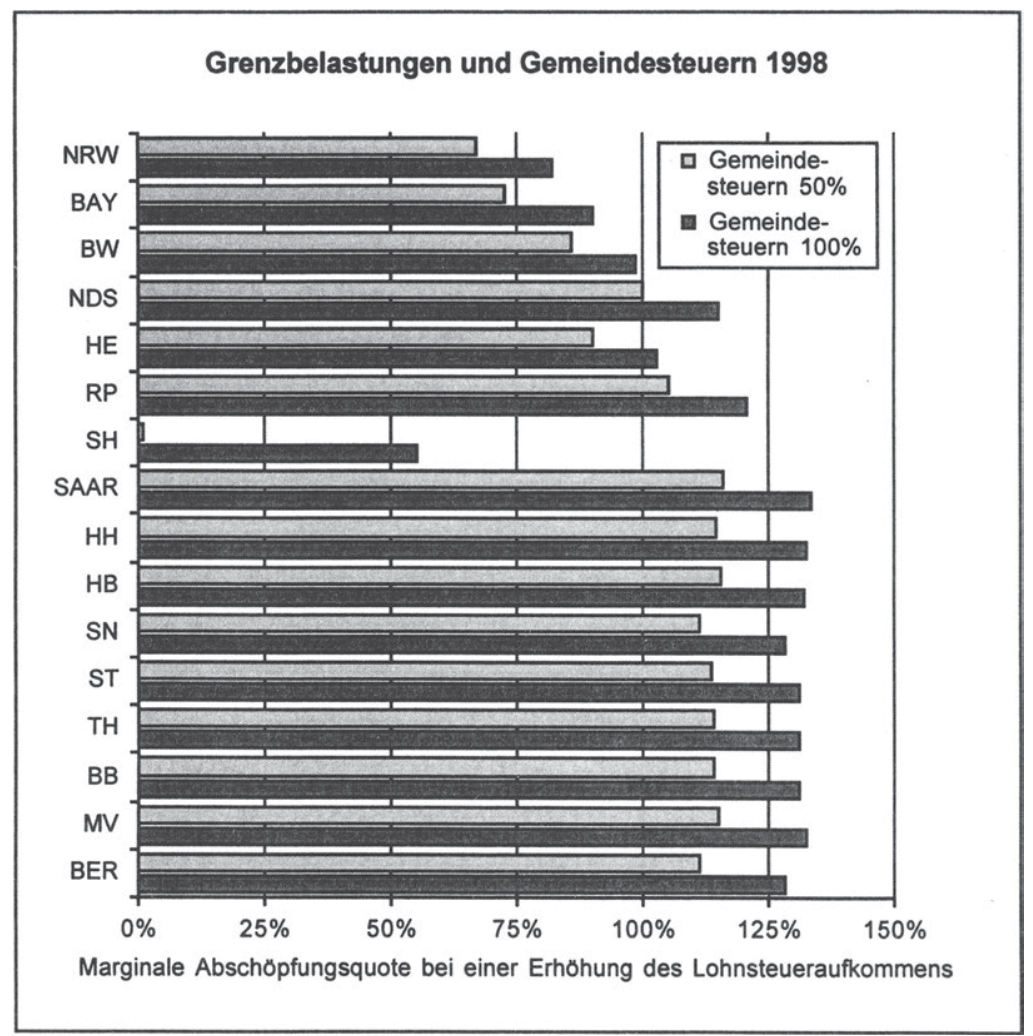

lativieren. So behauptet Trzaskalik in seiner Stellungnahme für RheinlandPfalz, daß "man vernünftigerweise nicht zwischen kommunaler und Landesebene differenzieren [kann]; es gibt kein ausgleichsrelevantes isoliertes Verhalten von Gemeinden einerseits und Land andererseits"1. Diese Behauptung ist aber völlig unplausibel. Huber weist zu Recht darauf hin, daß

1 Trzaskalik, 1999, S. 35 f. 
die Interessenkonflikte in einem Bundesland auf der Hand liegen, wenn die Gemeindekasse gefüllt, die Landeskasse aber geschmälert wird1. "Diese Einnahmenverluste im Landeshaushalt lassen sich auch nicht einfach mit den Mehreinnahmen der Kommunen verrechnen, zumal das Land keinen unmittelbaren Zugriff auf die Einnahmen der Kommunen hat"2. Im übrigen betragen selbst die auf Länder und Gemeinden bezogenen Grenzbelastungen in neun Bundesländern mehr als $94,5 \%$. Dies kann wohl kaum als hinreichend anreizfreundlich bezeichnet werden.

Vor dem Hintergrund der außerordentlichen Nivellierungsintensität des heutigen Länderfinanzausgleichs und seiner absurden Grenzbelastungseffekte kann eine hundertprozentige Einbeziehung der kommunalen Finanzkraft in das bestehende Ausgleichsverfahren nicht ernsthaft in Erwägung gezogen werden. Die derzeitige Regelung ist vielmehr als Schutz der finanzstarken Länder vor einer noch weitergehenden Inanspruchnahme durch die finanzschwachen Länder zu interpretieren. Die volle Anrechnung der Gemeindefinanzen würde die Ausgleichsverpflichtungen der finanzstarken Länder steigern und damit die negativen Anreizwirkungen des Länderfinanzausgleichs intensivieren. Eine aus finanzwissenschaftlicher Sicht vertretbare stärkere Einbeziehung der kommunalen Einnahmen setzt somit eine deutliche Reduktion der Ausgleichsintensität des Länderfinanzausgleichs voraus.

\section{c. Verteilungseffekte der hälftigen Anrechnung}

Die Verteilungseffekte der Einbeziehung der Gemeindesteuern in den Länderfinanzausgleich können anhand eines Vergleichs der hälftigen Anrechnung der Gemeindesteuern mit dem Extremfall der vollständigen Anrechnung aufgezeigt werden (vgl. Tabelle 7).

Die nur fünfzigprozentige Anrechnung der kommunalen Steuerkraft entlastet die Länder Baden-Württemberg, Bayern, Bremen, Hamburg, Hessen, Nordrhein-Westfalen und Schleswig-Holstein im Rahmen des Länderfinanzaus-

1 Vgl. Huber, 1999 b, S. 9 f.

2 Huber, 1999 b, S. 11. Selbst wenn sich langfristig aus der höheren kommunalen Finanzkraft geringere Finanzierungspflichten des Landes ergeben sollten, ist eine kurzfristige Kompensation nahezu ausgeschlossen. 
gleichs im engeren Sinne um insgesamt 5.143 Mio. DM. Es sind also die finanzstarken westdeutschen Flächenländer sowie die Stadtstaaten Hamburg und Bremen, die von der derzeitigen Regelung des FAG profitieren. Durch unterlassene Ausgleichszahlungen belastet sind mit 4.981 Mio. DM im wesentlichen die neuen Bundesländer und Berlin sowie mit 162 Mio. DM die alten Länder Niedersachsen, Rheinland-Pfalz und Saarland. Einen zusätzlichen Nachteil erfahren diese Länder, weil ihnen Fehlbetrags-Bundesergänzungszuweisungen in Höhe von 653 Mio. DM entgehen. Auch dieser Verlust konzentriert sich mit 521 Mio. DM auf die neuen Bundesländer.

\section{Tabelle 7}

Verteilungseffekte der Anrechnung der Gemeindesteuern 1998

\begin{tabular}{|c|c|c|c|c|c|}
\hline \multirow[t]{2}{*}{ Land } & \multicolumn{2}{|c|}{ GuV } & USt & LFA & BEZ \\
\hline & $\mathrm{DM} / \mathrm{E}$ & Mio. DM & \multicolumn{3}{|c|}{ Mio. DM } \\
\hline NRW & 69,99 & $1.257,7$ & 0,0 & $1.255,6$ & 0,0 \\
\hline BAY & 89,89 & $1.084,6$ & 0,0 & $1.086,5$ & 0,0 \\
\hline BW & 130,66 & $1.360,0$ & 0,0 & $1.361,0$ & 0,0 \\
\hline NDS & $-6,58$ & $-51,6$ & 0,0 & $-21,2$ & $-31,7$ \\
\hline HE & 153,73 & 927,3 & 0,0 & 927,1 & 0,0 \\
\hline RP & $-31,13$ & $-125,1$ & 0,0 & $-50,1$ & $-75,1$ \\
\hline SH & 6,62 & 18,3 & 0,0 & 18,1 & 0,0 \\
\hline SAAR & $-113,81$ & $-122,6$ & 0,0 & $-91,2$ & $-31,4$ \\
\hline $\mathrm{HH}$ & 272,41 & 463,3 & 0,0 & 463,8 & 0,0 \\
\hline HB & 55,96 & 37,5 & 0,0 & 31,3 & 6.7 \\
\hline SN & $-345,25$ & $-1.556,1$ & 0,0 & $-1.426,4$ & $-129,8$ \\
\hline ST & $-351,38$ & $-945,3$ & 0,0 & $-868,6$ & $-76,7$ \\
\hline TH & $-371,31$ & $-917,3$ & 0,0 & $-847,5$ & $-69,8$ \\
\hline BB & $-304,78$ & $-786,6$ & 0,0 & $-714,0$ & $-72,6$ \\
\hline MV & $-359,47$ & $-648,3$ & 0,0 & $-597,3$ & $-51,0$ \\
\hline BER & $-189,83$ & $-648,7$ & 0,0 & $-527,1$ & $-121,6$ \\
\hline West & 75,12 & $4.849,4$ & 0,0 & $4.980,9$ & $-131,6$ \\
\hline Ost & $-314,97$ & $-5.502,4$ & 0,0 & $-4.980,9$ & $-521,4$ \\
\hline Alle & $-7,96$ & $-653,0$ & 0,0 & 0,0 & $-653,0$ \\
\hline $\begin{array}{l}\text { GuV } \\
\text { USt }\end{array}$ & Länder & rminde & & erkı & \\
\hline
\end{tabular}

Allerdings kann man die von einer verstärkten Einbeziehung der kommunalen Finanzkraft in den Länderfinanzausgleich ausgehenden Belastungen für den Bundeshaushalt nicht einfach als potentiellen Gewinn der Länder verbuchen. Es erscheint vielmehr angebracht, die Verschiebungen zwischen Bundes- und Länderhaushalten für Vergleichszwecke zu neutralisie- 
ren. In Betracht kommt eine kompensatorische Senkung der Ausgleichsquote bei den Fehlbetrags-Bundesergänzungszuweisungen oder eine Verminderung des Umsatzsteueranteils der Länder. Da die volle Anrechnung der Gemeindesteuern eine Art Substitut für einen höheren Ausgleichssatz darstellt, bietet sich im vorliegenden Fall eine Verminderung der Ausgleichsquote (von $90 \%$ auf $80,9 \%$ ) bei den Fehlbetrags-Bundesergänzungszuweisungen an ${ }^{1}$. Diese Kompensationslösung würde nur die finanzschwachen Länder berühren. Ihre in Tabelle 7 ausgewiesenen Mindereinnahmen infolge der hälftigen Berücksichtigung der Gemeindesteuern überzeichnen die Belastungswirkungen ein wenig, weil sie den Effekt der modifizierten Bundesergänzungszuweisungen nicht enthalten².

Entscheidend für die finanzwissenschaftliche Beurteilung der Verteilungswirkungen der unvollständigen Anrechnung der kommunalen Finanzkraft ist aber nicht allein der in Tabelle 7 durchgeführte Vergleich mit einer Vollanrechnung. Die Gegenüberstellung abstrahiert von der überzogenen Nivellierungsintensität des heutigen Systems, von der die finanzschwachen Bundesländer erheblich profitieren. Daher sind die aufgezeigten Verteilungseffekte auch keineswegs als Benachteiligung dieser Länder anzusehen. Sie stellen nur einen gewissen Ausgleich für die anderweitig verursachten übermäßigen Belastungen der finanzstarken Länder dar. Dies gilt erst recht unter Berücksichtigung der oben diskutierten Grenzbelastungsproblematik, die durch eine Vollanrechnung der Gemeindesteuern erheblich verstärkt würde.

Die Schutzfunktion der heutigen Regelung spricht prinzipiell für ihren Fortbestand. Eine stärkere Anrechnung der Gemeindefinanzkraft im Länderfinanzausgleich würde jedoch die Leistungsunterschiede der kommunalen Gebietskörperschaften besser abbilden und damit die Ausgleichsgerechtig-

1 Eine Senkung des Umsatzsteueranteils (von $49,5 \%$ auf $49,2 \%$ ) würde die finanzstarken Länder bei Vollanrechnung der Gemeindefinanzkraft noch zusätzlich belasten.

2

Unter Berücksichtigung der Senkung der Ausgleichsquote bleiben die Bundesergänzungszuweisungen trotz Vollanrechnung der Gemeindesteuern absolut konstant. Sie werden aber anders verteilt. Dadurch fallen die Mindereinnahmen in den neuen Bundesländern, in Rheinland-Pfalz und im Saarland effektiv geringer aus. Niedersachsen und Bremen verzeichnen dagegen Mehreinnahmen. Niedersachsen wird durch den hälftigen Einbezug der Gemeindesteuern also nur scheinbar benachteiligt (vgl. Tabelle 7). Faktisch profitiert das Land (ebenso wie Bremen) von relativ höheren FehlbetragsBundesergänzungszuweisungen. 
keit von dieser Seite her vergrößern ${ }^{1}$. Unter der zwingenden Voraussetzung einer Korrektur des effektiven Ausgleichsniveaus im horizontalen Länderfinanzausgleich (unter Einschluß des Umsatzsteuer-Vorwegausgleichs und der Fehlbetrags-Bundesergänzungszuweisungen) kann daher eine begrenzte Erhöhung der Einbeziehungsquote der Gemeindesteuern aus finanzwissenschaftlicher Sicht nicht abgelehnt werden. Eine Vollanrechnung kommt allerdings wegen der grundgesetzlich garantierten Finanzautonomie der Kommunen (Art. 28 Abs. 2 Satz 3 GG) nicht in Betracht.

\section{Die Ermittlung der Finanzkraft der Gemeinden}

Die Berücksichtigung der kommunalen Finanzkraft im Länderfinanzausgleich reduziert sich nicht auf die Frage nach der ökonomisch vertretbaren Einbeziehungsquote. Sie ist auch mit spezifischen Problemen der Bestimmung der Finanzkraft- und der Ausgleichsmeßzahl verbunden. Im Kontext mit der Finanzkraftmeßzahl steht vor allem die korrekte Ermittlung und Normierung der Einnahmen der Gemeinden zur Diskussion.

\section{a. Abgrenzung der ausgleichsrelevanten Einnahmen}

Bei der Ermittlung der kommunalen Finanzkraftmeßzahl sind - genauso wie bei den Ländereinnahmen - grundsätzlich alle Einnahmen einzubeziehen, die eine ökonomische Dispositionskraft begründen. Allerdings können im Länderfinanzausgleich solche Einnahmen unberücksichtigt bleiben, deren Aufkommen quantitativ nicht ausgleichsrelevant ist, die zwischen den Ländern in etwa gleichmäßig streuen und bei denen der Aufwand, der mit der Ermittlung der Einnahmen verbunden wäre, größer ist als der Ausgleichseffekt, der damit erreicht werden kann².

1 Profitieren würden insbesondere die neuen Bundesländer mit ihren finanzschwachen Gemeinden. Der Bund könnte daher auch seine Sonderbedarfs-Bundesergänzungszuweisungen an die neuen Länder, die nicht nur zum Abbau teilungsbedingter Sonderlasten, sondern eben auch zum Ausgleich der geringen Finanzkraft der ostdeutschen Kommunen dienen, in gewissem Umfang reduzieren. Dadurch würde ein Spielraum für eine Anhebung des Umsatzsteueranteils der Länder entstehen.

2 Vgl. BVerfGE 72, 330, S. 400; Peffekoven, 1992, S. 350; Grawert, 1989, S. $63 \mathrm{ff}$. 
Für die Kommunen folgt daraus, daß örtliche Verbrauch- und Aufwandsteuern, Gebühren und Beiträge, Einnahmen aus Unternehmensbeteiligungen und Finanzzuweisungen bei der Ermittlung der Finanzkraftmeßzahl außer Ansatz bleiben müssen1. Aus finanzwissenschaftlicher Sicht sind diese Einschränkungen auch deshalb geboten, weil sie zu einer Vereinfachung und Entlastung des Ausgleichsverfahrens führen. Außer den explizit im Finanzausgleichsgesetz genannten Steuereinnahmen verdienen allenfalls die Konzessionsabgaben, die ökonomisch als Produktionsfaktorsteuern zu interpretieren sind, eine Berücksichtigung im Lănderfinanzausgleich2. Auf die damit verbundenen Probleme wird im folgenden jedoch nicht năher eingegangen.

\section{b. Die Normierung der Einnahmen aus den Realsteuern}

Bei der Grundsteuer und der Gewerbesteuer hăngen die effektiven Einnahmen der Gemeinden auch von ihrer Hebesatzpolitik ab. Damit die autonomen Entscheidungen der Kommunen den Finanzausgleich nicht verfälschen, muß bei allen Steuern, die ein Hebesatzrecht vorsehen, eine Normierung des Aufkommens mit Hilfe sogenannter Nivellierungshebesătze erfolgen ${ }^{3}$. Andernfalls könnten die Gebietskörperschaften die Konsequenzen ihrer autonomen Entscheidungen über den Finanzausgleich zum Teil auf Dritte abwälzen. Beispielsweise würden Gemeinden, die ihre Unternehmen bei der Gewerbesteuer entlasten, ohne Normierung des Gewerbesteu-

1 (1) Vor allem aufgrund ihrer lediglich lokalen Bedeutung erscheint es gerechtfertigt, die Aufwand- und Verbrauchsteuern im Länderfinanzausgleich nicht zu berücksichtigen. Eine Ausnahme bildet vielleicht die Vergnügungsteuer mit einem Aufkommen von insgesamt rund 500 Mio. DM im Jahr 1997. (2) Gebühren und Beiträge dienen der Finanzierung bestimmter kommunaler Leistungen nach dem Áquivalenzprinzip. Ihre primäre Aufgabe besteht nicht in einer Erweiterung der Dispositionskraft, sondern in der Kompensation der Kosten, die den Gemeinden aus der Bereitstellung spezieller zurechenbarer Leistungen entstehen. (3) Die Ermittlung der Einnahmen aus Unternehmensbeteiligungen würde erhebliche Schwierigkeiten bereiten und ein stetiger Einnahmezufluß als Voraussetzung für die Berücksichtigung im Finanzausgleich wäre nicht gesichert. Konsequenterweise müßten auch Verluste der Kommunen im Finanzausgleich berücksichtigt werden. Einzelne Länder könnten also das Risiko ihrer wirtschaftlichen Aktivităten teilweise auf die Ländergesamtheit abwälzen. (4) Schon um Doppelzăhlungen zu vermeiden, dürfen Finanzzuweisungen nicht als ausgleichsrelevante Einnahmen betrachtet werden. Sie stammen aus den Einnahmen der Lănder oder - bei den Gemeindeverbänden - aus den Einnahmen der Kommunen (Umlagen), die ohnehin in der Finanzkraftmeßzahl enthalten sind.

2 Vgl. Wissenschaftlicher Beirat beim Bundesministerium der Finanzen, 1992, S. 55.

3 Gleiches gilt für Ländersteuern, die mit einem Zuschlagsrecht versehen werden. 
eraufkommens überhőhte Finanzzuweisungen im kommunalen Finanzausgleich erhalten 1 .

Ein vergleichbares Problem stellt sich im Länderfinanzausgleich. Verwendet man die tatsächlichen Einnahmen aus der Gewerbesteuer 2 in einem Bundesland als Maßstab der kommunalen Steuerkraft, so werden die Grundbeträge, die als Bemessungsgrundlage das Gewerbesteuerpotential abbilden, in den einzelnen Lăndern nach Maßgabe der jeweiligen Hebesătze und damit in unterschiedlichem Maße im Finanzausgleich berücksichtigt. Länder, deren Gemeinden im Landesdurchschnitt Hebesätze anwenden, die unter dem Bundesdurchschnitt liegen, könnten damit einen Teil ihrer Grundbeträge dem Finanzausgleich vorenthalten. Umgekehrt müßten sich Länder, deren Gemeinden überdurchschnittliche Hebesätze anwenden, eine überhöhte Finanzkraft anrechnen lassen ${ }^{3}$.

Neben den ungerechten Verteilungswirkungen wäre die Verwendung des unbereinigten Steueraufkommens mit Fehlanreizen verbunden. Die Länder hätten grundsätzlich ein Interesse an niedrigen Hebesătzen. Sie würden daher eine Kommunalpolitik, die Unternehmen mit geringen Steuersătzen zu attrahieren versucht, eher unterstützen als eine Politik, die das gleiche Ziel mit einer besonders guten Infrastrukturausstattung unter Inkaufnahme relativ hoher Hebesătze zu erreichen trachtet. Der kommunale Standortwettbewerb könnte daher verzerrt werden. Allerdings haben die Länder keinen direkten Einfluß auf die Hebesatzpolitik ihrer Gemeinden.

Die Normierung des Gewerbesteueraufkommens dient also der sachgerechten Ermittlung der kommunalen Finanzkraft zum Zwecke des Länderfinanzausgleichs. Die Normierung als solche ist nicht umstritten; die Wahl

1 Vgl. zur Problematik der Nivellierungshebesătze Scherf, 2000.

2 Für die nicht gesondert betrachtete Grundsteuer gelten die folgenden Überlegungen weitgehend analog.

3 Das Bundesverfassungsgericht sieht dies nicht anders: „Strukturschwache Gemeinden können versuchen, mit niedrigen Hebesătzen Standortnachteile auszugleichen, sie können aber auch durch überdurchschnittlich hohe Hebesătze ihre Einnahmenlage zu verbessern suchen. So unangemessen es im ersten Fall erscheinen mag, einen fiktiven Fehlbetrag zuzurechnen, so unangemessen wäre es im zweiten Fall, die zusătzlichen Einnahmen, für die Standortnachteile in Kauf genommen worden sind, in voller Höhe in den Länderfinanzausgleich einzubeziehen". BVerfGE 86, 148, S. 230 f.

Wolfgang Scherf - 978-3-631-75181-7 
des Nivellierungssatzes bereitet aber Probleme. Jeder einheitliche Nivellierungssatz gewährleistet zwar die relativ gleichmäßige Einbeziehung der Grundbeträge in den Finanzausgleich. Das absolute Volumen der ausgleichsrelevanten Gewerbesteuerkraft scheint aber auch von der Höhe des Nivellierungssatzes abzuhăngen. Dessen Niveau hătte dann eine erhebliche Bedeutung für die Ergebnisse des Ausgleichverfahrens.

Dies ist jedoch im Länderfinanzausgleich nicht der Fall. Zwar sieht das Finanzausgleichsgesetz einen Hebesatz von $250 \%$ bei der Gewerbesteuer vor, mit dem die jeweiligen Grundbeträge zu multiplizieren sind. Die Wahl eines anderen (positiven) Hebesatzes hătte aber keinen Einfluß auf die Finanzkraftmeßzahl der Gemeinden. De facto bestimmt das FAG nämlich die Gewerbesteuerkraft so, daß $50 \%$ des bundesdurchschnittlichen tatsächlichen (Vorjahres-) Aufkommens in den Länderfinanzausgleich eingehen. Der Anteil der einzelnen Länder richtet sich nach ihrem Anteil an den Grundbeträgen. Der Nivellierungssatz hat nur die Funktion, die relativen Anteile festzulegen. Das so berechnete Aufkommen stimmt noch nicht mit der Hälfte des tatsächlichen Aufkommens überein, sondern liegt darüber ${ }^{1}$. Die Differenz wird aber durch Anwendung eines einheitlichen (Absenkungs-) Prozentsatzes auf die zunächst ermittelten Finanzkraftzahlen kompensiert ( 88 Abs. 5 FAG).

Das zweistufige Verfahren verschleiert ein wenig den wahren Charakter der Finanzkraftmessung. Im Ergebnis entspricht die Gewerbesteuerkraft, die einem Bundesland zugerechnet wird, der Hälfte seiner Grundbeträge multipliziert mit dem bundesdurchschnittlichen Hebesatz, der in Wirklichkeit als $\mathrm{Ni}$ vellierungssatz herangezogen wiro?. Diese Vorgehensweise ist grundsätzlich umstritten, weil dadurch einem Land, dessen Gemeinden mit unterdurchschnittlichen Hebesătzen operieren, fiktive Einnahmen zugerechnet werden, die tatsächlich nicht vorhanden sind.

1 Der halbe bundesdurchschnittliche Hebesatz der Gewerbesteuer (1997: 0,5 × $387 \%$ ), mit dem die Grundbeträge multipliziert werden, ist geringer als der Nivellierungssatz.

2 Diese Aussage ist äquivalent zu der vorstehenden Anmerkung. Es spielt keine Rolle, ob man die Grundbeträge mit dem halben bundesdurchschnittlichen Hebesatz oder die halben Grundbeträge mit dem bundesdurchschnittlichen Hebesatz multipliziert. 
Infolge der nur fünfzigprozentigen Einbeziehung der Gemeindesteuern in den Länderfinanzausgleich konnte dieser Fall bislang praktisch nicht eintreten. Heute werden die Grundbetrăge der Länder gewissermaßen nur mit der Hălfte des bundesdurchschnittlichen Hebesatzes multipliziert, so daß die zugerechnete nie über der tatsächlichen Gewerbesteuerkraft liegt. Bei einer Vollanrechnung der kommunalen Einnahmen würde das bisherige Normierungsverfahren aber wohl auf Kritik stoßen.

Eine Anrechnung fiktiver Einnahmen wäre ausgeschlossen, wenn man nicht den bundesdurchschnittlichen, sondern den niedrigsten landesdurchschnittlichen Hebesatz zur Normierung verwenden würde'. Allerdings blieben dann Teile des im gesamten Bundesgebiet vorhandenen Gewerbesteueraufkommen im Finanzausgleich unberücksichtigt. Dies hätte folgende Konsequenzen, die für den Fall einer verstärkten Einbeziehung der Gemeindesteuerkraft bedacht werden müssen:

(1) Die Anwendung eines gegenüber dem bundesdurchschnittlichen Hebesatz abgesenkten Nivellierungshebesatzes wirkt wie ein Abschlag auf die Realsteuern und stellt eine Begünstigung gegenüber den Gemeindeanteilen an der Einkommen- und an der Umsatzsteuer dar. Dies mag, wie oben erwähnt, mit Blick auf den Áquivalenzcharakter der Realsteuern ein erwünschter Effekt sein.

(2) Der abgesenkte Nivellierungshebesatz schmälert das im Finanzausgleich angerechnete Gewerbesteueraufkommen in allen Ländern. Davon profitieren die Lănder mit hohen Grundbeträgen, $d$. h. vor allem die gewerbesteuerstarken westlichen Bundesländer. Ein niedriger Nivellierungshebesatz hat also keine Schutzfunktion für die finanzschwachen Länder, sondern kommt den finanzstarken Lăndern zugute 2 .

Vor diesem Hintergrund kann aus finanzwissenschaftlicher Sicht keine der beiden Möglichkeiten vorbehaltlos empfohlen werden. Der Gesetzgeber kann wählen und muß abwägen zwischen den tendenziell günstigeren Ver-

1 Vgl. Wissenschaftlicher Beirat beim Bundesministerium der Finanzen, 1992, S. 52.

2 Im Prinzip wirkt ein reduzierter Nivellierungshebesatz wie eine Reduktion der Einbeziehungsquote der Gemeindesteuern. 
teilungseffekten des heutigen Verfahrens und der Einbeziehung fiktiver Gewerbesteuereinnahmen in den Finanzausgleich. Letzteres erscheint auf den ersten Blick nicht gerechtfertigt, doch enweisen sich die Bedenken, soweit sie auf die Schonung finanzschwacher Länder abstellen, als unbegründet.

\section{Die Problematik der Einwohnerwertung der Gemeinden}

Mit der Einwohnerwertung der Gemeinden wird - ebenso wie mit der Einwohnerwertung der Stadtstaaten - das Prinzip des gleichen Pro-Kopf-Finanzbedarfs durchbrochen. Die Veredelung erhöht fiktiv die Einwohnerzahl der Gemeinden (gestaffelt nach der Gemeindegröße), wodurch die kommunale Ausgleichsmeßzahl im Verhältnis zur Finanzkraftmeßzahl steigt. Davon profitieren im Lănderfinanzausgleich die Lănder mit einem überdurchschnittlichen Anteil bevölkerungsstarker Gemeinden. Bei finanzschwachen Ländern steigen die Zuweisungen, während bei finanzstarken Ländern die Ausgleichsverpflichtungen sinken. Im folgenden ist die ökonomische Berechtigung der besonderen Einwohnerwertung der Gemeinden zu überprüfen.

\section{a. Zur Begründung der Einwohnerwertung}

Die Veredelung der Gemeindeeinwohner im deutschen Finanzausgleich basiert im wesentlichen immer noch auf den Arbeiten von Brecht und Popitz aus den dreißiger Jahren ${ }^{1}$.

(1) Brecht stellte in einer empirischen Untersuchung eine hohe Korrelation zwischen Urbanisierungsgrad, Bevölkerungsdichte und offentlichen Ausgaben fest. Sein ${ }_{n}$ Gesetz von der progressiven Parallelităt zwischen Staatsausgaben und Bevölkerungsmassierung" besagt, daß die offentlichen Ausgaben pro Einwohner mit der Bevölkerungsdichte und der Urbanisierung zunehmen. Die Hauptursache hierfür sieht Brecht in der aufwendigeren öffentlichen Leistungserstellung in Ballungsgebieten gegenüber den ländlichen Regionen. Die relative Verteuerung ist sowohl auf eine Preiskomponente (z. B. in Form von höheren Bodenpreisen in

1 Vgl. Brecht, 1932; Popitz, 1932. 
Verdichtungsräumen), als auch auf eine Mengenkomponente (z. B. in Form eines Anstiegs polizeilicher Aufgaben) zurückzuführen.

(2) Annliche Vorstellungen finden sich bei Popitz, der davon ausgeht, daß die Gemeinden mit steigender Einwohnerzahl nicht nur einen absolut höheren Finanzbedarf, sondern auch einen höheren Finanzbedarf pro Kopf aufweisen. Popitz sah seine These empirisch bestătigt und versuchte sie normativ zu erklären. Er vermutete, daß in größeren Städten und Gemeinden die Bedürfnisse nach offentlichen Gütern ausgeprägter sind als in kleinen ländlichen Gemeinden. „Je mehr Menschen auf einem örtlichen Siedlungsgebiet konzentriert sind, desto mehr steigt die Bedeutung der Leistungen der Gemeinden für die Befriedigung der $\mathrm{Be}-$ dürfnisse der in ihr wohnenden Bevölkerung “1.

Die Argumente von Brecht und Popitz, die einen mit der Einwohnerzahl überproportional zunehmenden Finanzbedarf der Gemeinden zu rechtfertigen versuchen, hängen eng mit den zentralörtlichen Funktionen der größeren Kommunen zusammen. Diese Gemeinden erbringen öffentliche Leistungen, die nicht nur den eigenen Bürgern, sondern auch den Einwohnern der umliegenden Kommunen zugute kommen ${ }^{2}$. Sofern man von einer $\mathrm{Ge}$ bührenfinanzierung absieht, führt dies in den zentralen Orten zu einer Erhöhung der Pro-Kopf-Ausgaben aufgrund eines Anstiegs der angebotenen Menge. Gleichzeitig sinken die Pro-Kopf-Ausgaben in den umliegenden Gemeinden, die von der zentralörtlich bereitgestellten Leistung profitieren ${ }^{3}$.

\section{b. Finanzwissenschaftliche Kritik der Einwohnerwertung}

Die Thesen von Brecht und Popitz können aus heutiger Sicht nicht mehr als stichhaltige Begründung einer Einwohnerveredelung bzw. einer Hauptansatzstaffel im kommunalen Finanzausgleich 4 akzeptiert werden.

1 Popitz, 1932, S. 280.

2 Klassische Beispiele hierfür sind Theater, Konzerte oder Museen.

3 Vgl. Kuhn, 1993, S. 135.

4 Die meisten Bundesländer operieren mit einer solchen Einwohnerstaffel. Ausnahmen sind Mecklenburg-Vorpommern, Rheinland-Pfalz und Schleswig-Holstein, die im kommunalen Finanzausgleich nach dem Einwohner-gleich-Einwohner-Prinzip verfahren. 
(1) Empirisch läßt sich die These, daß der Finanzbedarf je Einwohner mit zunehmender Gemeindegröße ansteigt, allenfalls im Hinblick auf wachsende Ausgaben, nicht aber im Hinblick auf einen wachsenden Finanzbedarf belegen. Schließlich dürfen die tatsächlichen Ausgaben der Gemeinden nicht mit den notwendigen Ausgaben bzw. dem Finanzbedarf gleichgesetzt werden. Eine Ursache für die höheren Pro-Kopf-Ausgaben der größeren Gemeinden kann auch darin liegen, daß sie über eine höhere Finanzkraft je Einwohner verfügen ${ }^{1}$. Es wäre in diesem Fall ein Zirkelschluß, aufgrund der höheren Finanzkraft und der daraus resultierenden höheren Ausgaben einen höheren Finanzbedarf zu postulieren.

(2) Neuere empirischen Studien kommen hinsichtlich der Gemeindegröße als Determinante der Pro-Kopf-Ausgaben zu ambivalenten Ergebnissen. „Zwar steigen die durchschnittlichen Ausgaben aller Gemeinden in den jeweiligen Größenklassen in der Regel mit steigender Einwohnerzahl an, es wird aber auch deutlich, daß die Pro-Kopf-Ausgaben der Gemeinden einer Größenklasse stark streuen. Dies ist nur so zu interpretieren, daß die Höhe der Pro-Kopf-Ausgaben neben der GemeindegröBe noch maßgeblich durch andere Faktoren beeinflußt wird"2.

(3) In Großstädten treten durchaus Agglomerationsnachteile auf, die sich Z. B. in höheren Bodenpreisen manifestieren. Allerdings müssen auch Agglomerationsvorteile, etwa die geringeren Transport- oder Informationskosten, berücksichtigt werden. Zudem sind in dünnbesiedelten ländlichen Räumen oftmals Deglomerationsnachteile, z. B. im Bereich der Abwasserentsorgung, zu beobachten, die zu höheren Pro-Kopf-Ausgaben führen und daher Ausgleichsrelevanz beanspruchen können ${ }^{3}$. Ob bei der Produktion offentlicher Leistungen Skalenerträge vorliegen oder nicht, hängt in erheblichem Maße von der Art der erstellten Leistung ab. Es kann jedenfalls nicht einfach von steigenden Kosten je Einwohner in den Ballungsgebieten ausgegangen werden.

1 Vgl. Littmann, 1977, S. $361 \mathrm{f}$.

2 Kuhn, 1993, S. 130.

3 Vgl. Kitterer, 1994, S. 19; Peffekoven, 1987, S. 203, Seiler, 1980, S. 35. 
(4) Unhaltbar ist - zumindest nach heutigen Maßstäben - die normative Begründung von Popitz für einen mit der Einwohnerzahl wachsenden Finanzbedarf pro Kopf. Die Vorstellung eines mit der Gemeindegroßße umfangreicheren oder besseren kommunalen Leistungsangebots widerspricht offenkundig dem verfassungsrechtlichen Postulat der "Gleichwertigkeit der Lebensverhältnisse“. Man kann heute auch nicht mehr davon ausgehen, daß sich die Bedürfnisse zwischen Stadt- und Landbevölkerung hinsichtlich der Versorgung mit öffentlichen Leistungen erheblich unterscheiden. Erwartet wird vielmehr ein für alle Bürger und damit in allen Gemeinden weitgehend übereinstimmendes Angebot1.

(5) Bei der traditionellen Einwohnerveredelung wird bezüglich der Wahrnehmung zentralörtlicher Funktionen unterstellt, daß diese mit der $\mathrm{Ge}$ meindegrőße an Bedeutung gewinnen. Von einem direkten Zusammenhang zwischen der Bevölkerungszahl der zentralen Orte und ihrem Zentralitătsgrad ${ }_{n}$ kann man jedoch nicht ohne weiteres ausgehen. Eine eindeutig nachweisbare und hinreichend abgesicherte Beziehung zwischen der Einwohnerzahl und den räumlichen Funktionen einer Stadt besteht nicht"2. Infolgedessen liefert auch der Ansatz der Zentralörtlichkeit keine stichhaltige Begründung für eine Abhängigkeit des Pro-Kopf-Finanzbedarfs von der Einwohnerzahl der Gemeinden³.

(6) Das Bundesverfassungsgericht hat auf einen weiteren siedlungsstrukturellen Aspekt hingewiesen, der gegen eine "Veredelung" der Einwohner spricht. Es erscheint ${ }_{n} z w e i f e l h a f t$, ob die Gemeindegröße, an die die gestaffelte Einwohnerwertung jeweils anknüpft, heute noch ein geeigneter Indikator für Siedlungsdichte sein kann. [...] Bildeten die Gemeinden vor der Gebietsreform meist geschlossene Siedlungen, was den Rückschluß von der Einwohnerzahl auf die Siedlungsdichte rechtfertigte, so ist durch die Bildung von Großgemeinden, die mehrere räumlich getrennte und zum Teil erheblich voneinander entfernte Siedlungszentren

1 Vgl. Hansmeyer/Kops, 1985, S. 39.

2 Kitterer, 1994, S 19. Vgl. auch Hanusch/Kuhn, 1985, S. 58; Kuhn, 1995, S. 105 f.

3 Den zentralortlichen Funktionen sollte daher im kommunalen Finanzausgleich nicht mit einer einwohnerzentrierten Hauptansatzstaffel, sondern mit besonderen Bedarfsansätzen Rechnung getragen werden. 
aufweisen, einem solchen Rückschluß weithin die Grundlage entzogen. Die Gemeindegrößenklassen erfassen zudem nicht Ballungsgebiete, die sich aus mehreren Gemeinden zusammensetzen ${ }^{“ 1}$.

(7) Die Einwohnerveredelung ist auch aus raumordnungspolitischer Sicht problematisch. Mit der räumlichen Ballung verbinden sich bestimmte Vorteile. Aus ökonomischer Sicht sprechen sinkende Durchschnittskosten bei der Bereitstellung offentlicher Leistungen für die Bildung von Agglomerationen und Städten. Diesen Vorteilen stehen jedoch auch Ballungskosten gegenüber, wie beispielsweise Lärm, Verkehr oder Kriminalităt, die einer zu starken regionalen Ballung entgegenwirken. „Im Gleichgewicht stimmen die Grenzvorteile und die Grenzkosten der Ballung überein, und so macht es wenig Sinn, allein die Kosten der Ballung im Finanzausgleich zu berücksichtigen“2. Wird dennoch eine Veredelung der Gemeindeeinwohner vorgenommen, so kommt es zu einer räumlich ineffizienten Situation, da die Kosten der Ballung nicht mehr über höhere Gebühren, Beiträge oder Steuern, verringerte Mengen oder geringere Qualităt der offentlichen Leistungen für die Bürger der Ballungsgebiete fühlbar werden ${ }^{3}$. Dadurch wird eine künstliche, über die optimale Ballung hinausgehende Tendenz zur räumlichen Konzentration geschaffen. Mit anderen Worten: Die Einwohnerwertung selbst trägt zu dem Problem bei, als dessen Lösung sie ausgegeben wird.

Insgesamt bleibt damit festzuhalten, daß die Einwohnergewichtung bei den Gemeinden aus ökonomischer Sicht nicht überzeugen kann. Die Hypothesen von Brecht und Popitz konnten weder theoretisch noch empirisch bestătigt werden. "Gleichwohl ist ihre Bedeutung für den Finanzausgleich in der Bundesrepublik nach wie vor ungebrochen. Dies ist nur mit der starren Beharrungstendenz von Regelungen zu erklären, die sich in der politischen Praxis scheinbar bewăhrt haben und politischen Kompromissen gut zugänglich sind. Okonomisch kann ihre Beibehaltung nicht gerechtfertigt werden ${ }^{4}$.

1 BVerfGE 86, 148, S. 235.

2 Homburg, 1994, S. 318.

3 Vgl. Sachverstăndigenrat zur Begutachtung der gesamtwirtschaftlichen Entwicklung, 1990, Z. 451.

4 Kuhn, 1993, S. 141 
Es wäre nun aber der falsche Weg, wollte man das Konzept der Einwohnerveredelung durch ein komplexes Indikatorensystem ersetzen, um den möglicherweise unterschiedlichen Finanzbedarf je Einwohner adäquat abzubilden ${ }^{1}$. Dies würde die Strategieanfälligkeit und Intransparenz des Länderfinanzausgleichs weiter vergroßern und neue Grundlagen für Streitigkeiten zwischen den Bundesländern schaffen. Schon die Auswahl der Indikatoren und ihre Gewichtung würde Spielräume für eine interessenorientierte politische Einflußnahme eroffnen. Die Wahrscheinlichkeit wäre groß, daß eine indikatorengestützte Finanzbedarfsmessung die Ungleichbehandlung der Länder erst herbeiführt, die das Verfahren eigentlich beseitigen soll2.

Die Alternative zur Einwohnerveredelung besteht nicht in der Perfektionierung der Finanzbedarfsmessung, sondern in der Vereinfachung des Länderfinanzausgleichs durch den Verzicht auf die ökonomisch fragwürdige Einwohnerwertung der Gemeinden. Da auch die Einwohnerwertung der Stadtstaaten (und die Hafenlastenregelung) entfallen sollte, würde das Verfahren durch die alleinige Verwendung des ungewichteten Einwohners bei der Bestimmung der Finanzkraft- und der Ausgleichsmeßzahl insgesamt erheblich an Konsistenz gewinnen3.

\section{c. Verteilungseffekte der kommunalen Einwohnerwertung}

Ein Blick auf die Verteilungswirkungen der Einwohnerwertung der Gemeinden unterstreicht die Problematik der heutigen Regelung (vgl. Tabelle 8). Auffallend ist zunăchst einmal, daß die Stadtstaaten Berlin, Bremen und Hamburg, die schon von ihrer speziellen Einwohnerveredelung profitieren,

1 Das Bundesverfassungsgericht hatte den Gesetzgeber aufgefordert, zu prufen, ob und inwieweit andere strukturelle Merkmale (z. B. Deglomerationsnachteile, Bevölkerungsstrukturmerkmale, Arbeitslose, Sozialhilfeempfänger) bei der Ermittlung des kommunalen Finanzbedarfs berücksichtigt werden sollen. Vgl. BVerfGE 86, 148, S. 236.

2 Abschreckendes Beispiel ist die Einkommensteuer. Das Streben nach möglichst groBer Einzelfallgerechtigkeit hat zu einer extremen Komplizierung des Steuerrechts und zu unüberschaubaren Sondervergünstigungen geführt, die letzten Endes in ihrer Gesamtwirkung die Steuergerechtigkeit gravierend beeinträchtigen.

3 Der „Erfolg“ der Einwohnerveredelung basiert auch auf der relativ hohen Transparenz, geringen Strategieanfälligkeit, grundsätzlichen Konsensfähigkeit und verwaltungstechnischen Einfachheit des Verfahrens. Vgl. Hansmeyer/Kops, 1985, S. 40. Diese Eigenschaften gelten aber in noch stärkerem Maße für das Einwohner-gleich-EinwohnerPrinzip. Mit dem Wegfall der Einwohnerwertung müßte also nicht auf die Vorteile der heutigen Regelung verzichtet werden. 
hier noch einmal die Hauptgewinner sind. Daneben profitiert als einziges Flächenland das bevölkerungsreiche und dicht besiedelte Nordrhein-Westfalen von der Einwohnerveredelung. Die Pro-Kopf-Vorteile sind für Berlin mit $132 \mathrm{DM}$ je Einwohner am größten. Auch der Bund ist Nutznießer der derzeit praktizierten Regelung, denn er spart im Vergleich zu einem System ohne Einwohnerwertung der Gemeinden Fehlbetrags-Bundesergănzungszuweisungen in Hơhe von 74 Mio. DM. Alle übrigen Lănder werden durch die Regelung des $\S 9$ Abs. 3 FAG schlechter gestellt. Besonders benachteiligt werden die dünn besiedelten neuen Länder Brandenburg, MecklenburgVorpommern, Sachsen-Anhalt sowie Thüringen, die zwischen 25 DM und $33 \mathrm{DM}$ je Einwohner verlieren.

\section{Tabelle 8}

\section{Verteilungseffekte der Einwohnerwertung der Gemeinden 1998}

\begin{tabular}{|l|rr|rrr|}
\hline \multicolumn{1}{|c}{ Land } & \multicolumn{2}{c}{ GuV } & \multicolumn{2}{c|}{ USt } & \multicolumn{2}{c|}{ LFA } & \multicolumn{1}{c|}{ BEZ } \\
\hline NRW & DM /E & Mio. DM & & \\
BAY & 13,88 & 249,5 & 0,0 & 251,8 & 0,0 \\
BW & $-13,87$ & $-167,3$ & 0,0 & $-168,6$ & 0,0 \\
NDS & $-15,20$ & $-158,2$ & 0,0 & $-159,5$ & 0,0 \\
HE & $-8,16$ & $-64,1$ & 0,0 & $-25,7$ & $-38,5$ \\
RP & $-10,18$ & $-61,4$ & 0,0 & $-61,8$ & 0,0 \\
SH & $-13,14$ & $-52,8$ & 0,0 & $-21,2$ & $-31,8$ \\
SAAR & $-14,33$ & $-39,6$ & 0,0 & $-15,9$ & $-23,7$ \\
HH & $-9,79$ & $-10,5$ & 0,0 & $-10,1$ & $-0,5$ \\
HB & 63,25 & 107,6 & 0,0 & 108,5 & 0,0 \\
SN & 49,84 & 33,4 & 0,0 & 16,8 & 16,7 \\
ST & $-18,11$ & $-81,6$ & 0,0 & $-77,9$ & $-3,7$ \\
TH & $-24,58$ & $-66,1$ & 0,0 & $-63,1$ & $-3,0$ \\
BB & $-30,47$ & $-75,3$ & 0,0 & $-71,9$ & $-3,4$ \\
MV & $-32,83$ & $-84,7$ & 0,0 & $-80,9$ & $-3,8$ \\
BER & $-29,89$ & $-53,9$ & 0,0 & $-51,5$ & $-2,4$ \\
West & 132,09 & 451,4 & 0,0 & 431,0 & 20,4 \\
Ost & $-2,53$ & $-163,5$ & 0,0 & $-85,7$ & $-77,8$ \\
Alle & 5,14 & 89,7 & 0,0 & 85,7 & 4,1 \\
\hline GuV & $-0,90$ & $-73,7$ & 0,0 & 0,0 & $-73,7$ \\
\hline USt & Erhöhung (+) bzw. Verminderung (-) der Ländereinnahmen gegenüber \\
\hline
\end{tabular}

Damit spiegelt sich in den Zahlen auch ein spezielles Problem des gesamtdeutschen Finanzausgleichs. Zwischen den ostdeutschen und den westdeutschen Lăndern bestehen erhebliche Unterschiede in der Siedlungs- 
struktur. Die ostdeutschen Länder sind - mit Ausnahme Sachsens - wesentlich dünner besiedelt als die westdeutschen Länder ${ }^{1}$. Zudem sind die ostdeutschen Kommunen im Durchschnitt wesentlich kleiner als die westdeutschen Kommunen ${ }^{2}$, und es gibt in den ostdeutschen Flächenländern keine Stadt mit mehr als 500.000 Einwohnern ${ }^{3}$. Die Einwohnerwertung der Gemeinden hat also vor allem für die neuen Länder negative Auswirkungen, obwohl doch gerade deren Kommunen hohe Infrastrukturdefizite und damit einen erheblichen finanziellen Nachholbedarf aufweisen 4 .

\section{Zur küntigen Behandlung der Gemeindesteuern}

Hinsichtlich der Berücksichtigung der kommunalen Finanzkraft im Länderfinanzausgleich sind folgende Punkte festzuhalten, die im Kontext einer Reform des Länderfinanzausgleichs Beachtung verdienen.

(1) Aus finanzwissenschaftlicher Sicht kann der nur hälftige Einbezug der kommunalen Finanzkraft nicht überzeugen. Es wäre grundsätzlich richtig, die Gemeindesteuern zu $100 \%$ bei der Ermittlung der Finanzkraftmeßzahl zu erfassen. Allerdings kann eine Vollanrechnung nur für den Fall einer deutlichen Reduktion des heutigen Ausgleichsniveaus ernsthaft in Erwägung gezogen werden. Bei sonst unverăndertem Länderfinanzausgleich würden sich - vor allem (aber nicht nur) bezogen auf die Länderhaushalte - inakzeptable Durchschnitts- und Grenzbelastungen ergeben. Sie stehen einer isolierten Variation der Einbeziehungsquote der Gemeindesteuern entgegen.

(2) Die Ermittlung der kommunalen Finanzkraftmeßzahl erfordert eine Normierung des Aufkommens der Realsteuern. Die heutige Losung operiert bei der Gewerbesteuer 5 materiell mit dem bundesdurchschnittlichen $\mathrm{He}$ -

1 Wăhrend in den alten Bundeslăndern im Durchschnitt 267 Menschen je Quadratkilometer leben, sind es in den neuen Ländern einschließlich Ost-Berlins nur 143 Personen. Vgl. Statistisches Bundesamt, 1998, S. 45, Tab. 3.1.2 und 3.1.3.

2 Vgl. Statistisches Bundesamt, 1998, S. 56 f., Tab. 3.7.

3 Die größten Städte sind Dresden mit 466.600 Einwohnern und Leipzig mit 465.200 Einwohnern. Vgl. Statistisches Bundesamt, 1998, S. 54 f., Tab. 3.6.

4 Vgl. Korioth, 1997, S. 597 f.; Fischer, 1992, S. 29.

5 Bei der Grundsteuer B ist diese Aussage wegen der Staffelung der Nivellierungssătze in Abhängigkeit von der Hơhe der Grundbeträge zu modifizieren. 
besatz als Nivellierungssatz, der allerdings nur auf die Hälfte der Grundbeträge der Gewerbesteuer angewandt wird. Sollte die Einbeziehungsquote im Zuge einer Reform des Länderfinanzausgleichs auf $100 \%$ angehoben werden, so ist die Anwendung des niedrigsten landesdurchschnittlichen Hebesatzes auf die gesamten Grundbeträge der Gewerbesteuer eine erwăgenswerte, aber keine zwingend notwendige Alternative zur Anwendung des bundesdurchschnittlichen Hebesatzes.

(3) Auf eine besondere Berücksichtigung des kommunalen Finanzbedarfs in Form der Einwohnerwertung sollte in Zukunft verzichtet werden. Die Einwohnerveredelung basiert auf überholten Vorstellungen über den Zusammenhang zwischen Pro-Kopf-Finanzbedarf und Gemeindegröße, die "theoretisch unfundiert und statistisch in keiner Weise abgesichert" ${ }^{41}$ sind. Da eine überzeugende Alternative in Form eines Indikatorensystems nicht zur Verfügung steht und auch nicht praktikabel wäre, spricht alles für den Übergang zum Einwohner-gleich-Einwohner-Prinzip. Die generelle Orientierung am ungewichteten Einwohner bietet zudem die Chance, das gesamte System des Lảnderfinanzausgleichs auf eine einheitliche Grundlage zu stellen.

Die Überlegungen zur Berücksichtigung der kommunalen Finanzkraft im Lănderfinanzausgleich zeigen insgesamt, daß auch auf diesem Gebiet ungenutzte Reformoptionen vorhanden sind, die zu einer Verbesserung des heutigen System beitragen könnten. Allerdings wurde auch einmal mehr deutlich, daß es vielfach nicht sinnvoll erscheint, einzelne Systemparameter isoliert zu betrachten und auf dieser Basis Ånderungen vorzuschlagen. Jeder Reformschritt bedarf der Einbettung in ein schlüssiges Gesamtkonzept, wenn in dem Bemühen um einen vernüntigeren Finanzausgleich nicht neue Defekte geschaffen oder alte Konstruktionsfehler verstärkt werden sollen.

1 Littmann, 1977, S. 360. 


\section{Die Problematik des progressiven Ausgleichstarifs}

Der Ausgleichstarif spielt im Streit über den horizontalen Länderfinanzausgleich eine herausragende Rolle. Die in der öffentlichen Diskussion beobachtbare Überbetonung der Tarifaspekte ist allerdings problematisch, weil sie von den bislang behandelten zentralen Fragen der ${ }_{n}$ Bemessungsgrundlagen“ des Finanzausgleichs abzulenken droht.

\section{Bestimmungen des Finanzausgleichsgesetzes}

Der Umverteilungstarif (§ 10 FAG) reguliert die Differenzen zwischen Ausgleichsmeßzahl und Finanzkraftmeßzahl. Fehlbeträge zwischen $92 \%$ und $100 \%$ werden zu 37,5\% ausgeglichen, so daß alle Länder nach horizontalem Finanzausgleich mindestens $95 \%$ der durchschnittlichen Finanzkraft erreichen (bezogen auf die gewichteten Einwohner). Die über dem Durchschnitt liegende Finanzkraft der "Nettozahler" wird stufenweise gestaffelt zur Finanzierung der Ausgleichszahlungen herangezogen.

Die Ausgleichssätze, die sich auf die über der Ausgleichsmeßzahl liegende Finanzkraft beziehen, betragen $15 \%$ in der ersten Zone zwischen $100 \%$ und $101 \%, 66 \%$ in der zweiten Zone zwischen $101 \%$ und $110 \%$ und $80 \%$ in der dritten Zone über $110 \%$. Die effektiven Ausgleichssätze weichen davon ab, weil die Ausgleichszahlungen mit Hilfe eines Proportionalitătsfaktors an die Ausgleichszuweisungen angepaßt werden. Dieser "Multiplikator" lag 1998 bei rund $108 \%$, so daß die Grenzbelastung in der dritten Zone effektiv auf $86,8 \%$ angehoben wurde 1 .

Im Mittelpunkt der Kritik am heutigen progressiven Umverteilungstarif steht die übermäßige Abschöpfung der überdurchschnittlichen Finanzkraft. Darüber hinaus ist der Tarif auch erstrangig verantwortlich für die extremen Grenzbelastungen der finanzstarken Länder. Die hohen Grenzbelastungen

1 Nach Anwendung des Ausgleichsverfahrens ist zu prüfen, ob sich die Finanzkraftreihenfolge der zahlungspflichtigen Ländern verändert hat. „Ein finanzschwächeres (,ausgleichspflichtiges') Land darf nămlich durch den Finanzausgleich höchstens zu dem vor inm liegenden finanzstärkeren Land aufschließen, und ein finanzstärkeres Land darf höchstens bis zu dem nächstschwächeren Land absinken (§ 10 Abs. 5 FAG)“. Arndt, 1999, S. 79. 
der finanzschwachen Länder basieren dagegen auf dem Umsatzsteuer-Vorwegausgleich und den Fehlbetrags-Bundesergänzungszuweisungen.

\section{Rechtliche Grenzen der Ausgleichspflicht}

In der aktuellen Debatte über das zulässige Ausmaß der Abschöpfung der überdurchschnittlichen Finanzkraft ausgleichspflichtiger Länder spielt der vom Bundesverfassungsgericht entwickelte Grundsatz der ${ }_{n}$ hälftigen Teilung zwischen privater und offentlicher Hand" eine wichtige Rolle1. Der Halbteilungsgrundsatz bezieht sich ursprünglich auf das Verhältnis zwischen steuerpflichtigem Bürger und Staat, wird aber teilweise auf die Solidarpflichten der finanzstarken Länder im Finanzausgleich übertragen². Die Forderung nach einer Begrenzung der Ausgleichsverpflichtungen auf die Hälfte der überdurchschnittlichen Finanzkraft basiert auf folgenden Argumenten.

(1) Die finanzstarken Länder müßten vor übermäßigen Ausgleichsansprüchen finanzschwacher Länder geschützt werden.

(2) Eine Solidaritätspflicht, die dazu zwingt, mehr als die Hälfte abzugeben, sei mit der Grundentscheidung für Eigenstaatlichkeit unvereinbar.

(3) Wirtschaftspolitischen Leistungen und Erfolge einzelner Länder dürtten nicht zu mehr als 50 \% über den Finanzausgleich umverteilt werden.

(4) Die Bürger würden um den Lohn ihrer Leistung gebracht, wenn mehr als die Hälfte der von innen erwirtschafteten überdurchschnittlichen Steuerzahlungen in andere Länder abfließen.

(5) Wähler können die Wirtschaftspolitik ihres Landes nur beurteilen und kontrollieren, wenn sie deren Auswirkungen spüren. Eine übermäßige Abschöpfung sei daher auch mit dem Demokratieprinzip unvereinbar.

$\mathrm{Ob}$ und inwieweit das Bundesverfassungsgericht dieser Auffassung nähertreten wird, ist eine offene Frage. Aus ökonomischer Sicht gibt es jedenfalls keinen überzeugenden Grund, den Ausgleichssatz gerade auf $50 \%$ festzu-

1 Vgl. BVerfGE 93, 121.

2 Vgl. zum folgenden Arndt, 1999, S. 81 f. 
legen. Eine gewisse Flexibilităt in diesem Punkt würde die Verständigung über einen neuen Ausgleichstarif vermutlich sehr erleichtern.

\section{3. Ökonomische Analyse alternativer Ausgleichstarife}

Die Unmöglichkeit einer wissenschaftlich fundierten Bestimmung des (noch) vertretbaren Ausgleichssatzes bedeutet nicht, daß sich der Umverteilungstarif einer okonomischen Analyse entzieht. Der Ausgleichsmechanismus hat bestimmte qualitative Anforderungen zu erfüllen, die nicht jede Lösung gestatten, und auch die okonomischen Konsequenzen der Umverteilung lassen sich tendenziell abschătzen und beurteilen.

\section{a. Anforderungen an den Ausgleichsmechanismus}

Eine Analyse des heutigen Umverteilungstarifs muß vor dem Hintergrund der Anforderungen an ein rationales Ausgleichsverfahren erfolgen. In diesem Zusammenhang spielen allgemeine, zielbezogene, durchführungstechnische und mathematisch-formale Kriterien eine Rolle1.

(1) Jedes rationale Ausgleichsverfahren muß vollständig und widerspruchsfrei sein. Ersteres bedeutet, daß die Beiträge stets ausreichen müssen, um die Zuweisungen zu decken. Letzteres verlangt, daß die Anwendung einzelner Regeln nicht zu Verstößen gegen andere Regeln führen darf.

(2) Der horizontale Länderfinanzausgleich dient primär distributionspolitischen Zielen. Die Verteilung der Finanzkraft nach Finanzausgleich soll gleichmäßiger ausfallen als die Verteilung der Finanzkraft vor Finanzausgleich. Der Ausgleichsstarif muß daher in erster Linie geeignet sein, die gewünschte Umverteilung herbeizuführen. Diese Forderung beinhaltet die Garantie einer Mindestfinanzkraft und darüber hinaus eine begrenzte Annäherung der relativen Finanzkraftpositionen der Länder.

(3) Bei der Verfolgung distributiver Ziele ist auf die Anreizkompatibilität zu achten. Sowohl die Empfänger als auch die Zahler dürfen das Interesse an der Stärkung ihrer eigenen Wirtschafts- und Finanzkraft nicht verlie-

1 Vgl. Lenk, 1998, S. $47 \mathrm{ff}$. 
ren. Dies impliziert den Verzicht auf eine übermäßige Nivellierung. Insbesondere dürfen die mit einer Steigerung der Steuerkraft einhergehenden Mehreinnahmen nicht voll durch geringere Zuweisungen oder höhere Zahlungen aufgezehrt werden.

(4) Eng verbunden mit den allokativen und distributiven Zielen ist die mathematisch-formale Monotonieforderung. Das Ausgleichsverfahren darf zumindest nicht zu einer Anderung der Finanzkraftreihenfolge der Lănder führen (einfache Monotonie). Unter Anreizaspekten erscheint aber auch eine vollständige Nivellierung problematisch. Daher könnte man verlangen, daß trotz Finanzausgleich gewisse Unterschiede bestehen bleiben sollten (strenge Monotonie). Allerdings steht diese Forderung in latentem Konflikt mit der Sockelgarantie.

(5) Aus der Anreizkompatibilităt läßt sich des weiteren ableiten, daß der Ausgleichstarif keine Sprungstellen aufweisen sollte, die zu schlagartigen Veränderungen der Be- und Entlastungseffekte führen (Kriterium der Stetigkeit). In dieselbe Richtung geht die Forderung nach geringer Sensitivităt des Verfahrens. Kleine Variationen der Anspruchsgrundlagen sollen keine abrupten Veränderungen der Ergebnisse bewirken.

(6) Unter durchführungstechnischen Aspekten sind die Praktikabilităt, die Verfahrenseffizienz und vor allem die Transparenz des Ausgleichsverfahrens von Interesse. Die Bestimmungen sollten eindeutig und verständlich sein ${ }^{1}$. „Transparenz im Sinne einer möglichst einfachen Prüfund Nachvollziehbarkeit der Regelungen erleichtert Aussagen über deren Geeignetheit im Hinblick auf den Normzweck, wirkt positiv auf die Praktikabilităt und ermöglicht gezielte Meinungsbildung und sachbezogene Auseinandersetzung“2.

Den genannten Anforderungen entspricht das heutige System des Länderfinanzausgleichs offenkundig nicht. Im folgenden stellt sich die Frage, inwieweit der Umverteilungstarif dafür (mit-) verantwortlich ist.

$1 \mathrm{DaB}$ diese Forderung heute nicht einmal ansatzweise erfüllt ist, dürften die bisherigen Überlegungen bereits hinreichend deutlich gemacht haben.

2 Lenk, 1998, S. 48. 


\section{b. Kritik des progressiven Stufentarifs}

Gemessen an den distributiven Aspekten wirkt der heutige Ausgleichsmechanismus weitgehend zielkonform, wenn man die Finanzkraftpositionen vor und nach horizontalem Länderfinanzausgleich i. e. S. nach den Maßstäben des FAG betrachtet (vgl. Abbildung 2, S. 53). Alle Länder erreichen ein Mindestniveau von $95 \%$ der Ausgleichsmeßzahl, und die finanzschwachen und finanzstarken Länder rücken durch den Finanzausgleich enger zusammen. Die Kritik ist daher in erster Linie allokationspolitisch motiviert. Sie richtet sich gegen das hohe Ausgleichsniveau und die mit dem heutigen Stufentarif verbundenen negativen Verhaltensanreize.

Die Dominanz der Umverteilungszielsetzung prägt das gesamte Ausgleichsverfahren. Den allokativen Aspekten wird im Zweifel keine ausschlaggebende Bedeutung beigemessen, was in der aktuellen Diskussion das Pendel manchmal nach der anderen Seite - hin zu einer einseitigen Betonung der Effizienzkriterien - ausschlagen läßt. Der grundsătzlich bestehende Zielkonflikt könnte aber entschärft werden, wenn man den nachfolgend genannten Bedenken gegenüber dem heutigen Ausgleichsmechanismus Rechnung tragen würde.

(1) Zehn von sechzehn Bundesländern befinden sich in der Sockelgarantiezone, in der kein fiskalischer Anreiz zur Verbesserung der eigenen Finanzkraft besteht. Mit $95 \%$ ist das Mindestniveau schon im horizontalen Ausgleich i. e. S. sehr hoch angesetzt. Die nochmalige Aufstokkung auf 99,5\% durch die Fehlbetrags-Bundesergänzungszuweisungen kann unter Anreizaspekten nur als völlig überzogen bezeichnet werden.

(2) Auch die Ausgleichsverpflichtungen gehen sehr weit. In der zweiten und insbesondere in der dritten Abschöpfungszone werden marginale Belastungen erreicht, die weit von einer hälftigen Teilung entfernt sind und kaum noch als anreizkompatibel gelten können. Daß die Ausgleichsbeiträge im Bedarfsfall nach oben, die Ausgleichszahlungen aber nicht nach unten angepaßt werden können, unterstreicht die derzeitige Dominanz der Umverteilungsziele und der Interessen der Nettoempfänger. 
(3) Der Staffelung der Abschöpfungszonen fehlt eine nachvollziehbare Tariflogik. Die erste Abschöpfungszone zwischen $100 \%$ und $101 \%$ ist so schmal und mit einem Ausgleichssatz von $15 \%$ so gering belastet, daß die Frage nach ihrer Berechtigung sich förmlich aufdrängt ${ }^{1}$. Der Sprung auf $66 \%$ in der zweiten und $80 \%$ in der dritten Zone fält auch dadurch bedingt recht kräftig aus. Wenn man schon einen Stufentarif verwendet, der den grundsätzlichen Nachteil der Belastungssprünge hat, sollte wenigstens über die Stufen hinweg auf einen relativ gleichmäßigen Belastungsanstieg geachtet werden.

Gegenüber diesen Einwänden sind die weiteren Verstöße gegen die oben genannten Kriterien von nachrangiger Bedeutung, zumal sie direkt mit den Hauptkritikpunkten zusammenhängen. Der Stufentarif gewăhrleistet in Verbindung mit der Ländersteuergarantie nach § 10 Abs. 3 FAG nicht ohne weiteres die Einhaltung der (einfachen) Monotoniebedingung, so daß im heutigen System mit weiteren Garantieklauseln operiert werden muß, um Ånderungen der Finanzkraftrangfolge auszuschließen. Diese Notwendigkeit zeigt auch, daß dem Kriterium der Widerspruchsfreiheit und der Transparenz nicht entsprochen wird. Da eine Reform des Umverteilungstarifs die Zusatzprobleme mitbeseitigen würde, können sich die weiteren Überlegungen auf das Ziel der Herstellung der Anreizkompatibilität konzentrieren.

Ausgehend von dem Befund, daß die zur Zeit praktizierte gestaffelte Umverteilung unnötig kompliziert und mit Fehlanreizen verbunden ist, wird von den meisten Kritikern aus Politik und (Finanz-) Wissenschaft der Wechsel zu einem linearen Ausgleichstarif propagiert ${ }^{2}$. Die Vorschläge unterscheiden sich vor allem in der Frage der (Nicht-) Berücksichtigung einer Sockelgarantie. Die Vorteile eines linearen Ausgleichstarifs (ohne Mindestfinanzkraftgarantie) liegen im wesentlichen darin, daß sein Aufbau sehr einfach und damit transparent ist. Ausgleichszuweisungen und Ausgleichsbeiträge

1 Die Anwort wird - wie so häufig im Lănderfinanzausgleich - rückblickend nur in einem politischen Kompromiß zu suchen sein, für den die damaligen finanziellen Konsequenzen der Regelung, nicht aber systematische Gründe ausschlaggebend waren.

2 Vgl. Wissenschaftlicher Beirat beim Bundesministerium der Finanzen, 1992, S. 77 ff.; Sachverständigenrat zur Begutachtung der gesamtwirtschaftlichen Entwicklung, 1992, Z. $370 \mathrm{ff}$.; Arndt, 1999, S. 84 ff.; Lichtblau, 1999, S. 107 ff. Einen nichtlinearen, exponentiellen Tarif befürwortet dagegen Lenk, 1998, S. $55 \mathrm{ff}$. 
werden nach derselben Regel bestimmt, und die Ausgleichs- und Abschöpfungsquoten stimmen stets überein. Die Finanzkraftreihenfolge ist durch die strenge Monotonie und Stetigkeit der linearen Ausgleichsfunktion automatisch und ohne komplizierte Garantieklauseln gesichert.

Ein Hauptgrund für die Einführung eines linearen Tarifs besteht darin, die Grenzbelastungen gegenüber dem gestaffelten Progressionstarif deutlich zu reduzieren. Da eine Herabsetzung der Nivellierungsintensităt im horizontalen Länderfinanzausgleich nicht sinnvoll wäre, wenn die positiven Wirkungen durch entgegengesetzte Effekte an anderer Stelle neutralisiert würden, sind neuere Modelle linearer Ausgleichstarife durchgăngig mit dem Vorschlag verbunden, die Fehlbetrags-Bundesergănzungszuweisungen abzuschaffen. Im Vorgriff auf die spătere Diskussion der Bundesergänzungszuweisungen (vgl. S. 185 ff.) schließen sich die weiteren Überlegungen dieser Vorgehensweise an. Es wäre sonst nicht möglich, alle Wirkungen eines linearen Ausgleichstarifs im Vergleich zum heutigen Verfahren deutlich zu machen.

\section{c. Verteilungseffekte des progressiven Stufentarifs}

Im ersten Schritt sollen die aus dem direkt progressiven Stufentarif resultierenden Verteilungseffekte gegenüber einem beispielhaften linearen Tarif mit „Halbteilung“ aufgezeigt werden. Der gewählte Ausgleichssatz von $50 \%$ bestimmt zwar das Ausmaß der Vor- und Nachteile der einzelnen Länder im Vergleich zur bestehenden Regelung. Die Verwendung anderer Quoten würde aber an der Struktur der Verteilungseffekte wenig ändern ${ }^{1}$. Bei diesen Berechnungen sind die Fehlbetrags-Bundesergänzungszuweisungen noch enthalten. Dadurch wird deutlich, wie stark der Bund indirekt von den Regelungen des Länderfinanzausgleichs betroffen ist, auch wenn diese zunächst nur den Ausgleich zwischen den Ländern tangieren.

Tabelle 9 zeigt im oberen Teil die Wirkungen des progressiven gegenüber einem linearen Tarif unter der Annahme, daß alle anderen Ausgleichsparameter unverändert bleiben. Erwartungsgemäß erweisen sich die finanzstar-

1 Häufig werden Ausgleichssätze zwischen $50 \%$ und $60 \%$ genannt. Vgl. z. B. Wissenschaftlicher Beirat beim Bundesministerium der Finanzen, 1992, S. 78; Sachverständigenrat zur Begutachtung der gesamtwirtschaftlichen Entwicklung, 1992, Z. 371. 
Tabelle 9

\section{Verteilungseffekte des progressiven Ausgleichstarifs 1998}

\begin{tabular}{|l|rr|rrr|}
\hline \multicolumn{1}{|c}{ Land } & \multicolumn{2}{c}{ GuV } & \multicolumn{1}{c|}{ USt } & \multicolumn{1}{c|}{ LFA } & \multicolumn{1}{c|}{ BEZ } \\
\hline NRW & DM /E & Mio. DM & & \multicolumn{1}{c|}{ Mio. DM } & \\
BAY & $-36,02$ & $-647,2$ & 0,0 & $-644,3$ & 0,0 \\
BW & $-56,75$ & $-684,8$ & 0,0 & $-684,9$ & 0,0 \\
NDS & $-90,61$ & $-943,1$ & 0,0 & $-946,1$ & 0,0 \\
HE & $-3,50$ & $-27,5$ & 0,0 & $-262,3$ & 236,1 \\
RP & $-189,90$ & $-1.145,5$ & 0,0 & $-1.152,3$ & 0,0 \\
SH & $-3,71$ & $-14,9$ & 0,0 & $-143,8$ & 129,4 \\
SAAR & 4,77 & 13,2 & 0,0 & 14,5 & 0,0 \\
HH & $-0,63$ & $-0,7$ & 0,0 & $-2,3$ & 2,1 \\
HB & $-80,23$ & $-136,4$ & 0,0 & $-136,5$ & 0,0 \\
SN & 50,92 & 34,1 & 0,0 & 377,0 & $-339,3$ \\
ST & 11,32 & 51,0 & 0,0 & 510,1 & $-459,1$ \\
TH & 11,66 & 31,4 & 0,0 & 313,7 & $-282,3$ \\
BB & 12,76 & 31,5 & 0,0 & 315,2 & $-283,7$ \\
MV & 9,44 & 24,4 & 0,0 & 243,7 & $-219,4$ \\
BER & 13,55 & 24,4 & 0,0 & 244,4 & $-219,9$ \\
West & 57,18 & 195,4 & 0,0 & $1.953,9$ & $-1.758,5$ \\
Ost & $-55,04$ & $-3.552,8$ & 0,0 & $-3.581,1$ & 28,3 \\
Alle & 20,50 & 358,1 & 0,0 & $3.581,1$ & $-3.223,0$ \\
\hline GuV & $-38,95$ & $-3.194,7$ & 0,0 & 0,0 & $-3.194,7$ \\
\hline USt & Erhöhung (+) bzw. Verminderung (-) der Ländereinnahmen gegenüber \\
\hline
\end{tabular}

\begin{tabular}{|c|c|c|c|c|c|}
\hline Land & \multicolumn{2}{|c|}{ GuV } & USt & LFA & BEZ \\
\hline & $\mathrm{DM} / \mathrm{E}$ & Mio. DM & \multicolumn{3}{|c|}{ Mio. DM } \\
\hline NRW & 2,32 & 41,7 & 697,4 & $-652,7$ & 0,0 \\
\hline BAY & $-18,41$ & $-222,1$ & 468,3 & $-690,6$ & 0,0 \\
\hline BW & $-52,26$ & $-543,9$ & 404,0 & $-951,0$ & 0,0 \\
\hline NDS & 34,41 & 270,1 & 304,7 & $-266,0$ & 232,8 \\
\hline HE & $-151,54$ & $-914,1$ & 234,1 & $-1.155,2$ & 0,0 \\
\hline RP & 34,19 & 137,4 & 156,0 & $-145,6$ & 127,7 \\
\hline SH & 43,10 & 119,0 & 107,1 & 13,2 & 0,0 \\
\hline SAAR & 37,27 & 40,1 & 41,8 & $-2,8$ & 1,6 \\
\hline $\mathrm{HH}$ & $-35,20$ & $-59,9$ & 66,0 & $-126,1$ & 0,0 \\
\hline HB & 101,41 & 68,0 & 26,0 & 381,1 & $-335,6$ \\
\hline SN & 49,24 & 221,9 & 174,9 & 508,0 & $-461,0$ \\
\hline ST & 49,58 & 133,4 & 104,4 & 312,5 & $-283,5$ \\
\hline TH & 50,68 & 125,2 & 95,9 & 314,0 & $-284,7$ \\
\hline BB & 47,37 & 122,2 & 100,2 & 242,5 & $-220,4$ \\
\hline MV & 51,47 & 92,8 & 70,0 & 243,5 & $-220,7$ \\
\hline BER & 107,69 & 368,0 & 132,6 & $1.975,0$ & $-1.739,6$ \\
\hline West & $-16,48$ & $-1.063,6$ & $2.505,4$ & $-3.595,5$ & 26,5 \\
\hline Ost & 60,88 & $1.063,6$ & 678,0 & $3.595,5$ & $-3.209,9$ \\
\hline Alle & 0,00 & 0,0 & $3.183,4$ & 0,0 & $-3.183,4$ \\
\hline $\begin{array}{l}\text { GuV } \\
\text { USt }\end{array}$ & \multicolumn{5}{|c|}{$\begin{array}{l}\text { Erhöhung }(+) \text { bzw. Verminderung (-) der Ländereinnahmen gegenüber } \\
\text { einem LFA mit linearem Ausgleichstarif (Ausgleichssatz 50\%) } \\
48,1 \% \text { Länderanteil }\end{array}$} \\
\hline
\end{tabular}


Tabelle 9 (Fortsetzung)

Quote der Fehlbetrags-Bundesergänzungszuweisungen angepaßt

\begin{tabular}{|c|c|c|c|c|c|}
\hline \multirow[t]{2}{*}{ Land } & \multicolumn{2}{|c|}{ GuV } & USt & LFA & BEZ \\
\hline & DM / E & Mio. DM & \multicolumn{3}{|c|}{ Mio. DM } \\
\hline NRW & $-36,02$ & $-647,2$ & 0,0 & $-644,3$ & 0,0 \\
\hline BAY & $-56,75$ & $-684,8$ & 0,0 & $-684,9$ & 0,0 \\
\hline BW & $-90,61$ & $-943,1$ & 0,0 & $-946,1$ & 0,0 \\
\hline NDS & 39,34 & 308,9 & 0,0 & $-262,3$ & 572,4 \\
\hline $\mathrm{HE}$ & $-189,90$ & $-1.145,5$ & 0,0 & $-1.152,3$ & 0,0 \\
\hline RP & 42,16 & 169,4 & 0,0 & $-143,8$ & 313,7 \\
\hline SH & 4,77 & 13,2 & 0,0 & 14,5 & 0,0 \\
\hline SAAR & 67,76 & 73,0 & 0,0 & $-2,3$ & 75,7 \\
\hline $\mathrm{HH}$ & $-80,23$ & $-136,4$ & 0,0 & $-136,5$ & 0,0 \\
\hline $\mathrm{HB}$ & 306,75 & 205,7 & 0,0 & 377,0 & $-167,7$ \\
\hline SN & 116,54 & 525,3 & 0,0 & 510,1 & 15,1 \\
\hline ST & 117,88 & 317,1 & 0,0 & 313,7 & 3,4 \\
\hline $\mathrm{TH}$ & 122,40 & 302,4 & 0,0 & 315,2 & $-12,8$ \\
\hline BB & 108,42 & 279,8 & 0,0 & 243,7 & 36,1 \\
\hline MV & 125,73 & 226,8 & 0,0 & 244,4 & $-17,6$ \\
\hline BER & 332,34 & $1.135,7$ & 0,0 & $1.953,9$ & $-818,2$ \\
\hline West & $-43,17$ & $-2.786,9$ & 0,0 & $-3.581,1$ & 794,1 \\
\hline Ost & 159,54 & $2.787,0$ & 0,0 & $3.581,1$ & $-794,0$ \\
\hline Alle & 0,00 & 0,1 & 0,0 & 0,0 & 0,1 \\
\hline GuV & $\begin{array}{l}\text { Erhöhung (+) b } \\
\text { einem LFA mit }\end{array}$ & em $A$ & Lär & $\begin{array}{l}\text { nahmen } \\
\text { issatz } 50\end{array}$ & \\
\hline USt & 49,5\% Lăndera & & & Ehlbetrags & Quote \\
\hline
\end{tabular}

ken westlichen Bundesländer als Verlierer des heutigen Systems. Mit Mindereinnahmen in Höhe von rund $190 \mathrm{DM}$ je Einwohner (bzw. insgesamt über 1,1 Mrd. DM) ist Hessen, das als einziges Bundesland in die dritte Abschöpfungszone fältt, besonders stark betroffen. Die größten Pro-Kopf-Gewinne verzeichnen die (im Sinne des FAG) finanzschwachen Stadtstaaten Berlin und Bremen. Der heimliche Hauptgewinner ist aber der Bund, der bei Anwendung eines linearen Ausgleichstarifs zusătzliche Fehlbetrags-Bundesergănzungszuweisungen in Höhe von 3,2 Mrd. DM zu leisten hătte.

Dieser Befund bestätigt zunächst einmal die These, daß es keinen Sinn macht, einen linearen Tarif im horizontalen Länderfinanzausgleich im engeren Sinne einzuführen, wenn die damit verbundenen erwünschten Umschichtungen durch die Bundesergänzungszuweisungen konterkariert werden. Natürlich kann man auch nicht erwarten, daß der Bund zu einer mehr als fünfzigprozentigen Aufstockung der Fehlbetrags-Bundesergänzungszu- 
weisungen bereit wäre. Um Verschiebungen zwischen Bund und Lăndergesamtheit zu neutralisieren, kommen wiederum eine Verminderung des Umsatzsteueranteils der Lănder (von $49,5 \%$ auf $48,1 \%$ ) oder eine Reduktion der Ausgleichsquote bei den Fehlbetrags-Bundesergänzungszuweisungen (von $90 \%$ auf $58 \%$ ) in Betracht. Beide Alternativen sind im zweiten und dritten Teil der Tabelle 9 dargestellt.

Die Angaben im oberen Teil der Tabelle 9 sind insofern irreführend, als sie der Ländergesamtheit einen fiktiven Verlust an Bundesergänzungszuweisungen bei Anwendung des Progressionstarifs anlasten und damit dessen Verteilungseffekte unterschătzen. Wenn die notwendige Anpassung über den Umsatzsteueranteil erfolgt, muß der Vergleich in Wahrheit auf die Differenzen zwischen dem heutigen System und einem Finanzausgleich mit linearem Tarif, aber geringerem Umsatzsteueranteil der Länder abstellen. Dementsprechend sind die effektiven Gewinne größer und die Verluste kleiner als es zunächst den Anschein hat ${ }^{1}$. Deutlich wird so auch, daß vier der vermeintlichen Verlierer des progressiven Tarifs - Niedersachsen, Rheinland-Pfalz, das Saarland und (in geringem Umfang) Nordrhein-Westfalen tatsächlich von der heutigen Lösung profitieren.

Gegenüber der Anpassung des Umsatzsteueranteils der Länder erscheint eine kompensatorische Senkung der Quote der Fehlbetrags-Bundesergänzungszuweisungen eher geeignet, den Zielen eines linearen Ausgleichstarifs Rechnung zu tragen. Die Bundesergänzungszuweisungen bleiben dann absolut unverändert, verteilen sich aber anders auf die Länder. Aus dieser im letzten Teil der Tabelle 9 eingenommenen Perspektive fallen die Vorund Nachteile des Progressionstarifs gegenüber den Berechnungen auf der Basis einer Umsatzsteueranpassung quantitativ weitaus stärker ins $\mathrm{Ge}$ wicht. Die Nutznießer des heutigen Systems sind die neuen Bundesländer, vor allem aber die Stadtstaaten Berlin und Bremen. Nordrhein-Westfaler, das bei der Umsatzsteueranpassung knapp zu den Gewinnern zählt, erweist sich als Nettoverlierer, wenn das heutige System mit einem linearen

1 Vor allem die Stadtstaaten profitieren vom höheren Umsatzsteueranteil der Länder im heutigen System. Dieser vergrößert ceteris paribus die durchschnittliche Länderfinanzkraft. Wegen der Einwohnerwertung steigen dadurch die Ausgleichsansprüche bzw. sinken die Ausgleichsbeiträge der Stadtstaaten im horizontalen Länderfinanzausgleich. 
Ausgleichstarif bei gleichzeitig abgesenkter Quote der Fehlbetrags-Bundesergänzungszuweisungen konfrontiert wird.

\section{d. Abbau der Grenzbelastungen durch einen linearen Tarif}

Die beispielhafte Darstellung der Umverteilungswirkungen des progressiven Stufentarifs erlaubt noch keine hinreichend fundierten Aussagen über die ökonomische Zweckmäßigkeit einer Tarifreform. Der Beitrag eines linearen Tarifs zur Entschärfung des Konflikts zwischen den allokativen und distributiven Zielen des Länderfinanzausgleichs kann deutlicher herausgearbeitet werden, wenn man die Grenzbelastungen des bestehenden Systems mit denen konfrontiert, die sich bei Anwendung eines linearen Tarifs einstellen würden.

In diesem Zusammenhang ist es für Vergleichszwecke erforderlich, die alternativen Ausgleichstarife ohne Fehlbetrags-Bundesergänzungszuweisungen zu betrachten. Deren Abschaffung hätte für sich genommen nur einen geringen oder gar keinen Effekt auf die marginalen Abschöpfungsquoten der meisten Länder. Die finanzstarken Länder erhalten keine FehlbetragsBundesergănzungszuweisungen, und die meisten finanzschwachen Länder verharren wegen des Umsatzsteuer-Vorwegausgleichs auf ihrem hohen Belastungsniveau. Nur bei den relativ finanzschwachen alten Ländern Niedersachsen und Rheinland-Pfalz spielen Fehlbetrags-Bundesergänzungszuweisungen derzeit eine entscheidende Rolle für das Ausmaß der marginalen Abschöpfung. Dort würden die Grenzbelastungen allerdings deutlich sinken, und zwar in Niedersachsen von $100,1 \%$ auf $41,0 \%$ und in Rheinland-Pfalz von $105,1 \%$ auf $42,3 \%$.

Diese Situation würde sich jedoch durch die Einführung eines linearen Ausgleichstarifs bei unveränderter 90-prozentiger Ausgleichsquote der Fehlbetrags-Bundesergänzungszuweisungen gravierend ändern. Die daraus resultierenden Mindereinnahmen der finanzschwachen Länder bedeuten eine Senkung ihrer relativen Finanzkraft. Sie würden daher in die FehlbetragsBundesergänzungszuweisungen hineinwachsen, die auf diese Weise massiv an Bedeutung gewinnen würden. Dies zeigten ja schon die im letzten 
Abschnitt durchgeführten Berechnungen zur Umverteilung, die für den Bund eine Mehrbelastung von 3,2 Mrd. DM bei einem Wechsel zum linearen Tarif ausweisen. Die Grenzbelastungen werden daher im folgenden unter der Annahme eines linearen Ausgleichstarifs ohne Fehlbetrags-Bundesergänzungszuweisungen diskutiert.

Der Vergleich der Grenzbelastungen eines reformierten Systems mit dem Länderfinanzausgleich 1998 erfolgt für zwei alternative Modelle. Modell 1 enthält eine Sockelgarantie in Form des bisherigen Umsatzsteuer-Vorwegausgleichs, während Modell 2 darauf verzichtet und sich auf den linearen Ausgleich beschränkt. Die Ergebnisse der ersten Reformoption illustriert Abbildung 14 für einen Anstieg des regionalen Lohnsteueraufkommens.

\section{Abbildung 14}

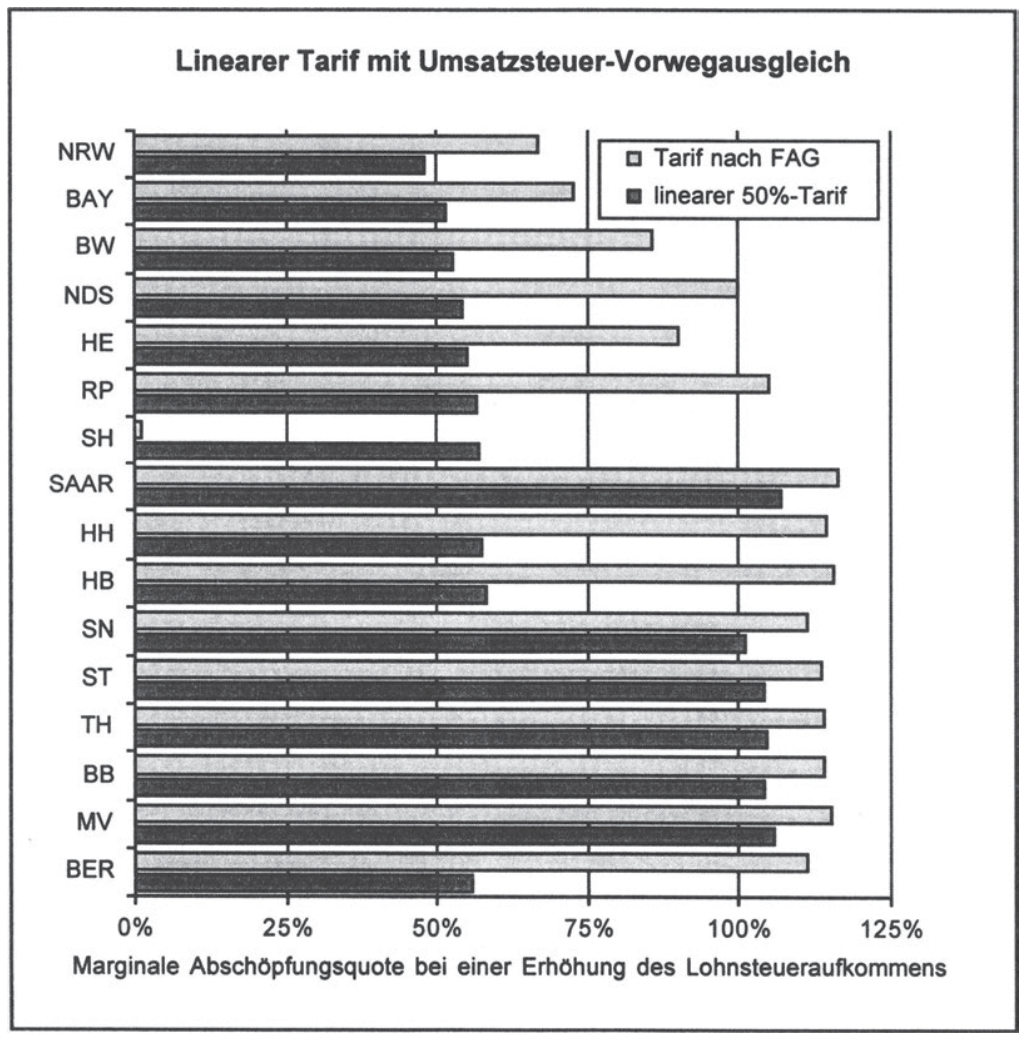


Der Rückgang der Grenzbelastungen der Länderhaushalte făllt überdeutlich aus ${ }^{1}$. Nur das Saarland und die neuen Bundesländer bleiben infolge der Sockelgarantie durch den Umsatzsteuer-Vorwegausgleich marginal hoch belastet. Immerhin geht auch bei diesen Ländern die Grenzbelastung um rund 10 Prozentpunkte zurück.

\section{Abbildung 15}

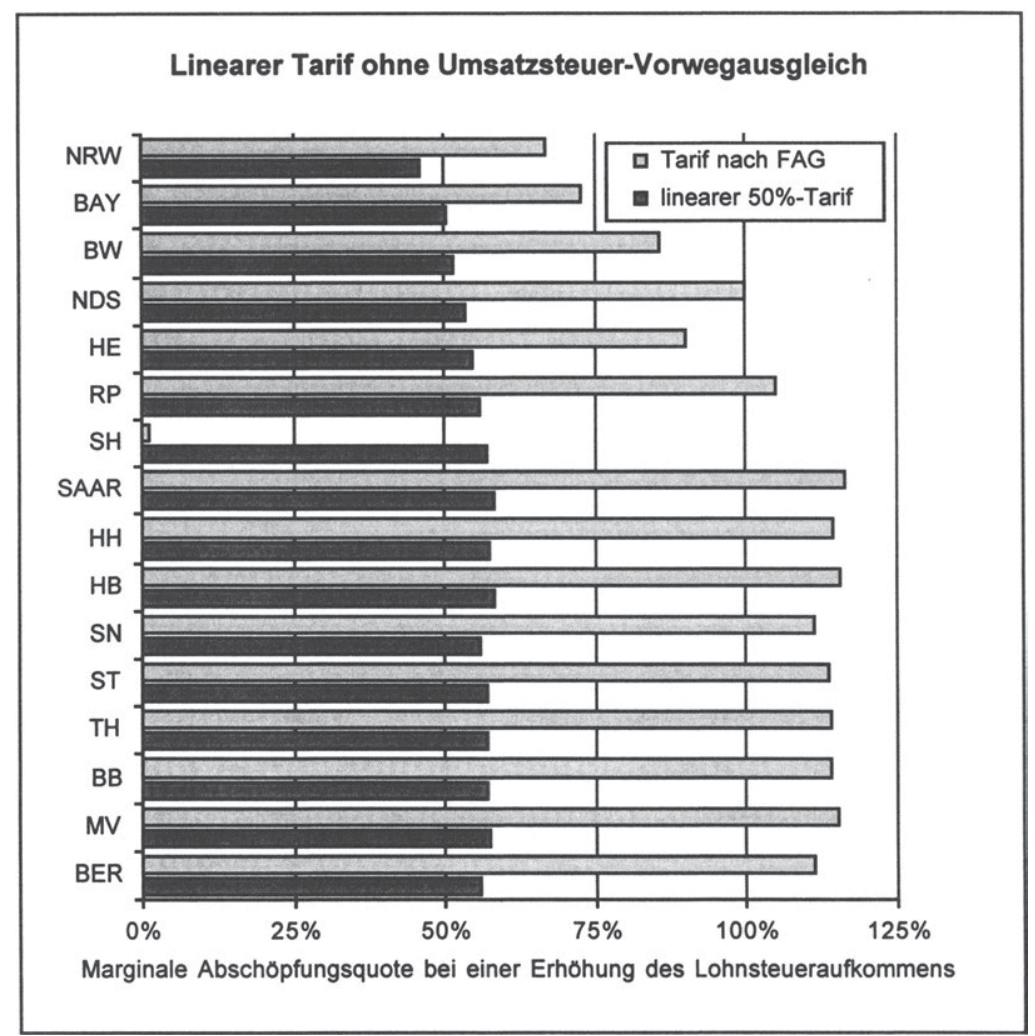

Im zweiten Modell, das ohne Sockelgarantie operiert, fällt die Grenzbelastung in allen Lăndern unter die 60 \%-Grenze. Unter Anreizgesichtspunkten

1 Vor allem wegen der fünfzigprozentigen Anrechnung der kommunalen Finanzkraft können die marginalen Abschöpfungsquoten der Länder nicht auf die Höhe des Ausgleichssatzes von 50 \% sinken. Der Gemeindeeffekt allein sorgt für einen Anstieg auf $58,8 \%$ (vgl. S. 177). 
erscheint dies vorteilhaft, steht aber im Widerspruch zum distributiven Ziel der Sicherstellung einer Mindestfinanzausstattung für alle Lănder. Dieser Zielkonflikt ist schwer aufzulösen. Leistungsanreize setzen voraus, daß ein Teil der Mehreinnahmen im Landeshaushalt verbleibt. Wenn die Sockelgarantie dennoch greifen soll, können die fiskalischen Anreize nur oberhalb dieses Niveaus angesiedelt werden.

\section{Ein Vorschlag zur Reform des Ausgleichstarifs \\ a. Entwicklung der Eckpunkte des Tarifmodells}

Im folgenden wird ein Modell entwickelt, das die Vorzüge des einfachen linearen Ausgleichstarifs mit dem Ziel der garantierten Mindestfinanzkraft auf anreizkompatible Weise zu verknüpfen versucht. Der Vorschlag basiert auf der Flexibilisierung des Ausgleichssatzes a eines grundsätzlich linearen Tarifs. Die relative Finanzkraft eines Landes i nach Finanzausgleich RFK $_{i}^{*}$ ergibt sich dabei aus seiner relativen Finanzkraft vor Finanzausgleich RFK $_{i}$ und dem ${ }_{n}$ normalen“ Ausgleichssatz $a_{n}$ :

(1) $\mathrm{RFK}_{i}^{*}=\mathrm{RFK}_{\mathrm{i}}+\mathrm{a}_{n}\left(1-\mathrm{RFK}_{\mathrm{i}}\right)$

Für den Fall, daß mit dem vorgegebenen Normalsatz die angestrebte Mindestfinanzkraft-Garantie nicht eingelöst werden kann, muß die Möglichkeit einer Anpassung nach oben bestehen. Mit Blick auf die negativen Konsequenzen zu hoher Grenzbelastungen ist aber auch das Ausmaß der maximal zulässigen Abschöpfungen (und Zuweisungen) zu limitieren'1.

Zunächst geht es um die Eingrenzung der Bestimmungsfaktoren des Ausgleichssatzes, der zur Sicherstellung der im Normalfall angestrebten relativen Mindestfinanzkraft $\overline{R F K}$ erforderlich ist. Dieser Ausgleichssatz $a_{\text {min }}$ muß so festgelegt werden, daß das relativ finanzschwächste Land, das vor Finanzausgleich über die relative Finanzkraft $\mathrm{RFK}_{m}$ verfügt, nach Finanzausgleich genau die normalerweise gewünschte Mindestfinanzkraft erreicht. Aus der Bedingung:

1 Es bedarf an dieser Stelle wohl keiner năheren Erläuterung mehr, daß die zulässige Grenzbelastung deutlich unter $100 \%$ liegen muß. 
(2) RFK $_{m}^{*}=\mathrm{RFK}_{m}+a_{\min }\left(1-\mathrm{RFK}_{m}\right)=\overline{\mathrm{RFK}}$

folgt für den Mindest-Ausgleichssatz:

(3) $a_{\min }=\frac{\overline{R F K}-R F K_{m}}{1-R_{m}}$

Der effektive Ausgleichssatz wird also nicht generell vorgegeben, sondern unter Umstănden (wie heute auch) erst im Finanzausgleich endgültig fixiert. Solange der mindestens erforderliche Ausgleichssatz unter dem Normalniveau (von beispielsweise $50 \%$ ) liegt, kommt allerdings der normale Satz $a_{n}$ zur Anwendung, andernfalls der höhere Satz $a_{\min }$ :
(4) $a=a_{n}$
für
$a_{\min }<a_{n}$
$a=a_{\min }$
für
$a_{n}<a_{\min }$

Der minimale Ausgleichssatz kann in diesem Modell den Normalsatz deutlich übersteigen, wenn die relative Mindestfinanzkraft gemessen am finanzschwächsten Land hoch angesetzt wird. Dann besteht auch die Gefahr, daß trotz linearem Tarif hohe Grenzbelastungen erreicht werden. Mit Blick auf die Anreizkompatibilităt muß daher eine Sicherung gegen übermäßige Belastungen der Lănderhaushalte eingebaut werden. Dies läßt sich durch die Flexibilisierung der garantierten Mindestfinanzkraft erreichen. Zwar wird die Sockelgarantie dadurch - ebenso wie der normale Ausgleichssatz - zu einer Zielgröße, die nicht unter allen Umständen eingehalten werden kann. Von der angestrebten Sockelgarantie ist aber nur dann ein Abschlag vorzunehmen, wenn die Grenzbelastungen der Zahler- und auch der Empfăngerländer andernfalls ein kritisches Niveau überschreiten.

Dessen Hơhe läßt sich am Beispiel der Lohnsteuer konkretisieren. Die marginale Abschöpfung der Lohnsteuereinnahmen der Länder $m$ hăngt $a b$ von der Einbeziehungsquote der Gemeindesteuern e, dem Ausgleichssatz a und den Anteilen der Länder I bzw. Gemeinden g an der Lohnsteuer ${ }^{1}$ :

1 Bei den anderen Gemeinschaftsteuern und den Ländersteuern ergeben sich andere marginale Abschøpfungsquoten. Die Lohnsteuer ist aber aufgrund ihrer quantitativen Bedeutung ein besonders geeignetes Beispiel für die Problematik der Grenzbelastungen im Länderfinanzausgleich. Auf die Besonderheiten der Realsteuern wurde bereits im Zusammenhang mit der Ermittlung der Grenzbelastungen hingewiesen. Vgl. S. 85. 
(5) $m=[1+e(g / l)] a$

Bei Einsetzen der heutigen Werte (e $=50 \%, g=15 \%, l=42,5 \%$ ) und einem Normalsatz von $\mathbf{5 0} \%$ im horizontalen Ausgleich erreicht $\mathrm{m}$ den Wert $58,8 \%$. Reicht der normale Ausgleichssatz jedoch nicht aus, um die Sokkelgarantie zu gewährleisten, wird er zunăchst gemäß Gleichung (3) angepaßt. Die Folge ist ein Anstieg der Grenzbelastung. Wenn die marginale Abschöpfung auf ein Maximalniveau $\bar{m}$ limitiert werden soll, muß der gerade noch als anreizkompatibel eingestufte und daher maximal zulässige Ausgleichssatz folgender Bedingung genügen:

(6) $a_{\max }=\frac{\bar{m}}{1+e(g / l)}$

Setzt man die maximale Grenzbelastung beispielsweise auf $80 \%$, dann darf der Ausgleichssatz bei den heutigen Werten von e, $g$ und I eine Obergrenze von $68 \%$ nicht überschreiten ${ }^{1}$. Liegt der nach Gleichung (3) ermittelte über dem maximalen Ausgleichssatz, dann muß die maximal mögliche Sockelgarantie $\overline{\mathrm{RFK}}_{\text {max }}$ folgendermaßen angepaßt werden:

(7) $\overline{\mathrm{RFK}}_{\text {max }}=\mathrm{RFK}_{\mathrm{m}}+\mathrm{a}_{\max }\left(1-\mathrm{RFK}_{\mathrm{m}}\right)$

Auf diese Weise kann der effektive Ausgleichssatz zwischen der Untergrenze gemäß Gleichung (3) und der Obergrenze gemäß Gleichung (6) gehalten werden ${ }^{2}$. Die Bedingungen, denen der effektive Ausgleichssatz insgesamt genügen muß, lassen sich folgendermaßen zusammenfassen:

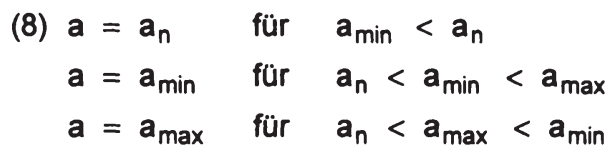

Das Grundmodell für eine Neuregelung des Ausgleichstarifs kann variiert werden. So wäre es wohl in der Praxis nicht sinnvoll, den minimalen Aus-

1 Im Falle einer Erhohung der Einbeziehungsquote der Gemeindesteuern auf $100 \%$ sinkt der maximal zulässige Abschøpfungssatz auf $59,1 \%$. Das Modell paßt sich so flexibel den allokativ bedeutsamen Verănderungen des Finanzausgleichs an. Die notwendige Bedingung für einen stärkeren Einbezug der Kommunalsteuern - eine deutliche Senkung der Grenzbelastungen - wird hier quasi automatisch gewăhrleistet.

2 Vgl. dazu auch Abbildung 16, S. 180. 
gleichssatz allein anhand der Finanzkraft des finanzschwächsten Landes zu bestimmen. Diesem Land würde dadurch ein unverhältnismäßig starker Einfluß auf die Ausgleichsparameter eingeräumt. Man könnte sich aber auch an der Finanzkraft einer kleineren Gruppe von beispielsweise drei besonders finanzschwachen Ländern orientieren und damit die Ermittlung des erforderlichen Ausgleichssatzes auf ein breiteres Fundament stellen. Der Finanzausgleich würde dadurch unabhängiger von zufälligen Schwankungen der Steuerkraft eines einzelnen Landes.

Eng damit verbunden ist ein zweiter Aspekt. Das finanzschwächste Land bzw. eine kleine Gruppe finanzschwacher Lănder bestimmt die Höhe des erforderlichen Ausgleichssatzes, wenn die Sockelgarantie mit dem Normalsatz nicht zu erreichen ist. Von einer Erhöhung des Ausgleichssatzes profitieren aber alle Empfängerländer, auch solche, die über der Sockelgarantie liegen und keine zusătzliche Aufstockung ihrer Finanzkraft benötigen. Naheliegend erscheint daher eine Differenzierung zwischen dem Abschöpfungstarif für finanzstarke und dem Ausgleichstarif für finanzschwache Lănder.

Mit einem gebrochen-linearen Tarif könnte man die Zuweisungsquote bereichsweise unter dem Abschöpfungssatz halten, wenn dieser über sein Normalniveau steigen muß. Dies würde das Einhalten der Sockelgarantie für die besonders finanzschwachen Länder unter Berücksichtigung der Limitierung der Grenzbelastung der finanzstarken Länder erleichtern. Allerdings wäre der gebrochen-lineare Tarif mit dem Nachteil verbunden, daß die Grenzbelastungen in den verschiedenen Tarifzonen variieren ${ }^{1}$. Außer-

1 Bei einem einfachen linearen Tarif wird der Ausgleichssatz im Bedarfsfall erhöht (z. B. auf $68 \%$ ), um den Zielwert der Sockelgarantie möglichst weitgehend zu erreichen. Damit steigt die Grenzbelastung für alle Länder in gleichem Maße (z. B. auf $80 \%$ ), und zwar bei den Zahlerländern durch erhöhte Abschöpfungen, bei den Empfängerländern durch erhöhte Zuweisungen. Ein gebrochen-linearer Tarif hat dagegen (mindestens) 3 Zonen. In der Zone 1 befinden sich die finanzschwächsten Länder, die gegenüber dem einfachen linearen Tarif höhere Zuweisungen erhalten. Die problematische Folge ist allerdings eine wachsende Grenzbelastung bei diesen Empfängerlăndern. Sie übersteigt das für die Zahlerländer als gerade noch zumutbar angesehene Niveau und steht daher der Anreizkompatibilităt des Tarifs entgegen. Die Tarifzone 2 umfaßt die Empfängerländer, die schon vor Länderfinanzausgleich über der Sockelgarantie liegen. Mit dem Zuweisungssatz sinkt deren Grenzbelastung gegenüber dem durchgängig linearen Tarif auf das durch den normalen Ausgleichssatz bestimmte Niveau. Für die Zahlerländer in der Zone 3 ändert sich nichts. Sie werden in der allokativ maximal vertretbaren Hơhe belastet, solange die Sockelgarantie dies erfordert.

Wolfgang Scherf - 978-3-631-75181-7 
dem würde die Transparenz des Ausgleichsverfahrens leiden und die automatische Übereinstimmung der Abschöpfungen und Zuweisungen verlorengehen. Infolgedessen ist ein gebrochen-linearer Tarif dem einfachen Tarifmodell nicht ohne weiteres überlegen ${ }^{1}$. Die bisherigen Erfahrungen mit dem Länderfinanzausgleich sprechen eher dafür, auf solche Versuche einer Perfektionierung des Ausgleichsverfahrens zu verzichten. Den Vorzug verdient im Zweifel ein überschaubares System, das die relevanten Ausgleichsziele und Nebenbedingungen ausgewogen berücksichtigt.

\section{b. Die Funktionsweise des Ausgleichsmechanismus}

Ein Beispiel soll die Funktionsweise des Grundmodells verdeutlichen. Der Normalsatz liege bei $50 \%$, die Sockelgarantie wird - in Anlehnung an den heutigen Umsatzsteuer-Vorwegausgleich - mit $92 \%$ angesetzt und die maximal zulässige Grenzbelastung sei $80 \%$. Der effektive Ausgleichssatz darf sich dann zwischen $50 \%$ und $68 \%$ bewegen, solange die heutigen Werte für die Einbeziehungsquote der Gemeindesteuern und die Anteile der Länder bzw. der Gemeinden an der Lohnsteuer gelten (vgl. Abbildung 16). Erreicht das finanzschwächste Bundesland ${ }^{2}$ vor Finanzausgleich (bei Verteilung der Umsatzsteuer nach Einwohnern) eine relative Finanzkraft von z. B. $60 \% 3$, dann beträgt der nach Gleichung (3) ermittelte erforderliche Ausgleichssatz zur Gewährleistung der 92-prozentigen Sockelgarantie $80 \%$. Zulässig sind aber - mit Blick auf die Grenzbelastungen - maximal $68 \%$, und dieser Wert ist nur mit einer reduzierten Sockelgarantie von $87,2 \%$ vereinbar 4 .

1 Dessen Vorteil besteht im wesentlichen darin, daß nicht alle Empfängerländer von der besonderen Finanzschwäche einiger Empfängerländer profitieren; ein Effekt, der sich bei einem erfolgreichen Aufholproze $B$ der besonders finanzschwachen Länder übrigens umkehrt. Relativiert wird der (hoffentlich) vorübergehende Vorteil der finanzstärkeren Empfängerländer auch dadurch, daß das einfache Modell mit Ausgleichssätzen operiert, die gegenüber dem heutigen Verfahren zu deutlich geringeren Ausgleichseffekten und Grenzbelastungen führen.

2 Man könnte, wie oben erwähnt, auch auf eine finanzschwache Lăndergruppe abstellen.

3 Dieser Wert wurde 1998 von allen Ländern überschritten, von den neuen Lándern allerdings nur knapp.

4 Die Sockelgarantie kann auf einem etwas höheren Niveau gehalten werden, wenn differenzierte Auffüll- und Abschöpfungsquoten zur Anwendung kommen. 


\section{Abbildung 16}

\section{Ausgleichssatz und Grenzbelastung}

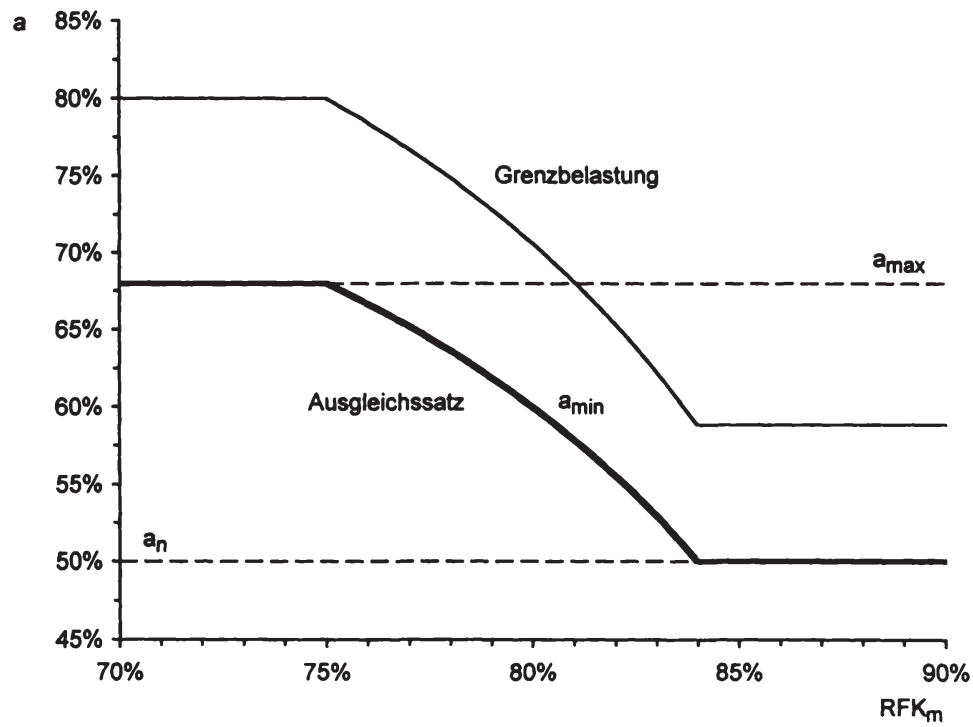

Im Zuge einer Verbesserung der relativen Finanzkraft des finanzschwächsten Bundeslandes würde die Sockelgarantie zunächst bis auf den Zielwert von $92 \%$ angehoben. Der Ausgleichssatz bliebe solange unverăndert auf seinem maximal zulässigen Niveau, bis die relative Finanzkraft des finanzschwächsten Bundeslandes $75 \%$ erreicht hat. Weitere Verbesserungen würden dann automatisch zu einer schrittweisen Reduktion des Ausgleichssatzes bis auf $50 \%$ und der Grenzbelastungen bis auf $58,8 \%$ führen (vgl. Abbildung 16). Realisierbar sind diese Werte, wenn es gelingt, die relative Finanzkraft des finanzschwächsten Bundeslandes auf 84 \% zu steigern1.

Das hier vorgeschlagene Modell verbindet die Vorzüge eines linearen Tarifs mit einer Mindestfinanzkraftgarantie, die so gestaltet ist, daß die finanzschwächeren Länder einen starken Anreiz zur Verbesserung ihrer Finanz-

1 Dieser Wert wurde 1998 von allen alten Bundesländer - gemessen an der Finanzkraft nach Pro-Kopf-Verteilung der Umsatzsteuer - überschritten. 
kraftposition behalten. Die begrenzte Flexibilisierung des Ausgleichssatzes und der Garantiegrenze ermöglicht einen Kompromiß zwischen den allokativen und distributiven Zielen des Finanzausgleichs. Das Gewicht der beiden Ziele variiert mit den Finanzkraftdifferenzen der Länder und paßt sich somit den Erfordernissen der jeweiligen Situation an.

Dies wird deutlich, wenn man das Modell auf die bundesdeutschen Verhältnisse überträgt. Solange die neuen Lănder mit einer ausgeprägten Finanzschwäche zu kämpfen haben, dominiert das Bemühen, eine Sockelgarantie zu realisieren, die möglichst nah bei der auf Dauer gewünschten Zielgröße liegt. Den ausgleichspflichtigen Ländern wird daher der unter Anreizaspekten gerade noch als vertretbar angesehene Ausgleichssatz zugemutet. Im Zuge eines ökonomischen Aufholprozesses der neuen Länder profitieren diese zunächst von der schrittweise auf ihr Normalniveau steigenden Sokkelgarantie. Anschließend werden weitere Fortschritte nur noch zur Verminderung der Grenzbelastungen des Finanzausgleichs genutzt, bis auch dort der Zielwert erreicht ist, der (implizit) über den Normalsatz des linearen Ausgleichstarifs bestimmt wird.

Das Modell zeichnet sich dadurch aus, daß dem Ziel einer garantierten Mindestfinanzkraft grundsătzlich Priorităt vor dem Ziel einer möglichst geringen, dem normalen Satz angenäherten Ausgleichsquote eingerăumt wird. Allerdings ist dabei die allokativ motivierte Nebenbedingung des Einhaltens einer Obergrenze der marginalen Abschöpfung zu erfüllen. Sobald die Sockelgarantie einer Senkung der Nivellierungsintensităt nicht mehr im Wege steht, wird die lineare Ausgleichsquote bis auf ihr Normalniveau reduziert. Damit gewinnen die allokativen Kriterien des Finanzausgleichs mit zunehmender Verringerung der Finanzkraftdifferenzen an Bedeutung. In einer optimistischen Perspektive - bei erfolgreichem Aufholproze $B$ in den ostdeutschen Lăndern - würde also auf Dauer ein Automatismus in Richtung auf einen stärker allokativ orientierten Finanzausgleich wirksam. Langfristig wäre dieses Ziel erreichbar, ohne die Anpassungs- und Ausgleichserfordernisse in der Übergangsphase zu vernachlässigen. 


\section{c. Unterschiede zu anderen Modellen}

Hinsichtlich der Flexibilităt, die besonders in der Übergangszeit, aber auch langfristig zweckmäßig erscheint, unterscheidet sich das hier skizzierte Modell von anderen Vorschlägen, die sofort zu einem linearen Ausgleichstarif ohne Sockelgarantie übergehen wollen. Um den daraus resultierenden Anpassungsfriktionen zu begegnen, will man den Empfăngerländern im Jahr der Einführung des neuen Systems den Status quo in Form von Festbeträgen garantieren, die in der Folgezeit schrittweise - z. B. mit jăhrlich 2 Prozentpunkten - abgebaut werden sollen'1. Der Vorteil einer solchen Lösung liegt darin, daß die Pauschaltransfers das Marginalkalkül der Lănder nicht mehr beeinflussen, da ihre Hőhe vorab feststeht und nicht von der Entwicklung der relativen Finanzkraft eines Landes abhängt. Dennoch kann von Modellen mit langjährigen Pauschaltransferregelungen nur abgeraten werden.

(1) Die Festbetrăge hăngen allein von den finanziellen Verhältnissen des Startjahres ab. Ein Land kann daher nach der Umstellung auf Jahre hinaus von einer im Startjahr besonders schlechten Finanzlage profitieren (und umgekehrt). Um dies zu vermeiden, sollte man zur Bestimmung der Pauschaltransfers wenigstens einen mehrjăhrigen Durchschnitt der Finanzausgleichssalden heranziehen.

(2) Mit zunehmender Entfernung vom Umstellungszeitpunkt wird es immer schwieriger, die Höhe der Pauschaltransfers zu rechtfertigen und zu akzeptieren. Politischer Streit ist vorprogrammiert, wenn nach zehn oder fünfzehn Jahren ein dann vielleicht relativ finanzstarkes Land immer noch hohe Transfers aufgrund seiner früheren Finanzschwäche erhält 2 .

(3) Der entscheidende Nachteil der einfachen linearen Tarife besteht darin, daß sie keine Mindestfinanzkraft garantieren können (oder wollen). Die geplanten Übergangsmodalităten sind geeignet, diesen Punkt ein wenig

1 Vgl. Huber/Lichtblau, 1997, 1998; Bayerisches Staatsministerium der Finanzen, 1998; Arndt, 1999, S. 85. Die Festbeträge sollen aus den Mehreinnahmen der Reformgewinner finanziert werden, um die politische Durchsetzbarkeit des Modells zu verbessern.

2 Dieser Nachteil der Pauschaltransfers laßßt sich durch eine Aktualisierung in mehrjährigen Abständen mildern. Allerdings năhert man sich damit wieder der anreizfeindlichen traditionellen Sockelgarantie, zumal die Länder kommende Neuregelungen antizipieren und ihre bisherige Finanzpolitik daher nur wenig ändern dürften. 
zu verschleiern. Länder, die nach der Umstellung in Schwierigkeiten geraten, kommen bei einem rein linearen Ausgleichstarif jedenfalls nicht mehr in den Genuß einer Sockelgarantie.

Solange das Mindestausgleichsniveau als wichtige Zielgröße einer distributiv vertretbaren Lősung anerkannt wird, ist der hier vorgeschlagene Weg einer schrittweisen, flexiblen und auch auf Dauer tragfähigen Tarifreform den Modellen mit Pauschaltransfers vorzuziehen. Deren primäres Anliegen - die Herabsetzung der Grenzbelastungen - läßt sich erreichen, ohne zentrale Prinzipien des Länderfinanzausgleichs aufgeben zu müssen.

\section{d. Der Reformvorschlag im Überblick}

Die wesentlichen Elemente und Eigenschaften des hier vorgeschlagenen Tarifmodells sollen abschließend noch einmal zusammengefaßt werden.

(1) Nur das jeweils finanzschwächste Land wird genau auf das unter den gegebenen Umständen maximal erreichbare Mindestniveau angehoben. Alle anderen liegen nach Finanzausgleich darüber, so daß die Forderung nach Anreizkompatibilität auch für finanzschwache Länder erfüllt ist. Ebenfalls gewährleistet ist die strenge Monotonie der Finanzkraftreihenfolge vor und nach Finanzausgleich.

(2) Der Ausgleichssatz variiert in Abhängigkeit von der notwendigen Mindestauffüllung. Diese Eigenschaft ist allen Systemen eigen, die eine Sockelgarantie gewährleisten wollen. Im vorliegenden Modell wird jedoch eine Obergrenze für den Ausgleichssatz eingezogen. Dieser darf nur so hoch sein, daß eine unter allokativen Gesichtspunkten festgelegte maximale Grenzbelastung der Länder nicht überschritten wird.

(3) Im Konfliktfall zwischen Sockelgarantie und Einhaltung des normalerweise gewünschten Ausgleichssatzes wird der Sockelgarantie Priorität eingeräumt; im Konfliktfall zwischen Sockelgarantie und Einhaltung der maximalen Grenzbelastung gibt die Grenzbelastung den Ausschlag. Die Sockelgarantie muß daher im Bedarfsfall angepaßt werden und kann ihr Normalniveau zeitweise unterschreiten. 
(4) Verbesserungen der relativen Finanzkraft finanzschwacher Länder erleichtern zunächst die Einhaltung der Sockelgarantie und führen anschließend zu einer automatischen Reduktion des Ausgleichssatzes und der Grenzbelastungen. Dies ist ein vernünftiger Kompromiß zwischen Umverteilung und Anreizkompatibilităt des Finanzausgleichs.

Da das Tarifmodell die Vorzüge eines linearen Ausgleichstarifs mit einer garantierten Mindestfinanzausstattung und allokativ vertretbaren Grenzbelastungen verknüpft, sollte es als geeignete Grundlage weitergehender Reformüberlegungen angesehen werden. Es sei aber noch einmal davor gewarnt, das Tarifproblem allein zum Gegenstand der Reformbemühungen zu machen. Genauso wichtig ist die Bereinigung der Bemessungsgrundlagen des Länderfinanzausgleichs im Sinne einer strikten Orientierung am ungewichteten Einwohner. 


\section{Die Bundesergänzungszuweisungen - „Mädchen für alles“1}

Die Bundesergänzungszuweisungen wurden nach der Deutschen Einheit erheblich ausgeweitet. Der Bund hat damit eine dominierende Stellung im System des Länderfinanzausgleichs gewonnen, die ökonomisch schon deshalb bedenklich erscheint, weil der horizontale Finanzkraftausgleich durch vertikale Elemente teils verstärkt, teils von Bedarfsgesichtspunkten überlagert wird. Die Vermischung der verschiedenen Ausgleichszwecke ist aber nicht das entscheidende Problem. Vielmehr stellt sich bei allen Bundesergänzungszuweisungen die Frage nach ihrer grundsätzlichen Berechtigung. Sollten sich die Bundesergănzungszuweisungen teilweise als ökonomisch unvertretbar erweisen, sind auch die mit innen einhergehenden Umverteilungseffekte insoweit inakzeptabel (vgl. S. 74 ff.). Sie verstoßen dann gegen das Gleichbehandlungsgebot und können auch eine Übernivellierung im engeren Sinne einer sachlich unbegründeten Vertauschung relativer Finanzkraftpositionen bewirken.

\section{A. Die Fehlbetrags-Bundesergănzungszuweisungen}

In engem Zusammenhang zu den vorstehend diskutierten Problemen des horizontalen Länderfinanzausgleichs stehen die Fehlbetrags-Bundesergănzungszuweisungen ( $(11$ Abs. 2 FAG). Sie stellen im Grunde eine Übertragung von Teilen des Umsatzsteueraufkommens an den Bund mit dem Ziel dar, durch eine Intensivierung des Länderfinanzausgleichs die Finanzkraft der finanzschwachen Länder auf mindestens $99,5 \%$ und damit nahezu auf den Länderdurchschnitt heraufzusetzen. „Es verbleibt ein halbes Prozent okonomische Vernunft"2.

Fehlbetrags-Bundesergănzungszuweisungen dienen dem (weiteren) Abbau horizontaler Finanzkraftdifferenzen der Länder. Sie haben keine darüber hinausgehende spezielle finanzausgleichspolitische Funktion. Daher dürfen auch nur solche Laander "Empfänger von Bundesergänzungszuweisungen sein, die nach den Ergebnissen des horizontalen Länderfinanzausgleichs

1 Die Bezeichnung stammt von Peffekoven, 1994, S. 298.

2 Homburg, 1996, S. 338. 
unter diesem Länderdurchschnitt geblieben sind, und die Ergänzungszuweisungen dürfen die Finanzkraft der Empfängerländer nicht über den Länderdurchschnitt hinaus erhöhen “1. Der intendierte weitere Abbau der Finanzkraftdifferenzen rechtfertigt aber keine vertikalen Zuweisungen mit horizontalem Effekt, denn er könnte ohne weiteres im Rahmen des dafür primär zuständigen horizontalen Länderfinanzausgleichs geleistet werden.

Die These von der nahezu perfekten Ersetzbarkeit der Fehlbetrags-Bundesergănzungszuweisungen durch den Finanzausgleich unter den Ländern kann anhand einiger Berechnungen für das Jahr 1998 bestätigt werden. Tabelle 10 enthält im oberen Teil die Verteilung der Bundesergänzungszuweisungen auf die einzelnen Lănder. Gemessen an den DM-pro-EinwohnerGewinnen profitieren die finanzschwachen Flächenländer und noch mehr die infolge der Einwohnerwertung finanzschwach gerechneten Stadtstaaten Berlin und Bremen. Dieses Bild ist jedoch irreführend, denn es berücksichtigt nicht, daß der Bund den Ländern über Fehlbetrags-Bundesergănzungszuweisungen rund 5,8 Mrd. DM zukommen läßt, die er der Lăndergesamtheit auch in Form eines von $49,5 \%$ auf 51,9 \% erhöhten Umsatzsteueranteils zur Verfügung stellen könnte.

Der zweite Teil der Tabelle 10 zeigt die Verteilungswirkungen der Fehlbetrags-Bundesergănzungszuweisungen im Vergleich zu einer Situation ohne diese Zuweisungen, aber mit kompensatorischer Anpassung der Umsatzsteuer. Dadurch wird klar, daß alle Lănder - auch die finanzschwachen heute implizit auf Umsatzsteuereinnahmen verzichten. Die im oberen Teil der Tabelle ausgewiesenen Gewinne überzeichnen also die Vorteile der Empfăngerländer um gut $50 \%$. Andererseits erkennt man aber auch die wahren Verlierer der heutigen Lösung. Die finanzstarken Länder müssen auf etwa 70 DM pro Einwohner verzichten, über die sie nach Abschaffung der Fehlbetrags-Bundesergänzungszuweisungen verfügen könnten, wenn im Gegenzug der Umsatzsteueranteil der Länder erhöht würde.

Dennoch kann man die Fehlbetrags-Bundesergänzungszuweisungen nicht einfach mit einer politisch gewünschte Umverteilung zugunsten der finanz-

1 BVerfGE 72, 330, S. 404. 
Tabelle 10

Fehlbetrags-Bundesergänzungszuweisungen 1998

\begin{tabular}{|c|c|c|c|c|c|}
\hline Land & \multicolumn{2}{|c|}{ GuV } & USt & LFA & BEZ \\
\hline & $\mathrm{DM} / \mathrm{E}$ & Mio. DM & \multicolumn{3}{|c|}{ Mio. DM } \\
\hline NRW & 0,00 & 0,0 & 0,0 & 0,0 & 0,0 \\
\hline BAY & 0,00 & 0,0 & 0,0 & 0,0 & 0,0 \\
\hline BW & 0,00 & 0,0 & 0,0 & 0,0 & 0,0 \\
\hline NDS & 150,35 & $1.180,5$ & 0,0 & 0,0 & $1.180,5$ \\
\hline $\mathrm{HE}$ & 0,00 & 0,0 & 0,0 & 0,0 & 0,0 \\
\hline RP & 161,00 & 647,0 & 0,0 & 0,0 & 647,0 \\
\hline SH & 0,00 & 0,0 & 0,0 & 0,0 & 0,0 \\
\hline SAAR & 193,98 & 208,9 & 0,0 & 0,0 & 208,9 \\
\hline $\mathrm{HH}$ & 0,00 & 0,0 & 0,0 & 0,0 & 0,0 \\
\hline $\mathrm{HB}$ & 212,50 & 142,5 & 0,0 & 0,0 & 142,5 \\
\hline $\mathrm{SN}$ & 193,61 & 872,6 & 0,0 & 0,0 & 872,6 \\
\hline ST & 193,32 & 520,1 & 0,0 & 0,0 & 520,1 \\
\hline TH & 193,05 & 476,9 & 0,0 & 0,0 & 476,9 \\
\hline BB & 192,94 & 498,0 & 0,0 & 0,0 & 498,0 \\
\hline MV & 193,08 & 348,2 & 0,0 & 0,0 & 348,2 \\
\hline BER & 258,09 & 881,9 & 0,0 & 0,0 & 881,9 \\
\hline West & 33,75 & $2.178,9$ & 0,0 & 0,0 & $2.178,9$ \\
\hline Ost & 205,94 & $3.597,7$ & 0,0 & 0,0 & $3.597,7$ \\
\hline Alle & 70,43 & $5.776,6$ & 0,0 & 0,0 & $5.776,6$ \\
\hline GuV & Erhöhung $(+)$ b & $\begin{array}{l}\text { erminde } \\
\text { lbetrag }\end{array}$ & $\begin{array}{l}\text { der Lär } \\
\text { sergänz }\end{array}$ & $\begin{array}{l}\text { nahmen } \\
\text { uweisung }\end{array}$ & \\
\hline
\end{tabular}

Umsatzsteueranteil der Lánder angepaßt

\begin{tabular}{|c|c|c|c|c|c|}
\hline Land & \multicolumn{2}{|c|}{ GuV } & USt & FA & BEZ \\
\hline & $\mathrm{DM} / \mathrm{E}$ & Mio. DM & \multicolumn{3}{|c|}{ Mio. DM } \\
\hline NRW & $-69,51$ & $-1.249,0$ & $-1.265,5$ & 16,7 & 0,0 \\
\hline BAY & $-69,51$ & $-838,7$ & $-849,8$ & 11,2 & 0,0 \\
\hline BW & $-70,30$ & $-731,7$ & $-733,0$ & 1,4 & 0,0 \\
\hline NDS & 80,59 & 632,8 & $-553,0$ & 5,0 & $1.180,5$ \\
\hline HE & $-70,42$ & $-424,8$ & $-424,8$ & 0,1 & 0,0 \\
\hline RP & 91,25 & 366,7 & $-283,0$ & 2,6 & 647,0 \\
\hline $\mathrm{SH}$ & $-70,38$ & $-194,3$ & $-194,4$ & 0,1 & 0,0 \\
\hline SAAR & 128,69 & 138,6 & $-75,9$ & 5,5 & 208,9 \\
\hline $\mathrm{HH}$ & $-95,28$ & $-162,1$ & $-119,8$ & $-42,3$ & 0,0 \\
\hline $\mathrm{HB}$ & 124,37 & 83,4 & $-47,2$ & $-11,9$ & 142,5 \\
\hline SN & 128,32 & 578,4 & $-317,4$ & 23,1 & 872,6 \\
\hline ST & 128,02 & 344,4 & $-189,5$ & 13,8 & 520,1 \\
\hline TH & 127,76 & 315,6 & $-174,0$ & 12,7 & 476,9 \\
\hline BB & 127,65 & 329,5 & $-181,8$ & 13,3 & 498,0 \\
\hline MV & 127,78 & 230,4 & $-127,0$ & 9,3 & 348,2 \\
\hline BER & 169,94 & 580,7 & $-240,7$ & $-60,5$ & 881,9 \\
\hline West & $-36,85$ & $-2.379,1$ & $-4.546,4$ & $-11,6$ & $2.178,9$ \\
\hline Ost & 136,18 & $2.379,0$ & $-1.230,3$ & 11,6 & $3.597,7$ \\
\hline Alle & 0,00 & $-0,1$ & $-5.776,7$ & 0,0 & $5.776,6$ \\
\hline $\begin{array}{l}\text { GuV } \\
\text { USt }\end{array}$ & $\begin{array}{l}\mathrm{ng}(+) \text { bz } \\
\text { FA ohn } \\
\text { Länder }\end{array}$ & $\begin{array}{l}\text { erminde } \\
\text { llbetrag }\end{array}$ & $\begin{array}{l}\text { der Länc } \\
\text { sergänzt }\end{array}$ & $\begin{array}{l}\text { hmen } \\
\text { eisun }\end{array}$ & \\
\hline
\end{tabular}


Tabelle 10 (Fortsetzung)

Auffüllquote im horizontalen Lănderfinanzausgleich angepaßt

\begin{tabular}{|c|c|c|c|c|c|}
\hline \multirow[t]{2}{*}{ Land } & \multicolumn{2}{|c|}{ GuV } & USt & LFA & BEZ \\
\hline & $\mathrm{DM} / \mathrm{E}$ & Mio. DM & \multicolumn{3}{|c|}{ Mio. DM } \\
\hline NRW & $-1,62$ & $-29,1$ & $-1.265,5$ & $1.241,3$ & 0,0 \\
\hline BAY & 5,65 & 68,2 & $-849,8$ & 922,1 & 0,0 \\
\hline BW & 7,02 & 73,1 & $-733,0$ & 809,7 & 0,0 \\
\hline NDS & $-3,68$ & $-28,9$ & $-553,0$ & $-664,6$ & $1.180,5$ \\
\hline HE & $-11,35$ & $-68,5$ & $-424,8$ & 357,5 & 0,0 \\
\hline RP & $-2,64$ & $-10,6$ & $-283,0$ & $-379,1$ & 647,0 \\
\hline SH & $-19,04$ & $-52,6$ & $-194,4$ & 142,2 & 0,0 \\
\hline SAAR & 1,64 & 1,8 & $-75,9$ & $-132,8$ & 208,9 \\
\hline $\mathrm{HH}$ & 27,53 & 46,8 & $-119,8$ & 167,7 & 0,0 \\
\hline HB & 3,88 & 2,6 & $-47,2$ & $-93,6$ & 142,5 \\
\hline SN & 0,14 & 0,6 & $-317,4$ & $-554,6$ & 872,6 \\
\hline ST & 0,03 & 0,1 & $-189,5$ & $-330,5$ & 520,1 \\
\hline TH & $-0,06$ & $-0,1$ & $-174,0$ & $-303,1$ & 476,9 \\
\hline BB & $-0,09$ & $-0,2$ & $-181,8$ & $-316,5$ & 498,0 \\
\hline MV & $-0,05$ & $-0,1$ & $-127,0$ & $-221,3$ & 348,2 \\
\hline BER & $-0,96$ & $-3,3$ & $-240,7$ & $-644,6$ & 881,9 \\
\hline West & 0,05 & 3,0 & -4.546 .4 & $2.370,4$ & $2.178,9$ \\
\hline Ost & $-0,17$ & $-3,0$ & $-1.230,3$ & $-2.370,4$ & $3.597,7$ \\
\hline Alle & 0,00 & $-0,1$ & -5.776 .7 & 0,0 & $5.776,6$ \\
\hline GuV & $\begin{array}{l}g(+) \text { b } \\
\text { FA ohn }\end{array}$ & $\begin{array}{l}\min 0 \\
\text { etra }\end{array}$ & ler Lä & $\begin{array}{l}\text { lahmen } \\
\text { weisun }\end{array}$ & \\
\hline USt & ândera & & & Auffüllq & $n$ LFA \\
\hline
\end{tabular}

schwachen Bundesländer rechtfertigen. Der nahezu gleiche Umverteilungseffekt ließe sich nämlich auch über den direkten Ausgleich unter den Ländern erzielen. Dies demonstriert der letzte Teil der Tabelle 10. Die Rechnung kombiniert die Wirkungen einer Abschaffung der Bundesergänzungszuweisungen bei kompensatorischer Anpassung des Umsatzsteueranteils der Länder mit einer Erhöhung der Auffüllquote im Länderfinanzausgleich von derzeit $37,5 \%$ auf nunmehr $88,25 \%$ für die Fehlbeträge zwischen $92 \%$ und $100 \%$ der durchschnittlichen Finanzkraft.

Die Folge wäre eine Anhebung der Finanzkraft finanzschwacher Lănder auf ca. $99 \%$ des um die Umsatzsteuer-Mehreinnahmen gewachsenen Länderdurchschnitts. Relativ zum heutigen System hätte die Maßnahmenkombination insgesamt so gut wie keinen Einfluß auf die Finanzkraft der Länder. Bei den Nutznießern der Ergänzungszuweisungen tendieren die Gewinne und Verluste gegen Null. Kleinere Verschiebungen unter den Nettozahlern ba- 
sieren auf den unterschiedlichen Verteilungswirkungen der höheren Umsatzsteuer gegenüber den höheren Beiträgen zum Länderfinanzausgleich.

Der Vergleich zeigt, daß die Fehlbetrags-Bundesergänzungszuweisungen nicht erforderlich sind, um die Verteilungseffekte des heutigen Systems zu produzieren. Nur würde niemand ernsthaft für den horizontalen Länderfinanzausgleich eine Auffüllquote von $88,25 \%$ in Erwägung ziehen. Genau darauf aber läuft das heutige Zusammenspiel der verschiedenen Stufen des Lănderfinanzausgleichs im Ergebnis hinaus. Da die Fehlbetrags-Bundesergänzungszuweisungen vordergründig die finanzstarken Länder nicht belasten, sind sie offenbar geeignet, die Nivellierungsintensităt des Finanzausgleichs auf ein mit horizontalen Ausgleichsmaßnahmen allein nie realisierbares Niveau zu steigern.

Die Problematik überhöhter Durchschnitts- und insbesondere Grenzbelastungen der Länder wurde bereits hinreichend deutlich gemacht. Die Feht betrags-Bundesergänzungszuweisungen tragen zu diesem gravierenden Konstruktionsfehler des bestehenden Verfahrens in zweierlei Hinsicht bei. Sie sorgen unmittelbar für einen Anstieg der marginalen Abschöpfungsquoten der finanzschwachen Länder, was deren Interesse an einer Verbesserung inrer Wirtschaftskraft fiskalisch unterminiert. Noch schlimmer sind aber die indirekten Konsequenzen. Die Fehlbetrags-Bundesergänzungszuweisungen verschleiern die effektiven Belastungseffekte und ermöglichen dadurch erst die dem bundesdeutschen Länderfinanzausgleichs eigene und im internationalen Vergleich beispiellose Nivellierung der relativen Finanzkraftpositionen.

Festzuhalten bleibt: Eine finanzwissenschaftliche Begründung für die Existenz der Fehlbetrags-Bundesergänzungszuweisungen und erst recht für ihre Höhe gibt es nicht. Der Fortbestand dieses Ausgleichsinstrumentes ist mit einer substantiellen Reform des Lănderfinanzausgleichs unvereinbar. Wenn die Fehlbetrags-Bundesergänzungszuweisungen im Zuge einer Neuregelung des Lănderfinanzausgleich $i$. w. S. abgeschafft werden, ist die damit einhergehende Entlastung des Bundes bei der Festsetzung der Umsatzsteueranteile von Bund und Ländern zu berücksichtigen. 


\section{B. Die Sonderbedarfs-Bundesergănzungszuweisungen}

Im Gegensatz zu den Fehlbetrags-Bundesergänzungszuweisungen dienen die übrigen Bundesergänzungszuweisungen der Berücksichtigung von Sonderbedarfen. Sie sind mit Ausnahme der Hilfen für die neuen Länder stark umstritten. Im folgenden werden okonomische Berechtigung, Gestaltung und Ansatzpunkte einer Reform der verschiedenen Sonderbedarfs-Bundesergänzungszuweisungen diskutiert.

Zuvor erscheint jedoch eine allgemeine Bemerkung zu diesen Bundesergänzungszuweisungen angebracht. Im Zusammenhang mit den "Hafenlasten“ wurde bereits auf die Problematik der Berücksichtigung von Sonderbedarfen im Länderfinanzausgleich hingewiesen (vgl. S. 110 ff.). Die Gefahr eines Bedarfswettlaufs besteht auch und gerade bei den Bundesergänzungszuweisungen. Die Länder können versuchen, einmal anerkannte Sonderbedarfe auf Dauer festzuschreiben und höher zu bewerten oder neue Sonderbedarfe geltend zu machen. Schon deshalb sollten Bundesergänzungszuweisungen allenfalls in begründeten Ausnahmefällen und zeitlich befristet gewährt werden.

Des weiteren sind die nach eingehender Prüfung ihrer Notwendigkeit eventuell gezahlten Bundesergänzungszuweisungen mit Blick auf die jeweiligen "Ergănzungstatbestănde" grundsätzlich flexibel zu gestalten. Ihr Volumen sollte an die Entwicklung (möglichst einfacher) Erfolgsindikatoren gekoppelt oder von vornherein zeitlich degressiv gestaffelt und auf diese Weise mit einer Auslaufgarantie versehen werden. Nur so besteht auf Dauer die Chance, die Bundesergănzungszuweisungen auf ihre subsidiäre Funktion im Finanzausgleich zu reduzieren.

\section{Zuweisungen wegen der Kosten politischer Führung}

\section{a. Die gesetzliche Regelung und ihre Verteilungseffekte}

Nach § 11 Abs. 3 FAG erhalten Länder mit weniger als 4 Millionen Einwohnern (mit Ausnahme Hamburgs) Sonderbedarfs-Bundesergänzungszuweisungen zum Ausgleich überdurchschnittlich hoher Kosten der politischen 
Führung und der zentralen Verwaltung. Die Regelung geht auf das Urteil des Bundesverfassungsgerichts zum Lănderfinanzausgleich aus dem Jahr 1986 zurück, in dem diese Kosten beiläufig als berücksichtigungsfähiger Sonderbedarf eingestuft wurden ${ }^{1}$. Der Gesetzgeber war nicht verpflichtet, die Kosten der politischen Führung anzuerkennen. Er tat dies dennoch mit dem Ziel, die Eigenständigkeit der Lănder zu stärken und sicherzustellen, daß sie ihren bundesstaatlich geprägten Aufgaben nachkommen können.

Interessanterweise erfolgte die Neuregelung der Berücksichtigung der Kosten der politischen Führung im Föderalen Konsolidierungsprogramm auf Vorschlag der Länder. Die Bundesregierung hatte in ihrem Gesetzentwurf zunächst auf eine Berücksichtigung völlig verzichtet. Stattdessen wurde der Empfängerkreis erweitert und das Volumen infolge der Aufnahme der Kosten der zentralen Verwaltung erhöht ${ }^{2}$. Derzeit erhalten die Länder Berlin, Brandenburg, Bremen, Mecklenburg-Vorpommern, Rheinland-Pfalz, Saarland, Sachsen-Anhalt, Schleswig-Holstein und Thüringen jährliche Zahlungen zwischen 126 Mio. DM und 219 Mio. DM.

Tabelle 11 enthält im oberen Teil die Verteilung der Zuweisungen auf die Länder. Relativ zur Einwohnerzahl profitiert Bremen als kleinstes Bundesland mit 188 DM pro Kopf am meisten von diesen Sonderbedarfs-Bundesergänzungszuweisungen. Es folgen das Saarland mit 142 DM und Mecklenburg-Vorpommern mit 91 DM je Einwohner. Die Höhe der Pro-Kopf-Zuweisungen wegen der "Kosten der Kleinheit" nimmt konsequenterweise mit der Einwohnerzahl ab. Eine Ausnahme bildet Berlin, das als Land mit der zweitgrößten Einwohnerzahl dieser Ländergruppe eigentlich an vorletzter Stelle bei den Zuweisungen pro Kopf liegen müßte, tatsächlich jedoch den fünften Platz in der Reihenfolge der "kleinen“ Länder einnimmt ${ }^{3}$.

1 BVerfGE 72, 330, S. 405. Die Mahnung, mit diesem Instrument zurückhaltend umzugehen, hat offenbar ihre Berechtigung, denn solche Einladungen zur Berücksichtigung von Sonderbedarfen werden nur zu gern angenommen.

2 Vgl. Stellungnahme der Bundesregierung zu den Normenkontrollantrăgen von BadenWürttemberg, Bayern und Hessen, 1999, S. 24.

3 Die Berechnung der Pro-Kopf-Ausgaben erfolgt auf der Basis der Länderdaten. Vgl. BT-Drucksache 12/4748, S. 130. Wonach sich die Höhe der Zuweisungen an die einzelnen Länder richtet, wird nicht näher erläutert und ist daher auch nicht nachvollziehbar. Vgl. Korioth, 1997, S. 655 (FN 817). Daß der Bundesgesetzgeber seiner Darstellungspflicht nicht hinreichend nachgekommen ist, kritisiert auch Häde, 1996, S. 283. 


\section{Tabelle 11}

\section{Ergänzungszuweisungen für Kosten politischer Führung 1998}

\begin{tabular}{|c|c|c|c|c|c|}
\hline Land & \multicolumn{2}{|c|}{ GuV } & USt & & BEZ \\
\hline & $\mathrm{DM} / \mathrm{E}$ & Mio. DM & \multicolumn{3}{|c|}{ Mio. DM } \\
\hline NRW & 0,00 & 0,0 & 0,0 & 0,0 & 0,0 \\
\hline BAY & 0,00 & 0,0 & 0,0 & 0,0 & 0,0 \\
\hline BW & 0,00 & 0,0 & 0,0 & 0,0 & 0,0 \\
\hline NDS & 0,00 & 0,0 & 0,0 & 0,0 & 0,0 \\
\hline $\mathrm{HE}$ & 0,00 & 0,0 & 0,0 & 0,0 & 0,0 \\
\hline RP & 54,50 & 219,0 & 0,0 & 0,0 & 219,0 \\
\hline SH & 59,41 & 164,0 & 0,0 & 0,0 & 164,0 \\
\hline SAAR & 142,06 & 153,0 & 0,0 & 0,0 & 153,0 \\
\hline $\mathrm{HH}$ & 0,00 & 0,0 & 0,0 & 0,0 & 0,0 \\
\hline HB & 187,87 & 126,0 & 0,0 & 0,0 & 126,0 \\
\hline SN & 0,00 & 0,0 & 0,0 & 0,0 & 0,0 \\
\hline ST & 60,96 & 164,0 & 0,0 & 0,0 & 164,0 \\
\hline $\mathrm{TH}$ & 66,38 & 164,0 & 0,0 & 0,0 & 164,0 \\
\hline BB & 63,54 & 164,0 & 0,0 & 0,0 & 164,0 \\
\hline MV & 90,94 & 164,0 & 0,0 & 0,0 & 164,0 \\
\hline BER & 64,09 & 219,0 & 0,0 & 0,0 & 219,0 \\
\hline West & 10,25 & 662,0 & 0,0 & 0,0 & 662,0 \\
\hline Ost & 50,09 & 875,0 & 0,0 & 0,0 & 875,0 \\
\hline Alle & 18,74 & $1.537,0$ & 0,0 & 0,0 & $1.537,0$ \\
\hline $\begin{array}{l}\text { GuV } \\
\text { USt }\end{array}$ & $\begin{array}{l}\text { g }(+) b \text {. } \\
\text { FA ohn }\end{array}$ & $\begin{array}{l}\text { erminder } \\
\text { für Kos }\end{array}$ & $\begin{array}{l}\text { der Lär } \\
\text { itischer }\end{array}$ & nen & \\
\hline
\end{tabular}

Umsatzsteueranteil der Lănder angepaßt

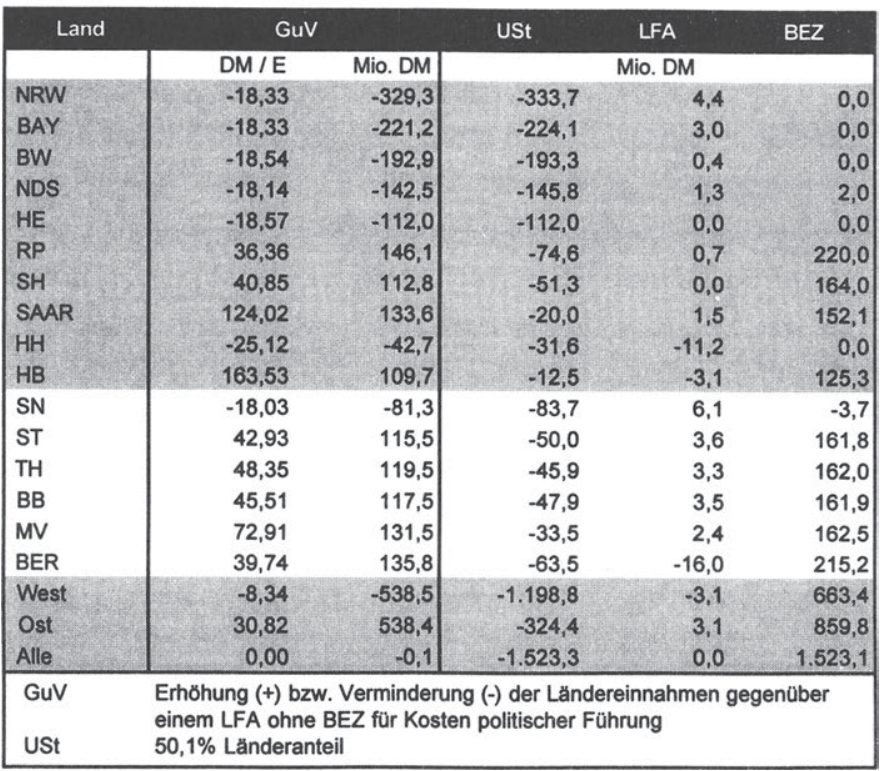


Die Gewinn-und-Verlust-Rechnung im unteren Teil der Tabelle 11 gibt Aufschluß über die effektiven Verteilungswirkungen der Bundesergănzungszuweisungen für die Kosten politischer Führung. Sie werden erkennbar, wenn man als Referenzsituation wiederum annimmt, daß die Zuweisungen des Bundes entfallen und dafür der Länderanteil an der Umsatzsteuer in entsprechendem Umfang erhöht wird (von 49,5\% auf 50,1\%). Da die zusätzlichen Umsatzsteuereinnahmen auch bei den bevölkerungsarmen bisherigen Empfängerländern anfallen, reduziert sich der Nettoeffekt der Zuweisungen auf $62 \%$ bis $87 \%$ der Bruttowerte.

Natürlich profitieren die "kleinen" Bundesländer nach wie vor in erheblichen Umfang von den Ergänzungszuweisungen. Hauptgewinner bleibt Bremen1, das durch den § 11 Abs. 3 FAG netto um 110 Mio. DM bzw. 164 DM je Einwohner bessergestellt wird. Netto durch entgangene Umsatzsteuereinnahmen belastet werden die bevölkerungsreichen Bundesländer, die alle etwas mehr als $18 \mathrm{DM}$ je Einwohner verlieren. Hauptverlierer ist jedoch paradoxerweise und im vollkommenen Widerspruch zur Intention der Regelung die Hansestadt Hamburg. Sie unterschreitet mit 1,7 Mio. Einwohnern zwar deutlich die 4-Millionen-Grenze, geht aber bei der Vergabe der Zuweisungen leer aus. In der Nettorechnung zeigt sich nun, daß ausgerechnet Hamburg durch die Berücksichtigung der "Kosten der Kleinheit" mit 25 DM je Einwohner am stärksten belastet wird.

\section{b. Kritik der Anrechnung der Kosten politischer Führung}

Die Frage, warum Hamburg keine Zuweisungen erhält, beantwortet das Bundesverfassungsgericht damit, daß Hamburg kein leistungsschwaches Land ist und damit ein Kriterium für die Vergabe von Bundesergänzungszuweisungen nicht erfüllt 2 . Diese Argumentation leidet jedoch offenkundig an der Vermischung eines allgemeinen Finanzkraftmaßstabs mit einem Sonderbedarfstatbestand. Es ist nicht einzusehen, warum ein Land, bei dem der besondere Sachverhalt vorliegt, der die Zuweisung rechtfertigt, mit dem Hin-

1 Bremen profitiert mit einer erstaunlichen Regelmäßigkeit von nahezu allen Sonderregelungen des Lănderfinanzausgleichs (inklusive Bundesergănzungszuweisungen).

2 Vgl. BVerfGE 86, 148, S. 276. 
weis auf seine in diesem Kontext völlig unmaßgebliche Finanzstärke anders behandelt werden soll1. Eine analoge Argumentation im Bereich der persönlichen Einkommensbesteuerung würde z. B. bedeuten, daß den Familien, die über ein überdurchschnittliches Einkommen verfügen, keine Kinderfreibetrăge eingerăumt werden müßten - eine Auffassung, die das Bundesverfassungsgericht bekanntlich nicht akzeptiert hat.

Im übrigen ist mit Blick auf die innere Logik der Regelung auch zu fragen, warum Schleswig-Holstein Zuweisungen für die Kosten der politischen Führung in den Jahren erhalten hat, in denen das Land ausgleichspflichtig war und eine Leistungsschwäche offensichtlich nicht vorlag. Des weiteren muß bemängelt werden, daß Rheinland-Pfalz, das bereits seit zwei Jahren die Grenze von 4 Millionen Einwohnern überschritten hat, eigentlich keine $\mathrm{Zu}$ weisungen mehr erhalten dürfte ${ }^{2}$. Insgesamt drängt sich daher "der Eindruck auf, daß diese Ergänzungszuweisungen nur dazu dienen, den finanzschwachen Ländern zusătzliche Mittel zu verschaffen, ohne in diesem Fall nach Auffassung des Finanzausgleichsgesetzgebers an das Nivellierungsverbot gebunden zu sein“3.

Größere Aufmerksamkeit als diese inneren Widersprüche der Gestaltung und Handhabung verdienen die okonomischen Rechtfertigungsversuche der Bundesergänzungszuweisungen für die Kosten politischer Führung. Ihnen liegt die Vorstellung einer subadditiven Kostenfunktion bei der Erstellung öffentlicher Güter zugrunde 4 . Sie läuft darauf hinaus, daß das gleiche Niveau an öffentlichen Leistungen in einem großen Land - bezogen auf die Einwohnerzahl - günstiger erstellt werden kann, als in zwei kleinen Ländern. Aus okonomischer Sicht wirft diese Hypothese zwei Probleme auf.

1 Mit derselben Berechtigung könnte man Hamburg auch von der (okonomisch allgemein unbegründeten) Anrechnung der Hafenlasten ausnehmen.

2 Die Schwierigkeit besteht darin, daß ein Bundesland bei Überschreiten der Einwohnergrenze seine gesamten Zuweisungen verliert, was anscheinend als unzumutbar angesehen wurde. Hier liegt der Fall des sogenannten Schwellenphänomens vor. Ein Bundesland, dessen Bevollkerungszahl sich in der Năhe der Einwohnergrenze bewegt, hat fiskalisch gesehen allen Grund, seine Bevolkerungszahl stabil zu halten, weil es andernfalls Gefahr läuft, Zuweisungen in erheblichem Umfang zu verlieren. Allerdings sind die Einflußmöglichkeiten der Landespolitik auf die Einwohnerzahl recht begrenzt, so daß ein praktisch relevantes Anreizproblem kaum bestehen dürfte.

3 Normenkontrollantrag des Landes Hessen, Kapitel C.V.3.b.bb.

4 Vgl. Homburg, 1994, S. 315 ff. 
Zunächst muß geprüft werden, ob eine subadditive Kostenfunktion bezogen auf die Einwohnerzahl tatsächlich existiert' ${ }^{1}$. Nur wenn dafür überzeugende Anhaltspunkte bestehen sollten, stellt sich die weitere Frage nach der Ausgleichsrelevanz der Kosteneffekte.

Zur realen Bedeutung der Kosten der Kleinheit liegen empirische Studien vor. Kitterer hat mit Hilfe einer Regressionsrechnung eine Ausgabenfunktion für den Aufgabenbereich politische Führung in den verschiedenen Bundesländern geschătzt ${ }^{2}$. Für die Lănderausgaben gelangt er in Abhängigkeit von der Einwohnerzahl zu einer linearen Ausgabenfunktion mit positivem Absolutglied. Es liegen demnach Fixkosten der Aufgabenerfüllung vor ${ }^{3}$, und diese müssen in kleinen Ländern eben auf weniger Köpfe verteilt werden, so daß die Pro-Kopf-Ausgaben mit rückläufiger Einwohnerzahl steigen. Die rechnerischen Kosten der Kleinheit lassen sich anhand eines Vergleichs der Kosten eines Landes mit einem Länderdurchschnitt beziffern 4 .

Keine Auskunft geben die statistischen Daten allerdings über die Notwendigkeit der anfallenden Kosten und ihre Bedeutung für den Länderfinanzausgleich. "Zwar läßt sich statistisch nachweisen, daß große Bundesländer für einige Aufgabenbereiche - zum Beispiel für die politische Führung oder

1 Homburg sieht in der subadditiven Kostenfunktion einen Widerspruch zur Einwohnerveredelung, die nur mit einer superadditiven Kostenfunktion, d. h. mit steigenden Kosten je Einwohner bei der offentlichen Leistungserstellung begründet werden kann. Vgl. Homburg, 1994, S. 316. Dies ist aber nicht der Fall, den die beiden Hypothesen beziehen sich auf unterschiedliche Einwohner-Kosten-Zusammenhänge. Die Einwohnerwertung basiert auf der (unbegründeten) Annahme steigender Pro-Kopf-Ausgaben bei wachsendem Agglomerationsgrad innerhalb der gegebenen Ländergliederung. Demgegenüber rekurrieren die Kosten der Kleinheit auf die Mehrausgaben zweier Länder bei gegebenem Agglomerationsgrad. Ein Stadtstaat kann so gesehen durchaus zusătzliche Kosten der Ballung und der Kleinheit aufweisen, und die Ballungskosten mögen z. B. im Rhein-Main-Gebiet ohnehin hoch sei, werden aber durch die Existenz zweier Bundesländer - Hessen und Rheinland-Pfalz - bestimmt nicht gesenkt.

2 Vgl. Kitterer, 1994, S. 55 ff. Die Untersuchung bezieht sich auf die acht westlichen Flächenländer und die Stadtstaaten Bremen und Hamburg.

3 Für die kommunalen Ausgaben konnten keine Fixkosten der Kleinheit ermittelt werden.

4 Solche Berechnungen könnten die Entscheidungen über die jeweilige Höhe der Bundesergänzungszuweisungen wenigstens auf eine nachvollziehbare empirische Grundlage stellen. Sie schützen auch vor bloßen Mutmaßungen über die Kosten der Kleinheit. So führt beispielsweise Korioth aus, daß kleine Ländern bei einigen Ausgabenposten vielleicht höhere Kosten tragen müssen, denen jedoch ein geringerer Umfang an Verwaltungsaufgaben gegenüberstehe. Er kommt so zu dem Ergebnis, daß nicht von vornherein festgestellt werden kann, ob ein höherer Aufwand in den kleinen Ländern tatsächlich vorliegt. Vgl. Korioth, 1997, S. 655. Dieser Punkt kann eben nur durch eine empirisch fundierte Gesamtbetrachtung geklärt werden. 
den Rechtsschutz - relativ weniger Mittel aufzuwenden haben als kleine; soweit kleine Lănder den Wert der Eigenstaatlichkeit schătzen, können sie aber manches tun, um diese ,Kosten der Kleinheit' niedrig zu halten. So gibt es zum Beispiel die Möglichkeit, sich gemeinsamer Einrichtungen wie etwa hoher Gerichte zu bedienen "1. Von den kleinen Ländern darf erwartet werden, daß sie solche Einsparpotentiale nutzen. Gegen die Bundesergänzungszuweisungen wegen überdurchschnittlich hoher Kosten politischer Führung spricht, daß die Berücksichtigung dieser Kosten im Länderfinanzausgleich das Interesse der begünstigten Länder an kostensenkenden Kooperationslösungen von vornherein reduziert.

Man kann aber noch einen Schritt weitergehen. Wenn bei den Kosten der politischen Führung eine subadditive Kostenfunktion vorliegt, ist unter dem Gesichtspunkt der Kosteneffizienz auch eine Neugliederung des Bundesgebietes in Betracht zu ziehen. Sie dürfte jedoch - wie das Beispiel der gescheiterten Fusion von Berlin und Brandenburg zeigt - auf den Widerstand der Bevölkerung und in der Regel wohl auch der jeweiligen Landesregierungen stoßen2. Dagegen ist prinzipiell auch wenig einzuwenden, soweit die politischen Entscheidungstrăger sich im Bewußtsein der Opportunitătskosten für oder gegen die Eigenstaatlichkeit entscheiden müssen. Eine daraus resultierende Lănderstruktur wäre ökonomisch effizient ${ }^{3}$.

Ein rationales Abwägen zwischen den Kosten und Nutzen der Eigenstaatlichkeit ist aber nur zu erwarten, wenn diese Überlegungen nicht durch Subventionen in Form von Bundesergänzungszuweisungen verzerrt werden. „Die Kosten politischer Führung den Verursachern anzulasten, zwingt die Betroffenen zu einer Präferenzenthüllung, und das Ergebnis ihrer Entscheidung, wie immer sie lautet, ist gesamtwirtschaftlich effizient. Die Subventionierung der Kleinstaaterei zu institutionalisieren, [...] verschiebt das Problem der Neugliederung der Länder auf den Sankt-Nimmerleins-Tag; denn nach-

1 Wissenschaftlicher Beirat beim Bundesministerium der Finanzen, 1992, S. 69.

2 Bei der angestrebten Fusion von Berlin und Brandenburg waren die beiden Landesregierungen allerdings die Initiatoren. Es steht also nicht von vornherein fest, daß sich die Landesregierungen gegen eine Fusion stellen.

3 Die unter Okonomen verbreitete Bereitschaft zu einer vermeintlich effizienzfördernden Neugliederung des Bundesgebietes steht übrigens in merkwürdigem Widerspruch zu den sonst betonten allokativen Vorzügen einer föderalen, dezentralen Ordnung. 
dem die Kosten der Kleinheit abgewälzt worden sind, kann man ernstlich weder von den Bürgern der betroffenen Lănder noch von den sie repräsentierenden Landesregierungen eine Zustimmung zu Neugliederungsplänen erwarten “1. Nichts spricht also dagegen, daß kleine Länder ihre Eigenständigkeit bewahren wollen, aber sie müssen schon bereit sein, die daraus resultierenden Zusatzkosten zu tragen 2 .

Neben der Verzerrung der politischen Entscheidungen spricht ein weiterer Gesichtspunkt gegen die Anrechnung der Kosten politischer Führung im Finanzausgleich. Das heutige System geht mit der Angleichung der relativen Finanzkraftpositionen auf mindestens $99,5 \%$ des Lănderdurchschnitts so weit, daß zusătzliche Leistungen mit zweifelhafter Berechtigung für einzelne Länder schon deshalb nicht in Betracht kommen, weil sie wahrscheinlich eine unzulässige Übernivellierung bewirken. Die Anforderungen an die Begründung spezieller Ergänzungszuweisungen sind daher besonders hoch anzusetzen. „Im Regelfall soll die Gewährung von Bundesergänzungszuweisungen auch bei der Berücksichtigung von Sonderlasten nicht dazu führen, daß die Finanzkraft des begünstigten Landes die durchschnittliche Finanzkraft der Länder nach dem horizontalen Finanzausgleich übersteig ‘3 3 .

Insgesamt läßt sich konstatieren, daß für eine besondere Berücksichtigung der Kosten der Kleinheit im Länderfinanzausgleich aus finanzwissenschaftlicher Sicht keine nachvollziehbaren Gründe angeführt werden können. Die Bundesergänzungszuweisungen wegen der Kosten politischer Führung sollten daher ersatzlos entfallen. Kurt Schmidt hat zu § 11 Abs. 3 FAG einmal treffend bemerkt: „Man darf vermuten, daß sich angesichts dieser Regelung mancher fragt, wie es um die Existenzberechtigung eines Staates steht, der sein Parlament, seine Regierung und seine zentrale Verwaltung nicht aus eigenen Mitteln bezahlen kann ${ }^{4}$. Dem ist nichts hinzuzufügen.

1 Homburg, 1994, S. 316.

2 Dem Problem der Ausgleichsrelevanz der Kosten politischer Führung geht Kitterer aus dem Weg, wenn er lapidar feststellt: „Da die kleinen Bundesländer für die Kosten der Kleinheit nicht selbst verantwortlich gemacht werden können, werden sie zum Teil von der Solidargemeinschaft übernommen". Kitterer, 1994, S. 96.

3 BVerfGE 72, 330, S. 405.

4 Schmidt, 1996, S. 330. 


\section{Die Übergangs-Bundesergănzungszuweisungen}

\section{a. Die gesetzliche Regelung und ihre Verteilungseffekte}

Nach § 11 Abs. 5 FAG erhalten die fünf alten Bundesländer Bremen, Niedersachsen, Rheinland-Pfalz, Saarland und Schleswig Holstein ÜbergangsBundesergănzungszuweisungen zum Ausgleich überproportionaler Belastungen infolge der Einbeziehung der neuen Bundeslănder in den Länderfinanzausgleich. Die besondere Belastung der finanzschwachen gegenüber den finanzstarken alten Ländern resultiert aus dem erheblichen integrationsbedingten Rückgang der länderdurchschnittlichen Finanzkraft. Dadurch verbessert sich die relative Finanzkraftposition der finanzschwachen alten Länder trotz absolut unveränderter Haushaltssituation, was schließlich zu einem (Teil-) Verlust an Zuweisungen aus dem Länderfinanzausgleich führt.

Die Übergangs-Bundesergănzungszuweisungen sollten bei ihrer Einführung im Jahr 1995 eine dem Durchschnitt der unterproportional belasteten alten Länder entsprechende Pro-Kopf-Belastung der finanzschwachen alten Lănder nach Lănderfinanzausgleich und Fehlbetrags-Bundesergänzungszuweisungen sicherstellen ${ }^{1}$. Auf diese Weise sollten die zusătzlichen Lasten neutralisiert und die Anpassung der betroffenen Länder an den gesamtdeutschen Finanzausgleich erleichtert werden. Entsprechend ihrer Zielsetzung reduzieren sich die ursprünglichen Zahlungen in Höhe von 1.345 Mio. DM seit 1996 jährlich um 10 Prozentpunkte und laufen im Jahr 2004 aus.

Tabelle 12 zeigt im oberen Teil die Verteilung der Übergangs-Bundesergänzungszuweisungen auf die Bundesländer im Jahr 1998. Bezogen auf die Einwohnerzahl profitieren Bremen mit 83,50 DM, und Rheinland-Pfalz mit 78,57 DM am stärksten. Es folgen Schleswig-Holstein mit 57,56 DM, das Saarland mit rund 52 DM und Niedersachsen, das noch 45,20 DM je Einwohner erhält. Da die Zuweisungen an alle Länder in prozentual gleichem Umfang gekürzt werden, ändert sich in den kommenden Jahren nichts an der Reihenfolge der begünstigten Länder².

1 Vgl. Stauch / Klusewitz / Gurgsdies, 1993, S. 25; Trzaskalik, 1999, S. 61.

2 Dabei wird von gravierenden Verănderungen in der Bevölkerungsentwicklung der einzelnen Länder abgesehen. 
Tabelle 12

Übergangs-Bundesergänzungszuweisungen 1998

\begin{tabular}{|c|c|c|c|c|c|}
\hline \multirow{2}{*}{ Land } & \multicolumn{2}{|c|}{ GuV } & USt & LFA & BEZ \\
\hline & $\mathrm{DM} / \mathrm{E}$ & Mio. DM & \multicolumn{3}{|c|}{ Mio. DM } \\
\hline NRW & 0,00 & 0,0 & 0,0 & 0,0 & 0,0 \\
\hline BAY & 0,00 & 0,0 & 0,0 & 0,0 & 0,0 \\
\hline BW & 0,00 & 0,0 & 0,0 & 0,0 & 0,0 \\
\hline NDS & 45,20 & 354,9 & 0,0 & 0,0 & 354,9 \\
\hline HE & 0,00 & 0,0 & 0,0 & 0,0 & 0,0 \\
\hline RP & 78,57 & 315,7 & 0,0 & 0,0 & 315,7 \\
\hline SH & 57,56 & 158,9 & 0,0 & 0,0 & 158,9 \\
\hline SAAR & 51,99 & 56,0 & 0,0 & 0,0 & 56,0 \\
\hline $\mathrm{HH}$ & 0,00 & 0,0 & 0,0 & 0,0 & 0,0 \\
\hline HB & 83,50 & 56,0 & 0,0 & 0,0 & 56,0 \\
\hline SN & 0,00 & 0,0 & 0,0 & 0,0 & 0,0 \\
\hline ST & 0,00 & 0,0 & 0,0 & 0,0 & 0,0 \\
\hline TH & 0,00 & 0,0 & 0,0 & 0,0 & 0,0 \\
\hline BB & 0,00 & 0,0 & 0,0 & 0,0 & 0,0 \\
\hline MV & 0,00 & 0,0 & 0,0 & 0,0 & 0,0 \\
\hline BER & 0,00 & 0,0 & 0,0 & 0,0 & 0,0 \\
\hline West & 14,58 & 941,5 & 0,0 & 0,0 & 941,5 \\
\hline Ost & 0,00 & 0,0 & 0,0 & 0,0 & 0,0 \\
\hline Alle & 11,48 & 941,5 & 0,0 & 0,0 & 941,5 \\
\hline $\begin{array}{l}\text { GuV } \\
\text { USt }\end{array}$ & $\begin{array}{l}\text { Erhöhung (+) b } \\
\text { einem LFA ohn } \\
49,5 \% \text { Ländera }\end{array}$ & $\begin{array}{l}\text { rminder } \\
\text { rgangs- }\end{array}$ & $\begin{array}{l}\text { der Länc } \\
\text { ergänzu }\end{array}$ & $\begin{array}{l}\text { innahmen } \\
\text { uxweisung }\end{array}$ & \\
\hline
\end{tabular}

Umsatzsteueranteil der Länder angepaßt

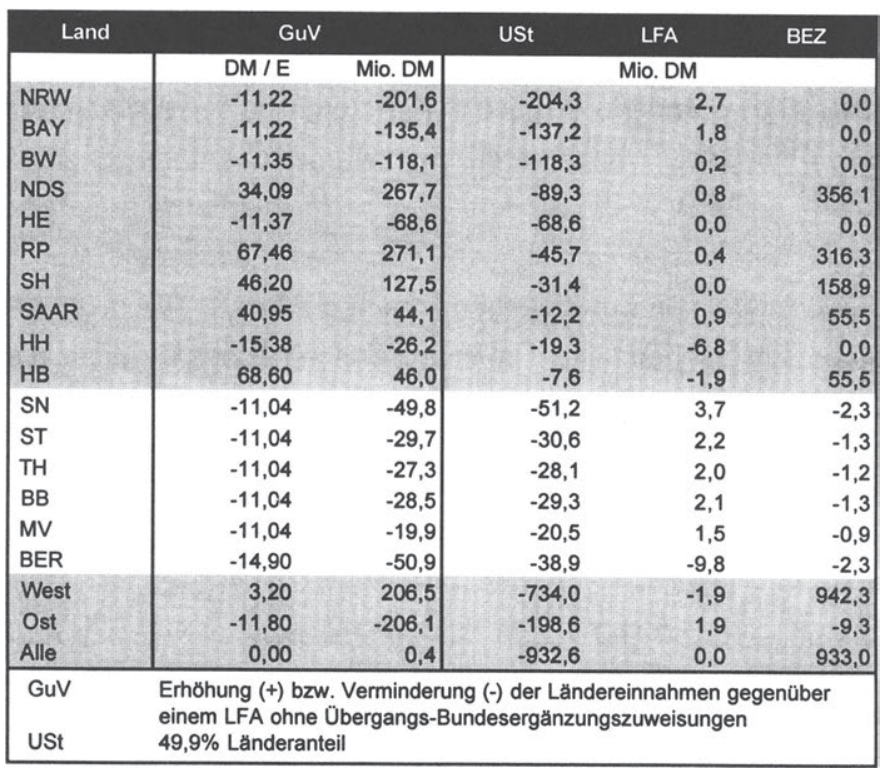


Die indirekte Belastung der übrigen Bundeslănder kommt im unteren Teil der Tabelle 12 zum Ausdruck. Der Bund könnte den Lăndern bei Wegfall der Übergangs-Bundesergänzungszuweisungen 1998 einen Anteil an der Umsatzsteuer in Hǒhe von 49,9 \% einrăumen, ohne dadurch netto belastet zu sein. Die Lănder - auch die Empfänger der Zuweisungen - verzichten also implizit auf Umsatzsteuereinnahmen in Höhe von 11 DM (Flächenländer) bis $15 \mathrm{DM}$ je Einwohner (Stadtstaaten). Allerdings ist deutlich darauf hinzuweisen, daß die ermittelten Verteilungswirkungen nur für das Jahr 1998 gelten, da sich - wie bereits erwăhnt - die Zahlungen an die finanzschwachen alten Länder von Jahr zu Jahr weiter reduzieren.

\section{b. Kritik der Übergangs-Bundesergănzungszuweisungen}

Die Berechtigung der besonderen Entschädigung für die relative Verbesserung der Finanzkraftposition der finanzschwachen alten Länder im Gesamtsystem des Finanzausgleichs ist vor allem im juristischen Schrifttum umstritten. Selmer hält die Übergangs-Bundesergänzungszuweisungen z. B. für unproblematisch, weil sie dem Bestandsschutzgedanken des Grundgesetzes Rechnung tragen würden 1 . Dagegen vertritt Korioth die Auffassung, daß Einbußen infolge einer Verănderung relativer Finanzkraftpositionen keinen Sonderbedarf begründen könnten, der vom Bund ausgeglichen werden dürfte. „Die verănderte Position der im Vergleich der Westländer finanzschwachen, im Gesamtländervergleich jetzt aber überdurchschnittlich ausgestatteten Länder Bremen, Niedersachsen, Rheinland-Pfalz, Saarland und Schleswig-Holstein ist vielmehr Ausprägung der bundesstaatlichen Solidarpflicht. Der Verlust von Zuweisungen kommt der in Art. 107 || GG geforderten Abgabe aus eigenen Mitteln im finanzwirtschaftlichen Ergebnis gleich“2.

Auch Heun stuft die Übergangs-Bundesergänzungszuweisungen als verfassungswidrig ein. Sie sind "aus einem doppelten Grund mit dem Grundgesetz unvereinbar. Erstens verstoßen sie gegen das Gleichbehandlungsgebot, da sie ihre Rechtfertigung nicht in einem Sonderbedarf im Sinne des Art. 107 Abs. 2 Satz 3 GG finden. Sie verstoßen aber zweitens auch inso-

1 Vgl. Selmer, 1994, S. 347 f.

2 Korioth, 1997, S. 678. 
fern gegen das Nivellierungsverbot, als sie im Ergebnis nichts anderes als verdeckte Fehlbedarfsergänzungszuweisungen sind, die die betreffenden Empfängerländer angesichts des ansonsten bereits erreichten hohen Ausgleichsniveaus über die durchschnittliche Finanzkraft anheben“1. Im Gegensatz zu den Fehlbetrags-Bundesergänzungszuweisungen gehen jedoch von den Übergangs-Bundesergänzungszuweisungen keine Fehlanreize aus, da ihre Höhe nicht von der aktuellen Finanzkraft der Lănder abhängt.

Die Übergangs-Bundesergănzungszuweisungen korrespondieren von ihrem Ziel her gesehen eng mit dem Beitragsrabatt für die finanzschwachen westdeutschen Lănder beim Fonds "Deutsche Einheit" (§ 1 Abs. 3 FAG). Damit erfolgt eine zweite Kompensation der überproportionalen Belastungen der Länder Bremen, Niedersachsen, Rheinland-Pfalz, Saarland und SchleswigHolstein infolge der Integration der neuen Bundesländer in den Finanzausgleich. Im Gegensatz zu den Übergangs-Bundesergänzungszuweisungen reduzieren sich die Beitragsnachlässe in den nächsten Jahren jedoch nicht gleichmäßig. Die länderspezifischen Ausgangsbetrăge werden vielmehr von 1996 bis 2000 um jeweils 5 Prozentpunkte und anschließend von 2001 bis 2005 um jeweils 15 Prozentpunkte pro Jahr gesenkt.

Vor diesem Hintergrund - und unabhängig von der verfassungsrechtlichen Problematik der Übergangs-Bundesergänzungszuweisungen - erscheinen zwei kritische Anmerkungen angebracht. Erstens muß man fragen, ob es trotz der Gewăhrung der Übergangs-Bundesergänzungszuweisungen sowie des allgemein hohen Ausgleichsniveaus im Länderfinanzausgleich tatsächlich erforderlich war, bei den Beiträgen zum Fonds "Deutsche Einheit" eine erneute Umverteilung zulasten der finanzsstarken westdeutschen Bundeslănder vorzunehmen ${ }^{2}$. Zweitens ist zu beanstanden, daß das gleiche Ziel der Kompensation überproportionaler Belastungen nicht mit einem, sondern

1 Normenkontrollantrag des Landes Hessen, Kapitel C.V.3.b.dd. Ahnlich aüßert sich Arndt: .Die Übergangs-Bundesergänzungszuweisungen können mit dem Gedanken eines Besitzstandsschutzes nicht gerechtfertigt werden und sind zudem als Sonderbedarfs-Bundesergänzungszuweisungen verfassungsrechtlich nicht ausreichend begründet. Diese Bundesergänzungszuweisungen können aber ... den Fehlbetrags-Bundesergänzungszuweisungen ... gleichgestellt werden. Deshalb gilt das vom BVerfG fur $\S 11$ Abs. 2 FAG statuierte Nivellierungsverbot auch für Zuweisungen nach $\S 11$ Abs. 5 FAG". Amdt, 1999, S. 83.

2 Vgl. Esser, 1994, S. 362. 
mit zwei unterschiedlichen Instrumenten verfolgt wird. Der Transparenz des Ausgleichsverfahrens dient diese Vorgehensweise jedenfalls nicht.

Es wäre einfacher und besser gewesen, die Belastungen der finanzschwachen alten Lănder nur über die Bundesergänzungszuweisungen zu berücksichtigen. $\mathrm{Da}$ dieser Weg nicht beschritten wurde, hängt vielleicht damit zusammen, daß die Übergangsregelungen des Finanzausgleichsgesetzes die formalen Lasten auf den Bund und die finanzstarken Bundeslănder verteilt haben. Es erscheint fraglich, ob die Empfängerländer Ausgleichsleistungen in gleicher Höhe allein gegenüber dem Bund oder den anderen westlichen Ländern hătten durchsetzen können.

\section{Tabelle 13}

Belastungen der alten Länder infolge der Integration der neuen Länder in den Länderfinanzausgleich im Jahr 1995

\begin{tabular}{|c|c|c|c|c|c|c|c|c|c|c|}
\hline & NRW & BAY & BW & NDS & $\mathrm{HE}$ & RP & SH & SAAR & $\mathrm{HH}$ & HB \\
\hline (1) & $0,2 \%$ & $0,3 \%$ & $0,5 \%$ & $-1,0 \%$ & $-0,9 \%$ & $0,4 \%$ & $-1,0 \%$ & $2,6 \%$ & $0,5 \%$ & $-2,2 \%$ \\
\hline 2 & $3,8 \%$ & $-2,3 \%$ & $1.9 \%$ & $-1,1 \%$ & $-6,2 \%$ & $0,6 \%$ & $-1,5 \%$ & $-2,7 \%$ & $0,7 \%$ & $-8,4 \%$ \\
\hline (3) & $0,6 \%$ & $-2,3 \%$ & $-1,4 \%$ & $3,0 \%$ & $-2,9 \%$ & $4,1 \%$ & $1,3 \%$ & $2,3 \%$ & $0,6 \%$ & $1,1 \%$ \\
\hline (2) & \multicolumn{10}{|c|}{$\begin{array}{l}\text { Wachstumsrate des Bruttoinlandsprodukts - Abweichung vom Durchschnitt der westlichen } \\
\text { Lander }(2,9 \%) \text { in Prozentpunkten. } \\
\text { Wachstumsrate der Steuereinnahmen vor Länderfinanzausgleich - Abweichung vom Durch- } \\
\text { schnitt der westlichen Länder }(0,2 \%) \text { in Prozentpunkten. } \\
\text { Wachstumsrate der Steuereinnahmen nach Länderfinanzausgleich - Abweichung vom Durch- } \\
\text { schnitt der westlichen Lander }(-1,7 \%) \text { in Prozentpunkten. }\end{array}$} \\
\hline & & & & & & & & & & \\
\hline
\end{tabular}

Dem Ziel der gleichmäßigen Verteilung der Belastungen, die den alten Bundesländern infolge der Integration der neuen Lănder in den Lănderfinanzausgleich entstanden sind, wurden die getroffenen Übergangsregelungen in der Realităt nicht gerecht. Tabelle 13 zeigt die Wachstumsraten des Bruttoinlandsprodukts (Zeile 1) und der Steuereinnahmen der alten Bundesländer vor (Zeile 2) und nach Finanzausgleich (Zeile 3) im Jahr 1995, jeweils als Differenz zum Durchschnitt der westlichen Lănder in Prozentpunkten. Die Integration der neuen Länder in den Länderfinanzausgleich hat deutliche Spuren hinterlassen, denn die alten Lănder mußten trotz eines 2,9-prozentigen Anstiegs ihres Bruttoinlandsprodukts einen 1,7-prozentigen Rückgang ihrer Einnahmen nach Finanzausgleich hinnehmen. 
Die Daten zeigen aber auch, daß alle Empfänger von Übergangs-Bundesergänzungszuweisungen erheblich begünstigt wurden. In den betreffenden Ländern liegen die Zuwachsraten der Steuereinnahmen zwar vor Finanzausgleich unter dem westlichen Durchschnitt (bzw. in Rheinland-Pfalz "nur" knapp darüber). Nach Finanzausgleich kehrt sich dieses Bild aber völlig um. Alle Empfängerländer weisen nun überdurchschnittliche Zuwachsraten auf. Sie können ihre relative Position nicht nur an den westlichen Durchschnitt angleichen, sondern die finanzstarken Länder sogar überholen. Mit anderen Worten: Aus einer ursprünglich intendierten Belastungsbegrenzung wurde in der Praxis offensichtlich eine Begünstigung der finanzschwachen gegenüber den finanzstarken alten Bundesländern.

Die effektiven Ergebnisse des Länderfinanzausgleichs belegen, daß die doppelte Berücksichtigung der (vermeintlich) überproportionalen Belastungen durch Übergangs-Bundesergänzungszuweisungen und BeitragsermäBigungen beim Fonds "Deutsche Einheit" nicht sinnvoll war. Es wurde insgesamt weit über das Ziel hinausgeschossen. Dennoch können die Übergangs-Bundesergänzungszuweisungen aus finanzwissenschaftlicher Sicht nicht rundweg abgelehnt werden.

Anpassungsprozesse für einen Übergangszeitraum finanziell abzufedern, um damit einen übermäßigen Anpassungsdruck für einzelne Gebietskörperschaften zu vermeiden, ist ein legitimes Anliegen der Wirtschaftspolitik. Die Gestaltung in Form zeitlich limitierter und degressiv gestaffelter Zahlungen gibt Anlaß zu der Hoffnung, daß aus den (überzogenen) Anpassungshilfen keine Dauersubventionen werden. Sofern der Gesetzgeber in dieser Hinsicht konsequent bleibt, erledigt sich das Problem der Übergangs-Bundesergänzungszuweisungen - ebenso wie das der Beitragsermäßigungen beim Fonds "Deutsche Einheit" - mit der Zeit von selbst. In der Diskussion über eine Reform des Länderfinanzausgleichs ab dem Jahr 2004 dürften beide Maßnahmen eigentlich keine Rolle mehr spielen.

Vor zuviel Optimismus sei aber gewarnt. Zu oft haben sich Übergangshilfen in der Vergangenheit als Dauerbrenner erwiesen. Man denke im Kontext des Lănderfinanzausgleichs nur an die Sanierungshilfen für Bremen und 
das Saarland, die zunăchst bis 1998 befristet waren, nun aber doch bis 2004 fortgesetzt werden. Ganz auszuschließen sind Antrăge auf Verlängerung auch bei den Übergangs-Bundesergănzungszuweisungen nicht. Die kontinuierliche Absenkung der Entlastung für die finanzschwachen alten Länder war politisch wohl an die Vorstellung geknüpft, daß der Aufholpro$z e ß$ in den neuen Ländern schon bald zu einer Entspannung der Finanzausgleichsbeziehungen beitragen würde. Da diese Normalisierung bislang kaum eingetreten ist, könnten die finanzschwachen alten Lănder durchaus auf die Idee kommen, eine Fortsetzung der Übergangshilfen zu verlangen.

Einem solchen Ansinnen müßte entschieden entgegengetreten werden. Die hier durchgeführten Vergleichsrechnungen zeigen, daß die Maßnahmen zugunsten relativ finanzschwacher alter Bundesländer in der Vergangenheit schon kräftig überdimensioniert waren. Im Jahr 2004 - fünfzehn Jahre nach der deutschen Einheit - wird hoffentlich niemand mehr ernsthaft behaupten wollen, daß die westdeutschen Länder nicht genügend Zeit gehabt hätten, die Aufgabe der vollständigen Integration der neuen Lănder in die bundesdeutsche Finanzverfassung zu bewältigen.

\section{Die Sanierungs-Bundesergănzungszuweisungen}

\section{a. Begründung und Verteilungseffekte der Zuweisungen}

Die Sanierungs-Bundesergänzungszuweisungen nach § 11 Abs. 6 FAG gehen auf das Urteil des Bundesverfassungsgerichts aus dem Jahr 1992 zurück. Das Gericht kam anhand eines Vergleichs der Kreditfinanzierungsquote $^{1}$ und der Zins-Steuer-Quote 2 mit dem jeweiligen Bundesdurchschnitt zu dem Ergebnis, daß sich Bremen und das Saarland in einer Haushaltsnotlage befinden, aus der sie sich nicht mehr selbst befreien können. Die anderen Länder und der Bund müssen die in Not geratenen Ländern unterstützen. „Im Falle der extremen Haushaltsnotlage eines Landes, wie sie gegenwärtig für das Saarland und Bremen besteht, ist das bundesstaatliche

1 Die Kreditfinanzierungsquote (Defizitquote) gibt an, welcher Teil der offentlichen Ausgaben durch eine Kreditaufnahme finanziert wird.

2 Die Zins-Steuer-Quote bringt zum Ausdruck, welcher Teil der Steuern für Zinszahlungen verwendet werden muß. 
Prinzip als solches berührt. Aus inm erwächst den anderen Gliedern der bundesstaatlichen Gemeinschaft die Pflicht, mit konzeptionell aufeinander abgestimmten Maßnahmen dem betroffenen Land beizustehen “1.

Das Bundesverfassungsgericht hat die Lasten einer Haushaltsnotsituation als berücksichtigungsfähigen Sonderbedarf eingestuft, wenn Abhilfe auf andere Weise nicht möglich ist ${ }^{2}$. Daher gewährt der Bund Ergänzungszuweisungen zur Unterstützung notleidender Länder. Trotz der gemeinsamen Verpflichtung zur Hilfe ist es nie gelungen, die übrigen Länder an den Zahlungen zu beteiligen. Allerdings leisten die Länder ihren Beitrag zumindest indirekt über einen geringeren Anteil an der Umsatzsteuer ${ }^{3}$. Auch kann der Bund flexibler auf eine finanzielle Belastung reagieren. Ihm stehen steuerliche Maßnahmen zur Verfügung, während die Länder nur die Möglichkeit haben, ihre Ausgaben zu kürzen oder ihre Kreditaufnahme zu erhöhen.

Nach $\S 11$ Abs. 6 FAG erhalten Bremen und das Saarland zwischen 1994 und 1998 Sonderbedarfs-Bundesergänzungszuweisungen zur Haushaltssanierung in Höhe von insgesamt 3,4 Mrd. DM jährlich. Davon entfallen 1,8 Mrd. DM auf Bremen und 1,6 Mrd. DM auf das Saarland. Bezogen auf die Einwohnerzahl wird Bremen 1998 mit 2.684 DM je Einwohner deutlich stärker entlastet als das Saarland, das immer noch Zuweisungen in Höhe von 1.486 DM je Einwohner erhält. Die Mittel sind zur Schuldentilgung einzusetzen. Die dadurch gesparten Zinsen müssen zur Verminderung der Nettokreditaufnahme oder für Investitionen verwendet werden; letzteres mit dem Ziel einer Stärkung der Wirtschafts- und Finanzkraft.

Die effektiven Verteilungswirkungen der Sanierungs-Bundesergănzungszuweisungen auf der Basis des Finanzausgleichsjahres 1998 illustriert Tabelle 14 unter der Annahme einer kompensatorischen Anpassung des Umsatzsteueranteils der Länder. Dieser könnte ohne die Hilfen an Bremen und das Saarland um immerhin 1,4 Prozentpunkte auf 50,9\% angehoben werden. Netto liegen die Vergünstigungen der Empfänger daher leicht unter den er-

1 BVerfGE 86, 148, S. 263.

2 Vgl. BVerfGE 86, 148, S. $260 \mathrm{f}$.

3 Voraussetzung ist eine sachgerechte Ermittlung der Deckungsquoten. Vgl. zu den Verteilungswirkungen die nachfolgende Tabelle 14. 
haltenen Zuweisungen. Belastet werden die übrigen Flächenländer mit rund 40 DM je Einwohner und die Stadtstaaten Berlin und Hamburg mit rund 55 DM je Einwohner. Mit der geplanten Reduktion des Zuweisungsvolumens werden die impliziten Verteilungseffekte der Sanierungshilfen in den kommenden Jahren schrittweise an Bedeutung verlieren ${ }^{1}$.

Tabelle 14

Sanierungs-Bundesergänzungszuweisungen 1998

Umsatzsteueranteil der Länder angepaßt

\begin{tabular}{|c|c|c|c|c|c|}
\hline \multirow[t]{2}{*}{ Land } & \multicolumn{2}{|c|}{ GuV } & USt & $F A$ & BEZ \\
\hline & $\mathrm{DM} / \mathrm{E}$ & Mio. DM & \multicolumn{3}{|c|}{ Mio. DM } \\
\hline NRW & $-40,54$ & $-728,5$ & $-738,1$ & 9,7 & 0,0 \\
\hline BAY & $-40,54$ & $-489,2$ & $-495,7$ & 6,6 & 0,0 \\
\hline BW & $-41,00$ & $-426,8$ & $-427,6$ & 0,8 & 0,0 \\
\hline NDS & $-40,13$ & $-315,1$ & $-322,5$ & 2,9 & 4,4 \\
\hline HE & $-41,07$ & $-247,8$ & $-247,8$ & 0,1 & 0,0 \\
\hline RP & $-40,13$ & $-161,3$ & $-165,1$ & 1,5 & 2,2 \\
\hline SH & $-41,05$ & $-113,3$ & $-113,4$ & 0,1 & 0,0 \\
\hline SAAR & $1.445,67$ & $1.557,0$ & $-44,2$ & 3,2 & $1.598,1$ \\
\hline $\mathrm{HH}$ & $-55,57$ & $-94,5$ & $-69,9$ & $-24,7$ & 0,0 \\
\hline HB & $2.630,02$ & $1.763,9$ & $-27,5$ & $-6,9$ & $1.798,4$ \\
\hline SN & $-39,89$ & $-179,8$ & $-185,1$ & 13,5 & $-8,1$ \\
\hline ST & $-39,89$ & $-107,3$ & $-110,5$ & 8,1 & $-4,9$ \\
\hline TH & $-39,89$ & $-98,5$ & $-101,5$ & 7,4 & $-4,5$ \\
\hline BB & $-39,89$ & $-102,9$ & $-106,0$ & 7,7 & $-4,7$ \\
\hline MV & $-39,89$ & $-71,9$ & $-74,1$ & 5,4 & $-3,3$ \\
\hline BER & $-53,85$ & $-184,0$ & $-140,4$ & $-35,3$ & $-8,3$ \\
\hline West & 11,53 & 744,5 & $-2.651,8$ & $-6,8$ & $3.403,0$ \\
\hline Ost & $-42,62$ & $-744,5$ & $-717,6$ & 6,8 & $-33,7$ \\
\hline Alle & 0,00 & 0,0 & $-3.369,4$ & 0,0 & $3.369,4$ \\
\hline $\begin{array}{l}\text { GuV } \\
\text { uSt }\end{array}$ & $\begin{array}{l}\text { Iung }(+) \text { b } \\
\text { LFA ohn }\end{array}$ & $\begin{array}{l}\text { erminder } \\
\text { ierungs- }\end{array}$ & $\begin{array}{l}\text { der Lär } \\
\text { sergänz }\end{array}$ & $\begin{array}{l}\text { hamen } \\
\text { eisun }\end{array}$ & über \\
\hline
\end{tabular}

\section{b. Der Stand der Konsolidierungsbemühungen}

Bremen und das Saarland haben in den vergangenen Jahren erhebliche Anstrengungen zur Haushaltskonsolidierung unternommen². Allerdings wurden bisher noch keine spürbaren Konsolidierungserfolge erzielt. Das

1 Die Einzelheiten der Neuregelung werden im folgenden Abschnitt erläutert.

2 Dies zeigen jedenfalls die Sanierungsberichte der Länder, aus denen auch die Angaben zur Haushaltsentwicklung stammen. Vgl. Senator für Finanzen der Freien Hansestadt Bremen, 1999; Ministerium für Wirtschaft und Finanzen des Saarlandes, 1999.

Wolfgang Scherf - 978-3-631-75181-7 
Saarland reduzierte seinen Schuldenstand von 1994 bis 1998 um lediglich 2 Mrd. DM (bzw. 1,7 Mrd. DM einschließlich Gemeinden). Im selben Zeitraum konnte Bremen trotz höherer Sanierungs-Bundesergänzungszuweisungen seine Verschuldung sogar nur um 1,1 Mrd. DM vermindern. Der Abbau des Schuldenstandes blieb also weit hinter dem Volumen der zu diesem Zweck gewährten Bundesergänzungszuweisungen zurück.

Das bescheidene Ausmaß der Konsolidierung wird deutlich, wenn man die Entwicklung der Pro-Kopf-Verschuldung betrachtet. Sie lag in Bremen 1993 bei $25.300 \mathrm{DM}$ und 1998 immer noch bei $25.100 \mathrm{DM}$. Die vergleichbaren Werte für das Saarland betragen 15.800 DM für 1993 und 13.600 DM für 1998. Selbst wenn beiden Ländern für ihre (Brutto-) Verschuldung pro Kopf eine mittlere Wachstumsrate zugestanden wird, die dem Durchschnitt der westlichen Länder entspricht (rund $4 \%$ ), hätten sie bei vollständiger Verwendung der jeweiligen Bundesergänzungszuweisungen für die Schuldentilgung im Jahr 1998 deutlich geringere Werte für den Pro-Kopf-Schuldenstand erreichen müssen. Das Saarland übertrifft den bei einer solchen Strategie erreichbaren Zielwert von 11.750 DM je Einwohner um rund $15 \%$. Bremen liegt sogar um rund $45 \%$ über seinem analog ermittelten Zielwert von $17.320 \mathrm{DM}$ je Einwohner'1.

Auch gemessen an den anderen Kennzahlen der Haushaltslage kann von einer Entspannung keine Rede sein. Die Zins-Steuer-Quote konnte zwar im Saarland (einschließlich Gemeinden) von $24,7 \%$ auf $21,0 \%$ und in Bremen von $28,1 \%$ auf $25,2 \%$ gesenkt werden. Die Werte lagen aber weiterhin klar über dem Durchschnitt der westdeutschen Länder von 11,1\%. Auch die Defizitquoten bewegen sich auf unverăndert hohem Niveau. Im Saarland blieben sie stabil bei $15 \%$, während Bremen nach 1995 immerhin einen leichten Rückgang von $22,8 \%$ auf $19,6 \%$ zu verzeichnen hatte. Gemessen am

1 Die Zielwerte ergeben sich aus dem jeweiligen Pro-Kopf-Schuldenstand D, der mittleren Wachstumsrate der durchschnittlichen Pro-Kopf-Verschuldung $w$ und den erhaltenen Pro-Kopf-Zuweisungen $B$ nach der Formel:

$D_{98}=D_{93}(1+w)^{5}-B$

Die quantitativen Angaben sollten nicht überinterpretiert werden, geben aber immerhin einen Eindruck vom Ausmaß des Konsolidierungserfolges bezogen auf die eingesetzten Mittel. Sie zeigen auch, daß das Saarland wesentlich erfolgreicher war als Bremen. 
Durchschnitt der westdeutschen Lănder, der parallel von $6 \%$ auf $2,6 \%$ gesunken ist, kann aber von einer Annäherung keine Rede sein 1 .

Bremen und das Saarland begründen die relativ geringen Fortschritte damit, daß die Einnahmenentwicklung erheblich hinter den ursprünglichen Erwartungen zurückgeblieben ist. Man muß in diesem Zusammenhang auch anmerken, daß die hohen marginalen Abschöpfungsquoten im Länderfinanzausgleich eine erfolgreiche Konsolidierungspolitik der Sanierungsländer geradezu konterkarieren. Nachdem eine vom Finanzplanungsrat eingesetzte Bund-Länder-Arbeitsgruppe 1998 festgestellt hatte, daß sich beide Länder weiterhin in einer extremen Haushaltsnotlage befinden, erhalten sie bis zum Jahr 2004 weitere Hilfen. Vorgesehen sind insgesamt Zahlungen in Höhe von 12,7 Mrd. DM; davon 7,7 Mrd. DM für Bremen und $5 \mathrm{Mrd}$. DM für das Saarland ${ }^{2}$. Die Zuweisungen sind degressiv gestaffelt und laufen mit dem Jahr 2004 endgültig aus ${ }^{3}$.

Durch die schrittweise Zurückführung sollen die beiden Länder dazu veranlaßt werden, sich auf das Ende der Sanierungshilfen vorzubereiten. Auch sind die Verwendungsauflagen jetzt enger gefaßt. Wie bisher müssen die Zuweisungen unmittelbar zur Schuldentilgung herangezogen werden. Neu ist aber die Verpflichtung zu einer restriktiven Haushaltspolitik im Gesetz. Die Wachstumsrate der Ausgaben muß unterhalb der allgemeinen Empfehlung des Finanzplanungsrates liegen. Zudem muß Bremen die aus der Schuldentilgung resultierenden Finanzierungsspielräume zur Senkung der Kreditaufnahme verwenden. Für das Saarland besteht weiterhin die Option, Investitionen zur Stärkung der Wirtschafts- und Finanzkraft durchzuführen.

1 Neben der Zins-Steuer-Quote und der Defizitquote existieren noch andere Indikatoren zur Charakterisierung der Haushaltslage. Die Deckungsquote beschreibt das Verhăltnis der gesamten regulären Einnahmen zu den Ausgaben. Die Zins-Ausgaben-Quote gibt an, welcher Teil der Ausgaben auf Zinszahlungen entfallt. Der Haushaltsnettobeitrag macht deutlich, welcher Teil der Kreditaufnahme nicht bereits durch Zinsverpflichtungen absorbiert wird. Eine genaue Analyse der Haushaltslage eines Landes erfordert prinzipiell die Berücksichtigung mehrerer Indikatoren und ihrer Determinanten (vor allem Zins und Wachstumsrate). Vgl. Kitterer, 1994, S. 31 ff.; Bösinger, 1999, S. 224 ff.

2 Die höheren Zuweisungen an Bremen werden mit der höheren Pro-Kopf-Zinsbelastung gegenüber dem Saarland gerechtfertigt.

3 Die Zuweisungen (in Mio. DM) werden im Zeitablauf folgendermaßen abgesenkt: $\begin{array}{lllllll}\text { Jahr } & 1999 & 2000 & 2001 & 2002 & 2003 & 2004\end{array}$

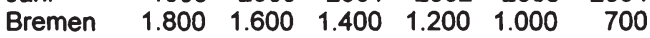

Saarland $\begin{array}{llllll}1.200 & 1.050 & 900 & 750 & 600 & 500\end{array}$ 
Die Differenzierung zwischen Bremen und dem Saarland wird damit begründet, daß Bremen die Finanzierungsspielräume zwischen 1994 und 1998 voll für zusätzliche Investitionen genutzt hat, während im Saarland zwei Drittel dieser Finanzmasse zur weiteren Begrenzung der Verschuldung eingesetzt wurde. Die beiden Länder sind im übrigen auch künftig verpflichtet, über den Fortgang des Konsolidierungsprozesses gegenüber dem Bundesministerium der Finanzen sowie den obersten Finanzbehörden der Länder Rechenschaft abzulegen 1 .

\section{c. Mögliche Ursachen einer Haushaltsnotlage}

Im Hinblick auf die Eignung der Sanierungshilfen zur Überwindung einer Haushaltnotlage stellen sich verschiedene Fragen grundsătzlicher und instrumenteller Art. Eine Analyse der Bestimmungsfaktoren der Finanzkrise eines Landes muß der Entwicklung einer Krisenbewältigungsstrategie vorausgehen. Im wesentlichen sind zwei Ursachen (-komplexe) zu beachten².

(1) Die Haushaltsnotlage kann aus einer regionalen Strukturkrise resultieren. Auslösende Faktoren sind z. B. Naturkatastrophen, ein ausgeprägter Mangel an Infrastruktur oder der Niedergang regional dominierender Branchen (im Saarland der Montanbereich, in Bremen die Werften).

(2) Ein Land kann auch durch eine übermäßige Verschuldung in früheren Jahren in eine Haushaltsnotlage geraten. Diese Verschuldung ist möglicherweise auf Sachverhalte zurückzuführen, die das betroffene Land nicht zu verantworten hat. Es kann sich jedoch auch um das Ergebnis einer verfehlten Wirtschafts- und Finanzpolitik handeln.

Struktur- und Verschuldungskrisen gehen in der Regel mit einem auf Dauer krisenverschärfenden Rückgang der öffentlichen Investitionen einher. Sie sind häufig miteinander verknüpft und verstärken sich gegenseitig. Letztlich führen beide dazu, daß die Vergleichbarkeit der Länder als Voraussetzung für einen regelgebundenen Finanzkraftausgleich nicht mehr gegeben ist.

1 Vgl. BT-Drucksache 14/487, S. 4.

2 Vgl. Wissenschaftlicher Beirat beim Bundesministerium der Finanzen, 1992, S. 89 f. 
Hinsichtlich der Problembewältigung liegen jedoch erhebliche Unterschiede vor. Während einer reinen Schuldenkrise mit finanziellen Hilfen beizukommen ist, erfordern Strukturkrisen gegebenenfalls den Einsatz der regionalen und sektoralen Strukturpolitik mit dem Ziel einer Verbesserung der regionalen Wirtschafts- und Finanzkraft.

Tendenziell liegt sowohl in Bremen als auch im Saarland eine Kombination aus Verschuldungs- und Strukturkrise vor. Allerdings lassen sich die internen und externen Ursachen einer Finanzkrise in der Praxis nur schwer differenzieren. "Die Unterscheidung zwischen objektiven, vorgegebenen und unverfügbaren Ursachen für Sonderbedarfe einerseits, durch eigene finanzielle Entscheidungen verursachten besonderen Ausgaben andererseits, die der Entscheidung über die (mögliche) finanzausgleichsrechtliche Relevanz der Sonderbedarfe zugrundeliegt, läßt sich im Fall der Haushaltsnotlage, die sich über Jahre hin aufgebaut hat und auf zahlreiche einzelne Ursachen zurückgeht, nicht durchführen "1. Daher wird dieser Frage hier auch nicht weiter nachgegangen. Vielmehr konzentrieren sich die weiteren Überlegungen auf die spezifischen ökonomischen Probleme, die mit dem Instrument der Sanierungs-Bundesergänzungszuweisungen verbunden sind.

\section{d. Ökonomische Fehlanreize durch Sanierungshilfen}

Ein ökonomisches Grundproblem besteht in den ungünstigen Verhaltensanreizen, die von Sanierungshilfen ausgehen, sofern sie von den Ländern antizipiert und einkalkuliert werden. Wenn einzelne Länder darauf vertrauen, daß sie vom Bund und den übrigen Ländern unterstützt werden, sobald eine Haushaltsnotlage eintritt, dann kann eine "rationale" Haushaltspolitik ins Defizit führen2. Dies erscheint vorteilhaft, weil ein Land und seine Bürger sich infolge der Verschuldung und der erwarteten Unterstützung wenigstens vorübergehend mehr leisten können, als es die eigenen Mittel zulassen. So

1 Korioth, 1997, S. 667.

2 Vgl. Homburg, 1994, S. 322. Verstärkt wird die Gefahr einer ineffizient hohen Verschuldung der Länder dadurch, daß die Risikominderung für die Kapitalgeber infolge der solidarischen Haftung Zinssenkungen für eigentlich riskante Schuldner bewirkt, welche die Kreditfinanzierung erleichtern und attraktiver machen. Vgl. Dickertmann/Gelbhaar, 1996 b, S. 494. 
gesehen fördern die Sanierungs-Bundesergänzungszuweisungen eine undisziplinierte Finanzpolitik der Bundesländer ${ }^{1}$ und tragen zu dem Problem bei, das sie bekämpfen sollen².

Der Anreiz, eine solche Politik zu betreiben, ist vor allem für kleine Länder gegeben. Große Länder dürfen kaum auf eine entsprechende Unterstützung hoffen, da die finanziellen Mittel, die in einer ähnlichen Situation zur Verfügung gestellt werden müßten, vom Bund und den übrigen Ländern nicht mehr aufgebracht werden könnten ${ }^{3}$. Rechnet man z. B. die SonderbedarfsBundesergänzungszuweisungen, die Bremen zur Sanierung im Jahr 1999 erhält, auf die Einwohnerzahl von Hessen hoch, so ergeben sich Zahlungen in Höhe von 16,2 Mrd. DM. Für Nordrhein-Westfalen liegt das vergleichbare Volumen bei 48,2 Mrd. DM.

Diese Zahlen machen klar, daß die Regierung eines bevölkerungsreichen Bundeslandes vernünftigerweise keine finanzpolitische Strategie verfolgen kann, die von vornherein finanzielle Hilfen der föderalen Solidargemeinschaft einkalkuliert. Auf der anderen Seite können große Länder eventuell eintretende Strukturkrisen aber auch eher meistern, weil die Abhängigkeit von einzelnen Branchen geringer und die Möglichkeiten des internen regionalen Finanzausgleichs größer sind. Beides dürfte dazu beigetragen haben, daß bislang nur kleine Länder in eine Haushaltsnotlage geraten sind.

Angesichts der möglichen Fehlanreize erscheint auch das Gesamtvolumen der Zuweisungen nicht ganz unproblematisch. Bremen erhält von 1994 bis 2004 Zahlungen in Höhe von insgesamt 16,7 Mrd. DM bzw. 24.900 DM je Einwohner. Die Subventionen entsprechen damit in etwa dem Pro-KopfSchuldenstand von 1993 (25.300 DM). Das Saarland bezieht im gleichen Zeitraum 13 Mrd. DM bzw.12.070 DM je Einwohner. Dies sind immer noch mehr als 75 \% der Pro-Kopf-Verschuldung des Jahres 1993 (15.800 DM).

1 Vgl. Huber, 1997, S. 28.

2 Diese Problematik hat auch das Bundesverfassungsgericht gesehen und betont, daß die Bundesergänzungszuweisungen ${ }_{n}$ nicht dazu bestimmt [sind], finanziellen Schwächen abzuhelfen, die eine unmittelbare und voraussehbare Folge eigener politischer Entscheidungen des Landes bilden“. BVerfGE 86, 148, S. 260.

3 Vgl. Homburg, 1994, S. 323. 
Bei der Bewertung des Umfangs der Subventionen ist zu berücksichtigen, $\mathrm{da} B$ das Bundesverfassungsgericht das Niveau des Landes mit der nächstniedrigeren Zins-Steuer-Quote als Sanierungsziel angegeben hat. Die Bundesergänzungszuweisungen müssen daher eigentlich nur so hoch sein, daß die Verschuldung im Sanierungszeitraum auf das mit der betreffenden ZinsSteuer-Quote kompatible Niveau gesenkt werden kann.

Angesichts des langen Anpassungszeitraums und des beträchtlichen Subventionsvolumens muß davon ausgegangen werden, daß Bremen und das Saarland ihre Haushaltsnotlage bis 2004 überwinden können. Schon wegen der Gefahr der dauerhaften Prämierung einer verfehlten Wirtschafts- und Finanzpolitik sollten anschließend keine weiteren Sanierungs-Bundesergänzungszuweisungen mehr gewährt werden. Eine zeitlich und quantitativ unbegrenzte Solidaritätspflicht kann es nicht geben.

Dem steht nicht entgegen, daß die beiden Länder auch im Jahr 2004 möglicherweise noch unter Strukturkrisen leiden, die eine Sanierung verhindern. Bundesergănzungszuweisungen sind eben kein geeigneter Ersatz für eine ursachenbezogene Therapie struktureller Schwächen. Hierfür bieten sich mit den Gemeinschaftsaufgaben, den Finanzhilfen oder der planmäßigen Berücksichtigung regional- und strukturpolitischer Aspekte bei den Standortentscheidungen des Bundes besser geeignete Instrumente an.

Im übrigen stellt sich auch in diesem Zusammenhang die Frage nach einer Neugliederung des Bundesgebietes; denn Länder, die sich in einer permanenten Haushaltsnotlage befinden, sind offensichtlich nicht dazu in der Lage, ihren Aufgaben auf Dauer eigenständig und wirksam nachzukommen ${ }^{1}$. Ein Problem besteht jedoch darin, daß gerade die schlechte Haushaltssituation ein Fusionshindernis darstellt. Sofern ein Zusammenschluß mit den Nachbarländern die einzige Chance ist, die Situation finanziell notleidender Länder zu verbessern, wäre es denkbar, für einen Übergangszeitraum Sonderbedarfs-Bundesergänzungszuweisungen mit dem Ziel einzusetzen, die

1 Nach Art. 29 Abs. 1 GG kann das Bundesgebiet neu gegliedert werden, um zu gewährleisten, daß die Länder nach Größe und Leistungsfăhigkeit die ihnen obliegenden Aufgaben wirksam erfüllen können. 
Bildung dauerhaft leistungsfăhiger Einheiten herbeizuführen ${ }^{1}$. Dauerhafte Sanierungshilfen schwächen dagegen den Föderalismus und können auch eine insgesamt vorteilhafte Fusion verhindern. So gesehen impliziert die derzeitige Rechtslage eine durchaus fragwürdige Bestandsgarantie für alle Länder, unabhängig von ihrer Leistungsstärke 2 .

\section{e. Finanzkrisen und Finanzverfassung}

Das Problem der Haushaltsnotlagen entsteht letzten Endes dadurch, daß die Länder "ihre Ausgaben zu hoch ansetzten und aus politischen oder wirtschaftlichen Gründen nicht in der Lage sind, sie aus laufenden Einnahmen zu finanzieren. Es werden daher Kredite aufgenommen, deren nachfolgender Schuldendienst die Haushalte belastet “3. Die Bundesergänzungszuwei sungen zur Haushaltssanierung stehen damit in engem Zusammenhang mit zwei allgemeinen Problemen der derzeitigen (Finanz-) Verfassung.

Die Sanierungsfälle dokumentieren, daß die Verfassung bislang keine geeigneten und verbindlichen Defizitgrenzen enthält, mit deren Hilfe Haushaltsnotlagen verhindert oder wenigstens limitiert werden könnten. Art. 115 GG und die entsprechenden Regelungen in den Landesverfassungen garantieren jedenfalls keinen Schutz vor einer übermäßigen Staatsverschuldung 4 . So ist ein Grund für die Haushaltsnotlage des Saarlandes möglicherweise auch darin zu sehen, daß die Landesverfassung eine Kreditfinanzierung über die Summe der Investitionen hinaus nicht nur zur Abwehr einer Störung des gesamtwirtschaftlichen Gleichgewichts, sondern auch für den Fall eines außerordentlichen Bedarfs zugelassen hat ${ }^{5}$.

Ein weiterer Schwachpunkt der Finanzverfassung liegt darin, daß die Länder über keine eigene Steuerkompetenz verfügen. Sie können ein größeres Angebot an offentlichen Leistungen im wesentlichen eben nur durch eine zusătzliche Kreditaufnahme finanzieren. Die fehlende Steuerautonomie ist

1 Vgl. Lutz, 1996, S. 159.

2 Vgl. Hăde, 1996, S. 316, der die Garantie aber nicht explizit als problematisch einstuft.

3 Kitterer, 1994, S. 31.

4 Vgl. Scherf, 1996, S. 376 ff.

5 Vgl. Gehlen, 1991, S. $237 \mathrm{ff}$. 
somit ein konstitutioneller Mangel, der die Gefahr von Haushaltsnotlagen vergrößert. Im übrigen könnten durch autonome Steuererhőhungen auch die Bürger der Lănder, die in eine Haushaltsnotlage geraten sind, stärker an der Finanzierung der Schulden beteiligt werden. Allerdings sind hierbei Ausweichreaktionen in Form von Wohnsitzverlagerungen zu beachten, die das Ausmaß der realisierbaren Mehrbelastung begrenzen.

Insgesamt bleibt festzuhalten, daß die Bundesergänzungszuweisungen zur Milderung von Haushaltsnotlagen aus finanzwissenschaftlicher Sicht nur im Ausnahmefall akzeptiert werden können. Sie sind problematisch, weil sie Anreize zu finanzpolitischem Fehlverhalten setzen. Daher dürfen solche Hilfen nur vorübergehend für einen fest vereinbarten Sanierungszeitraum gewährt werden. Auch sind sie an laufende Erfolgskontrollen zu binden. Die ab 1999 geltende Regelung stellt in dieser Hinsicht einen deutlichen Fortschritt dar. Sollte das Konsolidierungsziel allerdings ein weiteres Mal verfehlt werden, so ist über andere Sanierungsstrategien nachzudenken, die nicht auf eine ergänzende Deckung des allgemeinen Finanzbedarfs, sondern auf die Behebung der strukturellen Ursachen der Finanzkrisen zielen.

\section{Bundesergänzungszuweisungen für die neuen Länder}

\section{a. Die gesetzliche Regelung und ihre Verteilungseffekte}

Die fünf neuen Bundesländer sowie Berlin erhalten nach § 11 Abs. 4 FAG bis zum Jahr 2004 Sonderbedarfs-Bundesergänzungszuweisungen zum Abbau teilungsbedingter Sonderlasten und zum Ausgleich unterproportionaler kommunaler Finanzkraft. Mit insgesamt 14 Mrd. DM pro Jahr handelt es sich um die zur Zeit quantitativ bedeutendsten Ergänzungszuweisungen. Der Betrag ist im Finanzausgleichsgesetz pauschal festgeschrieben. Die Verteilung auf die einzelnen Lănder erfolgt auf der Basis der Einwohnerzahl der Länder im Jahr 1992. Vorgesehen ist also eine gleichmäßige Förderung gemessen an den Pro-Kopf-Zuweisungen.

Veränderungen in der Bevölkerungszahl haben zwischenzeitlich bewirkt, daß sich die Zuweisungen je Einwohner zwischen den einzelnen Ländern unterscheiden (vgl. Tabelle 15). Mecklenburg-Vorpommern und Sachsen- 
Tabelle 15

\section{Bundesergänzungszuweisungen für die neuen Länder 1998}

\begin{tabular}{|c|c|c|c|c|c|}
\hline \multirow[t]{2}{*}{ Land } & \multicolumn{2}{|c|}{ GuV } & USt & & BEZ \\
\hline & $\mathrm{DM} / \mathrm{E}$ & Mio. DM & \multicolumn{3}{|c|}{ Mio. DM } \\
\hline NRW & 0,00 & 0,0 & 0,0 & 0,0 & 0,0 \\
\hline BAY & 0,00 & 0,0 & 0,0 & 0,0 & 0,0 \\
\hline BW & 0,00 & 0,0 & 0,0 & 0,0 & 0,0 \\
\hline NDS & 0,00 & 0,0 & 0,0 & 0,0 & 0,0 \\
\hline $\mathrm{HE}$ & 0,00 & 0,0 & 0,0 & 0,0 & 0,0 \\
\hline RP & 0,00 & 0,0 & 0,0 & 0,0 & 0,0 \\
\hline $\mathrm{SH}$ & 0,00 & 0,0 & 0,0 & 0,0 & 0,0 \\
\hline SAAR & 0,00 & 0,0 & 0,0 & 0,0 & 0,0 \\
\hline $\mathrm{HH}$ & 0,00 & 0,0 & 0,0 & 0,0 & 0,0 \\
\hline HB & 0,00 & 0,0 & 0,0 & 0,0 & 0,0 \\
\hline SN & 811,58 & $3.658,0$ & 0,0 & 0,0 & $3.658,0$ \\
\hline ST & 820,76 & $2.208,0$ & 0,0 & 0,0 & $2.208,0$ \\
\hline $\mathrm{TH}$ & 812,80 & $2.008,0$ & 0,0 & 0,0 & $2.008,0$ \\
\hline BB & 769,09 & $1.985,0$ & 0,0 & 0,0 & $1.985,0$ \\
\hline MV & 820,11 & $1.479,0$ & 0,0 & 0,0 & $1.479,0$ \\
\hline BER & 778,99 & $2.662,0$ & 0,0 & 0,0 & $2.662,0$ \\
\hline West & 0,00 & 0,0 & 0,0 & 0,0 & 0,0 \\
\hline Ost & 801,39 & $14.000,0$ & 0,0 & 0,0 & $14.000,0$ \\
\hline Alle & 170,68 & $14.000,0$ & 0,0 & 0,0 & $14.000,0$ \\
\hline GuV & $\begin{array}{l}\text { Erhëhung }(+) b \\
\text { einem LFA } \\
49.5 \% \text { Län }\end{array}$ & $\begin{array}{l}\text { Verminde } \\
\text { EZ zum A } \\
\text { L }\end{array}$ & Lä & $\begin{array}{l}\text { men } \\
\text { onde }\end{array}$ & \\
\hline
\end{tabular}

Umsatzsteueranteil der Länder angepaßt

\begin{tabular}{|c|c|c|c|c|c|}
\hline Land & \multicolumn{2}{|c|}{ GuV } & USt & FA & BEZ \\
\hline & $\mathrm{DM} / \mathrm{E}$ & Mio. DM & \multicolumn{3}{|c|}{ Mio. DM } \\
\hline NRW & $-166,94$ & $-2.999,7$ & $-3.039,3$ & 40,0 & 0,0 \\
\hline BAY & $-166,93$ & $-2.014,3$ & $-2.041,0$ & 26,9 & 0,0 \\
\hline BW & $-168,84$ & $-1.757,3$ & $-1.760,5$ & 3,3 & 0,0 \\
\hline NDS & $-165,25$ & $-1.297,5$ & $-1.328,1$ & 12,0 & 18,0 \\
\hline $\mathrm{HE}$ & $-169,13$ & $-1.020,2$ & $-1.020,3$ & 0,3 & 0,0 \\
\hline RP & $-165,24$ & $-664,0$ & $-679,7$ & 6,1 & 9,2 \\
\hline $\mathrm{SH}$ & $-169,02$ & $-466,6$ & $-466,9$ & 0,3 & 0,0 \\
\hline SAAR & $-164,24$ & $-176,9$ & $-182,2$ & 13,3 & $-8,0$ \\
\hline $\mathrm{HH}$ & $-228,84$ & $-389,2$ & $-287,7$ & $-101,6$ & 0,0 \\
\hline HB & $-221,69$ & $-148,7$ & $-113,4$ & $-28,5$ & $-6,7$ \\
\hline SN & 647,33 & $2.917,7$ & $-762,4$ & 55,6 & $3.624,5$ \\
\hline ST & 656,52 & $1.766,2$ & $-455,0$ & 33,2 & $2.188,0$ \\
\hline TH & 648,56 & $1.602,2$ & $-417,9$ & 30,5 & $1.989,6$ \\
\hline BB & 604,85 & $1.561,1$ & $-436,6$ & 31,8 & $1.965,8$ \\
\hline MV & 655,87 & $1.182,8$ & $-305,0$ & 22,2 & $1.465,6$ \\
\hline BER & 557,26 & $1.904,3$ & $-578,0$ & $-145,4$ & $2.627,7$ \\
\hline West & $-169,38$ & $-10.934,5$ & $-10.919,1$ & $-27,9$ & 12,5 \\
\hline Ost & 625,91 & $10.934,3$ & $-2.954,9$ & 27,9 & $13.861,4$ \\
\hline Alle & 0,00 & $-0,1$ & $-13.874,0$ & 0,0 & $13.873,8$ \\
\hline $\begin{array}{l}\text { GuV } \\
\text { USt }\end{array}$ & $\begin{array}{l}\mathrm{g}(+) \mathrm{b} \\
\mathrm{FA} \text { ohn } \\
\text { ändera }\end{array}$ & erminde & $\begin{array}{l}\text { der Lär } \\
\text { ilungsb }\end{array}$ & $\begin{array}{l}\text { men } \\
\text { ond }\end{array}$ & \\
\hline
\end{tabular}


Anhalt erhalten mit jeweils rund 820 DM je Einwohner die relativ höchsten Zuweisungen. Es folgen Sachsen und Thüringen mit etwa 812 DM pro Kopf. Etwas geringere Zuweisungen fließen an Berlin mit 779 DM und an Brandenburg mit 770 DM je Einwohner.

Auch und gerade die Sonderbedarfs-Bundesergănzungszuweisungen zum Abbau teilungsbedingter Sonderlasten sind mit starken Verteilungswirkungen unter den Lăndern verbunden. Dies wird deutlich, wenn man nach den Mitteln fragt, die den anderen Lăndern implizit entgehen, weil der Bund infolge der Belastung durch die Zuweisungen über einen relativ höheren Umsatzsteueranteil verfügen muß. Ein Wegfall der Bundesergänzungszuweisungen würde 1998 eine Anhebung des Länderanteils an der Umsatzsteuer von $49,5 \%$ auf $55,4 \%$ ermöglichen, ohne den Bund schlechter zu stellen. Tabelle 15 enthält im unteren Teil die effektiven Verteilungseffekte der Sonderbedarfs-Bundesergănzungszuweisungen zum Abbau teilungsbedingter Sonderlasten gemessen an dieser Referenzsituation.

Mit 165 DM bis 169 DM je Einwohner in den Flächenländern sowie $222 \mathrm{DM}$ bzw. 229 DM je Einwohner in den Stadtstaaten Bremen und Hamburg leisten die alten Bundesländer einen erheblichen Solidaritătsbeitrag zur Dekkung des Sonderbedarfs der neuen Bundesländer. Deren Vorteile fallen in der Nettobetrachtung entsprechend geringer aus. Die durchschnittliche Nettozuweisung liegt mit 626 DM um 175 DM bzw. $22 \%$ unter der durchschnittlichen Bruttozuweisung von 801 DM je Einwohner.

§ 11 Abs. 4 FAG sieht vor, daß die Zuweisungen im Jahr 1999 von Bund und Ländern gemeinsam überprüft werden müssen, wenn wesentliche $A b$ weichungen von den zugrundeliegenden Erwartungen zu konstatieren sind. Bei dieser Klausel handelt es sich um ein Zugeständnis der Länder an den Bund. Dieser hatte im Rahmen der Verhandlungen über das föderale Konsolidierungsprogramm zunächst vorgeschlagen, die Zuweisungen über einen Zeitraum von zehn Jahren linear-degressiv abzubauen. Damit konnte er sich jedoch nicht gegen die Lănder durchsetzen, die eine unbefristete Hilfe ohne zeitliche Staffelung gefordert hatten 1 .

1 Vgl. Korioth, 1997, S. $656 \mathrm{ff}$. 
Den Bundesergänzungszuweisungen in Zielsetzung und Wirkung vergleichbar sind die Investitionsbeihilfen zum Ausgleich der unterschiedlichen Wirtschaftskraft und zur Förderung des wirtschaftlichen Wachstums. Sie werden den neuen Ländern einschließlich Berlin bis 2004 in Höhe von 6,6 Mrd. DM jährlich gewährt und sollen Mängel im öffentlichen Kapitalstock beseitigen 1 .

\section{b. Zur Begründung der Hilfen für die neuen Länder}

Die grundsätzliche Berechtigung der Bundesergănzungszuweisungen zum Abbau teilungsbedingter Sonderlasten wird nach wie vor anerkannt und ist auch verfassungsrechtlich weitgehend unumstritten ${ }^{2}$. Es steht außer Frage, daß derzeit immer noch ein hoher Nachholbedarf in den neuen Bundesländern besteht, der weitere Hilfen erforderlich macht. Die aus dem Nachholbedarf resultierenden Belastungen sind zum jetzigen Zeitpunkt (noch) nicht auf eigene politische Entscheidungen der ostdeutschen Länder zurückzuführen, sondern durch die Planwirtschaft der ehemaligen DDR begründet.

Im vorliegenden Fall der Infrastrukturdefizite können Transferzahlungen an die neuen Länder gesamtwirtschaftlich effizienzsteigernd wirken ${ }^{3}$. Ein autonomer Anpassungsprozeß mag zwar langfristig zu einer räumlich effizienten Verteilung der Infrastruktur führen, aber der Übergang selbst wäre ineffizient, solange die Grenzproduktivität der Infrastruktur im Osten größer ist als im Westen. Die Ineffizienz des Anpassungsprozesses spricht für allokationspolitische Maßnahmen mit dem Ziel, den Übergang zu beschleunigen und die Infrastruktur-Grenzproduktivitäten einander anzugleichen.

Die Bereitstellung der Mittel zur Deckung des Nachholbedarfs bei der Infrastruktur geht über die Sicherstellung der laufenden Haushaltsführung der neuen Länder hinaus. Sie kann daher auch nicht über den horizontalen Länderfinanzausgleich erfolgen. Insofern stellt die Wahl vertikaler Zuweisungen eine grundsätzlich sachgerechte Lösung dar, über deren Gestaltung im ein-

1 Vgl. Andel, 1998, S. 527 f.

2 Vgl. Normenkontrollantrag des Landes Hessen, Kapitel C.V.3.b.cc. Selmer stuft diese Bundesergänzungszuweisungen dagegen als verkappte Fehlbetragszuweisungen ein, weil die Mittelverteilung nach der Einwohnerzahl erfolgt. Vgl. Selmer, 1994, S. 347.

3 Vgl. Homburg, 1993, S. 467 ff. 
zelnen allerdings noch zu reden sein wird. Daß die Hilfen zu einem Anstieg der Pro-Kopf-Finanzkraft in den Empfängerländern führen, der sie in der Finanzkraftrangfolge nach Finanzausgleich weit vorrücken läßt, ist jedenfalls unproblematisch, da (und soweit) die Bundesergănzungszuweisungen ihre Rechtfertigung außerhalb des Finanzausgleichs unter den Ländern finden 1 .

\section{c. Der Ausgleich der kommunalen Finanzschwäche}

Die prinzipielle Berechtigung der Transferzahlungen an die neuen Länder bedeutet noch nicht, daß mit den Bundesergänzungszuweisungen auch das aus ökonomischer Sicht optimale Instrument gewăhlt wurde. Die Eignung der Zuweisungen bedarf einer Überprüfung im Hinblick auf die angestrebten Ziele. Dabei stellt sich insbesondere die Frage, ob die derzeit gewährten ungebundene Finanzhilfen das beste Mittel zum Abbau der teilungsbedingten Sonderlasten darstellen.

Vorweg soll aber kurz auf das zweite Ziel und damit auf die Tauglichkeit der Bundesergänzungszuweisungen zum Ausgleich der kommunalen Finanzschwäche eingegangen werden. Im Zusammenhang mit der Berücksichtigung der Gemeinden im Länderfinanzausgleich wurde bereits darauf hingewiesen, daß von einer vollen Anrechnung der kommunalen Finanzkraft gegenüber der bestehenden Lősung des nur hälftigen Einbezugs insbesondere die neuen Lăndern mit ihren finanzschwachen Gemeinden profitieren würden. Da hier nicht der besondere Finanzbedarf, sondern die relative Finanzschwäche das ausschlaggebende Argument ist, dürfte die Anhebung der Einbeziehungsquote der Gemeindesteuern dem Ausgleichsziel besser gerecht werden als die Bundesergănzungszuweisungen.

Die Ergänzungszuweisungen an die neuen Lănder müßten entsprechend reduziert und die freigesetzten Mittel der Ländergesamtheit über einen höheren Umsatzsteueranteil zur Verfügung gestellt werden. Allerdings darf

1 "Das Nivellierungsverbot beansprucht jedoch bei der Abgeltung von Sonderlasten durch Bundesergänzungszuweisungen keine strikte Geltung, sondern kann ausnahmsweise durchbrochen werden. Der besondere Nachholbedarf der neuen Länder, dessen angemessene Abgeltung im horizontalen Lảnderfinanzausgleich nicht möglich ist, gibt dafür einen rechtfertigenden Grund“. Korioth, 1997, S. 658. 
dieser Weg - wie mehrfach betont - nur beschritten werden, wenn der mit der vollständigen Integration der kommunalen Finanzkraft verbundene Anstieg der Grenzbelastungen durch eine Reduktion der Nivellierungsintensităt des gesamten Lănderfinanzausgleichs aufgefangen wird ${ }^{1}$.

\section{d. Der Abbau der teilungsbedingten Sonderlasten}

Die (verbleibenden) vertikalen Bundesergänzungszuweisungen zum Abbau teilungsbedingter Sonderlasten sind durchaus geeignet, den zusätzlichen Finanzbedarf der neuen Länder zu decken. Dennoch kann ihre Gestaltung in einigen Punkten nicht überzeugen. Dies betrifft (1) die fehlende Zweckbindung, (2) den Verzicht auf eine Eigenbeteiligung, (3) die Verteilung nach der Einwohnerzahl und (4) die pauschale Höhe der Zuweisungen.

Die Möglichkeit der freien Mittelverwendung liefert den zentralen ökonomischen Einwand gegen die heutige Lösung. Dadurch erscheint ein effizienter Mitteleinsatz zur Stärkung der Wirtschaftskraft über Infrastrukturinvestitionen nicht gewährleistet. Unter allokationspolitischen Aspekten wäre es besser gewesen, die Zuweisungen an eine investive Verwendung zu knüpfen und auch eine fühlbare Selbstbeteiligung vorzusehen, um eine rationale Vorauswahl der Investitionsprojekte durch die Länder zu erreichen².

Auf diese Kriterien hatte der Wissenschaftliche Beirat beim Bundesministerium der Finanzen frühzeitig aufmerksam gemacht und „Ergänzungszuweisungen neuer $\mathrm{Art}^{4}$ empfohlen: „Die neuen Länder sollten nachweisen müssen, daß sie die Ergänzungszuweisungen neuer Art zur Beseitigung wichtiger Infrastrukturrückstände verwendet haben, und sie sollten sich an der Finanzierung beteiligen müssen. Dies ist die Voraussetzung dafür, daß die

1 Die volle Berücksichtigung der Gemeindesteuern kuriert allerdings - ebenso wie die heutigen Bundesergänzungszuweisungen - nur am Symptom. "Eigentlich müßte die Wurzel des Problems der geringen kommunalen Steuerkraft angegangen werden. Das könnte wohl nur mit einer grundlegenden Reform des Gemeindesteuersystems geschehen“. Peffekoven, 1994, S. 300. In Betracht käme vor allem ein Ersatz der Gewerbesteuer durch eine kommunale Wertschopfungsteuer mit Hebesatzrecht.

$2 \mathrm{Vgl}$. zur ökonomischen Analyse der Wirkungen verschiedener Zuweisungsformen Peffekoven, 1980, S. 622 ff.; Fischer, 1988, S. 31 ff. Die den neuen Ländern gewährten Investitionsbeihilfen zum Ausgleich unterschiedlicher Wirtschaftskraft und zur Förderung des wirtschaftlichen Wachstums sind übrigens zweckgebunden und mit einer Beteiligungsquote von $10 \%$ versehen. Vgl. Andel, 1998, S. 528. 
Zusatz-Förderung der Ost-Lănder nicht gegen das verfassungsrechtliche Nivellierungsverbot verstö $ß \mathrm{t}^{\mathrm{1}}$.

Zweckbindung und Eigenbeteiligung der Zuweisungen an die neuen Länder sind nicht unumstritten. Der Zweckbindung wird bisweilen entgegenhalten, sie würde die Finanzautonomie der Bundesländer zu sehr einschränken. Die neuen Lănder würden am „goldenen Zügel“ des Bundes hăngen und „Zur Schaffung eines Zwei-Klassen-Bundesstaates beitragen“2. Zudem wäre eine Zweckbindung auch gar nicht erforderlich, da die neuen Bundesländer schon aus eigenem Interesse die Zuweisungen zum Abbau der strukturellen Schwächen nutzen würden.

Die beiden Gegenargumente sind widersprüchlich; denn im Falle einer freiwilligen, aus eigenem Interesse erfolgenden Verwendung der Mittel für den beabsichtigten Zweck kann von einer Bevormundung durch den Bund keine Rede sein. Entscheidend ist aber, daß die Zielsetzung des Abbaus von Infrastrukturrückständen eine Zusatzförderung über das normale Maß des Finanzausgleichs begründet. Die Autonomie der Länder kann wohl kaum dadurch gefährdet werden, daß man ihnen Sonderleistungen gewährt.

Keines der neuen Länder wird ein solches Angebot mit dem Hinweis auf die „autonomiefeindlichen“ Verwendungsauflagen ablehnen ${ }^{3}$. Im Gegenteil: Die Zweckbindung erleichtert es vorausschauenden Landespolitikern, die Quote der öffentlichen Investitionen möglichst hoch zu halten und Ansprüche ungeduldiger Wähler auf konsumtive Staatsleistungen abzuwehren ${ }^{4}$. Ob die Landesregierungen dazu auch ohne Verwendungsauflagen bereit und in der Lage sind, erscheint vor dem Hintergrund der nach wie vor hohen Arbeitslosigkeit in den ostdeutschen Bundesländern eher zweifelhaft. Eine Zweckbindung der Aufbauhilfen ist demnach mindestens solange empfehlenswert, wie die Gefahr der konsumtiven Mittelverwendung besteht und die neuen

1 Wissenschaftlicher Beirat beim Bundesministerium der Finanzen, 1992, S. 118.

2 Korioth, 1997, S. 661.

3 Eine Zweckbindung muß nicht so weit gehen, daß einzelne Investitionsprojekte vorgeschrieben werden. Es könnte auch nur eine allgemeine Bindung an Investitionen erfolgen, die geeignet erscheinen, die Infrastrukturdefizite der neuen Lănder zu beseitigen. Die Länder hătten dann immer noch die Möglichkeit, eigene Schwerpunkte zu setzen.

$4 \mathrm{Vgl}$. Wissenschaftlicher Beirat beim Bundesministerium der Finanzen, 1992, S. 120. 
Lănder die Konsequenzen solcher Fehlentscheidungen über den Finanzausgleich auf die anderen Lănder und den Bund abwălzen können.

Die ebenfalls anzuratende finanzielle Beteiligung der Empfänger dient vor allem der Effizienz der Mittelverwendung. Manche überzogenen (Groß-) Projekte in den neuen Ländern wären wohl nicht in der gleichen Form geplant und durchgeführt worden, wenn die regionalen Entscheidungseinheiten mit einem spürbaren Eigenanteil gerechnet hätten. Allerdings können gerade die finanzschwachen Länder mit hohen Infrastrukturdefiziten erhebliche Schwierigkeiten haben, die vorgesehene Eigenbeteiligungsquote aufzubringen. Dies spricht nicht gegen das Konzept, erfordert aber gegebenenfalls eine Staffelung der Quote nach der Finanzkraft der Länder ${ }^{1}$.

Ein weiteres Problem der heutigen Bundesergănzungszuweisungen für die neuen Länder besteht in der Verteilung nach der Einwohnerzahl. Sie kann im vorliegenden Fall nicht als Konsequenz eines universalen Einwohnergleich-Einwohner-Prinzips ausgegeben werden; denn der Zweck der Zuweisungen besteht in der gezielten Berücksichtigung von Nachholbedarfen bei der Infrastruktur, die nicht anhand der Einwohnerzahl ermittelt werden können. Dies wäre allenfalls vertretbar, wenn sich teilungsbedingte Sonderlasten (und kommunale Finanzschwächen) gleichmäßig auf die neuen Länder verteilen würden. „Das mag bei der Vereinigung im Jahre 1990 noch der Fall gewesen sein. Heute dürtten sich beim Aufbau der Infrastruktur und der neuen Wirtschaftsbasis bereits erhebliche regionale Unterschiede entwickelt haben“2. Daher müßten die Bundesergänzungszuweisungen prinzipiell nach Indikatoren verteilt werden, die am Niveau der regionalen Infrastruktur anknüpfen, z. B. an der statistisch faßbaren Größe des staatlichen Bruttoanlagevermögens pro Kopf.

Die Verteilung der Bundesergănzungszuweisungen nach Einwohnern steht einer sachgerechten Erfolgskontrolle schon deshalb entgegen, weil sie kei-

1 Vgl. Wissenschaftlicher Beirat beim Bundesministerium der Finanzen, 1992, S. 119. Denkbar wäre auch, daß nur ein Teil der bisherigen Bundesergänzungszuweisungen mit einer Zweckbindung und Eigenbeteiligung ausgestattet wird. Mit fortschreitendem Aufholprozeß könnten die Eigenbeteiligungsquoten schrittweise erhöht werden.

2 Peffekoven, 1994, S. 300. 
nen Bezug zu den eigentlich interessierenden Infrastrukturdifferenzen zwischen den Ländern herstellt. Verstärkt wird dieser Defekt durch die zehnjährige Festschreibung der so ermittelten Werte. In dieser Zeit haben unterschiedliche wirtschaftliche Entwicklungen der neuen Länder keinen Einfluß auf die regionale Verteilung der Zuweisungen. Der einzige, wenn auch nicht unerhebliche Vorteil einer solchen Lösung besteht in der Unabhängigkeit der Transfers von der aktuellen Länderfinanzkraft, so daß von dieser Seite keine weitere Erhöhung der Grenzbelastungen droht.

Wenn die Rechtfertigung der Hilfen für die neuen Länder jedoch in ihrem Infrastrukturrückstand gegenüber den alten Lănder liegt, kommt man auf Dauer - spätestens bei der 2004 anstehenden Neuregelung - nicht daran vorbei, die Hőhe der Bundesergănzungszuweisungen an die Entwicklung der Infrastruktur zu binden. Die Zuweisungen verlieren ihre Anspruchsgrundlage, wenn der Infrastrukturbestand eines ostdeutschen Landes das Niveau eines schwach ausgestatteten westdeutschen Bundeslandes erreicht hat. Die Koppelung der weiteren Hilfen an geeignete Indikatoren der Infrastrukturausstattung ${ }^{1}$ erscheint auch notwendig, um Daueransprüchen und Gewöhnungseffekten entgegenzuwirken ${ }^{2}$.

\section{e. Bewertung der Bundesergänzungszuweisungen}

Im Gegensatz zu allen anderen Bundesergănzungszuweisungen steht die prinzipielle Berechtigung der Sonderbedarfs-Bundesergänzungszuweisungen für die neuen Bundesländer außer Frage. Sie tragen erheblich zum Aufholprozeß im Osten bei. Dennoch gibt es bessere Wege der Förderung, die wenigstens bei einer Neuregelung eingeschlagen werden sollten.

(1) Für den Ausgleich unterproportionaler kommunaler Steuerkraft bedarf es keiner Bundesergănzungszuweisungen. Diesem Problem wäre durch

1 Derartige Indikatoren könnten sich auch an dem Indikatorsystem der Gemeinschaftsaufgabe zur Verbesserung der regionalen Wirtschaftsstruktur orientieren.

2 "Dies bedeutet, daß in den jeweiligen Gesetzen und Verwaltungsabkommen ein Ablauftermin vorgesehen wird; eine Programmverlängerung wird von Anfang an nur für zulässig erklärt, wenn Einigkeit darüber erzielt wird, daß die Infrastrukturdifferenzen beim Eintritt des jeweiligen Termins noch unzumutbar hoch sind“. Wissenschaftlicher Beirat beim Bundesministerium der Finanzen, 1992, S. $120 \mathrm{f}$. 
eine volle Einbeziehung der kommunalen Steuerkraft in den Länderfinanzausgleich - unter Beachtung der Rückwirkungen auf die Grenzbelastung - wirksam zu begegnen. Die Bundesergänzungszuweisungen könnten dann zugunsten eines höheren Umsatzsteueranteils der Lănder reduziert werden.

(2) Zweck- und damit investitionsgebundene Zuweisungen des Bundes mit einer Selbstbeteiligung der neuen Länder dürften die Effizienz der Mittelverwendung deutlich verbessern. Vorteilhaft wäre sowohl die Bindung an Infrastrukturinvestitionen als auch die kritischere Prüfung der Investitionsprojekte seitens der Empfängerländer. Im Gegensatz zu den heutigen ungebundenen Transfers würden zweckgebundene Zuweisungen unmittelbar die Strukturschwäche und nicht ihre Folge - die mangelnde Finanzkraft der Lănder - bekämpfen 1 .

(3) Eine Bindung der Förderung der Infrastrukturinvestitionen in den neuen Ländern an die Veränderungen in diesem Bereich ist unumgänglich. Andernfalls besteht die Möglichkeit, daß eine besondere Form der Übernivellierung eintritt. Diese wäre gegeben, wenn ein altes Bundesland mit bescheidener Infrastrukturausstattung von einem der subventionierten neuen Länder überholt werden könnte.

Angesichts der vorhandenen und besser geeigneten Instrumente einer zielgerichteten Förderung der neuen Länder wäre die bloße Fortsetzung der bisherigen Sonderbedarfs-Bundesergänzungszuweisungen nach dem Jahr 2004 ein wirtschaftspolitischer Fehler ${ }^{2}$. Im Zuge der ohnehin anstehenden Reform des gesamten Länderfinanzausgleichs können die Hilfen für den Aufbau Ost wohl noch nicht abgeschafft werden. Dies steht jedoch einer effizienzsteigernden Neuregelung verbunden mit einem glaubwürdigen Plan für die Beendigung der Förderprogramme nicht entgegen.

1 Vgl. Peffekoven, 1994, S. 301.

2 Im Grunde müßte schon die gesetzlich vorgesehene Überprüfung der Zuweisungen im Jahr 1999 für eine Modifikation des Vergabeverfahrens genutzt werden. 
Wolfgang Scherf - 978-3-631-75181-7

Downloaded from PubFactory at 01/11/2019 07:24:58AM

via free access 


\section{Konsequenzen für eine Reform des Länderfinanzausgleichs}

In der öffentlichen Diskussion über den Länderfinanzausgleich dominiert der Eindruck eines Streits der Gebietskörperschaften über knappe Haushaltsmittel. Hinter dem Ringen um einen fairen Anteil an den staatlichen Einnahmen verbergen sich jedoch eine Reihe gravierender ökonomischer Probleme und grundsätzlicher Fragen der Finanzverfassung.

\section{A. Übermäßige Nivellierung und extrem hohe Grenzbelastungen}

Der heutige Länderfinanzausgleich ist ein für den außenstehenden Beobachter verwirrendes System der Umverteilung der Finanzkraft unter den Ländern. Der Ausgleich durchläuft mehrere Stufen, die ineinandergreifen, sich teils ergänzen, teils auch widersprechen, und insgesamt zu einer weitreichenden Nivellierung der Finanzausstattung der Länder führen.

Das zentrale Problem des Lănderfinanzausgleichs sind die enormen Grenzbelastungen der Länderhaushalte. Beispielsweise führen Mehreinnahmen bei der Lohnsteuer in den meisten Bundesländern zu Mindereinnahmen in der Landeskasse. Diese Grenzbelastungen müssen deutlich sinken, wenn sie das Bemühen der Länder um eine wachstums- und beschäftigungsorientierte Standortpolitik nicht weiterhin fiskalisch unterminieren sollen.

Die hohen Grenzbelastungen betreffen die finanzstarken und noch mehr die finanzschwachen Länder. Letztere befinden sich in einer Art "Armutsfalle“, denn ihre Anstrengungen zur Verbesserung der Wirtschafts- und Finanzkraft zahlen sich derzeit finanziell nicht aus. Betroffen sind in erster Linie die neuen Bundeslănder sowie Bremen und das Saarland.

Der Länderfinanzausgleich muß einen tragfähigen Kompromiß zwischen der ökonomischen Effizienz und der Umverteilungsfunktion des Systems herstellen. Die dem heutigen Verfahren eigene Überbetonung der distributiven Ziele steht einer solchen Lơsung entgegen. Die allokativen Grenzen der Umverteilung werden bislang zuwenig gesehen und berücksichtigt. 
Die weitgehend anerkannte Forderung nach einer angemessenen - aber nicht gleichen - Finanzausstattung der Lănder ist mit einer effizienzsteigernden Reform des Ausgleichsverfahrens vereinbar. Der Finanzausgleich sollte weiterhin eine Mindestfinanzkraft garantieren und eine Annăherung der Finanzkraftpositionen herbeiführen, muß aber durch eine allokativ begründete Obergrenze der Belastung der finanzstarken Lănder ergănzt werden.

Die Mindestfinanzkraftgarantie kann wie bisher über den Umsatzsteuer-Vorwegausgleich sichergestellt, oder - bei einer Pro-Kopf-Verteilung der Umsatzsteuer - in den horizontalen Ausgleich unter den Ländern eingelagert werden. Entscheidend ist, daß die marginalen Belastungen generell $100 \%$ erheblich unterschreiten müssen, wenn die Länder ein fiskalisches Interesse an der Pflege ihres Standortes und ihrer Steuerquellen behalten bzw. wieder erlangen sollen. Dies ist mit einem linearen Ausgleichstarif erreichbar, sofern der Ausgleichssatz klar unter dem Spitzensatz des heutigen Progressionstarifs von 80 \% bleibt. Der Übergang zu einem solchen Tarif würde den Finanzausgleich vereinfachen und transparenter gestalten.

\section{B. Zweifelhafte Maßstäbe im horizontalen Lănderfinanzausgleich}

Eine substantielle Reform des Lănderfinanzausgleichs darf sich allerdings nicht allein auf die Limitierung der Umverteilung konzentrieren und die bisherigen Maßstäbe des Finanzausgleichsgesetzes unverăndert beibehalten. Fast noch wichtiger als der Umverteilungstarif ist nămlich aus finanzwissenschaftlicher Sicht die Abgrenzung der Bemessungsgrundlagen, also die Ermittlung der Finanzkraft und des Finanzbedarfs der einzelnen Länder.

Der Länderfinanzausgleich dient in erster Linie dem Ziel der Sicherstellung einer bestimmten Pro-Kopf-Finanzkraft relativ zum Durchschnitt der Lănder. Die Finanzkraft je Einwohner bildet die Bemessungsgrundlage für den Finanzausgleich, und ihre Bedeutung wird für alle Lănder - ohne Differenzierung nach speziellen Bedarfslagen - anerkannt. Der allgemeine Finanzbedarf eines Landes manifestiert sich also in der mittleren Pro-Kopf-Finanzkraft.

Sonderbedarfe haben dagegen grundsătzlich keinen Platz in diesem System des allgemeinen Finanzkraftausgleichs. In begründeten Ausnahmefällen mo- 
gen Sonderbedarfe einzelner Länder durchaus vorliegen. Sie sollten aber nicht in unsystematischer Weise mit dem Ausgleich der Finanzkraft vermischt und auf diese Weise der ständigen Überprüfung ihrer Berechtigung und Gestaltung entzogen werden.

Der heutige Lảnderfinanzausgleich weist genau in dieser Hinsicht entscheidende Defekte auf. Dies beginnt schon mit der Bestimmung der Finanzkraft, bei der einige (nicht alle) Küstenländer sogenannte "Hafenlasten" von ihren ausgleichsrelevanten Einnahmen absetzen können. Wenn solche Lasten überhaupt existieren, wofür es keine überzeugenden Anhaltspunkte gibt, können sie jedenfalls nicht im Länderfinanzausgleich abgegolten werden.

Ahnliches gilt für das "Stadtstaatenprivileg“. Die Einwohner von Berlin, Bremen und Hamburg werden bei der Ermittlung der Ausgleichsmeßzahl, die den Finanzbedarf kennzeichnet, um $35 \%$ höher gewichtet als die Einwohner der Flächenländer. Dies stellt einen Verstoß gegen das Einwohner-gleichEinwohner-Prinzip dar und hat eine massive finanzielle Vergünstigung zur Folge, die nicht mit der spezifischen Situation der Stadtstaaten zu rechtfertigen ist. Der ökonomischen Bedeutung der Stadtstaaten für das Umland sollte in Zukunft aber durch eine teilweise Zerlegung der Lohnsteuer nach Betriebsstätten und damit nach Arbeitsplätzen Rechnung getragen werden.

Die Einwohnerwertung spielt auch im Zusammenhang mit der Einbeziehung der Gemeindesteuern in den Länderfinanzausgleich eine Rolle, denn der Finanzbedarf der Gemeinden wird bei der Ermittlung der Ausgleichsmeßzahl mit wachsender Gemeindegrőße höher gewichtet. Die kommunale Einwohnerwertung basiert auf der traditionellen, aber weder theoretisch noch empirisch fundierten Vermutung eines positiven Zusammenhangs zwischen ProKopf-Finanzbedarf und Gemeindegröße. Sie sollte daher genauso entfallen wie die Einwohnerwertung der Stadtstaaten.

Bislang werden die kommunalen Einnahmen nur zur Hälfte in den Länderfinanzausgleich einbezogen. Dies erscheint grundsătzlich nicht gerechtfertigt, ist aber angesichts der überzogenen Nivellierungsintensităt des heutigen Systems letztlich nur ein (schwacher) Schutz der finanzstarken Länder vor einer noch weitergehenden Abschöpfung. Da die Anrechnung der kommu- 
nalen Finanzkraft die Grenzbelastungen der Länder für sich genommen vergrößert, kommt eine höhere Einbeziehungsquote nur in Betracht, wenn die Grenzbelastungen durch andere Reformschritte erheblich reduziert werden.

Der horizontale Lănderfinanzausgleich allein führt heute nicht zu einer Vertauschung der Finanzkraftrangfolge der Länder und verstößt daher auch nicht gegen das Nivellierungsverbot, sofern man die problematischen Maßstäbe des Finanzausgleichsgesetzes akzeptiert. Legt man dagegen ókonomische Kriterien zugrunde, so führen die vielfältigen Abweichungen von der Orientierung an der tatsächlichen Einwohnerzahl zu unbegründeten Rangplatzvertauschungen und in diesem Sinne auch zu einer Übernivellierung.

\section{Bundesergănzungszuweisungen - notwendig oder überflüssig?}

Das Problem der Übernivellierung gewinnt an Schärfe durch die Bundesergänzungszuweisungen, die den horizontalen Länderfinanzausgleich teils mit anderen Mitteln fortsetzen, teils durch die Berücksichtigung besonderer Bedarfslagen zu ergănzen trachten. Vertikale Zuweisungen des Bundes an die Länder können im Ausnahmefall gerechtfertigt sein, und sie lassen sich dann auch so gestalten, daß der Finanzausgleich im Ergebnis davon profitiert. Die Praxis sieht jedoch anders aus. Die meisten Bundesergänzungszuweisungen sind mit einem rationalen Finanzausgleich nicht zu vereinbaren.

Unter dem Gesichtspunkt der Nivellierung der Finanzkraft üben insbesondere die Fehlbetrags-Bundesergănzungszuweisungen einen schädlichen Einfluß aus. Sie sorgen für eine nahezu vollständige Angleichung der allgemeinen Finanzausstattung der Länder nach Finanzausgleich. Eine ernstzunehmende Reform des Länderfinanzausgleichs nach dem Jahr 2004 erfordert im Interesse einer reduzierten Nivellierungsintensität die Abschaffung der Fehlbetrags-Bundesergănzungszuweisungen. Die dadurch freiwerdenden Mittel könnten der Ländergesamtheit in Form eines höheren Anteils an der Umsatzsteuer wieder zur Verfügung gestellt werden.

Mit Ausnahme der Leistungen für den Aufbau in den neuen Lăndern sollten auch die Sonderbedarfs-Bundesergänzungszuweisungen spätestens nach dem Jahr 2004 entfallen. Vorgesehen ist dies jetzt schon für die Übergangs- 
und Sanierungs-Bundesergänzungszuweisungen. Erstere haben die Funktion einer Anpassungshilfe für finanzschwache alte Bundesländer an die Folgen der Integration der noch finanzschwächeren neuen Bundesländer in den Länderfinanzausgleich. Wenn die Übergangs-Bundesergänzungszuweisungen ihren Namen zu Recht tragen, können sie keinesfalls über 2004 hinaus fortgesetzt werden.

Gleiches gilt für die Sanierungs-Bundesergänzungszuweisungen, die Bremen und dem Saarland zu einer nachhaltigen Konsolidierung ihrer ungleichgewichtigen offentlichen Haushalte verhelfen sollen. Dieses Ziel rechtfertigt aber keine Dauersubventionen. Angesichts der bislang gewährten und im verbleibenden Anpassungszeitraum noch reichlich fließenden Sanierungshilfen kann von den beiden Empfängerländern erwartet werden, daß sie nach 2004 ohne besondere Unterstützungszahlungen auskommen. Der zukünftige Ertrag eigener Anstrengungen wäre übrigens grőßer, wenn die Grenzbelastungen im Finanzausgleich allgemein sinken würden.

Neben den ohnehin auslaufenden Bundesergänzungszuweisungen sollten im Zuge einer Neuregelung auch die Ergänzungszuweisungen wegen überdurchschnittlicher Kosten politischer Führung in "kleinen " Ländern ersatzlos gestrichen werden. Innen fehlt jede ökonomische Berechtigung. Ob die tatsächlichen Pro-Kopf-Ausgaben mit der Einwohnerzahl sinken, spielt für diesen Befund keine Rolle. Ausschlaggebend ist vielmehr, daß die Transferzahlungen die grundsătzlich selbst zu tragenden Kosten politischer Führung externalisieren und damit landespolitische Entscheidungen verzerren.

Die bislang diskutierten Bundesergänzungszuweisungen verstoßen teilweise gegen das Gleichbehandlungsgebot und können auch eine Übernivellierung im Sinne sachlich unbegründeter Rangplatzvertauschungen bewirken. Dies gilt nicht für die Bundesergănzungszuweisungen zum Abbau teilungsbedingter Sonderlasten, die durch den unstrittig erforderlichen „Aufbau Ost“ hinreichend begründet erscheinen. Allerdings werden sie ihrer Hauptaufgabe, der Überwindung von Infrastrukturdefiziten in den neuen Ländern, nur mit Einschränkungen gerecht, weil keine Zweckbindung der Mittel und auch keine Selbstbeteiligung der Empfăngerlănder vorgesehen ist. 
Insgesamt kann aus der okonomischen Analyse des heutigen Länderfinanzausgleichs nur die Konsequenz gezogen werden, daß auf nahezu allen Stufen des Ausgleichsverfahrens erheblicher Reformbedarf besteht. Es ist in erster Linie Aufgabe der politischen Entscheidungsträger (und nicht des Bundesverfassungsgerichts), diesem Reformbedarf gerecht zu werden und eine neue Balance zwischen Effizienz und Verteilung im Finanzausgleich herzustellen. Dies erfordert auch ein Denken über die kurzfristigen fiskalischen Eigeninteressen hinaus. Auf Dauer ist der Lănderfinanzausgleich eben kein Nullsummenspiel. Von einem anreiz- und wachstumsfreundlicheren System, das die Finanzkraft nicht nur besser verteilt, sondern auch ihre okonomischen Grundlagen sichert, können alle Beteiligten letztlich nur profitieren. 


\section{Literaturverzeichnis}

Andel, N. (1998), Finanzwissenschaft, 4. Auflage, Tübingen.

Arndt, H.-W. (1997), Finanzausgleich und Verfassungsrecht, Gutachten im Auftrag der Länder Baden-Württemberg und Bayem, Mannheim.

Arndt, H.-W. (1999), Verfassungsrechtlicher Spielraum für eine Reform des Finanzausgleichs, in: Morath, K. (Hrsg.), Reform des Fodderalismus, Bad Homburg, S. 75 ff.

Amim, H. H. v. (1999), 50 Jahre Föderalismus in Deutschland: Perversion einer Idee, in: Morath, K. (Hrsg.), Reform des Fodderalismus, Bad Homburg, S. $37 \mathrm{ff}$.

Bayerisches Staatsministerium der Finanzen (1998), Der neue Finanzausgleich: einfach foderal - gerecht. Das Modell zur Neuordnung, München.

Blankart, Ch. B. (1998), Offentliche Finanzen in der Demokratie, 3. Auflage, München.

Blankart, Ch. B. (1999), Zehn Thesen zur Zentralisierung der Staatstătigkeit, in: Morath, K. (Hrsg.), Reform des Föderalismus, Bad Homburg, S. $145 \mathrm{ff}$.

Bösinger, R. (1999), Die Neuordnung des bundesstaatlichen Finanzausgleichs 1995, Frankfurt/Main u.a.O.

Brecht, A. (1932), Internationaler Vergleich der offentlichen Ausgaben, Leipzig / Berlin.

Brümmerhoff, D. (1996), Finanzwissenschaft, 7. Auflage, München / Wien.

Buchanan, J. M. (1950), Federalism and Fiscal Equity, in: American Economic Review, Vol. 40, S. $583 \mathrm{ff}$.

Buhl, H.-U. (1986), Ein finanzwissenschaftlich-methodischer Diskussionsbeitrag zur Neuordnung des Länderfinanzausgleichs, in: Finanzarchiv, N.F., Bd. 44, S. 476 ff.

Buhl, H.-U. / Pfingsten, A. (1986), Eigenschaften und Verfahren für einen angemessenen Landerfinanzausgleich in der Bundesrepublik Deutschland, in: Finanzarchiv, N.F., Bd. 44, S. $98 \mathrm{ff}$.

Buhl, H.-U. / Pfingsten, A. (1991), Zehn Gebote für Finanzausgleichsverfahren und ihre Implikationen, in: Wirtschaftsdienst, Heft 9, S. $481 \mathrm{ff}$.

Bundesministerium der Finanzen (1998), Finanzbericht 1999, Bonn.

Bundesministerium der Finanzen (1999 a), Stellungnahme der Bundesregierung zu den Normenkontrollanträgen von Baden-Württemberg, Bayern und Hessen, Bonn.

Bundesministerium der Finanzen (1999 b), Der Gemeindeanteil an der Einkommensteuer in der Gemeindefinanzreform, BMF Dokumentation, Bonn.

Bundesministerium für Verkehr (1998), Verkehr in Zahlen, Bonn.

Bundesverfassungsgericht (1981), Entscheidungen des Bundesverfassungsgerichts, Bd. 55, Tübingen, S. $274 \mathrm{ff}$.

Bundesverfassungsgericht (1986), Entscheidungen des Bundesverfassungsgerichts, Bd. 72, Tübingen, S. $330 \mathrm{ff}$.

Bundesverfassungsgericht (1992), Entscheidungen des Bundesverfassungsgerichts, Bd. 86, Tübingen, S. $148 \mathrm{ff}$.

Bundesverfassungsgericht (1996), Entscheidungen des Bundesverfassungsgerichts, Bd. 93, Tübingen, S. $121 \mathrm{ff}$.

Carl, D. (1995), Bund-Länder-Finanzausgleich im Verfassungsstaat, Baden-Baden.

Deubel, I. (1999), Wettbewerb um Steuerquellen: Anmerkungen aus praktischer Sicht, in: Morath, K. (Hrsg.), Reform des Föderalismus, Bad Homburg, S. $67 \mathrm{ff}$.

Dickertmann, D. / Gelbhaar, S. (1996 a), Finanzverfassung und Finanzausgleich - Okonomische Grundfragen und methodische Konzepte, in: WSU, Heft 4, S. 385 ff. 
Dickertmann, D. / Gelbhaar, S. (1996 b), Finanzverfassung und Finanzausgleich - Darstellung und Kritik des Finanzausgleichs in Deutschland, in: WSU, Heft 5, S. 486 ff.

Eckey, H.-F. I Klemmer, P. (1988), Die Einwohnergewichtung des Stadtstaates Hamburg im Lănderfinanzausgleich (Manuskript), Schauenburg und Sprockhövel.

Esser, C. (1994), Der neue Lănderfinanzausgleich: Undurchschaubarkeit als Prinzip, in: Wirtschaftsdienst, Heft 7, S. $358 \mathrm{ff}$.

Färber, G. (1993), Reform des Lănderfinanzausgleichs, in: Wirtschaftsdienst, Heft 6 , S. $305 \mathrm{ff}$.

Färber, G. (1999), Probleme der regionalen Steuerverteilung im bundesstaatlichen Finanzausgleich, Gutachten im Auftrag der saarländischen Landesregierung, Speyer.

Fischer-Menshausen, H. (1980): Finanzausgleich II: Grundzüge des Finanzausgleichsrechts, in: Handwörterbuch der Wirtschaftswissenschaft, Bd. 2, Stuttgart u.a.O., S. $636 \mathrm{ff}$.

Fischer, H. (1988), Finanzzuweisungen, Berlin.

Fischer, H. (1989), Zur ${ }_{\text {Reform }}$ des Länderfinanzausgleichs, in: WiSt, Heft 3, S. 112 ff.

Fischer, H. (1992), Hat der Länderfinanzausgleich im vereinten Deutschland Zukunft?, in: Wegener, E. (Hrsg.), Finanzausgleich im vereinten Deutschland, Marburg, S. $17 \mathrm{ff}$.

Föttinger, W. I Spahn, P. B. (1993), Für einen kostenorientierten Lănderfinanzausgleich, in: Wirtschaftsdienst, Heft 5, S. $237 \mathrm{ff}$.

Fuest, W. I Lichtblau, K. (1991), Finanzausgleich im vereinten Deutschland, Institut der deutschen Wirtschaft (Hrsg.), Beiträge zur Wirtschafts- und Sozialpolitik, Nr. 192, Köln.

Gawel, E. (1992), Finanzausgleichsprobleme eines okologieorientierten Steuer- und Abgabensystems, in: Wirtschaftsdienst, Heft $8, S .428 \mathrm{ff}$.

Gehlen, H. (1991), Kreditfinanzierung im saarländischen Haushalt und ihre verfassungsrechtlichen Grenzen, in: Die öfentliche Verwaltung, Heft 6, S. 237 ff.

Geske, O.-E. (1991), Die Finanzierung der ostdeutschen Lănder nach dem Einigungsvertrag, in: Wirtschaftsdienst, Heft 1, S. 33 ff.

Geske, O.-E. (1992), Der Länderfinanzausgleich wird ein Dauerthema, in: Wirtschaftsdienst, Heft 5, S. $250 \mathrm{ff}$.

Geske, O.-E. (1993), Unterschiedliche Anforderungen an den neuen Länderfinanzausgleich, in: Wirtschaftsdienst, Heft 2, S. $71 \mathrm{ff}$.

Geske, O.-E. (1998), Eine neue Finanzverfassung zur Wiederherstellung eines strikten Konnexitätsprinzips?, in: Wirtschaftsdienst, Heft 9, S. $556 \mathrm{ff}$.

Gottfried, P. I Wiegard, W. (1991), Finanzausgleich nach der Vereinigung: Gewinner sind die alten Länder, in: Wirtschaftsdienst, Heft 9, S. 453 ff.

Grawert, R. (1989), Die Kommunen im Länderfinanzausgleich, Berlin.

Grossekettler, H. (1994), Die deutsche Finanzverfassung nach der Finanzausgleichsreform. Eine okonomische Analyse des ab 1995 geltenden Rechts, in: Hamburger Jahrbuch für Wirtschafts- und Gesellschaftspolitik, S. $83 \mathrm{ff}$.

Häde, U. (1993), Solidarität im Bundesstaat, in: Die offentliche Verwaltung, Heft 11, S. $461 \mathrm{ff}$.

Häde, U. (1996), Finanzausgleich. Die Verteilung der Aufgaben, Ausgaben und Einnahmen im Recht der Bundesrepublik Deutschland und der Europäischen Union, Tübingen.

Haller, H. (1981), Die Steuem, 3. Auflage, Tübingen.

Hansmeyer, K.-H. / Kops, M. (1985), Die Popitz'sche Hauptansatztafel, in: Akademie für Raumforschung und Landesplanung (Hrsg.), Răumliche Aspekte des kommunalen Finanzausgleichs, Forschungs- und Sitzungsbericht 159, Hannover, S. $15 \mathrm{ff}$. 
Hansmeyer, K.-H. / Kops, M. (1990), Die Gliederung der Länder in einem vereinten Deutschland, in: Wirtschaftsdienst, Heft 5, S. $234 \mathrm{ff}$.

Hanusch, H. I Kuhn, T. (1985), Messung des kommunalen Finanzbedarfs - Ein alternativer Ansatz für die Schlüsselzuweisungen, in: Akademie für Raumforschung und Landesplanung (Hrsg.), Răumliche Aspekte des kommunalen Finanzausgleichs, Forschungsund Sitzungsbericht 159, Hannover, S. $55 \mathrm{ff}$.

Heilmann, M. (1992), Vorschläge zur Neuordnung des Bund-Länder-Finanzausgleichs im vereinten Deutschland - eine kritische Bestandsaufnahme, in: Wegener, E. (Hrsg.), Fi nanzausgleich im vereinten Deutschland, Marburg, S. $17 \mathrm{ff}$.

Henke, K.-D. (1993), Maßnahmen zur Stärkung der Eigenverantwortlichkeit der Länder und die Finanzierung der deutschen Einheit, in: Staatswissenschaften und Staatspraxis, S. $10 \mathrm{ff}$.

Henke, K.-D. (1995), Möglichkeiten zur Stärkung der Länderautonomie, in: Staatswissenschaften und Staatspraxis, S. $643 \mathrm{ff}$.

Hirte, G. (1996), Effizienzwirkungen von Finanzausgleichsregelungen, Frankfurt/Main u.a.O.

Homburg, S. (1993), Eine Theorie des Lănderfinanzausgleichs: Finanzausgleich und Produktionseffizienz, in: Finanzarchiv, N.F., Bd. 50, S. 458 ff.

Homburg, S. (1994), Anreizwirkungen des deutschen Finanzausgleichs, in: Finanzarchiv, N.F., Bd. 51, S. $312 \mathrm{ff}$.

Homburg, S. (1996), Notwendigkeit einer Finanzreform, in: Wirtschaftsdienst, Heft 7 , S. $336 \mathrm{ff}$.

Huber, B. (1997), Der Finanzausgleich im deutschen Föderalismus, in: Aus Politik und Zeitgeschichte, Beilage zur Wochenzeitung das Parlament, B 24/97, S. 22 ff.

Huber, B. (1999 a), Steuerwettbewerb im Föderalismus - Ideal und Wirklichkeit, in: Morath, K. (Hrsg.), Reform des Föderalismus, Bad Homburg, S. 55 ff.

Huber, B. (1999 b), Okonomische Wirkungen des Finanzausgleichs, Gutachten im Auftrag der Bayerischen Landesregierung, München.

Huber, B. I Lichtblau, K. (1997), Systemschwăchen des Finanzausgleichs - Eine Reformskizze, IW-Trends, Nr. 4, S. $1 \mathrm{ff}$.

Huber, B. / Lichtblau, K. (1998), Konfiskatorischer Finanzausgleich verlangt eine Reform, Wirtschaftsdienst, Heft 3, S. $142 \mathrm{ff}$.

Hummel, M. / Leibfritz, W. (1987 a), Die Stadtstaaten im Länderfinanzausgleich, in: ifoSchnelldienst, Heft 20, S. 7 ff.

Hummel, M. / Leibfritz, W. (1987 b), Die Stadtstaaten im Lảnderfinanzausgleich, ifo-Studien zur Finanzpolitik, Bd. 45, München.

Hummel, M. / Nierhaus, W. (1994), Die Neuordnung des bundesstaatlichen Finanzausgleichs im Spannungsfeld zwischen Wachstums- und Verteilungszielen, ifo-Studien zur Finanzpolitik, Bd. 54, München.

Kaehler, J. (1982), Agglomeration und Staatsausgaben - Brechtsches und Wagnersches Gesetz im Vergleich, in: Finanzarchiv, N.F., Bd. 40, S. $445 \mathrm{ff}$.

Kitterer, W. (1994), Finanzausgleich im vereinten Deutschland, Heidelberg.

Kommission für die Finanzreform (1966), Gutachten über die Finanzreform in der Bundesrepublik Deutschland, 2. Auflage, Stuttgart u.a.O.

Kops, M. (1989), Mőglichkeiten und Restriktionen einer Berücksichtigung von Sonderbedarfen im Lănderfinanzausgleich, Opladen.

Korioth, S. (1996), Die bundesstaatliche Finanzverfassung ist besser als ihr Ruf, in: Wirtschaftsdienst, Heft 7, S. 339 ff. 
Korioth, S. (1997), Der Finanzausgleich zwischen Bund und Lăndern, Tübingen.

Kuhn, T. (1993), Determinanten der Staatsausgaben: Bevőlkerung und Ubanisierung, in: ifo-Studien, Heft 2, S. $127 \mathrm{ff}$.

Kuhn, T. (1995), Theorie des kommunalen Finanzausgleichs, Heidelberg.

Lammers, K. (1999), Neugliederung des Bundesgebietes zwischen Standortwettbewerb und Finanzverfassung, in: Wirtschaftsdienst, Heft 7, S. 429 ff.

Laufer, H. (1991), Das fóderative System der Bundesrepublik Deutschland, 6. Auflage, München.

Lenk, T. (1995), Vergleich alternativer Ausgleichsmechanismen für den Länderfinanzausgleich, in: Zeitschrift für Wirtschafts- und Sozialwissenschaft (ZWS) 115, S. $231 \mathrm{ff}$.

Lenk, T. (1998), Länderfinanzausgleich: Reform des Ausgleichsmechanismus, in: RWMitteilungen, Heft 1/2, S. $39 \mathrm{ff}$.

Lenk, T. (1999 a), Bei der Reform der Finanzverfassung die neuen Bundesländer nicht vergessen!, in: Wirtschaftsdienst, Heft 3, S. 164 ff.

Lenk, T. (1999 b), Kooperativer Föderalismus - Wettbewerbsorientierter Föderalismus, Diskussionsbeitrăge Nr. 7, Wirtschaftswissenschaftliche Fakultăt, Universităt Leipzig.

Lenk, T. / Schneider, F. (1999), Zurück zum Trennsystem als Königsweg zu mehr Föderalismus in Zeiten des "Aufbau Ost"?, Arbeitspapier 9909 des Instituts für Volkswirtschaftslehre der Johannes Kepler Universităt Linz.

Lichtblau, K. (1999), Finanzausgleich: Reformoptionen und ein konkreter Vorschlag, in: Morath, K. (Hrsg.), Reform des Föderalismus, Bad Homburg, S. 95 ff.

Littmann, K. (1977), Offentliche Ausgaben II: Die "Gesetze“ ihrer langfristigen Entwicklung, in: Handwörterbuch der Wirtschaftswissenschaft, Bd. 1, Stuttgart u.a.O., S. 349 ff.

Littmann, K. (1993), Probleme der Finanzverfassung im vereinten Deutschland, in: Probleme des Finanzausgleichs in nationaler und internationaler Sicht, Beihefte der Konjunkturpolitik, Heft 41, Berlin, S. 53 ff.

Lutz, P. F. (1996), Wege zur Neugliederung des Bundesgebietes nach dem Scheitern der Länderfusion Berlin-Brandenburg, in: Staatswissenschaften und Staatspraxis, S. $137 \mathrm{ff}$.

Michalk, J. (1989), Die Garantieklauseln im Länderfinanzausgleich, in: Wirtschaftsdienst, Heft 9, S. $446 \mathrm{ff}$.

Milbradt, G. H. (1991), Die neuen Bundesländer zügig in die Finanzverfassung einbeziehen - nicht abkoppeln!, in: Wirtschaftsdienst, Heft 2, S. 59 ff.

Ministerium für Wirtschaft und Finanzen des Saarlandes (1999), Bericht des Saarlandes zur Sanierung des Landeshaushalts - Sanierungsbericht 1998, Saarbrücken.

Müller-Overheu, T. (1994), Der bundesstaatliche Finanzausgleich im Rahmen der deutschen Einheit, Frankfurt/Main u.a.O.

Münzenmaier, W. (1999), Zur okonomischen Begründung der Einwohnenwertung von Stadtstaaten im Lănderfinanzausgleich, in: Statistisches Landesamt Baden-Württemberg (Hrsg.), Materialien und Berichte, Heft 24, Stuttgart.

Musgrave, R. A. (1961), Approches to a Fiscal Theory of Political Federalism, in: National Bureau of Economic Research (Ed.), Public Finance: Needs, Sources, and Utilization, Princeton, S. $97 \mathrm{ff}$.

Musgrave, R. A. (1969), Finanztheorie, 2. Auflage, Tübingen.

Neumark, F. (1970), Grundsătze gerechter und okonomisch rationaler Steuerpolitik, Tübingen.

Normenkontrollantrag der Bayerischen Staatsregierung, Schriftsatz des Verfahrensbevollmächtigten K. Vogel vom 30 . Juli 1998, Stamberg. 
Normenkontrollantrag der Hessischen Landesregierung, Schriftsatz des Verfahrensbevollmächtigten W. Heun vom 5. Januar 1999, Göttingen.

Normenkontrollantrag der Regierung des Landes Baden-Württemberg, Schriftsatz des Verfahrensbevollmächtigten K. Dolde vom 29. Juli 1998, Stuttgart.

Oates, W. E. (1972), Fiscal Federalism, New York.

Oates, W. E. (1977), Ein okonomischer Ansatz zum Foderalismusproblem, in: Kirsch, G. (Hrsg.), Fodderalismus, Stuttgart / New York, S. 15 ff.

Olsen, M. (1977), Das Prinzip „fiskalischer Gleichheit": Die Aufteilung der Verantwortung zwischen verschiedenen Regierungsebenen, in: Kirsch, G. (Hrsg.), Foderalismus, Stuttgart / New York, S. $66 \mathrm{ff}$.

Pagenkopf, H. (1981), Der Finanzausgleich im Bundesstaat, Stuttgart.

Peffekoven, R. (1980), Finanzausgleich I: Wirtschaftstheoretische Grundlagen, in: Handwörterbuch der Wirtschaftswissenschaft, Bd. 2, Stuttgart u.a.O., S. $608 \mathrm{ff}$.

Peffekoven, R. (1987), Zur Neuordnung des Länderfinanzausgleichs, in: Finanzarchiv, N.F., Bd. 45, S. $181 \mathrm{ff}$.

Peffekoven, R. (1988), Berücksichtigung der Seehafenlasten im Länderfinanzausgleich?, in: Finanzarchiv, N.F., Bd. 46, S. $397 \mathrm{ff}$.

Peffekoven, R. (1990), Finanzausgleich im vereinten Deutschland, in: Wirtschaftsdienst, Heft 7, S. $346 \mathrm{ff}$.

Peffekoven, R. (1992), Das Urteil des Bundesverfassungsgerichtes zum Lănderfinanzausgleich, in: Wirtschaftsdienst, Heft 7, S. 349 ff.

Peffekoven, R. (1993), Finanzausgleich im Spannungsfeld zwischen allokativen und distributiven Zielsetzungen, in: Probleme des Finanzausgleichs in nationaler und internationaler Sicht, Beihefte der Konjunkturpolitik, Heft 41, Berlin, S. $11 \mathrm{ff}$.

Peffekoven, R. (1994), Reform des Finanzausgleichs - eine vertane Chance, in: Finanzarchiv, N.F., Bd. 51, S. $281 \mathrm{ff}$.

Peffekoven, R. (1999), Stellungnahme zum Gutachten des RW „Zur finanzwissenschaftlichen Beurteilung der Einwohnerwertung der Stadtstaaten im Länderfinanzausgleich", Mainz.

Planco Consulting GmbH (1998), Regionale und nationale Vorteile der Bremischen Häfen im Zusammenhang mit der Hafenlastenabgeltung im Lănderfinanzausgleich, Essen.

Popitz, J. (1932), Der künftige Finanzausgleich zwischen Reich, Ländern und Gemeinden, Berlin.

Quantz, J. (1995), Reform der Finanzverfassung, in: Staatswissenschaften und Staatspraxis, S. $695 \mathrm{ff}$.

Reformkommission Soziale Marktwirtschaft (1998), Reform der Finanzverfassung, Bertelsmann Stiftung / Heinz Nixdorf Stiftung / Ludwig-Erhard-Stiftung.

Renner, P. (1982), Finanzausgleich unter den Ländem und Bundesergänzungszuweisungen, in: Bundesministerium der Finanzen (Hrsg.), Die Finanzbeziehungen zwischen Bund, Ländern und Gemeinden aus verfassungsrechtlicher und finanzwirtschaftlicher Sicht, Bonn.

Renzsch, W. (1991), Finanzverfassung und Finanzausgleich, Bonn.

Renzsch, W. (1996), Finanzreform - ein politisches Problem, in: Wirtschaftsdienst, Heft 7 , 1996, S. $331 \mathrm{ff}$.

RM - Rheinisch-Westfälisches Institut für Wirtschaftsforschung (1999), Zur finanzwissenschaftlichen Beurteilung der Einwohnerwertung der Stadtstaaten im Länderfinanzausgleich, Gutachten im Auftrag der Freien und Hansestadt Hamburg, Essen. 
Sachverständigenrat zur Begutachtung der gesamtwirtschaftlichen Entwicklung (1990), Jahresgutachten 1990/91, Stuttgart.

Sachverstăndigenrat zur Begutachtung der gesamtwirtschaftlichen Entwicklung (1991), Jahresgutachten 1991/92, Stuttgart.

Sachverständigenrat zur Begutachtung der gesamtwirtschaftlichen Entwicklung (1992), Jahresgutachten 1992/93, Stuttgart.

Scherf, W. (1996), Politische Ursachen und Moglichkeiten einer konstitutionellen Begrenzung der staatlichen Neuverschuldung, in: Staatswissenschaften und Staatspraxis, S. $365 \mathrm{ff}$.

Scherf, W. (2000), Die Bedeutung der Nivellierungshebesătze im kommunalen Finanzausgleich, in: Lüdeke, R. / Scherf, W. / Steden, W. (Hrsg.), Wirtschaftswissenschaft im Dienst der Verteilungs-, Geld- und Finanzpolizik, Berlin, S. 499 ff.

Schlie, Markus (1999), Finanzausgleich in Deutschland: Struktur, finanzielle Auswirkungen und Reformvorschläge, in: Die Weltwirtschaft, Heft 2, S. $188 \mathrm{ff}$.

Schmidt, K. (1996), Mehr Klarheit im Finanzgefüge zwischen Bund und Ländern, in: Wirtschaftsdienst, Heft 7, S. 327 ff.

Schuppert, G. F. (1993), Maßstäbe für einen künftigen Länderfinanzausgleich, in: Staatswissenschaften und Staatspraxis, S. $27 \mathrm{ff}$.

Schuppert, G. F. (1995), Der bundesstaatliche Finanzausgleich: Status-quo-Denken oder Reformprojekt?, in: Staatswissenschaften und Staatspraxis, S. $675 \mathrm{ff}$.

Schuppert, G. F. I Dahrendorf, F. (1985), Verfassungsrechtliche und finanzwissenschaftliche Aspekte des Länderfinanzausgleichs, Baden-Baden.

Scott, A. D. (1964), The Economic Goals of Federal Finance, in: Public Finance/Finances Publiques, Den Haag, S. 241 ff.

Seiler, G. (1980), Ziele und Mittel des kommunalen Finanzausgleichs, in: Pohmer, D. (Hrsg.) Probleme des Finanzausgleichs II, Schriften des Vereins für Socialpolitik, N.F., Bd. 96/I, Berlin, S. $11 \mathrm{ff.}$

Selmer, P. (1994), Die gesetzliche Neuordnung der bundesstaatlichen Finanzbeziehungen, in: Finanzarchiv, N.F., Bd. 51, S. $331 \mathrm{ff}$.

Senator fur Finanzen der Freien Hansestadt Bremen (1999), Sanierung der bremischen Haushalte - Jahresbericht 1998, Bremen.

Sörgel, A. (1998), Der Länderfinanzausgleich. Teil des Problems oder Teil der Lösung? En Beitrag aus Bremen, in: WSI Mitteilungen, Heft 3, S. $204 \mathrm{ff}$.

Statistisches Bundesamt (1998), Statistisches Jahrbuch für die Bundesrepublik Deutschland, Stuttgart.

Stauch, M. / Klusewitz, S. / Gurgsdies, M. (1993), Die Neuordnung des bundesstaatlichen Finanzausgleichs durch die Finanzreform 1995 einschließlich der Regelungen zur Haushaltssanierung Bremens und des Saarlandes, in: Senator für Finanzen der Freien Hansestadt Bremen (Hrsg.), Neuordnung des Finanzausgleichs zwischen Bund und Lăndern und ihre Auswirkungen auf das Land Bremen, Bremen.

Taube, R. (1990), Ein Vorschlag zur Reform des Länderfinanzausgleichs, in: Wirtschaftsdienst, Heft 7, S. $372 \mathrm{ff}$.

Thiel, E. (1993), Neugliederung des Bundesgebiets und Konsequenzen für das System des Finanzausgleichs, in: Probleme des Finanzausgleichs in nationaler und internationaler Sicht, Beihefte der Konjunkturpolitik, Heft 41, Berlin, S. 99 ff.

Tiebout, C. M. (1956), A Pure Theory of Local Expenditures, in: Joumal of Political Economy, Vol. 64, S. $416 \mathrm{ff}$. 
Tiebout, Ch. M. (1977), Eine okonomische Theorie fiskalischer Dezentralisierung, in: Kirsch, G. (Hrsg.), Foderalismus, Stuttgart / New York, S. 36 ff.

Trzaskalik, C. (1999), Stellungnahme im Auftrag der theinland-pfälzischen Landesregierung zu den Normenkontrollanträgen der baden-württembergischen Landesregierung vom 29.07.1998 bzw. der bayerischen Staatsregierung vom 30.07.1998, Mainz.

Tullock, G. (1977), Foderalismus: Zum Problem der optimalen Kollektivgroße, in: Kirsch, G. (Hrsg.), Föderalismus, Stuttgart / New York, S. 27 ff.

van Suntum, U. (1997), Deutschland braucht eine umfassende Finanzreform, in: Wirtschaftsdienst, Heft 10, S. $560 \mathrm{ff}$.

van Suntum, U. (1999), Die Idee des wettbewertlichen Föderalismus, in: Morath, K. (Hrsg.), Reform des Föderalismus, Bad Homburg, S. $13 \mathrm{ff}$.

Vesper, D. (1993), Die Problematik der Verschmelzung eines Flächen- und eines Stadtstaates im Länderfinanzausgleich: Der Fall Berlin-Brandenburg, in: Probleme des Finanzausgleichs in nationaler und internationaler Sicht, Beihefte der Konjunkturpolitik, Heft 41, Berlin, S. $115 \mathrm{ff}$.

Vesper, D. (1996), Sind die Finanzprobleme in Ostdeutschland durch die Neuordnung des Finanzausgleichs gelठst?, in: DIW-Wochenbericht 17/96, S. 267 ff.

Vesper, D. (1998 a), Länderfinanzausgleich - besteht Reformbedarf?, DW Diskussionspapier Nr. 170, Berlin.

Vesper, D. (1998 b), Länderfinanzausgleich: Neuer Verteilungsstreit zwischen West und Ost, in: DIW-Wochenbericht 7/98, S. 133 ff.

Weiß, R. (1996), LFA 95 - Der Lănderfinanzausgleich zum Selberrechnen und Simulieren (Handbuch), Wiesbaden.

Wieland, J. (1991), Die Konzessionsabgabe. Zur Belastung wirtschaftsverwaltungsrechtlicher Erlaubnisse mit Abgaben, Berlin.

Wieland, J. (1999), Aktuelle finanzverfassungsrechtliche Fragen des bundesstaatlichen Finanzausgleichs sowie der zugrunde liegenden Steuerverteilung, Rechtsgutachten erstattet im Auftrag der Länder Berlin, Bremen, Niedersachsen, Saarland und SchleswigHolstein, Bielefeld.

Wissenschaftlicher Beirat beim Bundesministerium der Finanzen (1992), Gutachten zum Länderfinanzausgleich in der Bundesrepublik Deutschland, Schriftenreihe des Bundesministeriums der Finanzen, Heft 47, Bonn.

Wissenschaftlicher Beirat beim Bundesministerium der Finanzen (1996), Einnahmenverteilung zwischen Bund und Ländem. Probleme und Lösungsmöglichkeiten, Schriftenreihe des Bundesministeriums der Finanzen, Heft 56, 2. Auflage, Bonn.

Wust, H. F. (1981), Foderalismus: Grundlage für Effizienz in der Staatswirtschaft, Gơttingen.

Zimmermann, H. (1983), Algemeine Probleme und Methoden des Finanzausgleichs, in: Handbuch der Finanzwissenschaft, Bd. 4, 3. Auflage, Tübingen, S. $1 \mathrm{ff}$.

Zimmermann, H. (1987), Foderalismus und "Einheitlichkeit der Lebensverhältnisse". Das Verhaltnis regionaler Ausgleichsziele zu den Zielen des föderativen Staatsaufbaus, in: Schmidt, K. (Hrsg.), Beitrăge zu okonomischen Problemen des Foderalismus, Schriften des Vereins für Socialpolitik, N.F., Bd. 166, S. 35 ff.

Zimmermann, H. / Henke, K.-D. (1994), Finanzwissenschaft, 7. Auflage, München. 


\section{FINANZWISSENSCHAFTLICHE SCHRIFTEN}

Band 1 Wemer Steden: Finanzpolitik und Einkommensverteilung. Ein Wachstums- und Konjunkturmodell der Bundesrepublik Deutschland. 1979.

Band 2 Rainer Hagemann: Kommunale Finanzplanung im foderativen Staat. 1976.

Band 3 Klaus Scherer: Maßstäbe zur Beurteilung von konjunkturellen Wirkungen des öffentlichen Haushalts. 1977.

Band 4 Brita Steinbach: "Formula Flexibility" - Kritische Analyse und Vergleich mit diskretionärer Konjunkturpolitik. 1977.

Band 5 Hans-Georg Petersen: Personelle Einkommensbesteuerung und Inflation. Eine theoretisch-empirische Analyse der Lohn- und veranlagten Einkommensteuer in der Bundesrepublik Deutschland. 1977.

Band 6 Friedemann Tetsch: Raumwirkungen des Finanzsystems der Bundesrepublik Deutschland. Eine Untersuchung der Auswirkungen der Finanzreform von 1969 auf die Einnahmenposition der untergeordneten Gebietskörperschaften und inrer regionalpolitischen Zieladäquanz. 1978.

Band 7 Wilhelm Pfähler: Normative Theorie der fiskalischen Besteuerung. Ein methodologischer und theoretischer Beitrag zur Integration der normativen Besteuerungstheorie in der Wohlfahrtstheorie. 1978.

Band 8 Wolfgang Wiegard: Optimale Schattenpreise und Produktionsprogramme für öffentliche Unternehmen. Second-Best Modelle im finanzwirtschaftlichen Staatsbereich. 1978.

Band 9 Hans P. Fischer: Die Finanzierung des Umweltschutzes im Rahmen einer rationalen Umweltpolitik. 1978.

Band 10 Rainer Paulenz: Der Einsatz finanzpolitischer Instrumente in der Forschungs- und Entwicklungspolitik. 1978.

Band 11 Hans-Joachim Hauser: Verteilungswirkungen der Staatsverschuldung. Eine kreislauftheoretische Inzidenzbetrachtung. 1979.

Band 12 Gunnar Schwarting: Kommunale Investitionen. Theoretische und empirische Untersuchungen der Bestimmungsgründe kommunaler Investitionstätigkeit in NordrheinWestfalen 1965-1972. 1979.

Band 13 Hans-Joachim Conrad: Stadt-Umland-Wanderung und Finanzwirtschaft der Kernstädte. Amerikanische Erfahrungen, grundsätzliche Zusammenhänge und eine Fallstudie für das Ballungsgebiet Frankfurt am Main. 1980.

Band 14 Cay Folkers: Vermögensverteilung und staatliche Aktivität. Zur Theorie distributiver Prozesse im Interventionsstaat. 1981.

Band 15 Helmut Fischer: US-amerikanische Exportförderung durch die DISC-Gesetzgebung. 1981.

Band 16 Günter Ott: Einkommensumverteilungen in der gesetzlichen Krankenversicherung. Eine quantitative Analyse. 1981.

Band 17 Johann Hermann von Oehsen: Optimale Besteuerung. (Optimal Taxation). 1982.

Band 18 Richard Kössler: Sozialversicherungsprinzip und Staatszuschüsse in der gesetzlichen Rentenversicherung. 1982.

Band 19 Hinrich Steffen: Zum Handlungs- und Entscheidungsspielraum der kommunalen Investitionspolitik in der Bundesrepublik Deutschland. 1983.

Band 20 Manfred Scheuer: Wirkungen einer Auslandsverschuldung des Staates bei flexiblen Wechselkursen. 1983. 
Band 21 Christian Schiller: Staatsausgaben und crowding-out-Effekte. Zur Effizienz einer Finanzpolitik keynesianischer Provenienz. 1983.

Band 22 Hannelore Weck: Schattenwirtschaft: Eine Möglichkeit zur Einschränkung der öftentlichen Verwaltung? Eine ökonomische Analyse. 1983.

Band 23 Wolfgang Schmitt: Steuem als Mittel der Einkommenspolitik. Eine Ergänzung der Stabilitătspolitik? 1984.

Band 24 Wolfgang Laux: Erhöhung staatswirtschaftlicher Effizienz durch budgetäre Selbstbeschränkung? Zur Idee einer verfassungsmäßig verankerten Ausgabengrenze. 1984.

Band 25 Brita Steinbach-van der Veen: Steuerinzidenz. Methodologische Grundlagen und empirisch-statistische Probleme von Länderstudien. 1985.

Band 26 Albert Peters: Ökonomische Kriterien für eine Aufgabenverteilung in der Marktwirtschaft. Eine deskriptive und normative Betrachtung für den Allokationsbereich. 1985.

Band 27 Achim Zeidler: Möglichkeiten zur Fortsetzung der Gemeindefinanzreform. Eine theoretische und empirische Analyse. 1985.

Band 28 Peter Bartsch: Zur Theorie der längerfristigen Wirkungen 'expansiver' Fiskalpolitik. Eine dynamische Analyse unter besonderer Berücksichtigung der staatlichen Budgetbeschränkung und ausgewählter Möglichkeiten der öffentlichen Defizitfinanzierung. 1986.

Band 29 Konrad Beiwinkel: Wehrgerechtigkeit als finanzpolitisches Verteilungsproblem. Möglichkeiten einer Kompensation von Wehrungerechtigkeit durch monetäre Transfers. 1986.

Band 30 Wolfgang Kitterer: Effizienz- und Verteilungswirkungen des Steuersystems. 1986.

Band 31 Heinz Dieter Hessler: Theorie und Politik der Personalsteuem. Eine Kritik ihrer Einkommens- und Vermögensbegriffe mit Blick auf die Leistungsfähigkeitstheorie. 1994.

Band 32 Wolfgang Schert: Die beschäftigungspolitische und fiskalische Problematik der Arbeitgeberbeiträge zur Rentenversicherung. Eine Auseinandersetzung mit der Kritik an der lohnbezogenen Beitragsbemessung. 1987.

Band 33 Andreas Mästle: Die Steuerunion. Probleme der Harmonisierung spezifischer Gütersteuern. 1987.

Band 34 Günter Ott: Internationale Verteilungswirkungen im Finanzausgleich der Europäischen Gemeinschaften. 1987.

Band 35 Heinz Haller: Zur Frage der zweckmäßigen Gestalt gemeindlicher Steuern. Ein Diskussionsbeitrag zur Gemeindesteuerreform. 1987.

Band 36 Thomas Kuhn: Schlüsselzuweisungen und fiskalische Ungleichheit. Eine theoretische Analyse der Verteilung von Schlüsselzuweisungen an Kommunen. 1988.

Band 37 Walter Hahn: Steuerpolitische Willensbildungsprozesse in der Europäischen Gemeinschaft. Das Beispiel der Umsatzssteuer-Harmonisierung. 1988.

Band 38 Ulrike Hardt: Kommunale Finanzkraft. Die Problematik einer objektiven Bestimmung kommunaler Einnahmemöglichkeiten in der gemeindlichen Haushaltsplanung und im kommunalen Finanzausgleich. 1988.

Band 39 Jochen Michaelis: Optimale Finanzpolitik im Modell überlappender Generationen. 1989.

Band 40 Bernd Raffelhüschen: Anreizwirkungen der sozialen Alterssicherung. Eine dynamische Simulationsanalyse. 1989.

Band 41 Berend Diekmann: Die Anleihe- und Darlehenstransaktionen der Europäischen Gemeinschaften. 1990.

Band 42 Helmut Kaiser: Konsumnachfrage, Arbeitsangebot und optimale Haushaltsbesteuerung. Theoretische Ergebnisse und mikroökonometrische Simulation für die Bundesrepublik Deutschland. 1990. 
Band 43 Rüdiger von Kleist: Das Gramm-Rudman-Hollings-Gesetz. Ein gescheiterter Versuch der Haushaltskonsolidierung. 1991.

Band 44 Rolf Hagedorn: Steuerhinterziehung und Finanzpolitik. Ein theoretischer Beitrag unter besonderer Berücksichtigung der Hinterziehung von Zinsertrăgen. 1991.

Band 45 Comelia S. Behrens: Intertemporale Verteilungswirkungen in der gesetzlichen Krankenversicherung der Bundesrepublik Deutschland. 1991.

Band 46 Peter Saile: Ein ökonomischer Ansatz der Theorie der intermediären Finanzgewalten Die Kirchen als Parafisci. 1992.

Band 47 Peter Gottfried: Die verdeckten Effizienzwirkungen der Umsatzsteuer. Eine empirische allgemeine Gleichgewichtsanalyse. 1992.

Band 48 Andreas Burger: Umweltorientierte Beschăftigungsprogramme. Eine Effizienzanalyse am Beispiel des "Sondervermögens Arbeit und Umwelt". 1992.

Band 49 Jeanette Malchow: Die Zuordnung verteilungspolitischer Kompetenzen in der Europäischen Gemeinschaft. Eine Untersuchung aufgrund einer Fortentwicklung der ökonomischen Theorie des Föderalismus. 1992.

Band 50 Barbara Seidel: Die Einbindung der Bundesrepublik Deutschland in die Europäischen Gemeinschaften als Problem des Finanzausgleichs. 1992.

Band 51 Ralph Wiechers: Markt und Macht im Rundfunk. Zur Stellung der öffentlich-rechtlichen Rundfunkanstalten im dualen Rundfunksystem der Bundesrepublik Deutschland. 1992.

Band 52 Klaus Eckhardt: Probleme einer Umweltpolitik mit Abgaben. 1993.

Band 53 Oliver Schwarzkopf: Die Problematik unterschiedlicher Körperschaftsteuersysteme innerhalb der EG. 1993.

Band 54 Thorsten Giersch: Bergson-Wohlfahrtsfunktion und normative Ökonomie. 1993.

Band 55 Li-Fang Chou: Selbstbeteiligung bei Arzneimitteln aus ordnungspolitischer Sicht. Das Beispiel der Bundesrepublik Deutschland. 1993.

Band 56 Harald Schlee: Einkommensteuerliche Behandlung von Transferzahlungen. Zur Neuordnung der Familienbesteuerung sowie der Besteuerung von Versicherungsleistungen und Sozialtransfers. 1994.

Band 57 Alexander Spermann: Kommunales Krisenmanagement. Reaktionen baden-württembergischer Stadtkreise auf steigende Sozialhilfekosten und Einnahmenausfälle (198092). 1993.

Band 58 Otto Roloff / Sibylle Brander / Ingo Barens / Claudia Wesselbaum: Direktinvestitionen und internationale Steuerkonkurrenz. 1994.

Band 59 Claudia Wesselbaum-Neugebauer: Intemationale Steuerbelastungsvergleiche. 1994.

Band 60 Stephanie Miera: Kommunales Finanzsystem und Bevölkerungsentwicklung. Eine Analyse des kommunalen Finanzsystems vor dem Hintergrund der sich abzeichnenden Bevölkerungsentwicklung am Beispiel Niedersachsens unter besonderer Berücksichtigung des Landkreises Wolfenbüttel und seiner Gemeinden. 1994.

Band 61 Wolfgang Schert: Die Bedeutung des kaldorianischen Verteilungsmechanismus für die gesamtwirtschaftlichen Wirkungen der staatlichen Neuverschuldung. 1994.

Band 62 Rainer Volk: Vergleich der Vergünstigungseffekte der verschiedenen investitionsfördemden Maßnahmen. 1994.

Band 63 Hans-Georg Napp: Kommunale Finanzautonomie und ihre Bedeutung für eine effiziente lokale Finanzwirtschaft. 1994. 2., unveränderte Auflage 1994.

Band 64 Bernd Rahmann / Uwe Steinborn / Günter Vornholz: Empirische Analyse der Autonomie lokaler Finanzwirtschaften in der Europäischen Gemeinschaft. 1994. 
Band 65 Carsten Kühl: Strategien zur Finanzierung der Altlastensanierung. 1994.

Band 66 Stephan Boll: Intergenerationale Umverteilungswirkungen der Fiskalpolitik in der Bundesrepublik Deutschland. Ein Ansatz mit Hilfe des Generational Accounting. 1994.

Band 67 Karl Justus Bernhard Neumärker: Finanzverfassung und Staatsgewalt in der Demokratie. Ein Beitrag zur konstitutionellen Finanztheorie. 1995.

Band 68 Christian Haslbeck: Zentrale versus dezentrale Internalisierung externer Effekte bei unvollständiger Information. 1995.

Band 69 Regina Müller: Horizontale oder vertikale Transfers zur Durchsetzung eines horizontalen Finanzausgleichs. 1995.

Band 70 Christian Hockenjos: Öffentliche Sportförderung in der Bundesrepublik Deutschland. Darstellung und finanztheoretische Analyse. 1995.

Band 71 Manfred Rosenstock: Die Kontrolle und Harmonisierung nationaler Beihilfen durch die Kommission der Europäischen Gemeinschaften. 1995.

Band 72 Christian Rüsch: Wohnungsbau- und Wohneigentumspolitik im Rahmen der Einkommensteuer. Eine Analyse unter steuersystematischen, verteilungspolitischen und fiskalischen Aspekten. 1996.

Band 73 Stephan Winters: Die kollektive Vorsorge für den Pflegefall im Alter. Eine Untersuchung am Beispiel der gesetzlichen Pflegeversicherung in den Niederlanden. 1996.

Band 74 Knut Blind: Allokationsineffizienzen auf Sicherheitsmärkten: Ursachen und Lösungsmöglichkeiten. Fallstudie: Informationssicherheit in Kommunikationssystemen. 1996.

Band 75 Barbara Petrick-Rump: Ökonomische Wirkungen von Steueramnestien. Untersuchung konkreter Erfahrungen ausgewählter Länder mit dem Einsatz von Steueramnestien an hand eines effizienten Steueramnestieprogramms. 1996.

Band 76 Georg Hirte: Effizienzwirkungen von Finanzausgleichsregelungen. Eine Empirische Allgemeine Gleichgewichtsanalyse für die Bundesrepublik Deutschland. 1996.

Band 77 Ulrike Kirchhoff: Die rheinland-pfälzischen Gemeinden im System des Finanzausgleichs. 1996.

Band 78 Kerstin Keil: Der soziale Mietwohnungsbau: Mängel und Alternativen. 1996.

Band 79 Bernhard Manzke: Kinderlastenausgleich versus verstärkte Einwanderung. Alternative Ansätze zur langfristigen Sicherung der Gesetzlichen Rentenversicherung. 1997.

Band 80 Hariolf M. Wenzler: Institutionenökonomik und öffentliche Finanzkontrolle. Eine Analyse am Beispiel der Europäischen Union. 1997.

Band 81 Joachim Nagel: Supply-Side Policy in den USA. Eine theoretische und empirische Analyse der angebotsorientierten Wirtschaftspolitik Reagans unter besonderer Berücksichtigung steuerlicher Aspekte. 1997.

Band 82 Heinz Lampert: Krise und Reform des Sozialstaates. 1997.

Band 83 Monika Hanswillemenke / Bernd Rahmann: Zwischen Reformen und Verantwortung für Vollbeschäftigung. Die Finanz- und Haushaltspolitik der sozial-liberalen Koalition von 1969 bis 1982.1997.

Band 84 Berthold Fürst: Die Maastrichter Budgetkriterien im Konflikt mit der Verschuldungsautonomie der deutschen Gebietskörperschaften. 1997.

Band 85 Burkhard Pahnke: Einkommensorientierte Förderung des sozialen Mietwohnungsbaues. Bestandsaufnahme und Kritik. 1998.

Band 86 Judith Safford: Staatsverschuldung im Vereinigten Königreich. Die öffentliche Verschuldung unter der Konservativen Regierung von 1979-1994. Ursachen und Auswirkungen. 1998. 
Band 87 Ralf Oberheide: Die Bekämpfung der Steuerumgehung. 1998.

Band 88 Achim Truger: Die neue Finanzwissenschaft zwischen Realitätsferne und Irrelevanz der Annahmen. Eine methodologische Analyse potentieller Verteidigungsstrategien der neuen Finanzwissenschaft gegen den Vorwurf der Realitätsferne ihres entscheidungstheoretischen Fundamentes. 1998.

Band 89 Karin Bickel: Familienbezogene Elemente im System der gesetzlichen Rentenversicherung. Unter besonderer Berücksichtigung von Ein-Eltem-Familien. 1999.

Band 90 Wolfgang Schert: Schlüsselzuweisungen und Kreisumlage. Die Problematik der Finanzierung der Landkreise am Beispiel des kommunalen Finanzausgleichs von RheinlandPfalz. 1998.

Band 91 Sandra Ehmann: Familienpolitik in Frankreich und Deutschland - ein Vergleich. 1999.

Band 92 Hendrik Suermann: Einkommensteuerliche Behandlung von Währungsgewinnen und -verlusten. Eine finanzwissenschaftliche Analyse des Steuerrechts in den USA und in Deutschland. 1999.

Band 93 Rolf Bösinger. Die Neuordnung des bundesstaatlichen Finanzausgleichs 1995. Eine theoretische und empirische Analyse unter Berücksichtigung von allokationstheoretischen und polit-ökonomischen Gesichtspunkten. 1999.

Band 94 Ulrich Ermschel: Finanzwirtschaftliche Konsequenzen beim Übergang auf das Ursprungslandprinzip im Europäischen Binnenmarkt. Eine Untersuchung am Beispiel des unvollikommenen oligopolistischen Neufahrzeugmarktes. 1999.

Band 95 Ute Hansen: Überwälzte Leistungen der Administration. Eine empirische und theoretische Analyse. 2000.

Band 96 Hans-Werner Seiler: Zur Durchsetzung der Einmalbesteuerung deutscher Körperschaftsgewinne. Strategien zur Vermeidung der im deutschen Körperschaftsteuersystem angelegten Benachteiligung ausländischer Anteilseigner. Eine finanzwissenschaftliche Analyse. 2000.

Band 97 Steffen Meyer: Zwischenstaatliche Finanzzuweisungen im zusammenwachsenden Europa. Zur Gestaltung eines Finanzausgleichs für die Europäische Union. 2000.

Band 98 Marion Hübner: Ökodumping? Umweltpolitik in internationalen Oligopolmärkten. 2000.

Band 99 Christhart Bork: Steuem, Transfers und private Haushalte. Eine mikroanalytische Simulationsstudie der Aufkommens- und Verteilungswirkungen. 2000.

Band 101 Wolfgang Schert: Der Länderfinanzausgleich in Deutschland. Ungelöste Probleme und Ansatzpunkte einer Reform. 2000. 


\section{Walter Naggl}

\section{Konjunktur}

Frankfurt/M., Berlin, Bern, New York, Paris, Wien, 1999. 221 S., zahlr. Abb. ISBN 3-631-33969-0 • br. DM 69.-*

Dieses Buch soll einen praxisorientierten Überblick der Verfahren zur Konjunkturanalyse und -prognose liefern. Es beginnt mit dem Verlauf der konjunkturellen Entwicklung in den USA und Deutschland seit den zwanziger Jahren. Danach werden das offizielle amerikanische Verfahren und von der Finanzpresse popularisierte Faustregeln der Datierung von Konjunkturzyklen dargestellt. Es folgt ein Abriß der wichtigsten Konjunkturtheorien und ihrer Aussagekraft bezüglich aktueller konjunktureller Fragestellungen. Die Schilderung typischer Muster des Konjunkturverlaufs bildet ein empirisches Pendant zu den Theorien. Es wird gezeigt, wie die Daten des ifo-Konjunkturtests und der Konsumentenstimmung zu Indizes verdichtet werden und welche Aussagekraft sie haben. Methoden zur Konstruktion von Frühindikatorindizes werden vorgestellt und deren Prognoseleistung diskutiert. Das Buch schließt mit einem Kapitel zur Inflation.

Aus dem Inhalt: Konjunkturzyklen in den USA und Deutschland und ihre Messung - Konjunkturtheorie und Muster der Konjunktur - Stimmungen, Erwartungen und Kaufpläne als Einzelindikatoren und ihre Verdichtung in einem Frühindikatorindex . Prognoseleistung von Vorlaufindikatoren . Historischer Überblick und Indikatoren der Inflation

Frankfurt/M - Berlin - Bern - Bruxelles - New York - Oxford - Wien

Auslieferung: Verlag Peter Lang AG

Jupiterstr. 15, CH-3000 Bern 15

Telefax (004131) 9402131

^inklusive Mehrwertsteuer

Preisänderungen vorbehalten 
Wolfgang Scherf - 978-3-631-75181-7

Downloaded from PubFactory at 01/11/2019 07:24:58AM

via free access 